
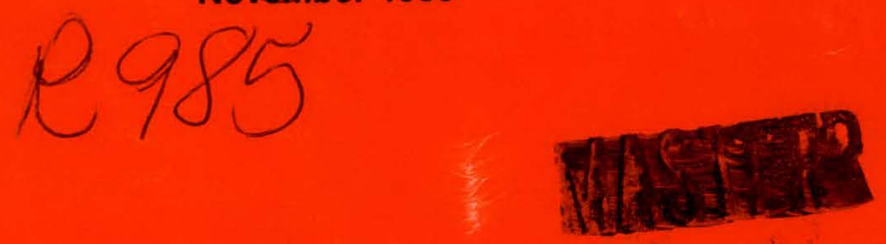

\title{
Passive Solar Energy Information User Study
}

W. W. Belew

B. L. Wood

T. L. Marle

C. L. Reinhardt
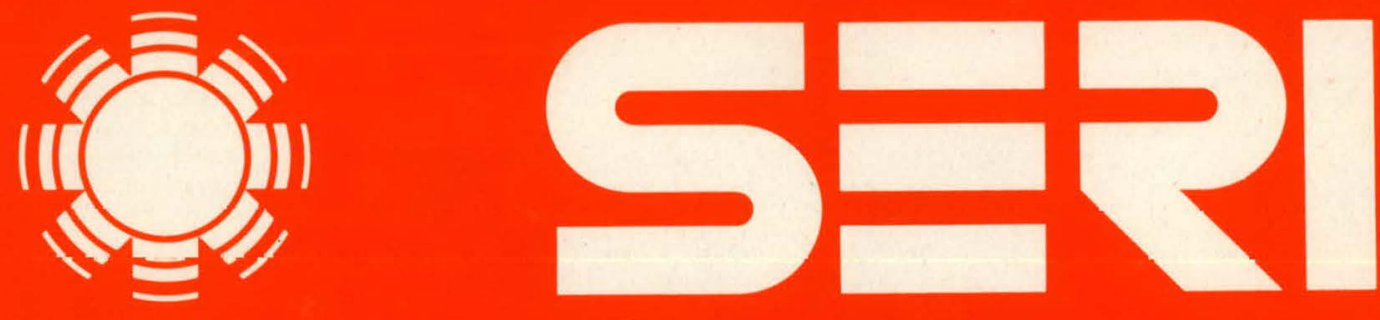

Solar Energy Research Institute

A Division of Midwest Rosearch Institute

1617 Cole Boulevard

Golden, Colorado 80401

Operated for the

U.S. Department of Energy

under Contract No. EG-77-C-01-4042 


\section{DISCLAIMER}

This report was prepared as an account of work sponsored by an agency of the United States Government. Neither the United States Government nor any agency Thereof, nor any of their employees, makes any warranty, express or implied, or assumes any legal liability or responsibility for the accuracy, completeness, or usefulness of any information, apparatus, product, or process disclosed, or represents that its use would not infringe privately owned rights. Reference herein to any specific commercial product, process, or service by trade name, trademark, manufacturer, or otherwise does not necessarily constitute or imply its endorsement, recommendation, or favoring by the United States Government or any agency thereof. The views and opinions of authors expressed herein do not necessarily state or reflect those of the United States Government or any agency thereof. 


\section{DISCLAIMER}

Portions of this document may be illegible in electronic image products. Images are produced from the best available original document. 
Printed in the United States of America Available from:

National Technical Information Service

U.S. Department of Commerce

5285 Port Royal Road

Springfield, VA 22161

Price:

Microfiche $\$ 3.00$

Printed Copy $\$ 10.75$

\begin{abstract}
NOTICE
This report was prepared as an account of work sponsored by the United States Government. Neither the United States nor the United States Department of Energy, nor any of their employees, nor any of their contractors, subcontractors, or their employees, makes any warranty, express or implied, or assumes any legal liability or responsibility for the accuracy, completeness or usefulness of any information, apparatus, product or process disclosed, or represents that its use would not infringe privately owned rights.
\end{abstract}


SER I /TR-751-746

UC CATEGORIES: UC-58c,59

PASSIVE SOLAR ENERGY

INFORMATION USER STUDY

W. W. BELEW

B. L. WOOD

T. L. MARLE

C. L. REINHARDT

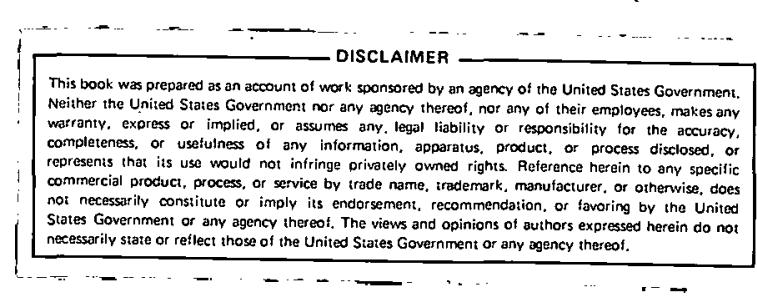

NOVEMBER 1980

PREPARED UNDER TASK NO. 8420.11

\section{Solar Energy Research Institute}

A Division of Midwest Research Institute

1617 Cole Boulevard

Golden, Colorado 80401

Prepared for the

U.S. Department of Energy

Contract No. EG-77-C-01-4042 
THIS PAGE

WAS INTENTIIONALLY

LEFT BLANK 


\section{FOREWORD}

This document reports the results of a series of studies of users of passive solar heating and cooling information. It identifies specific passive solar information user group needs, the priority of those needs, and methods of disseminating information to each group. This is one of a series of ten reports covering many different solar technologies. These results will play an.integral part in the planning of new information products and data bases for the Solar Energy Information Data Bank (SEIDB).

This study was performed under Contract No. ET-77C-01-4042, FY 1980 Task Number 8420.11.

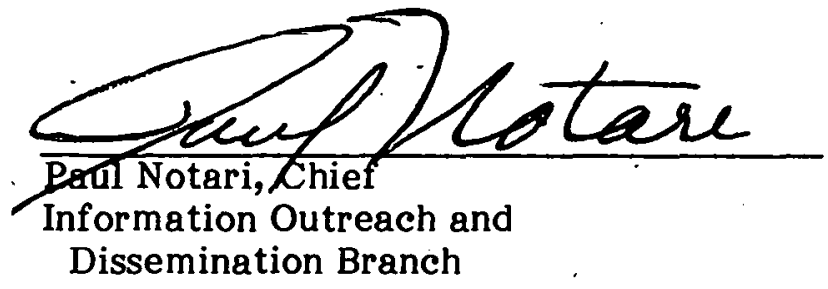

Approved for

SOLAR ENERGY RESEARCH INSTITUTE

Herbert B. Landau, Manager
Information Systems Division

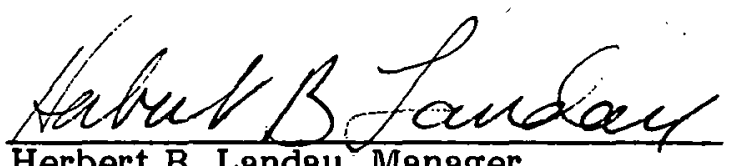


THIS PAGE

WAS IN'TENTIONALLY

LEFT BLANK 


\section{ACKNOWLEDGMENTS}

The authors would like to thank the following people for their valuable technical advice and review.

M. Ballen

National Solar Heating and Cooling Information Center

J. O. Borden

Southern Solar Energy Center

D. S. Bremer

AIA Research Corporation

N. Carlisle

Buildings Applications and Policy

SERI

D. Chan

Northeast Solar Energy Center

S. Chen

Northeast Solar Energy Center

R. Farrington

Systems Development

SERI

H. Landau, Division Manager

Information Systems

SERI

L. Morrison

Buildings Systems

SERI
W. Nichols

Communico-Seton Village

P. Notari, Branch Chief

Information Outreach and Dissemination SERI

P. A. Perucci

Meridian Corporation

P. Pollock

Community and Consumer Branch

SERI

D. M. Roha

Vitro Laboratories Division

J. C. Sesso

National Center for Appropriate

Technology

R. Vories

Community and Consumer Branch

SERI

F. C. Weinstein

National Solar Heating and Cooling Information Center 
Blank

vi 


\section{PASSIVE SOLAR HEATING AND COOLING \\ INPORMATION USER STUDY \\ MANAGEMENT SUMMARY}

This report describes the results of a series of telephone studies of potential users of information on passive solar heating and cooling. These studies, part of a larger study covering many different solar technologies, identified:

- the types of information each group of information users needed, and

- the ways to get information to that group.

This passive solar report is one of ten discussing the results of these studies. Nine of these deal with specific technologies, the tenth is a summary report.

\section{BACKGROUND}

The purpose of the overall study was to obtain baseline data about the information needs of the solar community. Very little previous work has been done in this area; the studies that have been done were generally restricted to solar heating and cooling of buildings. The present study is the only one known to investigate all of the following technological areas:

- Photovoltaics

- Passive Solar Heating and Cooling

- Active Solar Heating and Cooling

- Biomass Energy

- Solar Thermal Electric Power

- Industrial and Agricultural Process Heat

- Wind Energy

- Ocean Encrgy

- Solar Energy Storage

There have been a few previous studies which asked homeowners what solar information they needed, but this is the only known study to provide data on the solar information that such groups as researchers, manufacturers, architects, engineers, installers, lawyers, bankers, insurers, public interest groups, state energy offices, and agricultural extension agents themselves say they want.

The data from this study will be used along with other data to determine what new information products and services the Solar Energy Research Institute (SERI), the Solar Energy Information Data Bank (SEIDB) Network, and the entire solar information outreach community should be preparing for and disseminating to the solar community. 


\section{STUDY CHARACTERISTICS}

Between 3 September 1979 and 13 October 1979 Market Opinion Research, Inc. of Detroit, Michigan-under subcontract to SERI-conducted telephone interviews with 86 distinct groups of solar information users taken from across the nine different technological areas. Approximately nine respondents were interviewed from each group. Interviews were based upon professionally reviewed and tested questionnaires that utilized a mixture of open-ended and closed-ended questions. The interviews took an average of 18 minutes to complete.

The respondents proved to be very cooperative. Considering the length and nature of the telephone interviews, it was surprising that only about $3 \%$ of the respondents terminated an interview or refused to be interviewed. This finding supported the interviewers' statements that the respondents were very interested in telling what they were doing in solar energy, in obtaining solar information, and in specifying what solar information would prove tlie most valuable.

\section{SAMPLE SIZE}

Studies of 86 groups, each interested either in one of nine different solar technologies or in solar energy in general, provided an extremely broad view of the information needs of the solar community. Although the sample size of only nine respondents per group was small, the data still proved to be adequate for planning purposes. It was possible to determine the information most important to the respondents and the best channel for dissemination. A variety of valid statistical tests were performed, both to compare the priorities a group gave to different information items and to compare the priorities different groups gave to the same item (see Section 2.3 and Appendix E).

\section{PASSIVE SOLAR GROUPS STUDIED}

The results of an earlier study identified the groups of information users constituting the passive solar community [1] and determined the priority (to accelerate commercialization of solar energy) of getting information to each user group. In the current study only high-priority groups were included. Considerable effort (e.g.; library searches, phone calls, subcontractors) went into obtaining the names of people professionally involved in passive solar energy. When the phone interviews were conducted, an elaborate screening process was used to guarantee that the potential respondent was truly involved in passive solar energy. Respondents in the following seven groups were queried about their need for information on passive solar technologies:

- Federally Funded Passive Researchers,

- Representatives of Passive Manufacturers,

- Architects who have been involved in passive projects,

- Builders who have been involved in passive solar technologies,

- Educators teaching college-level courses in passive solar technologies,

- Cooperative Extension Service (CES) County. Agents who will be needing information on passive solar energy, and

- Homeowners with passive solar systems. 
Groups desirable to study, but for whom adequate lists of names could not be obtained, included passive facility or systems designers and users of remote-location passive systems. Several of the groups discussed in another report from this study [2] also indicated an interest in information on passive solar energy (see Section 2.2.4).

\section{RESULTS}

\section{Usefulness of General Types of Information}

The most important result obtained from this study was the identification of the passive information categories ranked the most useful by each group of respondents (see Table S-1). Passive respondents in almost every group gave high ratings to information on:

- climatological data;

- passive systems. cost/performance;

- passive systems installation/operation costs; and

- tax credits, grants, incentives.

\section{Usefulness of Specific Information Products}

The same question also provided information on how valuable a set of specifically proposed information products would be to the respondents (see Table S-2). The first seven of these products could be targeted for large segments of the passive community rather than for specific groups. The three items which received the strongest support were all related to systems design:

- manual analytical tools for passive system design;

- passive system diagrams or schematics; and

- passive system design/installation handbooks, reference tables.

\section{Sources Used to Obtain Information}

Table S-3 lists the proportion of each group that had used different sources to obtain any type of solar information in the past few years. It will be noted that a column is given for all passive respondents; these summary figures are indicators (not estimates) of the familiarity of the entire passive community with these information sources. In planning how specific information is to be transmitted, however, it will be essential to fully specify both the information products or services and the groups to be reached before making the decision of which information channels are to be used. One can not assume, for example, that the two or three top-rated sources should be used for all- or even most- of the information transmissions to the passive community.

The passive respondents seemed particularly oriented towards obtaining solar information from: 
Täble S-1: COMPARATIVE USEFULNESS OF GENERAL TYPES OF INFORMATION ON PASSIVE SOLAR HEATING AND COOLING

\begin{tabular}{|c|c|c|c|c|c|c|c|}
\hline General Information Types & $\begin{array}{l}\text { Passive } \\
\text { Research- } \\
\text { ers }\end{array}$ & $\begin{array}{l}\text { Passive } \\
\text { Manufac- } \\
\text { turer } \\
\text { Reps }\end{array}$ & $\begin{array}{l}\text { Passive } \\
\text { Archi- } \\
\text { tects }\end{array}$ & $\begin{array}{l}\text { Passive } \\
\text { Builders }\end{array}$ & $\begin{array}{l}\text { Passive } \\
\text { Educa- } \\
\text { tors }\end{array}$ & $\begin{array}{l}\text { Passive } \\
\text { County } \\
\text { Agents }\end{array}$ & $\begin{array}{l}\text { Passive } \\
\text { Home- } \\
\text { Owners }\end{array}$ \\
\hline & Ranking ${ }^{\mathbf{a}}$ & Ranking & Ranking & Ranking & Ranking & Ranking & Ranking \\
\hline $\begin{array}{l}\text { State of the Art in Passive Research } \\
\text { Passive Research in Progress } \\
\text { Passive Systems Installation/Operation Costs } \\
\text { Passive Systems Cost/Performance } \\
\text { Local Building Codes, Regulations } \\
\text { Climatological Data }\end{array}$ & $\begin{array}{l}9 \\
4 \\
7 \\
3 \\
7 \\
1\end{array}$ & $\begin{array}{r}11 \\
6 \\
2 \\
4 \\
6 \\
1\end{array}$ & $\begin{array}{r}10 \\
10 \\
2 \\
4 \\
6 \\
1\end{array}$ & $\begin{array}{l}8 \\
8 \\
8 \\
4 \\
2 \\
2\end{array}$ & $\begin{array}{r}7 \\
10 \\
3 \\
1 \\
12 \\
8\end{array}$ & $\begin{array}{r}13 \\
10 \\
1 \\
1 \\
10 \\
3\end{array}$ & $\begin{array}{r}5 \\
2 \\
12 \\
2 \\
5 \\
1\end{array}$ \\
\hline $\begin{array}{l}\text { Marketing Statistics and Sales Projections } \\
\text { for Passive Systems } \\
\text { Passive Systems Marketing ("How To Market") } \\
\text { Educational Institutions Offering Passive- }\end{array}$ & $\begin{array}{r}14 \\
\text { NA }\end{array}$ & $\begin{array}{l}11 \\
14\end{array}$ & $\begin{array}{l}\text { NA } \\
\text { NA }\end{array}$ & $\begin{array}{r}17 \\
\text { NA }\end{array}$ & $\begin{array}{l}20 \\
21\end{array}$ & $\begin{array}{l}\text { NA } \\
\text { NA }\end{array}$ & $\begin{array}{r}19 \\
\text { NA }\end{array}$ \\
\hline $\begin{array}{l}\text { Related Courses } \\
\text { Standards, Specifications, or Certification }\end{array}$ & 19 & 19 & 13 & 19 & 3 & 14 & 10 \\
\hline $\begin{array}{l}\text { for Passive Systems } \\
\text { Institutional, Social, Environmental, or }\end{array}$ & 11 & 6 & 10 & 8 & 16 & 14 & 17 \\
\hline $\begin{array}{l}\text { Legal Aspects of Passive Applications } \\
\text { Expected Developm ents in Fassive }\end{array}$ & 17 & 18 & 18 & 13 & 13 & 16 & 12 \\
\hline $\begin{array}{l}\text { ("Next } 10 \text { Years") } \\
\text { International P.assive Solar Markets, Research, }\end{array}$ & 11 & 11 & 13 & 4 & 3 & 6 & 16 \\
\hline Programs, Industry & 14 & 14 & 19 & 17 & 17 & NA & NA \\
\hline Tax Credits, Grants, Incentives & 2 & $\begin{array}{r}2 \\
20\end{array}$ & $\begin{array}{r}3 \\
13\end{array}$ & 1 & $\begin{array}{r}8 \\
19\end{array}$ & $\begin{array}{r}3 \\
16\end{array}$ & 10 \\
\hline Passive Inf ormation Sources & 9 & 16 & 6 & $\begin{array}{r}10 \\
6\end{array}$ & 10 & 7 & $\begin{array}{r}10 \\
7\end{array}$ \\
\hline Technical Experts on Passive Systems & 14 & 6 & 17 & 13 & 15 & 10 & 7 \\
\hline Local Passive Inf rastructure $\mathrm{e}^{\mathrm{e}}$ & 18 & 16 & 6 & 6 & 17 & 8 & 14 \\
\hline $\begin{array}{l}\text { Technical Descriptions of Passive Systems } \\
\text { Non-Technical Descriptions of Passive }\end{array}$ & 5 & 6 & 5 & 16 & I & 16 & 4 \\
\hline $\begin{array}{l}\text { Systems } \\
\text { Passive Systems Design }\end{array}$ & $\begin{array}{r}20 \\
6\end{array}$ & $\begin{array}{r}\text { NA } \\
5\end{array}$ & $\begin{array}{r}16 \\
6\end{array}$ & $\begin{array}{l}20 \\
12\end{array}$ & $\begin{array}{r}13 \\
6\end{array}$ & $\begin{array}{l}\mathbf{5} \\
\mathbf{9}\end{array}$ & $\begin{array}{r}14 \\
9\end{array}$ \\
\hline Sample Size & 9 & 9 & 9 & 9 & g & $\mathbf{9}$ & 9 \\
\hline
\end{tabular}

${ }^{a}$ The Ranking was based upon asking respondents how useful each item would be to them (see text of main report). If items were tied, they were all given the highest possible rank.

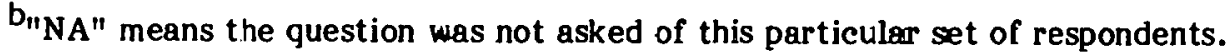

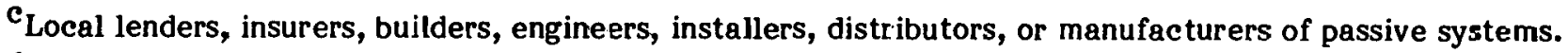

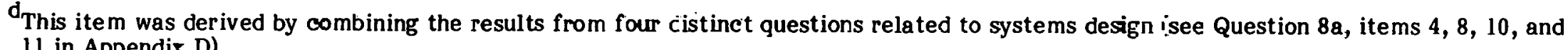
11 in Appendix D). 


\section{Table S-2. VALUE ASSESSMENT OF SPECIFIC PASSIVE SOLAR HEATING \& COOLING INFORMATION PRODUCTS}

\begin{tabular}{|c|c|c|c|c|c|c|c|c|}
\hline \multirow[t]{2}{*}{ Specific Information Products } & $\begin{array}{l}\text { Passive } \\
\text { Research- } \\
\text { ers }\end{array}$ & $\begin{array}{l}\text { Passive } \\
\text { Manufac- } \\
\text { turer } \\
\text { Reps }\end{array}$ & $\begin{array}{l}\text { Passive } \\
\text { Archi- } \\
\text { tects }\end{array}$ & $\begin{array}{l}\text { Passive } \\
\text { Builders }\end{array}$ & $\begin{array}{l}\text { Passive } \\
\text { Educa- } \\
\text { tors }\end{array}$ & $\begin{array}{l}\text { Passive } \\
\text { County } \\
\text { Agents }\end{array}$ & $\begin{array}{l}\text { Passive } \\
\text { Home- } \\
\text { Owners }\end{array}$ & $\begin{array}{l}\text { All } \\
\text { Passive } \\
\text { Respon- } \\
\text { dents }\end{array}$ \\
\hline & Percent $^{\mathbf{a}}$ & Percent & Percent & Percent & Percent & Percent & Percent & Percent $^{b}$ \\
\hline $\begin{array}{l}\text { Bibliography of General Readings } \\
\text { on Passive Systems } \\
\text { Calendar of Passive Conf erences }\end{array}$ & 33 & 33 & 33 & 56 & 56 & 44 & 67 & 46 \\
\hline $\begin{array}{l}\text { and Prograrns } \\
\text { Passive System Diagrams or. }\end{array}$ & 44 & 22 & 56 & 44 & 22 & 11 & 33 & 33 \\
\hline $\begin{array}{l}\text { Schematics } \\
\text { Passive System Design/Installation }\end{array}$ & 56 & 78 & 78 & 44 & 56 & 89 & 67 & 67 \\
\hline $\begin{array}{l}\text { Handbooks, Reference Tables } \\
\text { Manual Analytical Tools for Passive }\end{array}$ & 44 & 56 & 78 & 78 & 78 & 56 & 78 & 67 \\
\hline $\begin{array}{l}\text { System Design } \\
\text { Computer Analytical Tools (Models) }\end{array}$ & 56 & 67 & 78 & 89 & 78 & 56 & 89 & 73 \\
\hline $\begin{array}{l}\text { for Passive System Design. } \\
\text { Lists of Local Passive Experts } \\
\text { Lists of Passive Technical Experts } \\
\text { Technical Descriptions of Passive }\end{array}$ & $\begin{array}{l}78 \\
11 \\
33\end{array}$ & $\begin{array}{l}67 \\
44 \\
56\end{array}$ & $\begin{array}{l}33 \\
67 \\
33\end{array}$ & $\begin{array}{l}56 \\
89 \\
56\end{array}$ & $\begin{array}{l}78 \\
33 \\
44\end{array}$ & $\begin{array}{l}11 \\
56 \\
44\end{array}$ & $\begin{array}{l}33 \\
56 \\
78\end{array}$ & $\begin{array}{r}51 \\
51 \\
X^{e}\end{array}$ \\
\hline $\begin{array}{l}\text { Systems } \\
\text { Nontechnical Descriptions of }\end{array}$ & 67 & 78 & 67 & 44 & 89 & 11 & 78 & $x^{e}$ \\
\hline $\begin{array}{l}\text { Passive Systems } \\
\text { List of Passive Inf ormation Sources }\end{array}$ & $\begin{array}{r}0 \\
33\end{array}$ & $\begin{array}{c}\mathrm{NA}^{\mathrm{d}} \\
56\end{array}$ & $\begin{array}{l}56 \\
56\end{array}$ & $\begin{array}{l}11 \\
78\end{array}$ & $\begin{array}{l}56 \\
67\end{array}$ & $\begin{array}{l}78 \\
56\end{array}$ & $\begin{array}{l}56 \\
78\end{array}$ & $\begin{array}{l}\mathrm{x}^{\mathrm{e}} \\
\mathrm{X}^{\mathrm{e}}\end{array}$ \\
\hline Sample Size & 9 & 9 & 9 & 9 & 9 & 9 & 9 & 63 \\
\hline
\end{tabular}

"Percent is the percentage of respondents rating the item as "essential" or "very useful" (as opposed to "somewhat useful" or "not at all useful").

${ }^{\text {b }}$ Although a percentage is given for All Passive Respondents, it may not be indicative of the percentage of the whole passive community interested in that item (since the proportion of each type of respondent in this study may not correspond to the proportion that group constitutes of the entire population).

Cocal lenders, insurers, builders, engineers, installers, manufacturers, or distributors for passive systems.

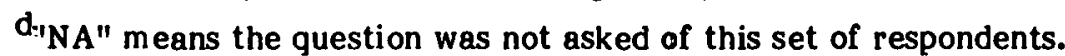

e" $X$ " indicates no overall percentage was calculated. For these items it may be necessary to develop different products/services for each group if their information needs are to be fully met. 
Table S-3. SOURC.ES USED TO OBTAIN SOLAR INFORMATION

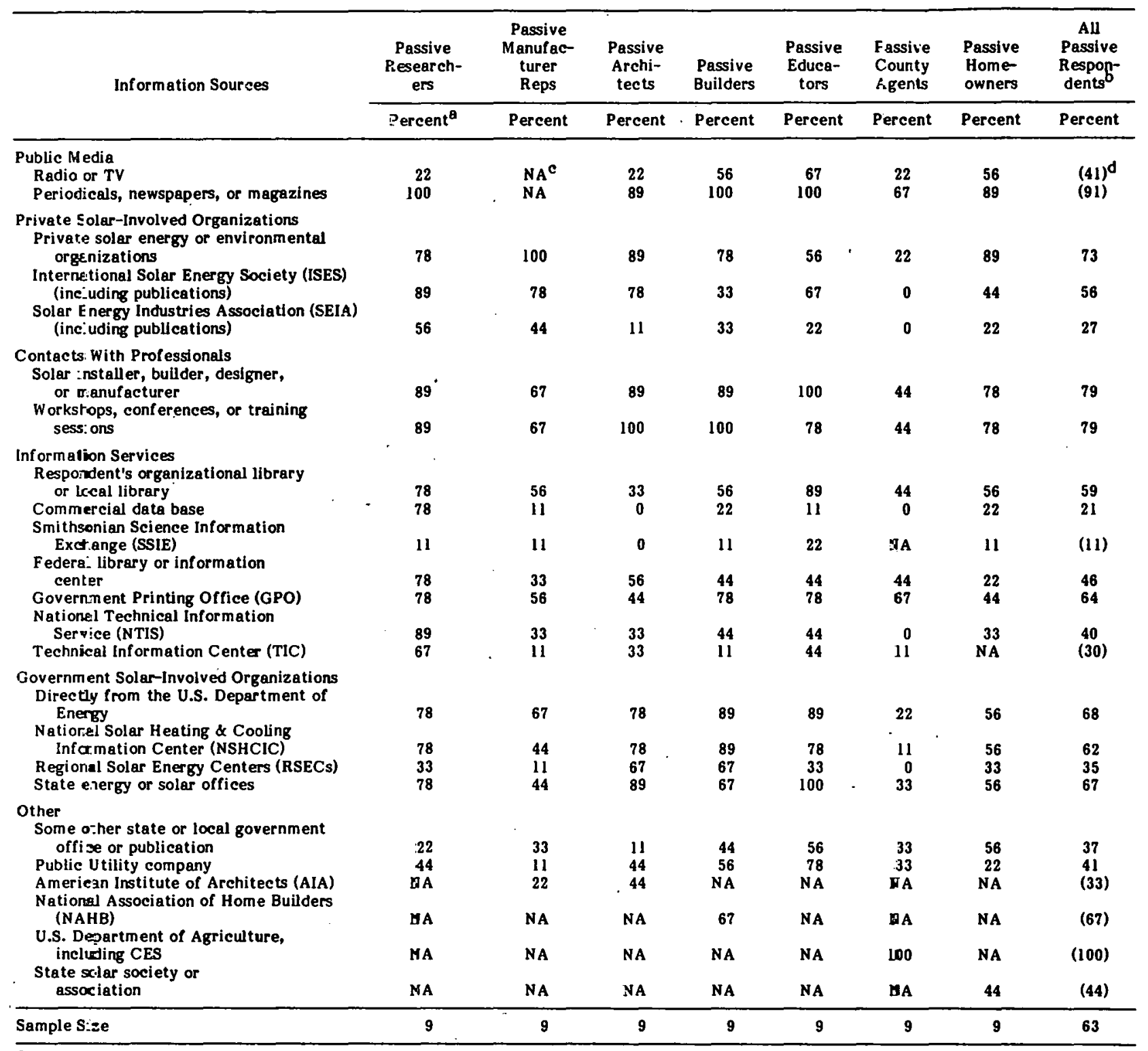

Percent is the percentage of respondents wha used the source to obtain any solar information in the past fes yee-s.

${ }^{b}$ Althought a percentage is given for All Passive Responcents, it may not be indicative of the percentage of the whole passive community interested in that Item (since the prcporti $n$ of each type of respondent in this study may not correspond to lhe proportion that group constitutes of the entire population).

C"NA" means the question was not asked of th= particular set of respondents.

$d_{1}($ )" means the question was not asked of al of the groups in the particular set of respondents. For exarpile, rit44)" means that 44 percent of those who were asked had used that source. Th $\mathrm{hc}$ case were fewer than nine respondents asked. 
- periodicals, newspapers, or magazines;

- a solar installer, builder, designer, or manufacturer;

- workshops, conf erences, or training sessions; and

- private solar energy or environmental organizations.

\section{Technical Areas of Interest}

Table S-4 lists the proportion of each group interested in information on different types of passive applications. The major results were:

- fairly high levels of interest in all applications, and

- the greatest interest in the collection and the storage of heat.

\section{Advanced Information Acquisition Methods}

Table S-5 lists the proportion of each group that had used selected advanced acquisition methods to obtain information in the past year. Passive respondents in general were not very accustomed to using these methods, especially microforms.

\section{Additional Findings}

- Passive Researchers were much more interested in direct applications than was the typical researcher. Their interest in system design, site-specific information ("climatological data" and "local building codes"), and "tax credits" were unusually high for researchers. Apparently, even at the research level there was confusion about which passive solar techniques were included under solar tax credits. This was the only passive group (and one of the few [9 of the 86] in the entire study) which prcferred computer analytic tools (models) to manual analytic tools.

- Representatives of Passive Manufacturers ..were much less likely to use the Regional Solar Energy Centers (RSECs) and the State Energy or Solar Offices to obtaln Infurmution than wcro the Representatives of active Solar Heating and Cooling (SHAC) Manufacturers. Although many of the Passive Manufacturers volunteered that marketing information was a critical need, when presented with 24 types of information to rate they ranked the two marketing-related items as 11 th and 14 th.

- Passive Architects were more likely than SHAC Architects to obtain information from solar-involved organizations in general and from RSECs, specifically. Passive Architects gave high ratings to systems design items, but they ranked computer analytical tools (models) only 22nd, while ranking manual analytical tools 2nd (see Fig. 5-1).

- Only three of the Passive Builders held a degree in architecture or engineering; the remainder were in business, economics, education, and psychology. In contrast, six of the nine SHAC Builders held technical degrees. Passive Builders were not as interested in systems design information as were SHAC Builders.

- Passive Educators seemed to be involved in applications of pașsive solar technologies, but were not doing very much research. They were typical of the 
Table S-4. INTEREST IN INFORMATION ON PASSIVE SOLAR HEATING AND COOLING TOPICS ${ }^{a}$

\begin{tabular}{|c|c|c|c|c|c|c|c|c|}
\hline Topic & $\begin{array}{l}\text { Passive } \\
\text { Research- } \\
\text { ers }\end{array}$ & $\begin{array}{c}\text { Passive } \\
\text { Manufac- } \\
\text { turer } \\
\text { Reps }\end{array}$ & $\begin{array}{c}\text { Passive } \\
\text { Archi- } \\
\text { tects }\end{array}$ & $\begin{array}{l}\text { Passive } \\
\text { Builders }\end{array}$ & $\begin{array}{l}\text { Passi-je } \\
\text { Educa- } \\
\text { tors }\end{array}$ & $\begin{array}{l}\text { Passive } \\
\text { County } \\
\text { Agents }\end{array}$ & $\begin{array}{c}\text { Passive } \\
\text { Home- } \\
\text { owners }^{a}\end{array}$ & $\begin{array}{c}\text { All } \\
\text { Passive } \\
\text { Respon- } \\
\text { dents }^{\mathrm{e}}\end{array}$ \\
\hline & Percent $^{b}$ & Percent & Percent & Percent & Percent & P.ercent & Percent $^{\mathrm{a}}$ & Percent $^{c}$ \\
\hline Building Design & 78 & 67 & 100 & 100 & 100 & 89 & $N A^{d}$ & $(89)^{e}$ \\
\hline Landscaping, Building Orientation & 78 & 22 & 78 & 56 & 67 & 78 & 100 & 68 \\
\hline Collection of Heat & 100 & 78 & 89 & 100 & 100 & 100 & NA & $(94)$ \\
\hline Greenhouses & 89 & 56 & 78 & 100 & 89 & 78 & 56 & 78 \\
\hline Storage of Heat & 100 & 56 & 89 & 100 & 100 & 100 & NA & $(91)$ \\
\hline Space Cooling & 56 & 67 & 67 & 78 & 78 & 100 & 22 & 67 \\
\hline Water Heating & 67 & 67 & 89 & 56 & 89 & 100 & NA & (78) \\
\hline Hybrid Systems & 78 & 78 & 78 & 78 & 100 & 100 & NA & (85) \\
\hline Sample Size & 9 & 9 & 9 & 9 & 9 & 9 & 9 & 63 \\
\hline
\end{tabular}

${ }^{2}$ For Passive Hom eowners the data refers to the percent whose system uses the specific application, rather than the percent interested in information on that topic. The data for users is not inclujed in All Passive Respondents.

${ }^{b}$ Percent is the percentage of respondents interested in the application.

${ }^{c}$ Although a percentage is given for All Passive Respondents, it may not be indicative of the percentage of the whole passive community interested in that item (since the proportion of each type of respondent in this study may not correspond to the proportion that group constitutes of the entire popslation).

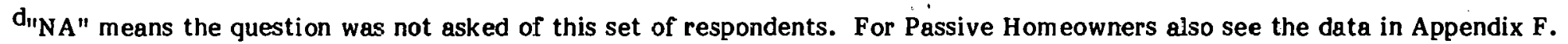

e"( )" means the question was not asked of all of the groufs in the particular set of respondents. For example, "(44)" means that 44 percent of those who were asked had usec that source. In no case were fewer than nine respondents asked. 
Table S-5. ADVANCED INFORMATION ACQUISTION METHODS USED

\begin{tabular}{|c|c|c|c|c|c|c|c|c|}
\hline \multirow[t]{2}{*}{ Acquisition Methods } & $\begin{array}{c}\text { Passive } \\
\text { Research- } \\
\text { ers }\end{array}$ & $\begin{array}{c}\text { Passive } \\
\text { Manuf ac- } \\
\text { turer } \\
\text { Reps }\end{array}$ & $\begin{array}{c}\text { Passive } \\
\text { Archi- } \\
\text { tects }\end{array}$ & $\begin{array}{l}\text { Passive } \\
\text { Builders }\end{array}$ & $\begin{array}{c}\text { Passive } \\
\text { Educa- } \\
\text { tors }\end{array}$ & $\begin{array}{l}\text { Passive } \\
\text { County } \\
\text { Agents }\end{array}$ & $\begin{array}{l}\text { Passive } \\
\text { Home- } \\
\text { owners }\end{array}$ & $\begin{array}{c}\text { All } \\
\text { Passive } \\
\text { Respon- } \\
\text { dents }^{b}\end{array}$ \\
\hline & Percent $^{Q}$ & Percent & Percent & Percent & Percent & Percent & Percent & Percent $^{b}$ \\
\hline $\begin{array}{l}\text { Computer Terminal Access to } \\
\text { Data Banks }\end{array}$ & 44 & 33 & 44 & 33 & il & 11 & $\mathrm{NA}^{\mathrm{C}}$ & (30) \\
\hline $\begin{array}{l}\text { Microf or } m \text { (microfiche, microfilm } \\
\text { sheets or rolls, CDM, etc.) }\end{array}$ & 11 & 22 & 0 & $\mathbf{0}$ & 11 & 22 & NA & (11) \\
\hline Sample Size & $\dot{9}$ & 9 & 9 & 9 & 9 & 9 & 9 & 54 \\
\hline
\end{tabular}

a Percent is the percentage of respondents who used the method in the past year.

${ }^{b}$ Although a percentage is given for All Passive Respondents, it may not be indicative of the percentage of the whole passive community interested in that ite $m$ (since the proportion of each type of respondent in this study may not correspond to the proportion that group constitutes of the entire population).

"NA" means the question was not asked of this set of respondents. 
educators surveyed in this study in level of involvement, degree of informedness, education level, and use of a variety of information sources.

- Passive County Extension Service Agents were extremely restricted in the range of solar information sources they used, depending even more heavily upon the U.S. Department of Agriculture than had been supposed. Their degree of involvement in passive solar technologies was less than that of County Extension Agents in SHAC.

- Of all the passive groups, Passive Homeowners gave the lowest ranking to "tax credits, grants, or other economic incentives." They were surprisingly interested in technical information, including "the state of the art in passive technologies" and "passive research in progress." It was interesting to note they ranked "a technical description of how a particular pussive system works" 5 th, but ranked "a non technical description" 18th. Similarly, they ranked manual analytiral tonls 2nd, but computer analy tieul tools 1 't th (see Fig. 9-1).

Since six of the nine Passive Hom eowners had owned their solar system for over three years, it seemed likely that most of this group were "early innovators;" [3] as such, their needs may not be typical. 


\section{TABLE OF CONTENTS}

Management Summary

1.0 Introduction $\ldots \ldots \ldots \ldots \ldots \ldots \ldots \ldots \ldots \ldots \ldots \ldots \ldots \ldots \ldots \ldots \ldots \ldots \ldots \ldots \ldots$

1.1 Background........................................

1.2 Solar Energy Information Data Bank (SEIDB) Program Planning $\ldots \ldots \ldots \ldots .2$

1.3 Report Contents ................................. 3

2.0 Study Description $\ldots \ldots \ldots \ldots \ldots \ldots \ldots \ldots \ldots \ldots \ldots \ldots \ldots \ldots \ldots \ldots \ldots \ldots \ldots$

2.1 Study Characteristics $\ldots \ldots \ldots \ldots \ldots \ldots \ldots \ldots \ldots \ldots \ldots \ldots \ldots \ldots \ldots \ldots$

2.2 Groups Studied................................... 5

2.2.1 Target Audiences, Classes, and Groups ............... 6

2.2.2 Criteria for Selection of Groups to Study $\ldots \ldots \ldots \ldots \ldots \ldots \ldots \ldots \ldots 7$

2.2.3 Groups Included in Passive Solar Study ................. 7

2.2.4 Passive-Concerned Groups Included in General Solar Study . . . . . . 13

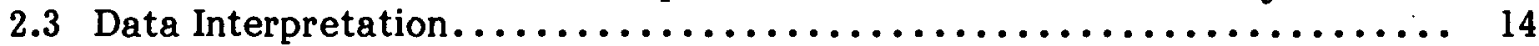

2.3.1 Impact of the Sample Frames: Who was Sampled? ........... 14

2.3.2 Statistical Tests .............................. 14

2.3.3 Hypotheses Versus Conclusions $\ldots \ldots \ldots \ldots \ldots \ldots \ldots \ldots \ldots \ldots \ldots \ldots \ldots$

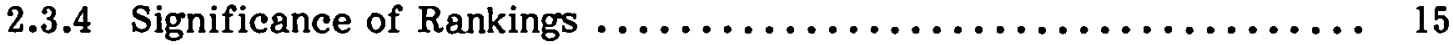

2.3.5 Alternative Measures of Usefulness ................... 15

2.3.6 Combining Results From Different Groups ................ 15

2.3.7 Specific Information Products...................... 16

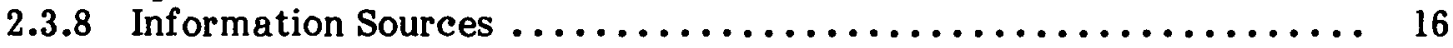

3.0 Study Findings: Passive Researchers...................... 17

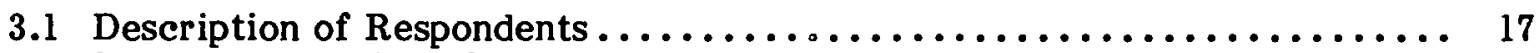

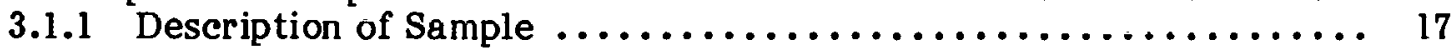

3.1.2 Current Status of Respondents .................... 18

3.1.3 Background of Respundents ........................ 19

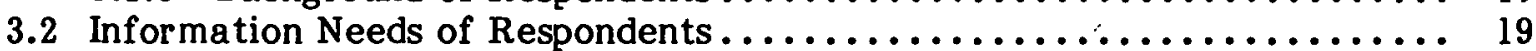

3.2 .1 Technical Areas............................... 19

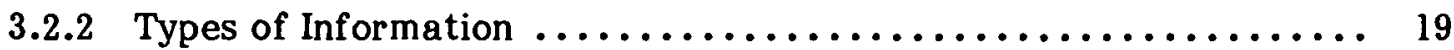

3.3 Acquisition of Infor mation by Respondents.................. 24

3.3.1 Use of Selected Information Sources ................. 24

3.3.2 Membership in Solar-Interested Organizations .............. 28

3.3.3 Exposure to Publications on Solar Energy ................. 28

3.3.4 Use of Special Acquisition Methods ................... 29

3.4 Summary and Comments ............................ 29

4.0 Study Findings: Passive Manufacturer Representatives .............. 31

4.1 Description of Respondents $\ldots \ldots \ldots \ldots \ldots \ldots \ldots \ldots \ldots \ldots \ldots \ldots \ldots \ldots \ldots \ldots$

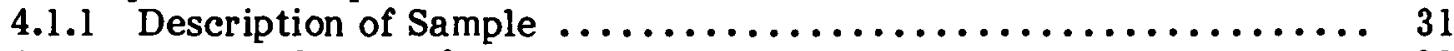

4.1 .2 Current Statue of Respondents ..................... 32

4.1.3 Background of Respondents ...................... 33 


\section{TABLE OF CONTENTS (continued)}

4.2 Information Needs of Respondents $\ldots \ldots \ldots \ldots \ldots \ldots \ldots \ldots \ldots \ldots \ldots \ldots$

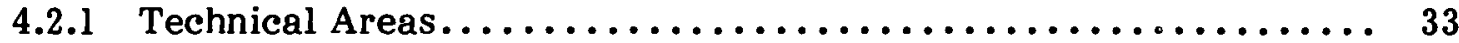

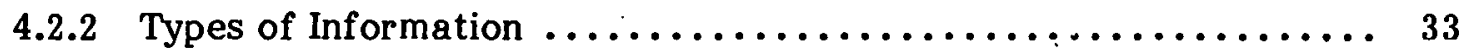

4.3 Acquisition of Infor mation by Respondents ................. 38

4.3.1 Use of Selected Information Sources ................. 38

4:3.2 Membership in Solar-Interested Organizations ............. 42

4.3.3 Exposure to Publications on Solar Energy ................ 42

4.3.4 Use of Special Acquisition Methods ..................... 42

4.4 Summary and Comments ............................. 43

5.0 Study Findings: Passive Architerts $\ldots \ldots \ldots \ldots \ldots \ldots \ldots \ldots \ldots \ldots \ldots \ldots \ldots \ldots$

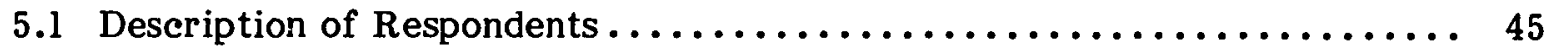

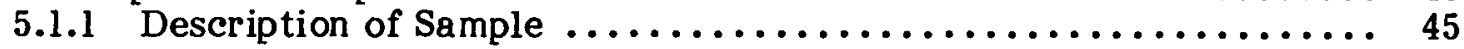

5.1 .2 Current Status of Respondents ..................... 45

5.1 .3 Background of Respondents ...................... 46

5.2 Information Needs of Respondents $\ldots \ldots \ldots \ldots \ldots \ldots \ldots \ldots \ldots \ldots \ldots$

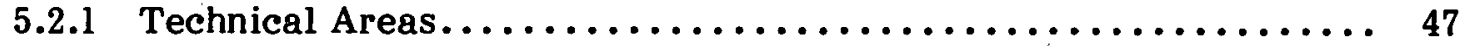

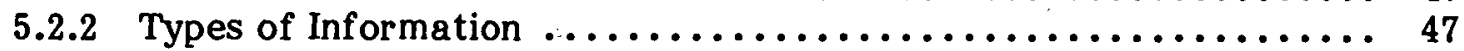

5.3 Acquisition of Infor mation by Respondents................ 51

5.3.1 Use of Selected Information Sources ................... 51

5.3.2 Membership in Solar-Interested Organizations . . . . . . . . . . . 54

5.3.3 Exposure to Publications on Solar Energy ................ 54

5.3 .4 Use of Special Acquisition Methods .................... 55

5.4 Summary and Comments .............................. 55

6.0 Study Findings: Passive Builders $\ldots \ldots \ldots \ldots \ldots \ldots \ldots \ldots \ldots \ldots \ldots \ldots \ldots \ldots$

6.1 Description of Respondents .......................... 57

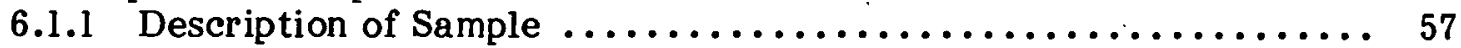

6.1 .2 Current Status of Respondents ..................... 57

6.1.3 Background of Respondents ...................... 58

6.2 Information Needs of Respondents $\ldots \ldots \ldots \ldots \ldots \ldots \ldots \ldots \ldots \ldots \ldots \ldots$

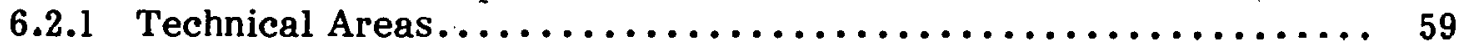

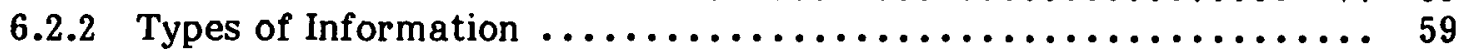

6.3 Acquisition of Information by Respondents................. 63

6.3 .1 Usc of Sclected Informution Suurces ................. 63

6.3.2 Membership in Solar-Interested Organizutions ............... 66

6.3.3 Exposure to Publications on Solar Energy ................. 66

6.3 .4 Use of Special Acquisition Methods ................. 67

6.4 Summary and Comments $\ldots \ldots \ldots \ldots \ldots \ldots \ldots \ldots \ldots \ldots \ldots \ldots \ldots \ldots \ldots$

7.0 Study Findings: Passive Educators....................... 69

7.1 Description of Respondents ......................... 69

7.1 .1 Description of Sample $\ldots \ldots \ldots \ldots \ldots \ldots \ldots \ldots \ldots \ldots \ldots \ldots \ldots \ldots \ldots$

7.1 .2 Current Status of Respondents ..................... 70

7.1.3 Background of Respondents ..................... 71 
TABLE OF CONTENTS (continued)

7.2 Information Needs of Respondents ..................... 71

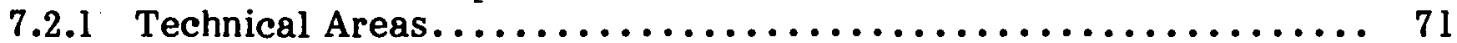

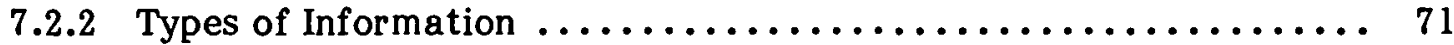

7.3 Acquisition of Information by Respondents................. 76

7.3.1 Use of Selected Information Sources .................. 76

7.3.2 Membership in Solar-Interested Organizations ............. 80

7.3.3 Exposure to Publications on Solar Energy ................ 80

7.3.4 Use of Special Acquisition Methods ................... 81

7.4 Summary and Comments $\ldots \ldots \ldots \ldots \ldots \ldots \ldots \ldots \ldots \ldots \ldots \ldots \ldots \ldots$

8.0 Study Findings: County Agents, Cooperative Extension

Service ...................................... 83

8.1 Description of Respondents ......................... 83

8.1.1 Description of Sample . ........................... 83

8.1 .2 Current Status of Respondents $\ldots \ldots \ldots \ldots \ldots \ldots \ldots \ldots \ldots \ldots \ldots \ldots . \ldots \ldots$

8.1.3 Background of Respondents ......................... 85

8.2 Information Needs of Respondents $\ldots \ldots \ldots \ldots \ldots \ldots \ldots \ldots \ldots \ldots \ldots \ldots$

8.2 .1 Technical Areas.............................. 85

8.2 .2 Types of Information $\ldots \ldots \ldots \ldots \ldots \ldots \ldots \ldots \ldots \ldots \ldots \ldots \ldots$

8.3 Acquisition of Information by Respondents................. 91

8.3.1 Use of Selected Information Sources .................. 91

8.3.2 Membership in Solar-Interested Organizations .............. 96

8.3.3 Exposure to Publications on Solar Energy ................ 97

8.3.4 Use of Special Acquisition Methods .................. 97

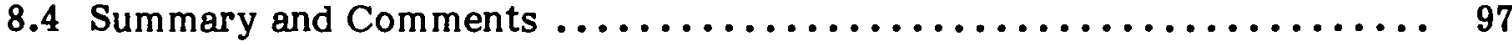

9.0 Study Findings: Passive Homeowners $\ldots \ldots \ldots \ldots \ldots \ldots \ldots \ldots \ldots \ldots \ldots \ldots \ldots$

9.1 Description of Respondents ......................... 99

9.1.1 Description of Sample ......................... 99

9.1.2 Current Status of Respondents .................... 99

9.1.3 Background of Respondents ........................ 100

9.2 Information Needs of Respondents $\ldots \ldots \ldots \ldots \ldots \ldots \ldots \ldots \ldots \ldots \ldots \ldots \ldots$

9.2.1 Technical Areas................................. 101

9.2.2 Types of Information ........................... 101

9.3 Acquisition of Information by Respondents................. 105

9.3.1 Initial Information Sources ...................... 105

9.3.2 Use of Selected Information Sources . . . . . . . . . . . . . 105

9.3.3 Membership in Solar-Interested Organizations ............. 108

9.3.4 Exposure to Publications on Solar Energy ................ 108

9.4 Summary and Comments $\ldots \ldots \ldots \ldots \ldots \ldots \ldots \ldots \ldots \ldots \ldots \ldots \ldots \ldots$

10.0 References $\ldots \ldots \ldots \ldots \ldots \ldots \ldots \ldots \ldots \ldots \ldots \ldots \ldots \ldots \ldots \ldots \ldots \ldots \ldots \ldots \ldots$ 
SEP

TR-746

TABLE OF CONTENTS (concluded)

Page

Appendix A: Groups Included in Study

113

Appendix B: Study Development and Procedure

119

Appendix C: Letter of Introduction

131

Appendix D: Study Questionnaire

135

Appendix E: Statistical Testing

161

Appendix F: Passive Solar Heating and Cooling Data Tables

165

$\mathbf{x x}$ 


\section{LIST OF FIGURES}

3-1 Usefulness of Selected Information Items: Passive

Researchers .................................... 21

3-2 Usefulness of Selected Information Items: Total Solar Heating and Cooling Researchers ............................. 22

3-3 Usefulness of Selected Information Items:

All Researchers..................................... 23

3-4 Usefulness of Selected Information Sources: Passive

Researchers ..................................... 25

3-5 Use of Selected Information Sources: Total Solar Heating and Cooling Researchers . . . . . . . . . . . . . . . . . . . . . . . 26

3-6 Use of Selected Information Sources: All Researchers $\ldots \ldots \ldots \ldots \ldots \ldots \ldots$

4-1 Usefulness of Selected Information Items: Passive Manufacturer Representatives ............................. 35

4-2 Usefulness of Selected Information Items: Total Solar Heating and Cooling Manufacturer Representatives ................... 36

4-3 Usefulness of Selected Information Items:

All Manufacturer Representatives ........................ 37

4-4 Use of Selected Information Sources:

Passive Manufacturer Representatives ........................ 39

4-5 Use of Selected Information Sources: Total Solar Heating and Cooling Manufacturer Representatives .................... 40

4-6 Use of Selected Information Sources: All Manufacturer Representatives .................................41

5-1 Usefulness of Selected Information Items: Passive Architects

5-2 Usefulness of Selected Information Items: Solar Heating and Cooling Architects .............................. 50

5-3 Use of Selected Information Sources: Passive Architects . . . . . . . . . . 52

5-4 Use of Selected Information Sources: Solar Heating

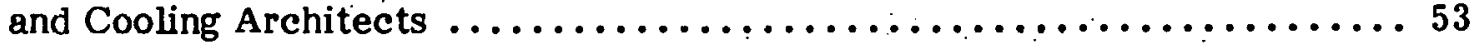


LIST OF FIGURES (continued)

$\underline{\text { Page }}$

6-1 Usefulness of Selected Information Items: Passive

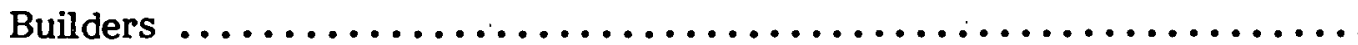

6-2 Use of Selected Information Items: Solar Heating

and Cooling Builders................................ 62

6-3 Use of Selected Information Sources: Passive Builders . . . . . . . . . . 64

6-4 Use of Selected Information Sources: Solar Heating and Cooling Builders................................ 65

7-1 Usefulness of Selected Information Items: Passive

Educators .......................................

7-2 Usefulness of Selected Information Items: Solar Heating

and Cooling Educators .............................. 74

7-3 Usefulness of Selected Information Items: All

Educators ....................................... 75

7-4 Use of Selected Information Sources: Passive Educators . . . . . . . . . . . 77

7-5 Use of Selected Information Sources: Solar Heating

and Cooling Educators .............................. 78

7-6 Use of Selected Information Sources: All Educators $\ldots \ldots \ldots \ldots \ldots \ldots \ldots \ldots \ldots$

8-1 Usefulness of Selected Information Items: Passive Cooperative

Extension Service County Agents......................... 87

8-2 Usefulness of Selected Information Items: SHAC Cooperative

Extension Service County Agents........................ 88

8-3 Usefulness of Selected Information Items: ALL Cooperative

Extension Service County Agents.........................

8-4 Usefulness of Selected Information Items: All Cooperative

Extensiun Servicc State Specialists ........................ 90

8-5 Use of Selected Information Sources: Passive Cooperative

Extension Service County Agents......................... 92

8-6 Use of Selected Information Sources: SHAC Cooperative

Extension Service County Agents......................... 93

8-7 Use of Selected Information Sources: All Cooperative

Extension Service County Agents. 
LIST OF FIGURES (concluded)

$\underline{\text { Page }}$

8-8 Use of Selected Information Sources: All Cooperative Extension Service State Specialists ....................... 95

9-1 Usefulness of Selected Information Items: Passive Homeowners ................................... 103

9-2 Use of Selected Information Items: Total Solar Heating and Cooling Homeowners............................. 104

9-3 Use of Selected Information Sources: Passive Homeowners ................................. 106

9-4 Use of Selected Information Sources: Total Solar Heating and Cooling Homeowners........................... 107

C-1 Letter of Introduction $\ldots \ldots \ldots \ldots \ldots \ldots \ldots \ldots \ldots \ldots \ldots \ldots \ldots \ldots \ldots \ldots \ldots$

D-1 Questionnaire.................................. 138

D-2 User Questionnaire $\ldots \ldots \ldots \ldots \ldots \ldots \ldots \ldots \ldots \ldots \ldots \ldots \ldots \ldots \ldots \ldots \ldots$

F-1 Passive Solar Heating and Cooling Data Tables ................. 172 
THIS PAGE WAS INTENTIONALLY LEFT BLANK 


\section{LIST OF TABLES}

$\underline{\text { Page }}$

S-1 Comparative Usefulness of General Types of Information on Passive Solar Heating and Cooling $\ldots \ldots \ldots \ldots \ldots \ldots \ldots \ldots$ x

S-2 Value Assessment of Specific Passive Solar Heating and Cooling Information Products $\ldots \ldots \ldots \ldots \ldots \ldots \ldots \ldots \ldots \ldots \ldots \ldots \ldots \ldots$

S-3 Sources Used to Obtain Solar Information.................... xii

S-4 Interest in Information on Passive Solar Heating and Cooling Topies .............................. xiv

S-5 Advanced Information Acquisition Methods Used $\ldots \ldots \ldots \ldots \ldots \ldots \ldots \ldots \ldots$

2-1 Passive Solar Heating and Cooling Information Users .............. 8

3-1 Completion of Interviews: Passive Researchers ................. 18

4-1 Completion of Interviews: Passive Manufacturer Representatives $\ldots \ldots \ldots \ldots .32$

5-1 Completion of Interviews: Passive Architects.................. 46

5-2 Areas of Interest: Passive Architects and Passive Builders............ 47

6-1 Completion of Interviews: Passive Builders $\ldots \ldots \ldots \ldots \ldots \ldots \ldots \ldots \ldots \ldots \ldots$

6-2 Areas of Interest: Passive Builders and Passive Architects............ 59

7-1 Completion of Interviews: Passive Educators $\ldots \ldots \ldots \ldots \ldots \ldots \ldots \ldots \ldots \ldots$

8-1 Completion of Interviews: Passive County Agents $\ldots \ldots \ldots \ldots \ldots \ldots \ldots \ldots$

9-1 Completion of Interviews: Passive Homeowners $\ldots \ldots \ldots \ldots \ldots \ldots \ldots \ldots$

9-2 Types of Systems Used by Passive Homeowners.................. 101

A-1 Groups Studied................................... 115

B-1 Cooperative Extension Service (CES) States Represented

in Samples ....................................... 127

D-1 Selected Organizations About which Passive Respondents

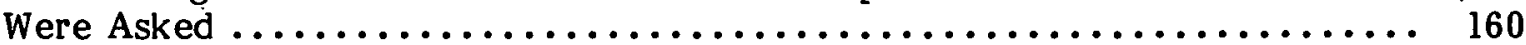

F-1 Groups and Combination Groups with Data Included in

Appendix F.................................... 168

F-2 Combination Groups $\ldots \ldots \ldots \ldots \ldots \ldots \ldots \ldots \ldots \ldots \ldots \ldots \ldots \ldots \ldots \ldots \ldots$

F-3 List of Passive Solar Heating and Cooling

Data Tables 


\section{SECTION 1.0}

\section{NTRODUCTION}

This report describes the results of a series of interviews with potential users of information on passive solar technologies. These interviews, part of a larger study covering nine different solar technologies, attempted to idențify:

- the type of information each distinctive group of information users needed, and

- the best way of getting information to that group.

This section explains the background of the study, places this report in the context of the overall program, and describes the structure of this report.

\subsection{BACKGROUND}

The rapid, widespread commercialization of solar energy will be necessary if the United States is to meet the energy crises of the next $\mathbf{5 0}$ years. But the use of solar energy will never reach meaningful levels without both the recognition that information transfer is essential to commercialization and the deliberate development of systems for the transfer of information. For example: scientists need the latest solar research results to enhance their own efforts; engineers and installers need performance data to design solar systems; public interest groups need environmental impact data to support solar technologies against conventional energy alternatives; potential owners of solar energy systems need cost information to make purchase decisions; the general public needs basic information to weigh which public policies to support.

In 1974 the Congress, noting the importance of information transfer and recognizing the value to the solar community of an integrated, comprehensive data collection and informution dissemination system, called for the implementation of a Solar Energy Information Data Bank (SEIDB). In The Solar Energy Research and Development Act (P.L. 93-473) Congress stated that the SEIDB should be established "for the purpose of collecting, reviewing, processing, and disseminating information and data ... in all of the solar energy technologies."

The U.S. Department of Energy (DOE) has assigned the Solar Energy Research Institute (SERI) the task of serving as the lead center to fulfill this Congressional mandate to collect all types of solar-related information, to convert it into a user-oriented format, and to disseminate this information to the widest possible range of persons and groups with an interest in solar energy. These groups range from decision makers at all levels of government to manufacturers of solar products; from solar architects, installers, and service persons to home or farm owners; and from banks and financial institutions to scientists and researchers. In accord, SERI's Information Systems Division (ISD) is now in the process of collecting solar information, building data bases, and preparing and disseminating information through a variety of products and services.

The long-range objective of the SEIDB is a centrally-coordinated network to ensure that all individuals concerned with solar energy have prompt and efficient access to whatever information is necessary to support suund decisions. Ultimately this information will be accessible through a variety of means (publications, computer data systems, audiovisual products, the Solar Energy Information Center, inquiry and referral services, etc.) to serve the diverse requirements of the solar community. 


\subsection{SEIDB PROGRAM PLANNING}

In the past decade, information scientists have studied many organizations responsible for data collection and information product development. A consistent finding of this research is that a key to the successful, efficient operation of such an organization is to design the entire system with the potential information user in mind. It is essential that development of information products and data bases be targeted for specific users rather than merely developed spontaneously. . The information users, their information needs, and the priority of those needs must all be identified before effective information products and services can be developed efficiently. To ensure that the SEIDB is responsive to the high-priority information needs of the solar community, the Information Market Research Section of ISD is performing the following tasks:

1. Defining the community of solar information users;

2. Setting priorities as to which groups of information users have the most important near-term information needs;

3. Determining the near-term information needs of the high-priority users;

4. Determining the information channels which can be effectively used to reach the high-priority users;

5. Determining what high-priority information needs are being met fully by existing products and services; and

6. Recommending additional, targeted, cost-effective information products and services to meet high-pririty needs.

The results of the first two tasks are described in a previous document [1]. Firsl, for each solar technology, those members or potential members of the solar community who will need solar information were identified; second, the relative importance of meeting the near-term information needs of each group of information users was described. This document provides guidelines to SEIDB planners as to who might be using the SEIDB and whose near-term needs are the most important.

The results of the third and fourth tasks are described in the current set of 10 reports (see Section 1.3). These reports document the high-priority information needs and the most familiar information channels for each of 86 groups which were interviewed by telephone.

T'here have been a few previous studies which asked homeowners what solar information they needed, but this is the only known study to provide data on the solar information that such groups as researchers, manufacturers, architects, engineers, installers, lawyers, bankers, insurers, publlc interest groups, state energy offices, and agricultural extension agents themselves say they want.

The data from this study will be used along with other data to determine what new information products and services SERI and the SEIDB Network-and the entire solar information outreach community-should be preparing for and disseminating to the solar community. These data will include (but not be limited to): contacts with SERI specialists; review of the Annual Operating Plans, Institutional Plans, and Program Plans of DOE and SERI; reviews of other solar literature; development of an "information user profile" data base from mailing list response cards; information user panels; direct contacts with members of the solar community at conferences, training sessions, etc.; visits to headquarters of national associations of users; and feedback provided by users of 
existing information products. Since information needs and priorities will continuously change, these tasks will necessarily be ongoing.

\subsection{REPORT CONTENTS}

This passive solar report is one of ten issued on the results of these studies of solar energy information users. The full set of reports covers:

- Photovoltaics

- Passive Solar Heating and Cooling

- Active Solar Heating and Cooling

- Biomass Energy

- Solar Thermal Electric Power

- Industrial and Agricultural Process Heat

- Wind Energy

- Ocean Energy

- Solar Energy Storage

- General Solar Energy

Section 2.0 of this report describes the type of study conducted and the resulting constraints. The method used to select these groups is also described in Section 2.0. Several groups discussed in other reports from this study also indicated an interest in information on passive solar heating and cooling. These groups are listed in Section 2.2.4. Sections 3.0 through 9.0 describe the results of studies of:

- Federally Funded Passive Researchers,

- Representatives of Passive Manufacturers,

- Architects who have been involved in passive projects,

- Builders who have been involved-in passive projects,

- Educators teaching college level courses in passive solar technologies,

- Cooperative Extension Service (CES) County Agents who will be needing information on passive, and

- Homeowners with passive solar systems.

These respondents were asked specifically about their needs for information on passive solar heating and cooling. In each of these sections describing study results, a standard presentation format has been used.

The appendices contain a list of all 86 groups interviewed (including the technologies other than passive solar). They also contain a description of how the study was developed, a copy of the letter of introduction, a sample questionnaire, a description of the statistical tests used, and the data from the studies of the passive solar groups. 


\section{SEPI}

1 


\section{SECTION 2.0}

\section{STUDY DESCRIPTION}

This section gives a brief description of the study. Appendix B gives additional information on how the study was designed and conducted. This section also explains how groups from the passive solar community were selected as those to be sampled and gives a few comments on interpretation of study results. The study findings are reported in Section 3.0 to 9.0 .

\subsection{STUDY CHARACTERISTICS}

Between 3 September 1979 and 13 October 1979 Market Opinion Research, Inc. (MOR) of Detroit, Michigan-under subcontract to the Solar Energy Research Institute (SERI)conducted telephone interviews with 86 distinct groups of solar information users. Approximately nine respondents were interviewed from each group. Interviews were based upon professionally reviewed and tested questionnaires (see Appendix D); they took an average of 18 minutes to complete. The 86 groups, selected to cover 9 solar technologies/applications, are listed in Appendix A. The results discussed in this report are from the 7 of those 86 studies which dealt specifically with passive solar.

Studies of 86 groups, each interested in either one of the nine different solar technologies or in solar technologies in general, provided an extremely broad view of the information needs of the solar community. Although the sample size of nine respondents per group was small, the data still proved to be quite adequate for planning purposes. It was possible to determine which information was the most important to the respondents and what was the best channel for disseminating that information. A variety of valid statistical tests were performed, both to compare the priorities a group gave to different information items and to compare the priorities different groups gave to the same item.

The respondents proved to be very cooperative. Considering the length and nature of the telephone interviews, it was surprising that only about $3 \%$ of the respondents terminated an interview or refused to be interviewed. This finding supported the interviewers' statements that the respondents were very interested in telling what they were doing in solar energy, in obtaining solar information, and in specifying what solar information would prove the most valuable. It was also observed that the number of respondents answering "don't know" or not answering a question was quite low. Including those cases where the potential respondent could not be reached within three attempts (or before the required number of interviews was completed), where the respondent refused to be interviewed, where the respondent terminated the interview prematurely, etc., the completion rate for the entire study was about 75 percent. The completion rate for each individual group is given in the section in which that group is discussed.

\subsection{GROUPS STUDIED}

One of the most important tasks was the selection of the groups of potential users of solar information to be studied. Before this could be done, however, it was necessary to list the important groups constituting the passive solar community and to develop a conceptual framework within which selections could be made. 


\subsubsection{Target Audiences, Classes, and Groups}

An important information science concept in developing information products and services is that of the "target audience" or "target group." These are generally defined as a collection of individuals or organizations who have similar information needs and information-acquiring habits. People in the same group tend to need information on the same subjects, at a similar technical level, and within a similar timeframe. In developing an information product program, it is important to begin with a typology that assigns information users who have similar needs to common groupings. This allows development of efficient, targeted information products to meet identified needs of specific users, without inundating other members of the solar community with unneeded information.

In Solar Information User Priority Study [1] such a typology was developed. Under this system members of the solar community were placed in distinct "user groups." A set $n f$ user groups formed a "iser class" and a colleclion of user classes formed a "target audience." For more precise definitions:

- A User Group is the most basic category of information users who can be combined together under a single definitive title (e.g., Civil Engineers). A single information user group should be addressable by many specific information products. The purpose of defining distinct information User Groups is to identify a single set of users who can be served by the same information product (e.g., a civil engineers' handbook).

- A User Class is a set of information user groups which exhibit many common distinguishing characteristics (e.g., Facility or System Designers). A single information user class should be addressable by many general information products. The purpose of defining separate information User Classes is to identify sets of two or more groups of users who can be served by similiar information products (e.g., solar heating and cooling system design models).

- A Target Audience is a set of information user classes which exhibit some common distinguishing characteristics (e.g., Researchers). A single target audience should be addressable by one or more distinct types of information products. The purpose of defining separate information user Target Audiences is to identify broad sets of users who can be served by the same generic types of information products (e.g., research-in-progress newsletters).

Following this system, all solar information users fall within one or more of five Target Audiences. These Target Audiences are defined as follows:

Researchers - those who are actively involved in researching, develnping, and terting of new state-of-the-art techical developments in solar energy.

Applications Technologists - those involved in translating research results into marketable equipment and services. This classification includes manufacture, distribution, sales, design, installation, and maintenance of solar systems or components.

Facilitators - those whose decisions or actions directly aid (in either a positive or negative manner) the commercialization of solar. Thus, congressmen would be Facilitators in that they have the ability to pass legislation giving incentives; lobbyists in that they can affect legislation; state energy offices in that they can initiate demonstration projects; and the Environmental Protection Agency (EPA) in that it I can forbid construction of a manufacturing plant at a specific site. 
Users or Prospective Users - those individuals or organizations who have already applied this type of solar energy technology in their operations or have a reasonable chance of doing so in the near future.

General Public - Individuals who are not likely to utilize solar energy in the near future. An important aspect of this audience is its ability to influence the course of solar technologies through political influence, pro or con.

Based upon this scheme, the passive solar information user community has been defined. Table 2-1 enumerates the user groups comprising the passive solar information community and shows into which target audience each falls [1] .

\subsubsection{Criteria for Selection of Groups to Study}

From Table 2-1, it is rapidly evident that there are many user groups who will eventually be needing information on passive solar energy. The problem was, thus, to select those groups to be surveyed as a part of this study. To determine which groups would be studied, each group was evaluated with respect to the following selection criteria:

- appropriateness of using a structured telephone interview to collect information from the group on information needs and habits,

- relative priority of the group's short-range or medium-range information needs, and

- availability of a sample frame for the group.

First, for many groups a structured telephone interview was not an appropriate method for defining information needs. It was not practical to interview DOE or an organization like the Electric Power Research Institute (EPRI), nor to survey a group like Congressional committee staff which would be too busy to respond. Rather than defining the information needs of these groups by telephone interviews, they will be contacted directly in FY 1981 .

Second, only those groups with a high immediate need or potential need for passive solar information were selected. Further, since fulfilling short-range information needs is critical, it was decluled that in most oases those people who were already involved with passive solar energy would be sampled. It was felt that these were the people who would be primary users of the Solar Energy Information Data Base (SEIDB) over the next few years. These groups had been identified earlier, in the Solar Information User Priority Study [1].

Finally, for many of the groups, lists of persons to be interviewed could not be developed or acquired. In the absence of sample frames, studies of such groups were not possible. (For more detail on sample frame development, see Appendix B.)

\subsubsection{Groups Included in the Passive Solar Study}

After all decision criteria and constraints had been applied, it was determined that studies of the following seven groups would be conducted to ask respondents about their need for information on passive solar energy: 
Table 2-1. PASSIVE SOLAR HEATING AND COOLING INFORMATION USERS

Target Audiences

User Classes

User Groups

$1.0 \quad$ Researchers

1.1 DOE-Funded Researchers or Developers

Contractors

National Laboratories

1.2 Non-DOE, Federally Funded Researchers or Developers

Department of Housing and Urban Development (HUD)

1.3 Nonfederally Funded Researchers or Developers

Universities

Solar Manufacturers

Trade Research Associations

Electric Power Research Institute (EPRI)

Gas Research Institute

Independent Research Organizations

Utilities

\subsection{Applications Technologists}

2.1 Passive or Passive-Related Manufacturers

Passive Equipment Manufacturers

Prefabricated Home Manufacturers

Mobile Home Manufacturers

Building Materials Manufacturers

2.2 Passive Facility or System Designers

Architects

System Designers/Engineers

Architectural/Engineering Design Firms

Mechanical Engineers

Heating, Ventilating, and Air Conditioning

(HVAC) Engineers

2.3 Builders, Developers, or Contractors

Homebuilders, Developers

Home Remodeling Contractors

General Contractors

Architectural/Engineering Construction Firms

Mechanical Engineering Contractors

HVAC Contractors

Plumbing Contractors

Construction Engineers 
Table 2-1. PASSIVE SOLAR HEATING AND COOLING INFORMATION USERS (continued)

2.4 Passive Systems Installers or Maintainers

Installers

Carpenters

Plumbers

Electricians

Sheet Metal Workers

Solar Maintenance Workers

2.5 Passive Thermal Equipment Distributors

2.6 Technical Specialists for Utility, Government, Commercial, or Industrial Organization Using a

Passive System

Operation Managers

Planners

\subsection{Facilitators}

3.1 Legislators or Staff

Congressmen

Congressional Committee Staff

State Legislators

National Conference of State Legislatures

3.2 Local Government Organizations

County Government Officials

Local Government Officials

Munlcipul Planners

Tax Assessors and Officials

3.3 Government Solar-Active Organizations

DOE-Conservation and Solar Energy (C\&SE)

DOE-Energy Information Administration (EIA)

DOE-Regional Solar Energy Centers (RSECs)

DOE/HUD-National Solar Heating and Cooling

Informatin Center (NSHCIC)

DOE-Regional Energy Offices

DOE-Energy Extension Service

United States Department of Agriculture (USDA)-

Cooperative Extension Service

USDA-Other

Department of Housing and Urban Development (HUD)

Department of Labor (DOL)-Comprehensive

Employment and Training Act (CETA)

Tennessee Valley Authority (TVA)

National Center for Appropriate Technology (NCAT)

State Governors' Offices

State Energy Offices

State Solar Energy Offices 
Table 2-1. PASSIVE SOLAR HEATING AND COOLING INFORMATION USERS (continued)

State Agricultural Offices

Municipal Energy Offices

3.4 Government Solar-Concerned Organizations

General Services Administration (GSA)

Department of Defense (DOD)

Small Business Administration (SBA)

Internal Revenue Service (IRS)

Council on Envirnnmental Quality (CEQ)

3.5 Nongovèrnment Solar-Active Orgurizutlons

Solar Trade $\Lambda$ s3ociativils

Building Materials Trade Association

Solar Professional Societies

Solar Public Interest Groups

Solar Lobbyists

3.6 Nongovernment Solar-Concerned Organizations

Community/Home Improvement Associations

Public Interest Organizations

Environmental Organizations

Chambers of Commerce

Nonsolar Professional Societies

Nonsolar Trade Associations

Farmer Co-ops

Farmer's Education and

Cooperative Union of America

3.7 Regulatory, Codes, or Standards Community

Environmental Protection Agency (EPA)

Occupational Safety and Health Administration (OSHA)

American Society of Heating, Refrigerating,

and Air Conditioning Engineers (ASHRAE)

American National Standards Institute (ANSI)

Building Officials and Code Administrators

(BOCA), Council of American Building Officials

(CABO), International Conference of Building

Officlals (ICBO), Southern Building Code

Congress (SBCC)

American Society of Mechanical Engineers (ASME)

Better Business Bureaus

Building Inspectors

3.8 Utility Community

Electric Power Companies

Gas Utilities

National Association of

Regulatory Utility Commissioners

State Utility Commissions 
Table 2-1. PASSIVE SOLAR HEATING AND COOLING INFORMATION USERS (continued)

Utility Trade Associations

Federal Power Marketing Agencies

DOE-Bonneville Power Administration

Tennessee Valley Authority (TVA)

3.9 Financial Community

Bankers

Venture Capital Brokers

Government Loan Agencies

Stock Brokers

3.10 Legal Community

3.11 Real Estate Community

Agencies

Salesmen

Appraisers

3.12 Insurance Community

Management

Agents

Actuaries

3.13 Educational Community

High School Science Teachers

University Faculty

Vocational Instructors

Career Counselors

Seminar Organizers and Instructors

3.14 Information Intermediaries

Fèderal Technical Libraries

Industrial Technical Libraries

Academic or Nonprofit Technical Libraries

Public Libraries

Federal Information Centers

On-Line Information Services

Bookstores

Film Distributors

$3.15 \cdot$ Media

Newspapers or Magazines

Technical and Trade Journals

Television

Radio

Book Publishers

Newspaper Farm Editors of America 
Table 2-1. PASSIVE SOLAR HEATING AND COOLING INFORMATION USERS (concluded)

\subsection{Labor Organizations \\ Carpentry Unions \\ Construction Unions \\ Bricklayers' Unions}

\subsection{Users or Prospective Users}

4.1 Government, Commercial or Industrial Passive Users

Department of Defense (DOD)

GSA-Public Building Service

Other Federal/State/Local Agencies Owning or

Holding Titles to Buildings

Owners of Large Buildings

New

Retrofit

Owners of Small Buildings

New

Retrofit

\subsection{Residential or Farming Users}

Homeowners

Custom Homes

Speculative Houses

Retrofits

Mobile Home Owners

Farmers, Ranchers

\subsection{General Public}

Secondary School Students

College Student.s

Adults 
- Federally funded passive researchers,

- Representatives of passive manufacturers,

- Architects who have been involved in passive projects,

- Builders who have been involved in passive projects,

- Educators teaching college-level courses in passive solar technologies,

- Cooperative Extension Service (CES) county agents who will be needing information on passive, and

- Homeowners with passive solar systems.

The results from these surveys are reported in Sections 3.0 through 9.0. Groups considered for the study, but for whom adequate sample frames could not be obtained, included passsive equipment distributors and owners/managers of commercial buildings with passive systems.

\subsubsection{Passive-Concerned Groups Included in the General Solar Study}

Additionally, as a part of the overall study a number of surveys were conducted in which the respondents were asked about their need for information on solar energy in general, rather than on a specific technology like passive solar heating and cooling. While it was determined that all respondents in these groups had some involvement with solar energy, for many of them it was likely that this involvement was not, nor would it become, a primary factor in their professional work. Rather, for most-if not all-of them, solar energy was a new, but minor, issue which they were beginning to address within the scope of their existing jobs. Because each of these groups had peripheral interests in more than one solar technology, yet had not yet become fully involved with any, they were asked for general solar information needs rather than technology-specific solar information needs.

The results of the general solar study are reported in another document [2] . For passive solar energy the following nine groups were especially relevant because for each group at least six of the nine respondents indicated passive solar energy was one of the areas in which they were "particularly interested in obtaining information."

- Utilities not known to have conducted solar experiments or demonstrations,

- Loan officers,

- Real Estate Appraisers,

- Tax Assessors,

- Insurers,

- Lawyers,

- Public Interest Groups,

- Information specialists at State CES Offices, and .

- Agricultural engineering specialists at State CES Offices.

The general solar energy report [2] also discusses the results of studies in which state solar/energy office representatives were asked about their general, rather than technology-specific, solar information needs. Ninety-eight percent of these representatives were interested in passive solar technology information. 


\subsection{DATA NTERPRETATION}

This subsection describes several points the reader should keep in mind in interpreting the data and results presented in the following sections.

\subsubsection{Impact of the Sample Frames: Who was Sampled?}

There were several ways in which the method of constructing the sample frames impacted the data. First, in some of the sample frames one geographic region was relatively over-represented, while another was relatively under-represented. For a study of sample size nine, however, such biases were generally not bothersome since the results were principally qualitative rather than quantitative.

Second, the sample frames were only as good as the sources. For example, the Emithsonian Science Information Exchange (SSIE) data base and DOE's Research in Progress (RIP) data base were principal sources in dcveloping lists of researchers. The SSIE was not always current, of ten did not include the name of the correct principal investigator, and did not contain much of the nonfederally funded research. RIP had similar problems, varying greatly in quality according to which technology was involved. Each of these problems could cause biases as to which researchers were included and which were excluded from the samples.

Third, many arbitrary decisions were necessary in developing the sample frames. For example, it was important not to interview a respondent more than once, even if he or she was working in more than one technical area. Thus, if Researcher $X$ at Company $Y$ was listed as principal investigator both for one project in photovoltaics and for another in passive, then $X$ was arbitrarily assigned to one of the two technologies, usually to the one with the smaller set of names.

The most important advice for the reader is to study carefully the description of liow the sample frame was developed for each individual group. Often a generic title was assigned to a group; the reader must review sample frame development carefully to understand just who was being surveyed.

\subsubsection{Statistical Tests}

The statistical tests used are described in Appendix E. In the following sections test results are reported only if the statistical tests were significant at the $P \quad \mathbf{0 . 0 5}$ level. Thus, if a test result indicated that a difference between two means was statistically significant ( $\bar{P}$ 0.05), it meant that there was a maximum of $n 1$ in 20 chance that the two means were not different.

\subsubsection{Hypotheses Versus Conclusions}

Because of the limitations of sample size it was not always possible to draw definitive conclusions. In certain cases, when definitive conclusions could not be drawn, the authors have instead formed hypotheses based upon the results. 


\subsubsection{Significance of Rankings}

One of the most valuable results of this study was the development of a ranked list of information topics or products which would be useful to the members of each group (for example, see Fig. 3-1). Typically, statistical significance tests (see Appendix E) indicated that the four-to-six top-ranked items were rated significantly higher than the bottom four-to-six items. Thus, typically there was no statistically significant difference between the top-rated item and the second-rated item-or even between the top-rated and the fourteenth-rated item. If the sample size had been greater, the number of combinations in which one item was rated significantly higher than the other would also have been greater. Even if every sample size had been raised by a factor of 10, however, it is highly unlikely that all pairs of items would have had significantly different ratings.

How, then, should the reader treat two items which were not significantly different in rating? Was there any meaning to the ranking system?

Yes, the fact that there were statistically significant differences between the top-rated and the bottom-rated items established the validity of the ranking scale as a whole. Despite the fact that two ratings are not significantly different, they still have the statistical property of being the Best Linear Unbiased Estimators. For example, even if Item 1 (with a rating of 3.4) was not significantly greater than Item 2 (with a rating of 3.1), Item 1 should still be considered the more important need unless there is additional, outside information to the contrary. (In determining which information products to develop, of course, one must also consider additional factors such as the cost of the product, the proportion of the group which will be reached, and the degree to which the information need will be met.)

\subsubsection{Alternative Measures of Usefulness}

The ranking of selected information items (in usefulness to the respondent) was based upon the rating developed by assigning a " 4 " for each response of "essential," a " 3 " for "very useful," a "2" for "somewhat useful," and a "1" for "not at all useful;" summing the responses for the entire group; then dividing by the number of responses in the group. Using the rating was the preferable way to establish rankings within a group because it fully used the information on the differences between "essential" and "very useful," between "somewhat useful" and "not at all useful."

There were several alternative ways of comparing the usefulness of items, one of which was to calculate the percentage of respondents who classified the item as either "essential" or "very useful". Using this percentage was quite handy in considering how useful a product designed for more than one group would be. For example, both "a calendar" (of solar events) and "lists of local lenders (etc)" were examples of information products that would be designed for many groups to use. In comparing the two potential products as to usefulness, this method (calculating for each item the percentage of the respondents who considered the item either "essential" or "very useful") provided a much more meaningful comparison than, for example, summing the ranks for all groups.

\subsubsection{Combining Results Prom Different Groups}

It should be pointed out that combining results from all passive solar groups interviewed will not provide unbiased estimates of the total passive solar community. First, the pro- 
portions of respondents from one group interviewed in this study may not correspond to the proportion of such persons in the entire community. Second, the peculiarities of each individual sample frame were responsible for varying degrees of bias for each group. Third, some of the important groups in the passive solar community were not surveyed (see Section 2.2).

Great care should be exercised in interpreting results from a combination of groups. It is too easy to get the impression that one product can fully meet the needs of all groups when, in fact, it may only partially meet the information needs of some of the groups involved.

\subsubsection{Specific Information Products}

Several specific information products were included among the items for which usefulness was assessed. It is important that responses to these items not be interpreted as totally generic responses. People who gave "a bibliography of general readings on passive solar" a low rating may have done so either because of the level and content of the subject matter (i.e., general readings on passive solar) or because of the format (i.e., bibliography). These people may or may not want bibliographies on other topics.

\subsubsection{Information Sources}

Another important question investigated how many respondents had used specific information sources. In using these results to plan how specific information is to be transmitted, it will be essential to specify fully both the information products or services and the groups to be reached before making the final decision of which information channels are to be used. One cannot assume, for example, that the two or three top-rated sources should be used for all, or even most, of the information transmissions to the group.

There were two other issues related to this question. The first was the decision not to ask respondents whether they had used SERI as an information source. The reasons are discussed in Appendix D.

The second issue concerned possible bias in responses to the question "have you obtained any solar information directly from the U.S. Department of Energy?" The intent of the question was to find out if respondents had contacted DOE directly for information, rather than if they had obtained DOE-produced information from other sources [such as SERI, National Technical Information Service (NTIS), Government Printing Office (GPO), National Solar Heating and Cooling Information Center (NSHCIC), Regional Solar Energy Centers (RSECE), libraries, ete]. Tlitre wus, however, no assurance that respondents interpreted the question in this light. In cases where the response "directly from DOE" was high, there was the possibility that respondents were referring to information authored or funded by DOE, but obtained from some other source. 


\section{SECTION 3.0}

\section{PASSIVE RESEARCHERS}

\subsection{DESCRIPTION OF RESPONDENTS}

\subsubsection{Description of Sample}

This section describes the results of a telephone study to determine the needs of Federally Funded researchers for information on passive solar energy technologies. Nine Federally Funded Passive Researchers were interviewed.

The sample frame for Passive Researchers was constructed by reviewing the May 1978 DOE document [4 for passive, projects and by searching the Research in Progress (RIP) [5] , Current Research Information System [6], and Smithsonian Science Information Exchange (SSIE) [7] data bases. Only those projects in progress during some part of FY 1978 or FY 1979 were included. Entries without contact names (i.e., principal investigators) were eliminated. Duplicates between this list and any other lists of passive contacts (e.g., manufacturers) were eliminated on the other lists. In addition, this sample frame was compared to other Researcher sample frames (active solar heating and cooling, wind, and energy storage), and duplicate principal investigator names were deleted. After all adjustments were made, the 9 interview candidates were randomly selected from a sample frame of approximately 50 names.

Respondents. In making the telephone calls to contact the randomly selected interview candidates, it sometimes occurred that the person could not be reached. In this event another randomly selected name was substituted for the original name. When individuals were contacted, it was verified that they had been involved in passive research, and that they would be needing information on passive solar technologies within the next year. If they were not both involved and needing information, they were asked if they could refer the interviewer to someone else in their organization who would be an appropriate respondent. If such a referral was made, a call was then made to this new candidate; if no intraorganizational referral was made, a new candidate was randomly selected from the sample frame. The results of this proness may be seen in Table 3-1.

Comparisons. For additional insight into the information needs and the information habits of these Passive Researchers, results from this group are compared to the results from Total Active Solar Heating and Cooling (SHAC) Researchers and to the results from all of the researchers interviewed in this study (All Researchers). The list of all the groups contained in Total SHAC Researchers and in All Researchers can be found in Table F-2 of Appendix F. In performing any statistical comparisons, the totals for Passive Researchers have been subtracted from the totals for All Researchers. The data for Pussive Researchers, Total SHAC Researchers, and All Researchers can be found in Appendix F. 
Table 3-1. COMPLETION OF INTER VIEWS: PASSIVE RESEARCHERS

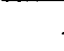

\section{Event}

Number of

Candidates

Interview completed with sample frame candidate

Interview completed with referral candidate

Refusal or candidate termination

Contact attempted: could not reach candidate within three

attempts, or before interviews were completed . 4

Subtotal

Contact attempted: invalid candidate (e.g.; inappropriate

ffeld nf interest, no telophonc).

TU'L'AL

Sumple frame error rate ${ }^{a}$ (Percent)

Completion rate ${ }^{b}$ (Percent)

anvalid candidates divided by TOTAL.

${ }^{b}$ Completed interviews divided by Subtotal.

\subsubsection{Current Status of Respondents}

Role. Five of the Passive Researchers were working for colleges, and 4 were employed by consulting firms. Most of the Passive Researchers interviewed were involved in development or demonstration projects. At least 5 of the respondents were designing passive structures including greenhouses, residences, and small commercial buildings. Development or verification of designs or design tools was also a major activity (for at least 5 of the respondents). Specific activities included: simulations, passive applications for livestock buildings, measuring the effects of attaching a greenhouse to a residence, and land planning.

Involvement. Six of the 9 (67\%) Passive Researchers said that they were "very involved" in passive solar technologies. This compares to 13 of the 18 (72\%) of Total SHAC Researchers who were "very involved" with SHAC. and 107 of the 181 (59\%) of All Researchers who were "very involved" with their respective solar technologies.

Informedness. Eight of the 9 (89\%) Passive Researchers considered themselves "very informed," compared to 15 of the 18 (83\%) Total SHAC Researchers and 117 of the 181 (65\%) All Researchers. Only 3 of the other 19 groups of researchers gave themselves as high marks for informedness as did the Passive Researchers.

Need for Information. All respondents indicated they would need information on passive technologies on the job during the next year. Only 3 of the 9 (33\%) Passive Researchers also needed information on passive solar technologies outside the job. This off-the-job information need was somewhat less than that of All Researchers who were asked this question, where 48 of the 117 (41\%) indicated they would need information on their own technology outside the job. In another comparison, 9 of the 18 (50\%) SHAC Researchers indicated they would need information on SHAC outside the job in the next year. It 
seems a bit surprising that more Passive Researchers were not interested in information for outside-the-job applications, especially since passive solar technologies are ready to be used today. It is unclear whether the Passive Researchers were personally less interested in applying their own technology, whether they will not need information within the next year because people do not build a new house every year (many passive applications lend themselves more readily to new construction than to retrofit), or whether this is merely a random result.

\subsubsection{Background of Respondents}

Five of the 9 Passive Researchers held a PhD, 3 held a master's degree, and 1 a bachelor's. Five had received degrees in engineering (including mechanical and agricultural) or physics. Other degrees were in sociology, horticulture, ecology, and architecture. Four received their most recent degree over 10 years ago, 4 from 5-10 years ago, and 1 within the past 5 years.

Three had been in their current profession for 5 or fewer years and 3 for over 10 years. Four were still in agricultural design or mechanical engineering. Two respondents described their present profession in terms of solar energy as solar design and solar physics. Other professions included project manager, architect, planner, researcher, instructor, and horticulturist.

\subsection{INFORMATION NEEDS OF RESPONDENTS}

\subsubsection{Technical Areas}

Passive Researchers were asked to choose those areas in which they were "particularly interested in obtaining information" from a list of selected technical areas in passive solar technology. More than half of the respondents expressed an interest in all eight of the areas about which they were asked. They seemed to be somewhat more interested in "collection of heat" (9), "storage of heat" (9), and "greenhouses" (8) than in "space cooling" (5). Seven of the 9 stated that they were interested in "building design," "landscaping and building orientation," and "hybrid systems," and 6 expressed an interest in "water heating."

\subsubsection{Types of Information}

Passive Researchers were asked to name the information about passive solar technologies that was important for them to obtain. Eight of the 9 Passive Researchers volunteered one or more items of information which they considered important. Five felt that performance information was important. Other topics included: heat flux; thermomass data; design guidelines; performance prediction; analysis tools; climatological data; new product information; a general directory of contacts; a central clearing house for information; and the effects of condensation, dehumidification, and daylighting.

Information that the Passive Researchers volunteered they needed but were unable to obtain included good climatological and performance data and system models of a specific hybrid building. 
Choice Between Specific Needs. A list of 11 types of passive information products and 14 types of passive information categories was read to each respondent. Each respondent described the usefulness of each particular item by. assigning it a value of "essential," "very useful," "somewhat useful," or "not. at all useful." The results for Passive Researchers are given in Fig. 3-1. For the purpose of comparison, Fig. 3-2 displays results for Total SHAC Researchers and Fig. 3-3 those for All Researchers.

Passive Researchers gave cost, site-specific, and design information relatively high ratings as classes. The five top-rated information categories/products were:

- Climatological data;

- Tax credits, g̀rants, or other economic incentives;

- Costs and performance of systems;

- Computer models for sizing and predicting performance or costs; and

- Research in progress.

This high a rating of "computer models" was unusual. Only one other group of Researchers (DOE-Funded Storage Researchers) rated this item as useful as did Passive Researchers. It was noted in Section 3.1.2, however, that at least 5 of the 9 were involved in development or verification of designs or design tools. "Manual methods" and "a technical description" also were rated highly.

Passive Researchers assigned the lowest relative ratings to:

- A nontechnical description of how a particular system works;

- Educational institutions and other organizations offering courses;

- Lists of local lenders, insurers, builders, engineers, installers, manufacturers, or distributors; and

- Institutional, social, environmental, and legal aspects.

All of these items were rated significantly $(P \quad 0.05)$ lower than were the 5 highest-rated items.

It should be noted that these lower-rated items were nnt neressarily of no worth to the Passive Researchers. For example, 1 of the 9 (11\%) thought "educational institutions" and "lists of local lenders (etc)" were either "essential" or "very useful." Thus, these information categories/products could be useful to some Passive Researchers but were of a lower relative priority to the entire group.

Statistical tests were used to determine whether the Passive Researchers rated any of these information items significantly higher (or lower) than they were rated by Total SHAC Researchers or by All Researchers. Some groups, however, tended to give higher scores in general than did other groups. To compensate for this effect, these statistical tests compared the "relative rating" given by one group to the "relative rating" given by the other groups. The procedure for calculating the relative rating is described in Appendix E. The overall average rating across all items was about the same for Passive Researchers (2.42) as it was for All Researchers (2.41). In comparison, that for Total SHAC Researchers was higher (2.56). 
Question \#8. I will read a list of potential information or information products on solar systems. For each, please lell me how useful that information would be to you. Would the following be: essential, very useful, somewhat useful, or nol at all useful?

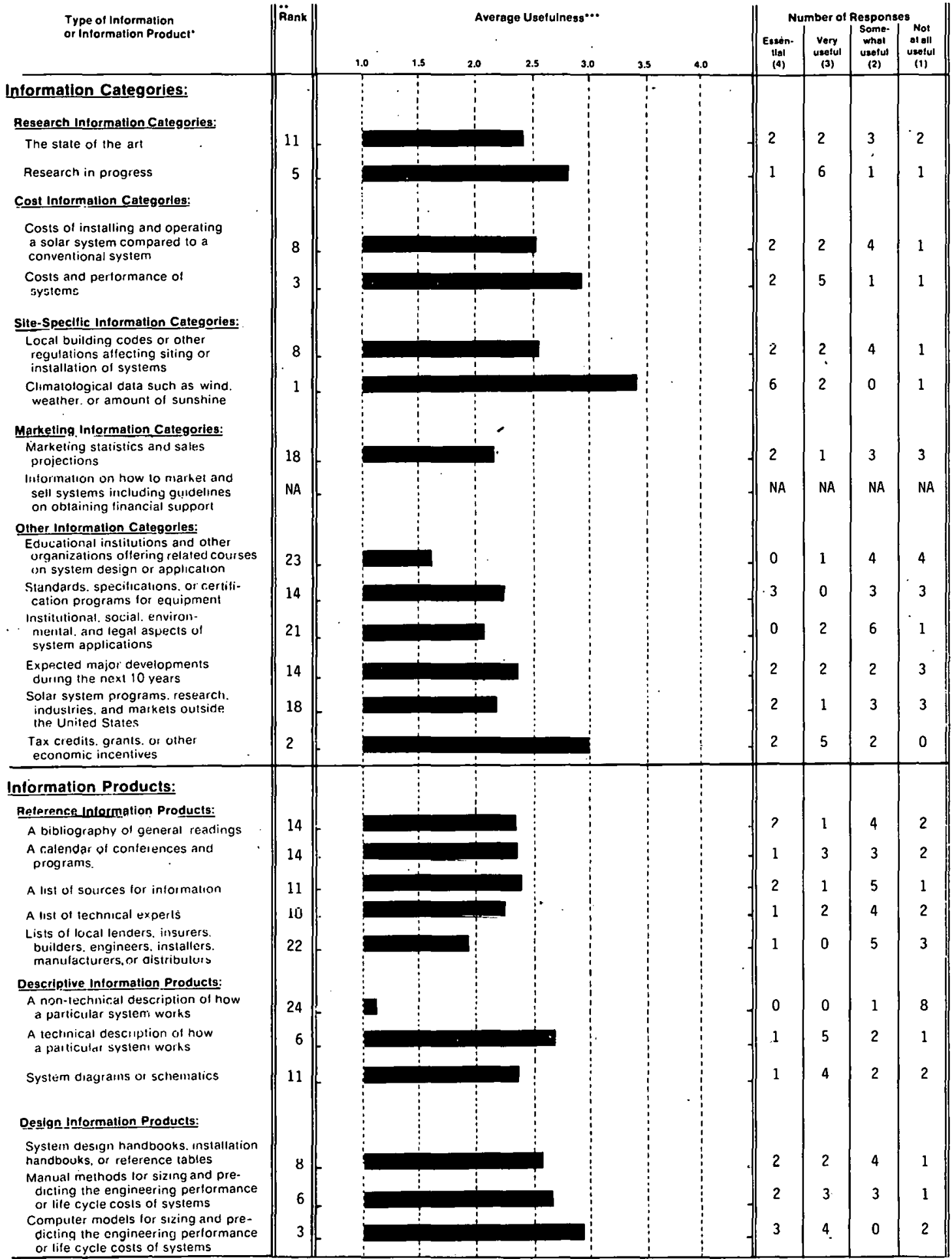

Each sample trame of users was questioned on infurmation and information products in the conievt nt theit sne.ific technoloay. Fot example. biomass sample frames were asked about "a bibliography or general reaoings un biusidss"." "a catcndar of upcoming biomass conterenress and proprems ". etc. Fank-Each inlormation product was assigned a rank based on overage usefulness. Thus, the product with Ithe highest average usetulness was assigned the rank of " 1 ": Ihe product with ine lowest nverage use/ulness would, be ranked " 25 where all items were asked. If wo or more intormation products were tied tor 2 nd. Ihey were both assigned a " 2 ". The ne $\times 1$

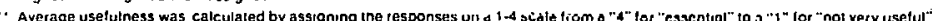

Figure 3-1. Usefulness of Selected Information Items: Passive Researchers 
Question \#8. I will read a list of potential information or information products on solar systems. For each, please tell me how useful that information would be to you. Would the following be: essential, very useful, somewhat useful, or not at all useful?

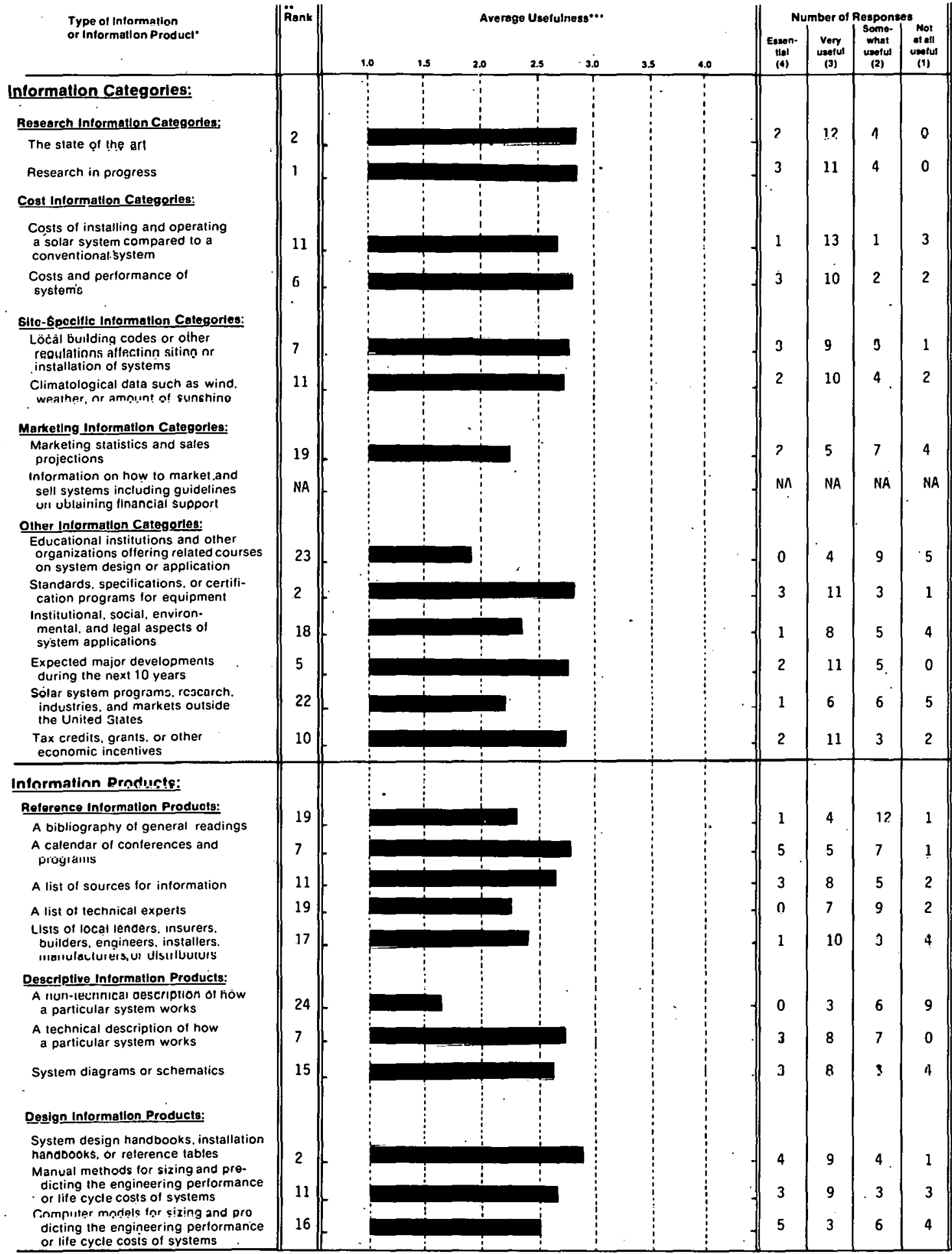

Each sample frame of users was questioned on intormation and intormation products in the context of their specific technology. For example, biomass sample frames were asked about "a bibliography of general readings on biomass", "a caiendar of upcoming biomass conterences and programs ". etc.

Rank-Eachintormation product was assigned a rank based on average usefulness. Thus, The product with the highest average useluiness was assigned the rank of " "I: the produc nignest renking was inen assigned a " "A:"

... Averagge usefulness was calculated by assigning ine responses on a $1-4$ gcale from a "4" for "essential" to a " 1 " for "not very useful".

Figure 3-2. Usefuiness of Selected Information Items: Total Active Solar Heating and Cooling Researchers 
Question \#8. I will read a list of potential information or information products on solar systems. For each, please tell me how useful that information would be to you. Would the following be: essential, very useful, somewhat useful, or not at all useful?

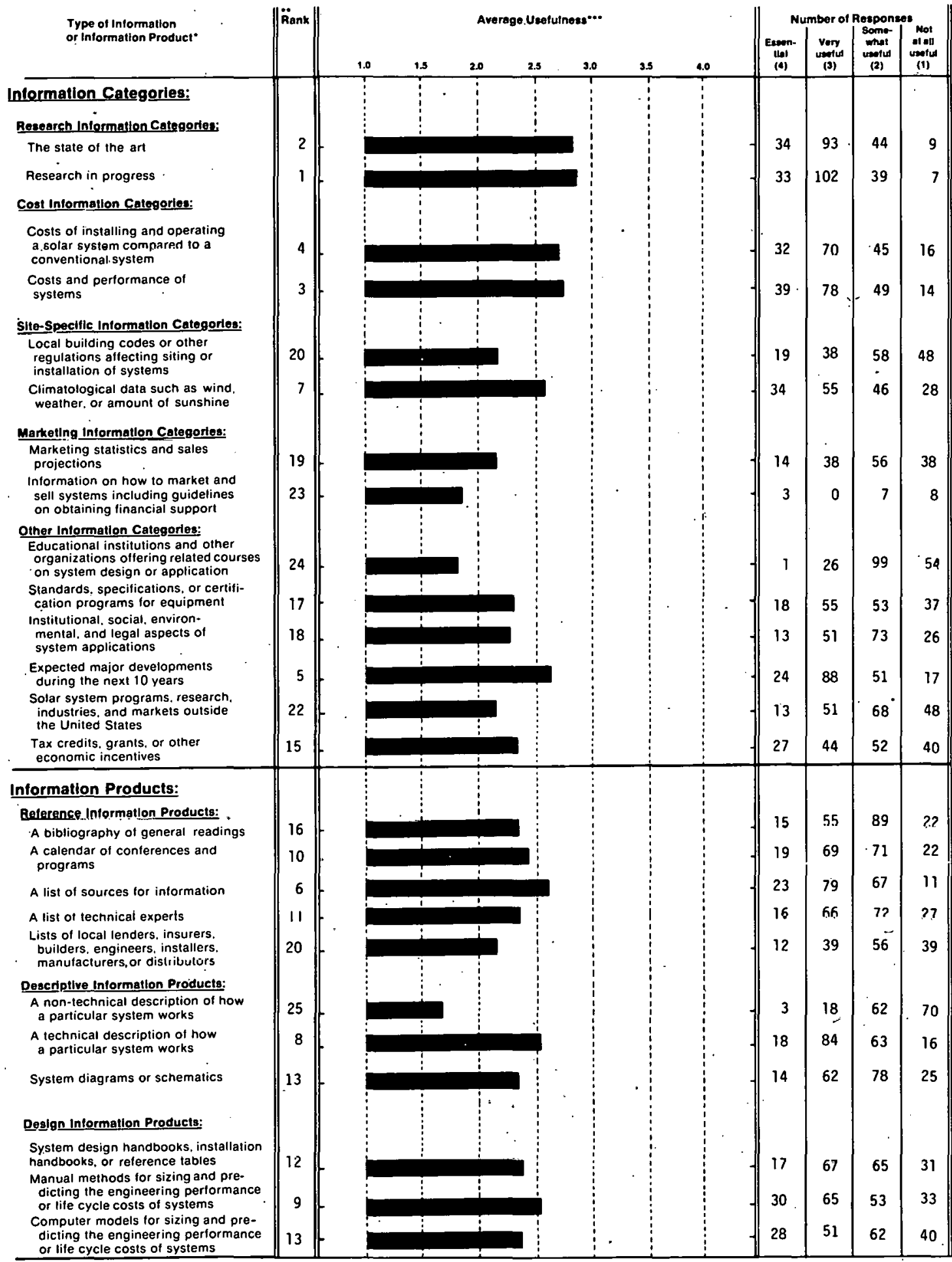

Each sample trame of users was questioned un infurmation and intormation products in the context of thoir epocitic cornnningy For exampla. biamass sempte frames were

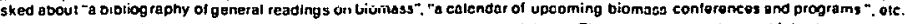
Aank-Each intormation product was assigned a rank based on average uselulness. Thus. The product with the highest average usetulness was assigned the rank of " 1 "; the product with the lowest average usotuliness would

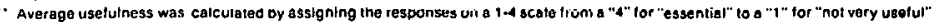

Figure 3-3. Usefulness of Selected Intormation ltems: All Researchers 
In comparing the results for Passive Researchers both to the results for Total SHAC Researchers and to those for All Researchers, the Passive Researchers were found to attach significantly (P 0.05) more usefulness to "climatological data." They gave significantly ( $P$ 0.05) lower ratings to "a nontechnical description" than did All Researchers. Passive Researchers gave significantly ( $P$ 0.05) higher ratings to "tax credits" and "climatalogical data" than did All Researchers. This could possibly be explained by the relative readiness of passive solar technologies for commercialization when compared to other solar technologies. The priority placed on incentives information was understandable, given the numerous unresolved issues regarding inclusion of passive technologies under both federal and state tax legislation.

\subsection{ACQUISIIION OF INFORMATION BY RESPONDENTS}

\subsubsection{Use of Selected Information Sources}

Passive Researchers were asked which of 20 different potential sources of solar information had they used in the past few years. For this question the respondents were not asked if they had obtained information on passive solar technologies, but instead were asked if they had obtained any solar information from each specific source. Thus, the question sought to determine which information sources were the most familiar to the respondents. The results are shown in Fig. 3-4. For comparison, Figs. 3-5 and 3-6 show the results for Total SHAC Researchers and for All Researchers.

The information sources mentioned most of ten by Passive Researchers were:

- Periodicals, newspapers, or magazines;

- International Solar Energy Society (ISES);

- An installer, builder, designer, or manufacturer;

- Workshops, conferences, or training sessions; and

- National Technical Information Service (NTIS).

The information sources mentioned least of ten by Passive Researchers were:

- Smithsonian Science Information Exchange (SSIE),

- Radio or TV,

- Some other state or local government office or publications, and

- Regional Solar Energy Centers (RSECs).

Passive Researchers appear to use a wide variety of information sources, with over half using 15 of the 20 information sources about which they were asked. Their overall average use for all sources was 0.67 , among the 7 highest of the 86 groups surveyed in this study and higher than any other Researcher group but one. In comparison to All Researchers, Passive Researchers were significantly ( $P$ 0.05) more likely to have used "a commercial data base," the National Solar Heating and Cooling Information Center (NSHCIC), state energy or solar offices, and ISES. Not surprisingly, a comparison to Total SHAC Researchers showed no statistically significant differences in the information sources used by the two groups. 
Question \#11. In the past few years, have you oblained any type of solar information from any of the following sources?

Information Sources

Percentage Responding Yes ${ }^{*}$

\section{Public Media:}

Radio or TV

Periodicals. newspapers or magazines

Private Solar-Involved Orgänizations:

Private solar energy or environmental organizations

The local chapter or national headquarters of International Solar Energy Society (ISES). including their publications

The local chapter or national headquarters of Solar Energy Industries Association (SEIA), including their publications

\section{Contacts with Professionals:}

An installer. builder. designer or manufacturer of solar systems

Workshops, conferences or training sessions

Information Services*:

Your organizational library or a local library

A commercial data base: for example. Lockheed, SDC. BRS

Smithsonian Science Information Exchange (SSIE)

A Federal library or information center; for example, the National Agricultural Library or the Environmental Data System

The Government Printing Office (GPO)

National Technical Information Service (NTIS)

Technical Information Center at Oak Ridge (TlC)

\section{Government Solar-Involved Organizations}

Directly from the U.S. Department of Energy

National Solar Heating \& Cooling Information Cènter

Regional Solar Energy Centers

State Energy or Solar Offices

Other:

Some other state or local government office or publication

A public utility company

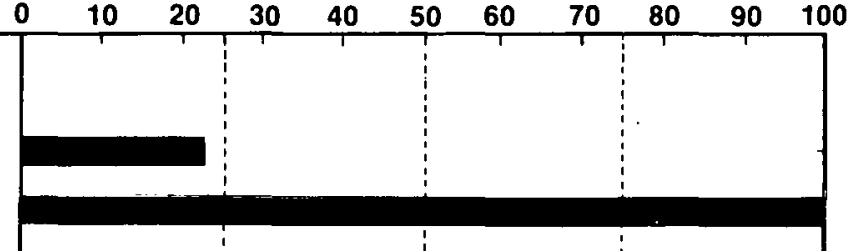

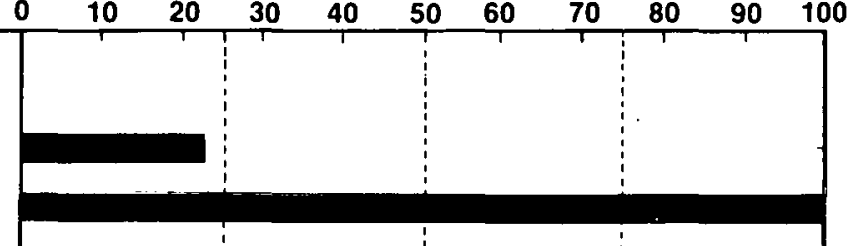


Question \#11. In the past few years, have you obtained any type of solar information from any of the following sources?

Information Sources

\section{Public Media:}

Radio or TV

Periodicals, newspapers or magazincs

Private Solar-Involved Organizations:

Private solar energy or environmental organizations

The local chapter or national headquarters of Internationa

- Solar Energy Society (ISES). including their publications

The local chapter or national headquarters of Solar Energy

Industries Association (SE|A). including their publications

Contacts with Protessionals:

An installer, builder, designer or manufacturer of solar systems

Workshops. conferences or training sessions

\section{Information Services*:}

Your organizational library or a local library

A commercial data base: for example. Lockheed, SDC, BRS

Smithsonian Science Information Exchange (SSIE)

A Federal library or information center; for example, the National Agricultural Library or the Environmental Data System

The Government Printing Office (GPO)

National Technical Information Service (NTIS)

Technical Information Center at Oak Ridge (TIC)

Government Solar-Involved Organizations

Directly from the U.S. Department of Ėnergy

National Solar Heating \& Cooling Information Center

Regional Solar Energy Centers

State Energy or Solar Otfices

Other:

Some other state or local government office or publication

A public utility company
Percentage Responding Yes ${ }^{\cdots *}$.

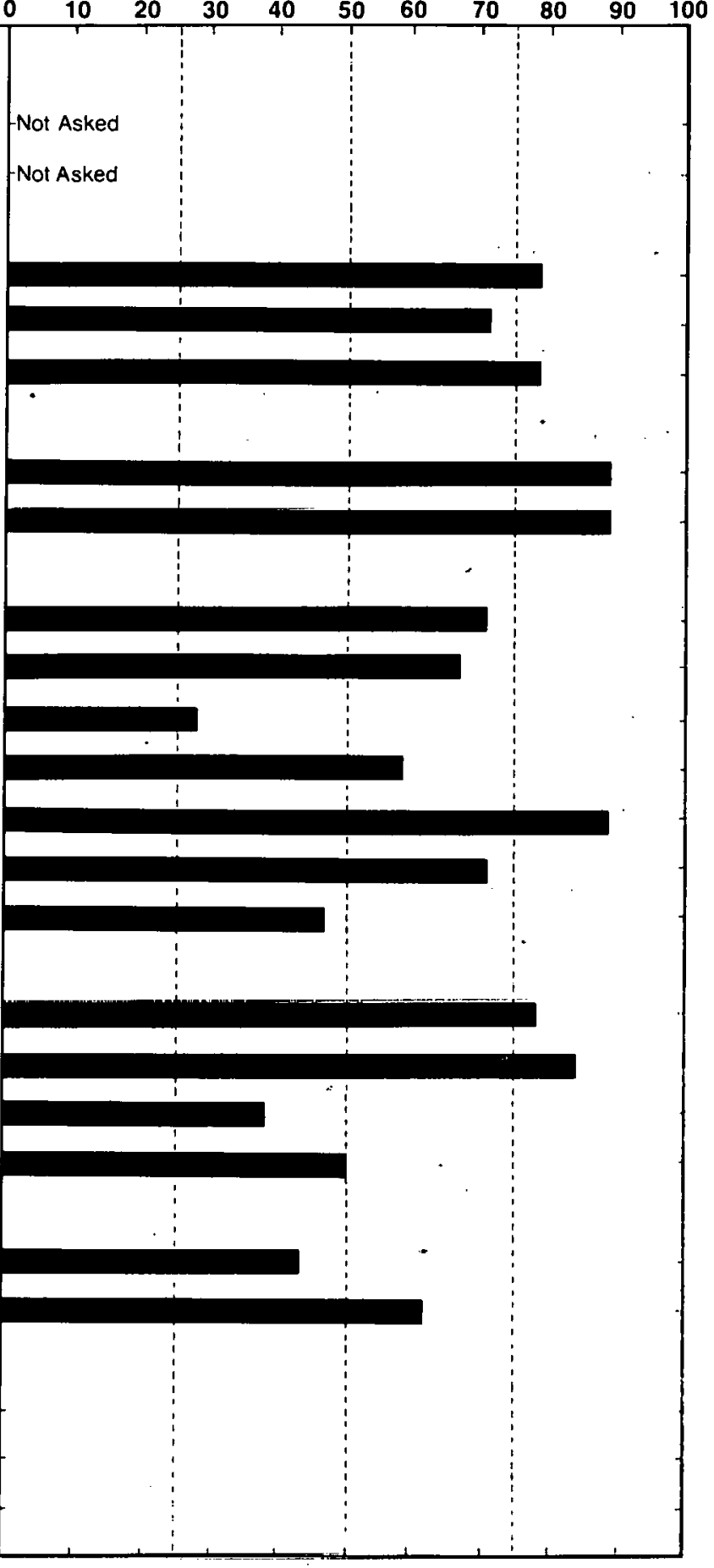

Services and centers whose primary purpose is to disseminate information.

Some sample frames were questioned about additional information sources which are applicable to their technology. For example. the manufacturers of biomass conversion equipment were also asked if they have obtained any type of solar intormation trom: "the local or national office of the U.S. Department of Agriculture. including Extension and Forestry."

... These data are based upon a total of 18 respondents.

Figure 3-5. Use of Selected Information Sources: Total Active Solar Heating and Cooling Researchers 
Question \#11. In the past few years, have you obtained any type of solar intormation from any of the following sources?

Information Sources

Percentage Responding Yes ...

\section{Public Media:}

Radio or TV

Periodicals. newspapers or magazines

Private Solar-Involved Organizations:

Private solar energy or environmental organizations

The local chapter or national headquarters of International Solar Energy Society (ISES). including their publications

The local chapter or national headquarters of Solar Énergy Industries Association (SEIA). including their publications

Contacts with Professionals:

An installer. builder, designer or manufacturer of solar systems

Workşhops, conferences or training sessions

Intormation Services*:

Your organizational library or a local library

A commercial data base: for example. Lockheed. SDC. BRS

Smithsonian Science Information Éxchange (SSIE)

A Federal library or information center; for example, the National Agricultural Library or the Environmental Data System

The Government Printing Office (GPO)

National Technical Information Service (NTIS)

Technica! Information Center at Oak Ridge (TIC)

Government Solar-Involved Organizations

Directly from the UIS. Department of Energy

National Solar Heating \& Cooling Information Centel

Regional Solar Energy Centers

State Energy or Solar Offices

Other:

Some other state or local government office or publication

A public utility company

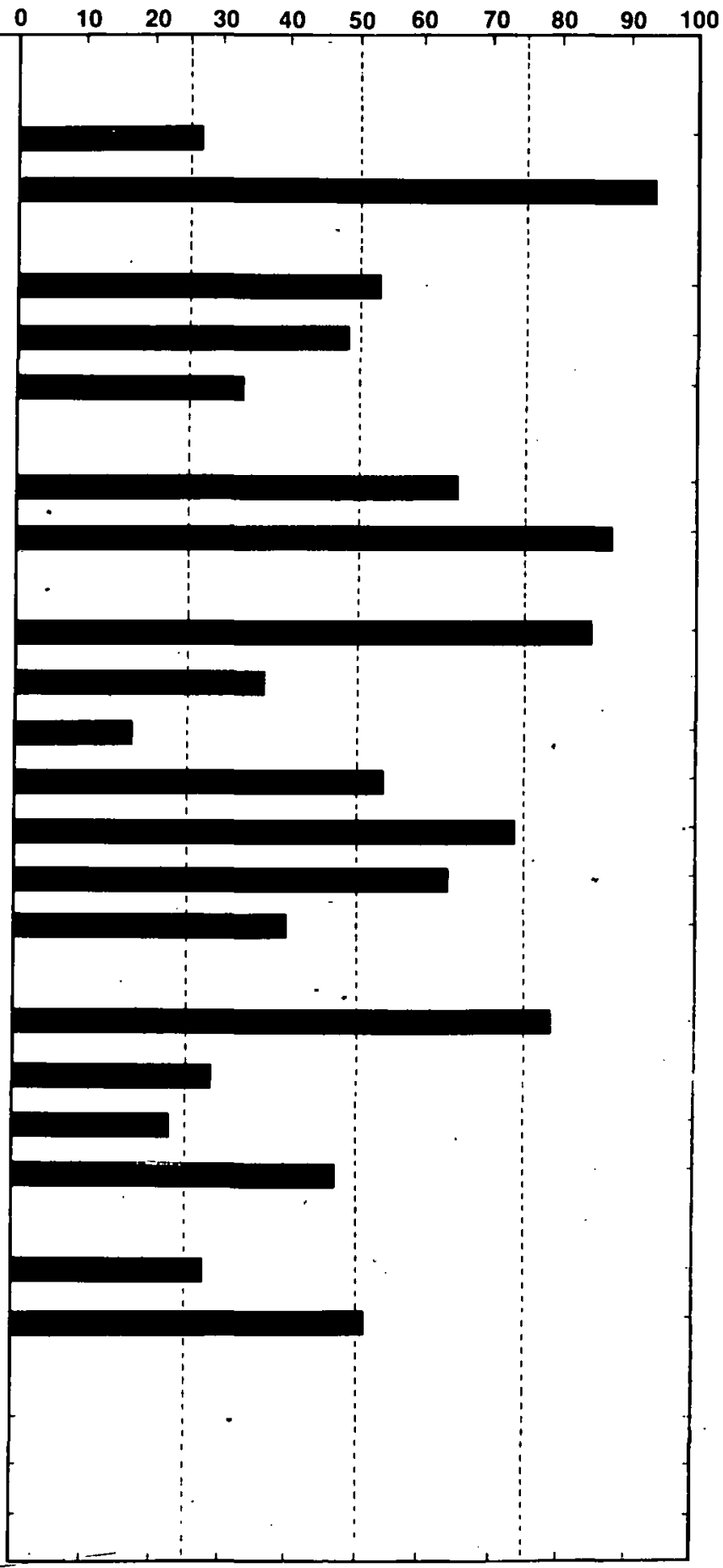

- Services and centers whosc primary purpose is to disseminate information

Some sample frames were questioned about additional information sources whicli are applicable to their technology. For example. the manufacturers of biomass conversion equipment were also asked if they have obtained any type of solar information from: "the local or intional office of the I.IS Department of Agriculture including Extension and Forestry.

$\because$ These data are based upon a total ol 181 respondonts.

Figure 3-6. Use of Selected Information Sources: All Researchers 


\subsubsection{Membership in Solar-Interested Organizations}

Eight of the 9 Passive Researchers surveyed were members of a professional, technical, or other organization with an interest in solar energy. These organizations (and the number of times mentioned) included:

- American Physical Society;

- American Society for Horticultural Science;

- American Society of Agricultural Engineers;

- American Society of Heating, Refrigerating, and Air Conditioning Engineers (ASHRAE) (3);

- American Society of Mechanical Engineers;

- ISES (5); and

- Northern California Solar Energy Society.

This combination of professional and solar societies was fairly typical of Researchers.

\subsubsection{Exposure to Publications on Solar Energy}

During the past 6 months, all 9 Passive Researchers had read publications which included information on passive solar technologies. The publications they could specify (and the number of times mentioned) included:

- ASHRAE publications;

- U.S. Department of Energy (DOE) publications (e.g.; monthly reports and symposium data on residential greenhouses)(2);

- Lawrence Berkeley Lab reports;

- Passive conference proceedings, 1979;

- Passive Solar Buildings (Sandia Lab, July 1979);

- Passive solar design competition publications;

- Passive Solar Energy Book (by Mazria)(3);

- Passive solar homes award publications;

- Solar Age(3);

- Solar conference proceedings, Seattle, 1979;

- Solar Dwelling Design Concepts (by AIA Research Corporation);

- Solar Energy;

- Solar heating and cooling meeting proceedings (3rd Annual); and

- Solar Heating and Cooling of Residential Buildings (University of Wisconsin).

Also mentioned were some publications that could not be verified by the authors. These included a "CCPS reference book," an "Energy Alternatives book," and a "Survey of Passive Solar Buildings book." 


\subsubsection{Use of Special Acquisition Methods}

The respondents were asked whether they had obtained any information (not just passive or solar energy) in the past year by computer terminal, by Computer Output Microform (COM), or by other microform (e.g.; microfiche, microfilm sheets, or rolls). Few Passive Researchers appeared accustomed to using these special acquisition methods. In the past year, 4 of the 9 had used a computer terminal and only 1 had used COM and other microforms. A comparison of Passive Researchers with Total SHAC Researchers and All Researchers showed no statistically significant differences in the proportion using computer terminals, COM, or other microforms.

\subsection{SUMMARY AND COMMENTS}

Nine researchers in passive solar technology were interviewed. Five of these researchers were employed by colleges or universities and four by consulting firms. The source of funding was not determined for the demonstration and development projects in which these researchers were involved. These projects included design of passive structures (greenhouses, residences, livestock buildings, and small commercial buildings), landscaping, and development of design tools. Their level of involvement and degree of informedness were similar to that of SHAC Researchers, although their average level of education was somewhat higher.

Passive Researchers attached the most utility to:

- Climatological data;

- Tax credits, grants, or other economic incentives for passive solar systems;

- Costs and performance of passive solar systems;

- Computer models for sizing and predicting performance or costs of passive solar systems; and.

- Passive solar rescarch in progress.

They were also interested in "manual methods for sizing and predicting performance or consts of passive solar systems" and in "a technical description of how a particular passive solar system works." Their ratings for "climatalogical data," "tax credits, (etc.)," and "computer models" were unusually high for Researchers. The priority placed on incentives information is understandable given the presently unresolved issues regarding the inclusion of passive technologies in both federal and state tax laws.

They gave low ratings for "a nontechnical description," "educational institutions," "lists of local lenders (etc.)" and "institutional, social, environmental, and legal aspects."

Passive Researchers appeared to need information in two principal areas: design and performance evaluation (including current research) and incentives information. They were particularly concerned about access to good climatological and performance data and systems models.

Passive Researchers did not appear to be high users of state or regional solar offices. More of them had obtained information from NTIS rather than directly from DOE. "Periodicals, (etc.)" (including those from the Solar Energy Industries Association (SEIA) and ISES) and "workshops, conferences" were also widely used as solar information sources. At least five were members of a local or national solar energy association. Engineering societies also served as important information disseminators. Mazria's Passive Solar Energy Book was cited by three of the nine. 


\section{SE리}


SECTION 4.0

\section{PASSIVE MANUFACTURER REPRESENTATIVES}

\subsection{DESCRIPTION OF RESPONDENTS}

\subsubsection{Description of Sample}

This section describes the results of a telephone study to determine the needs of representatives of manufacturers of passive solar heating and cooling equipment for information on passive solar heating and cooling. Nine representatives of Passive Manufacturers were interviewed.

The sample frame for Passive Manufacturer Representatives was constructed from the Solar Energy Information Data Bank (SEIDB) [8] on Passive Manufacturers. Manufacturers were selected who specified manufacturing one or more of the following products: greenhouses, passive or hybrid solar systems, thermosyphon water heaters, trombe walls, roof ponds, phase change storage modules, or moveable insulation. Manufacturers who only produced swimming pool covers were excluded from the list. When the SEIDB was cross-referenced to the National Solar Heating and Cooling Information Center (NSHCIC) "Manufacturers of Passive Design Products" list [9], some additional companies were added to the sample frame. The NSHCIC passive manufacturers' list was not used as a source by itself for sample selection, however, because no contact names were provided. After all adjustments were made, the 9 interview candidates were randomly selected from a sample frame of 45 names.

Respondents. In making the telephone calls to contact the randomly selected interview candidates, it sometimes occurred that the person could not be reached. In this event another randomly selected name was substituted for the original name. When individuals were contacted, it was verified that they really were a representative of a Passive Manufacturer and that they would be needing information on passive solar heating and cooling within the next year. If they were not both involved and needing information, they were asked if they could refer the interviewer to someone else in their organization who would be an appropriate respondent. If such a referral was made, a call was then made to this new candidate; if no intraorganizational referral was made, a new candidate was randomly selected from the sample frame. The results of this process may be seen in Table 4-1.

Comparisons. For additional insight into the information needs and the information habits of these representatives of Passive Manufacturers, results from this group are compared to the results from Total SHAC (Active Solar Heating and Cooling) Manufacturer Representatives and All Manufacturer Representatives. The list of all the groups contained in Total SHAC Manufacturer Representatives and All Manufacturer Representatives can be found in Table F-2 of Appendix F. In performing any statistical comparisons, the totals for Passive Manufacturer Representatives have been subtracted from the totals for All Manufacturer Representatives. The data for Passive Manufacturer Representatives, Total SHAC Manufacturer Representatives and All Manufacturer Representatives can be found in Appendix F. 


\section{Table 4-1. COMPLETION OF INTERVIEWS: PASSIVE MANUFACTURER REPRESENTATIVES}

Interview completed with sample frame candidate

Interview completed with referral candidate

3

Refusal or candidate termination

Contact attempted: could not reach candidate within three

attempts, or before interviews were completed

1

2

Subtotal

12

Contact attempted: invalid candidate (e.g., inappropriate field of interest, no telephone)

TOTAL

Sample frame error rate ${ }^{a}$ (Percent)

Completion rate ${ }^{b}$ (Percent)

a Invalid candidates divided by TOTAL

${ }^{b}$ Completed interviews divided by Subtotal

\subsubsection{Current Status of Respondents}

Role. The passive-related activities in which the 9 manufacturers surveyed were involved included the production of greenhouses (2), duct work, fiber glass panels, insulated glazing material, passive hybrid air systems (attic collector type of system), and movable-insulation systems. One respondent was also an inventor and researcher of passive solar systems.

Involvement. Seven of the 9 (78\%) respondents felt that they were "very involved" in passive solar heating and cooling, 1 felt that they he/she was "moderately involved", and 1 was "slightly involved." Statistical comparisons with Total SHAC Manufacturer Representatives (26 of the 34 or $76 \%$ "very involved") and All Manufacturer Representatives (77 of the 96 or $80 \%$ "very involved") showed no significant (P 0.05 ) differences in degree involved.

Informedness. Five of the $9(56 \%)$ representatives of Passive Manufacturers felt they were "very informed," and the remaining 4 were "moderately informed." Of the 10 manufacturer groups surveyed, only one other group had proportionately fewer respondents informed on their uppropriate technology.

Need for Information. All respondents indicated they would need information on passive solar heating and cooling on the job during the next year. Five of the 9 (56\%) also needed information on passive outside the joh. This did not differ significantly fruIll All Manufacturer Representatives, with 93 of the 96 (97\%) having interest in information on their own distinct technology on the job and 47 of the 96 (49\%) outside the job. 


\subsubsection{Background of Respandents}

Five of the 9 representatives of Passive Manufacturers held bachelor's degrees. The remaining 4 held a master's degree, a doctoral degree, a law degree, or a degree in dentistry. The degree field most common to this group was chemistry, received by 4 respondents. The remaining 5 respondents received the following various degrees: industrial construction engineering, psychology, law, English literature, and dentistry. Three received their most recent degree over 35 years ago, 3 from 15-30 years ago, and 3 from 5-10 years ago. The educational level and the year of their most recent degree did not appear to differ from that of Total SHAC Manufacturer Representatives or of All Manufacturer Representatives.

The degree of professional experience varied among the group with 1 in his/her current profession for 2 or fewer years, 3 for 3-5 years, 2 for 6-10 years, and 3 for over 10 years. This level of experience was similar for Total SHAC Manufacturer Representatives and All Manufacturer Representatives. Five of the Passive Manufacturer Representatives were involved technically (technician, chemist, researcher/inventor, designer/ researcher, and writer). Another 3 respondents were more business oriented (manager or marketing development), and one stated his/her profession as a solar equipment manufacturer.

\subsection{INFORMATION NERDS OF RESPONDENTS}

\subsubsection{Technical Areas}

Representatives of Passive Manufacturers were asked to choose those areas in which they were "particularly interested in obtaining information" from a list of selected technical areas of passive solar heating and cooling. Interest was not dominant in any one area but appeared fairly high in all areas with the exception of "landscaping or orientation of building on site" ( 2 of the 9). Seven of the 9 (78\%) were interested in "collection of heat" and "hybrid systems (combining active and passive)," 6 of the 9 (67\%) in "building design" and "space cooling," while "storage of heat" and "greenhouses" each had 5 of the 9 (56\%) interested. Passive Manufacturer Representatives did not volunteer any other technical areas of interest.

\subsubsection{Types of Information}

Representatives of Passive Manufacturers were asked to name the information about passive solar heating and cooling that was important for them to obtain. All 9 Passive Manufacturer Representatives volunteered one or more items of information which they considered important. Four felt marketing information was important, including projections for residential markets and the potential for 100\% solar heating and cooling systems. Another 4 respondents mentioned performance data including insulation values and the performance of materials under various conditions (2) (e.g., performance of related materials for highest energy conservation versus price factor of the materials). Other topics included: availability of products, lower cost materials, installation data (the optimum angle for placement of panels by geographical area), testing methods for passive systems, financing information, and educational programs on passive solar.

Three of the 9 Passive Manufacturer Representatives stated that there was information they needed but were not able to get. The type of information needed included more information on incorporating both passive and active SHAC in existing buildings, 
information on performance, and computer modeling. Total. SHAC Manufacturer Representatives also mentioned these products as difficult to obtain.

Choice Between Specific Needs. A list of 10 types of passive information products and 14 types of passive information categories was read to each respondent. Each respondent described the usefulness of each particular item by assigning it a value of "essential," "very useful," "somewhat useful," or "not at all useful." The results are given. in Fig. 4-1. For the purpose of comparison, those for Total SHAC Manufacturer Representatives and All Manufacturer Representatives are shown in Figs. 4-2 and 4-3, respectively.

Representatives of Passive Manufacturers were especially interested in the type of data necessary for evaluation of passive solar heating and cooling as a commercially viable technology. The six top-rated information categories/products were:

- Climatological data;

- Costs of installing and operating a passive system compared to a conventional system;

- Tax credits, grants, or other economic incentives;

- Manual methods for sizing and predicting performance or costs;

- Costs and performance of systems; and

- Computer models for sizing and predicting performance or costs.

Representatives of Passive Manufacturers assigned the lowest relative ratings to:

- Calendars of conferences and programs;

- Educational institutions and other organizations offering courses;

- A bibliography of general readings; and

- Institutional, social, environmental, and legal aspects.

Statistical tests indicated that differences between the ratings for these six highest and four lowest information. items were significant ( $P$ 0.05) for Passive Manufacturer Representatives. It is interesting to note that although 4 Passive Manufacturer Representatives volunteered marketing information as important (see Section 4.2.2), when presented with 24 types of information to rate, they rated the two marketing-related items as 13 th and 17 th.

It should be noted that these lower-rated items are not necessarily of no worth to the Passive Manufacturer Representatives. For example, 3 of the 9 (33\%) thought "institutional, social, environmental, and legal aspects" was either "essential" or "very useful." Thus, these information categories/products could be useful to some Passive Manufacturer Representatives but were of a lower relative priority to the entire group.

Statistical tests were also used to determine whether the Passive Manufacturer Representatives rated any of these information items significantly higher (or lower) than they were rated by the Total SHAC Manufacturer Representatives and All Manufacturer Representatives. Some groups, however, tended to give higher scores in general than did other groups. To compensate for this effect, these statistical tests compared the "relative rating" given by one group to the "relative rating" given by the other groups. The procedure for calculating the relative rating is described in Appendix E. The average 
Question \#8. I will read a list of potential information or information products on solar systems. For each, please tell me how useful that information would be to you. Would the following be: essential; very useful, somewhat useful, or not at all useful?

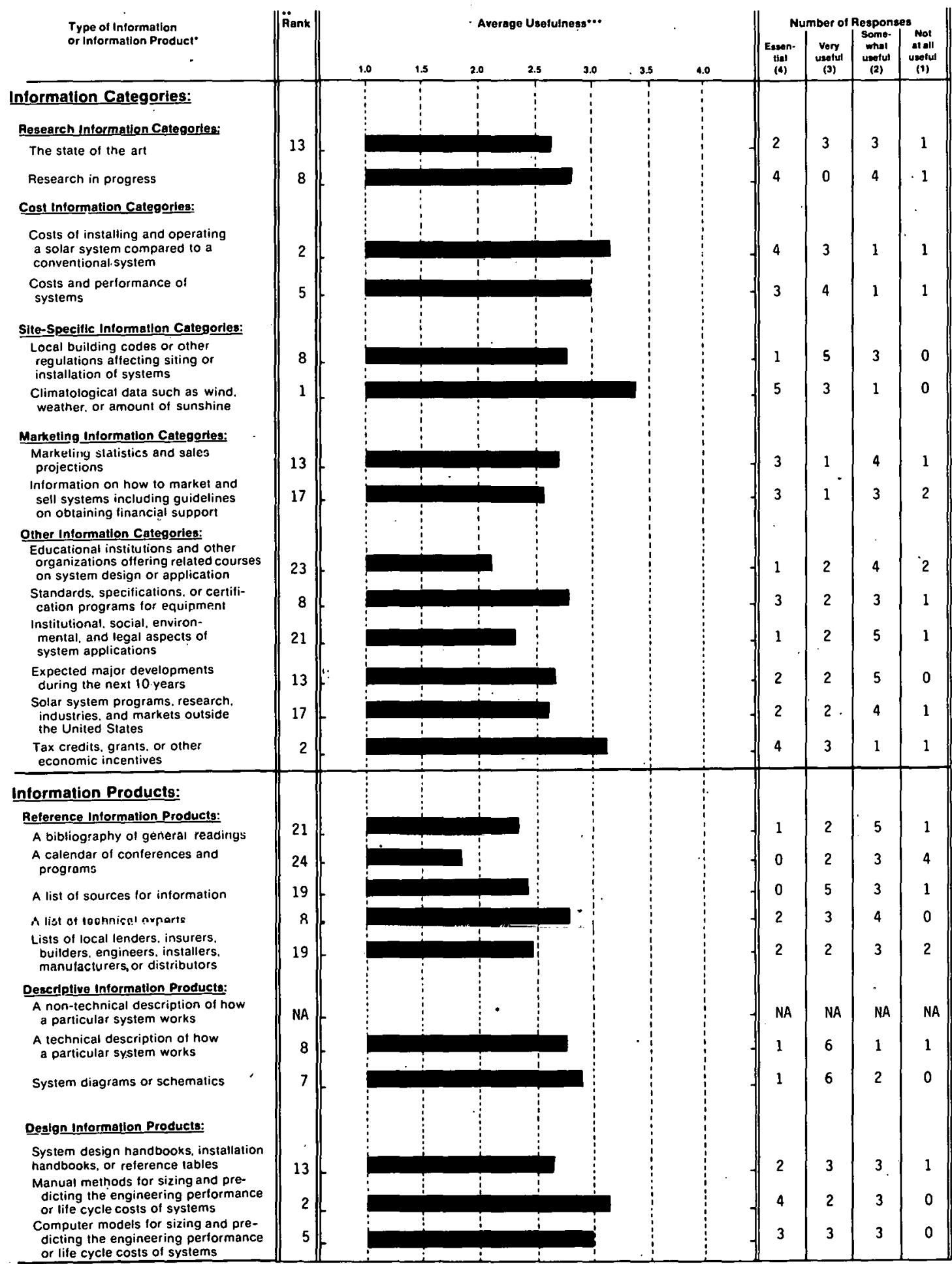

Each sampta trame of users was questioned on intormation and intormation products in the contęxl ol their specifie technotogy. For example. biomass sample trames were

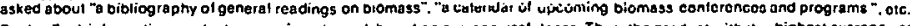
Rank-Eactinitormation product was assigned a rank based on average usefulness. Thus, the product with the highest average uselulness was assigned the rank of " 1 "; the product with the lowest averaga useluliness would
nighest ranking was then assigned a "4.

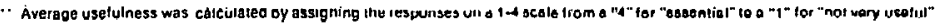

Figure 4-1. Usefulness of Selected Information Items: Passive Manufacturer Representatives 
Question \#8. I will read a list of potential information or information products on solar systems. For each, please fell me how useful that information would be to you. Would the tollowing be: essenlial, very useful, somewhat useful, or nol at all useful?

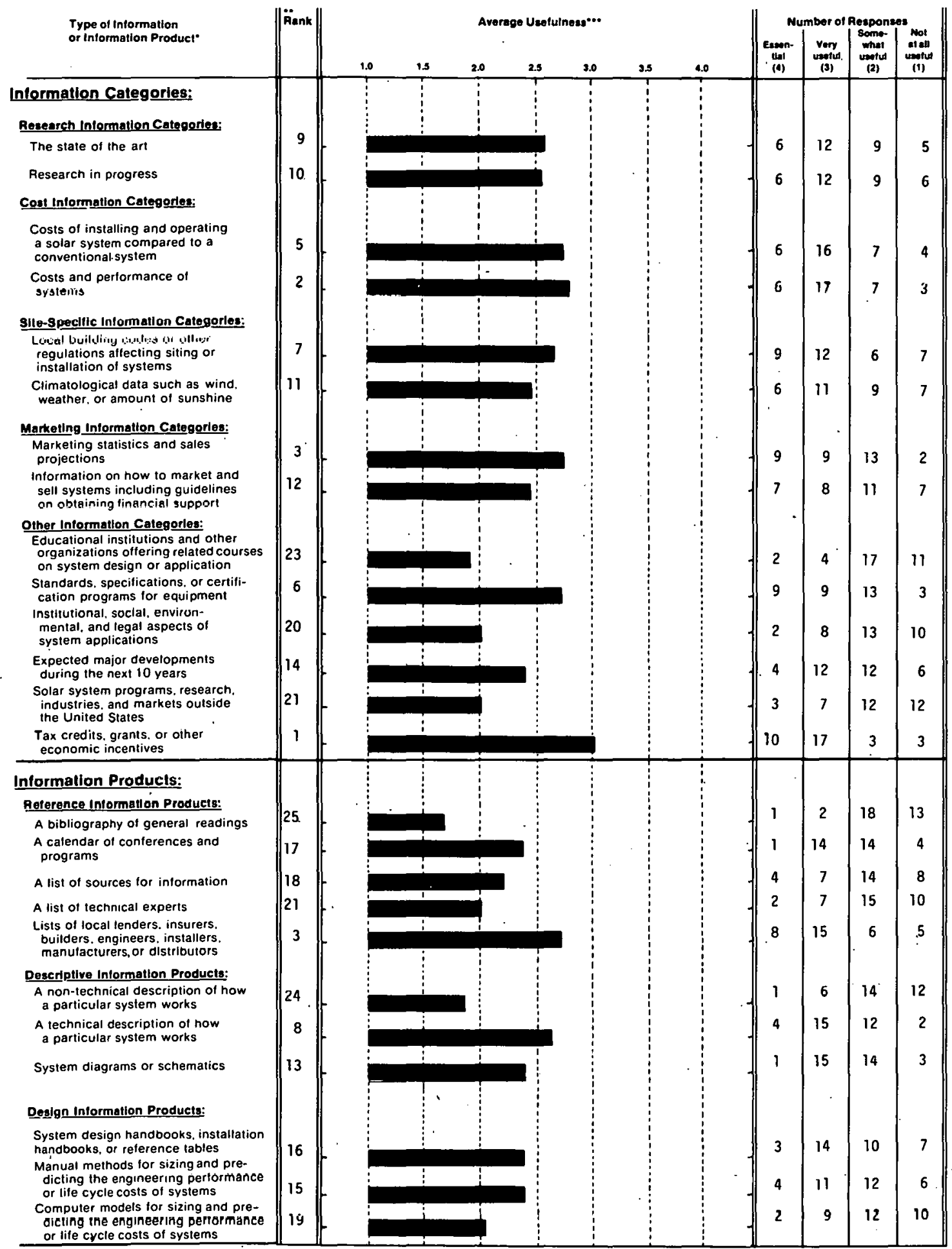

- Each sample Irame of users was questioned on informetion and information products in the context of their specific technotogy. For example, biomass sampla Irames were
asked about "a bibliography of general readings on biomass". "A calendar of upcoming biomass conferences and programs ". etc.

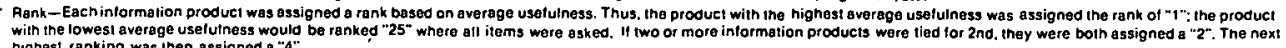

... Average usetulness was calcutated by assigning the responses on a $1-4$ scale trom a "4" tor "essential" to a "1" for "not very useful".

Figure 4-2. Winfulnese of Selected Informatton Items: Total Actlve Solar Heating and Coollng Manufacturer Representatives 
Question \#8. I will read a list of polential information or information products on solar systems. For each, please tell me how useful that information would be to you. Would the following be: essential, very useful, somewhat useful, or not at all useful?

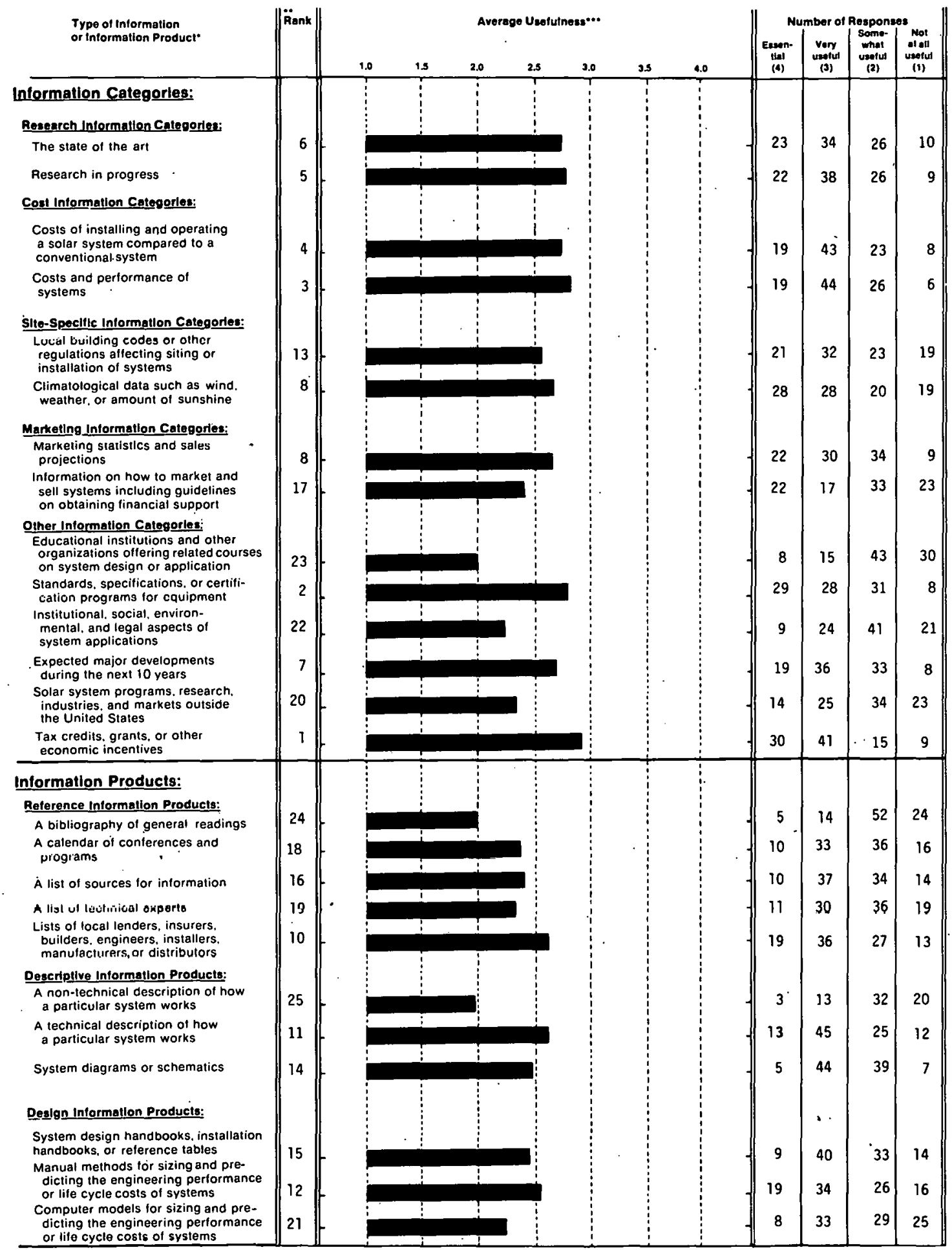
or life cycle costs of systems

- Each sampla trame of users was Questioned on intormation and information products in the context of their specilic technology. For exsmple. biomass sampte trames were Each sampla rame of users was auestioned on information and information products in the context of reir specilic technology.

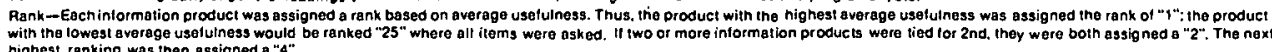

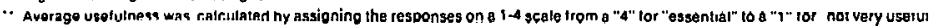

Figure 4-3. Usefulness of Selected Information Items: All Manufacturer Representatives 
overall rating was much higher for Passive Manufacturer Representatives (2.70) than it was for Total SHAC Manufacturer Representatives (2.40) and for All Manufacturer.Representatives (2.51).

Comparisons to Total SHAC Manufacturer Representatives and to All Manufacturer Representatives showed Passive Manufacturer Representatives to be significantly ( $P$ 0.05) more interested than were both groups in "climatological data," "computer models," and "a nontechnical description" and significantly ( $P$ 0.05) less interested in "calendars of conferences and programs." In general, Passive Manufacturer Representatives appeared more similar to Total SHAC Manufacturer Representatives than to All Manufacturer Representatives.

\subsection{ACQUISTION OF NNORMATION BY RESPONDENTS}

\subsubsection{Use of Selected Information Sources}

Representatives of Passive Manufacturers were asked which of 19 different potential sources of solar information they had used in the past few years. For this question the respondents were not asked if they had obtained information on passive, but instead were asked if they had obtained any solar information from each specific source. Thus, the question sought to determine which information sources were the most familiar to the respondents. The results are shown in Fig. 4-4. For comparison, those for Total SHAC Manufacturer Representatives and All Manufacturer Representatives are provided in Figs. 4-5 and 4-6, respectively.

The information sources mentioned most of ten by Passive Manufacturer Representatives were:

- Private solar energy or environmental organizations;

- International Solar Energy Society (ISES);

- An installer, builder, designer, or manufacturer;

- Workshops, conferences, or training sessions; and

- Directly from the U.S. Department of Energy (DOE).

The information sources mentioned least often by Passive Manufacturer Representatives were:

- A commercial data base,

- Bmithsünian Science Information Exchange (SSIE),

- Technical Information Center (TIC),

- Regional Solar Energy Centers (RSECs), and

- A public utility conmpany.

Representatives of Passive Manufacturers appear to rely most heavily on professional contacts at solar-related organizations and less on information dissemination services for obtaining information on solar energy. A comparison of Passive Manufacturer Representatives to Total SHAC Manufacturers showed the passive group mentioning the RSECs and State Energy/Solar Offices significantly (P 0.05$)$ less often. That only one of the 9 
Question \#11: In the past few years, have you obtained any type of solar information from any of the following sources?

Information Sources

Public Media:
Radio or TV
Periodicals, newspapers or magazines
Privale Solar-Involved Organizations:
Private solar energy or environmental organizations
The local chapter or national headquarters of International
Solar Energy Society (ISES). including thelr publications
The local chapter or national headquarters of Solar Energy
Industries AsSociation (SEIA), including their publications
Contacts with Professionals:

An installer, builder, designer or manufacturer of solar systems

Workshops, conferences or training sessions

\section{Information Services:}

Your organizational library or a local library

A commercial data base; for example, Lockheed. SDC. BRS

Smithsonian Science Information Exchange (SSIE)

A Federal library or information center: for example, the National Agricultural Library or the Environmentai Data System

The Government Printing Office (GPO)

National Technical Information Service (NTIS)

Technica' Information Center at Oak Ridge (TIC)

Government Solar-Involved Organizations

Directly from the U.S. Department of Energy

National Solar Heating \& Cooling Information Center

Peyivial Golnr Enorgy ranters

State Energy or Solar Offices

Other:

Some other state or local government office or publication

A public utility company

Sources for this specific sample frame**:

American Institute of Architects
Percentage Responding Yes ${ }^{\cdots}$

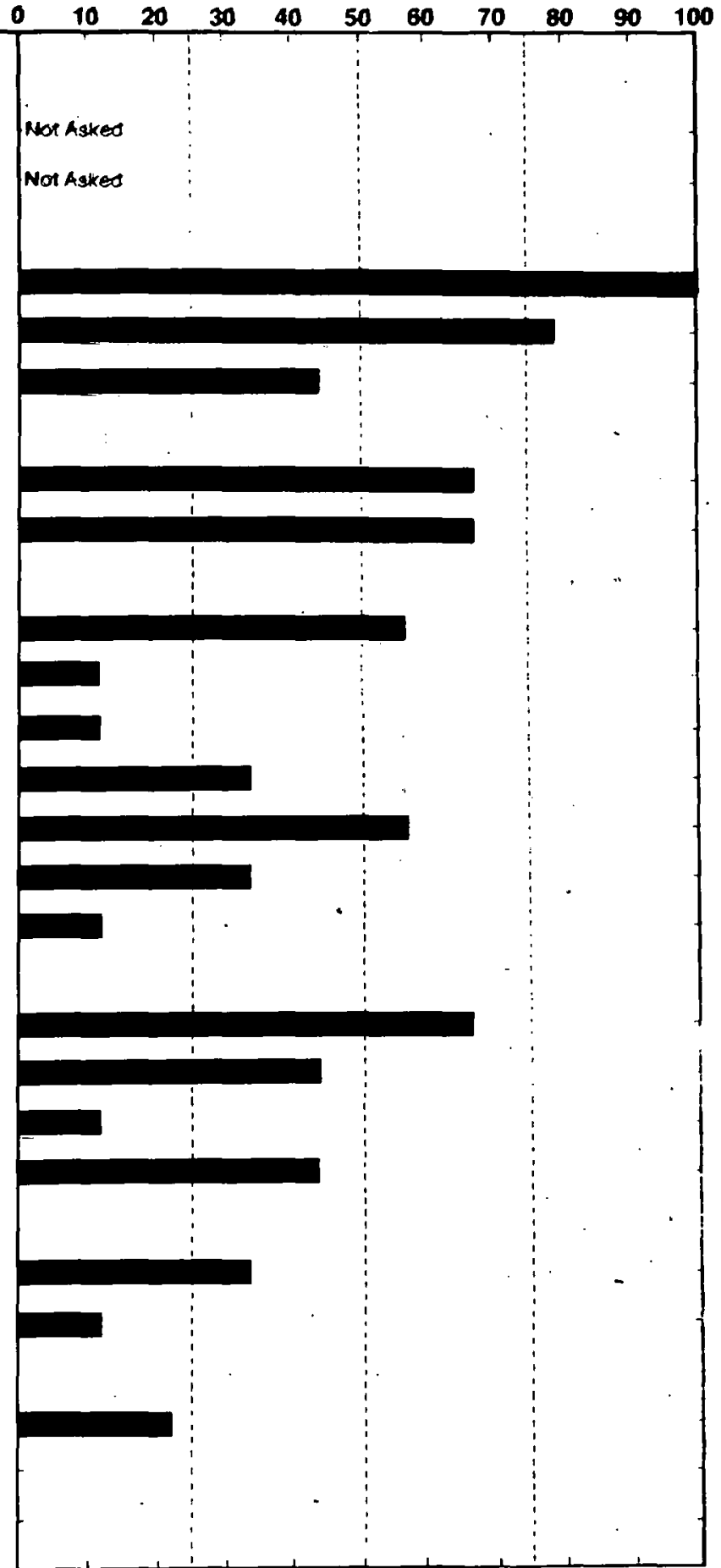

- Services and centers whose primary purpose is to disseminate information.

- Some sample trames were questioned about additional information sources which are applicable to their technology. For example. the manufacturers of biviliss convergion oquipment were alsn asked it they have obtained any type of solar information from: "the local or national office of the U.S. Department of Agriculture. including Extension and rorestry"

... These data are based ujon a total of 9 rcspondents.

Figure 4-4. Use of Selected Information Sources: Passive Manufacturer Representatives 
Question \#11. In the past few years, have you obtained any type of solar information from any of the following sources?

Information Sources

Public Media:

Radio or TV

Periodicals. newspapers or magazines

\section{Private Solar-Involved Organizations:}

Private solar energy or environmental organizations

The local chapter or national headquarters of International Solar Energy Society (ISES), including their publications

The local chapter or national headquarters of Solar Energy Industries Association (SEIA), including their publications

\section{Contacts with Professionals:}

An installer, builder, designer or manufacturer of solar systems

Workshops. conferences or training sessions

\section{Intormation Services*:}

Your organizational Jibrary or a local library

A commercial data base: for example. Lockheed, SDC. BRS

Smithsonian Science Information Exchange (SSIE)

A Federal library or information center; for example, the National Agricultural Library or the Environmental Data System

The Government Printing Office (GPO)

National Technical Information Service (NTIS)

Technical Information Center at Oák Ridge (TIC)

Government Solar-Involved Organizations

Directly from the U.S. Department of Energy

National Solar Heating \& Cooling Information Centeı

Regional Solar Energy Centers

State Energy or Solar Offices

Other:

Some other state or local government office or publication

A punlir. utility company
Percentage Responding Yes

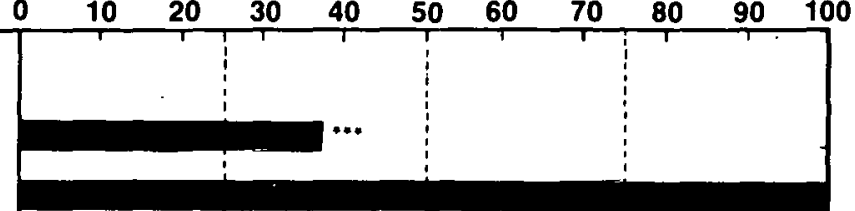
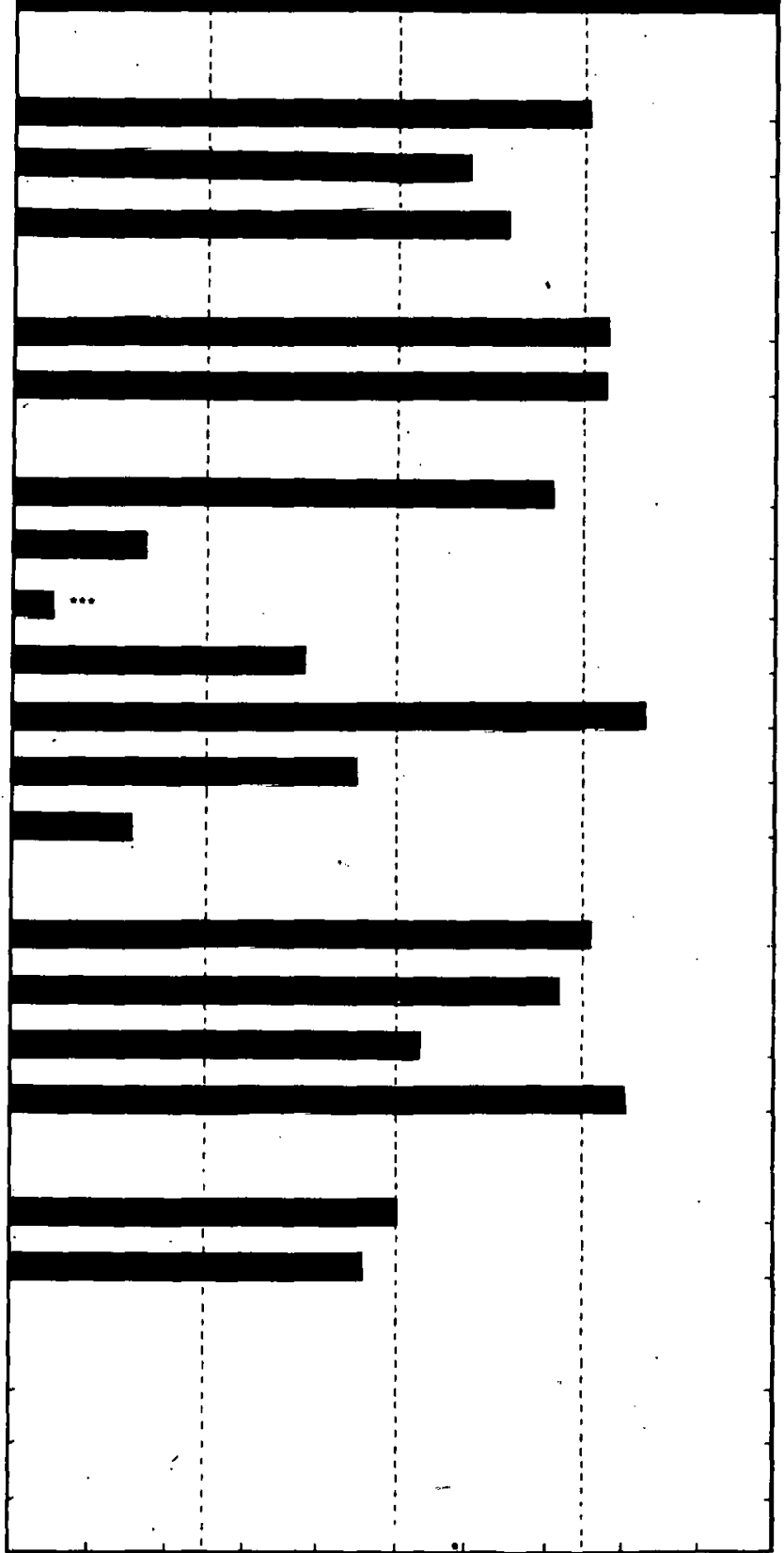

- Services and centers whose primary purpose is to disseminate information

- Some sample frames were questioned about additional information sources which are applicable to their technology. For example. the manufacturers of biomass conversion equipment were also asked if they have obtained any type of solar information from: "the Iocal or national office of the U.S. Department of Agriculture. including Extension and Forestry"

** Only asked of Non-concentrating Collectors Manufacturers and Other Components Manufacturers

$\therefore$ These data are based upon a total of 34 respondents.

Figure 4-5. Use of Selected Information Sources: Total Active Solar Heating and Cooling Manufacturer Representatives 
Question \#11. In the past few years, have you obtained any type of solar information from any of the following sources?

Information Sources

Public Media:
Radio or TV
reriodlcals, rewsjajués or magazincs

Private Solar-Involved Organizations:

Private solar energy or environmental organizations

The local chapter or national headquarters of International Solar Energy Society (ISES), including their publications

The Incal chapter or national headquarters of Solar Energy Industries Association (SEIA). including their publications

Contacts with Professionals:

An installer, builder, designer or manufacturer of solar systems

Workshops, conferences or training sessions

Information Services":

Your organizational library or a local library

A commercial data base; for example, Lockheed, SDC. BRS

Smithsonian Science Information Exchange (SSIE)

A Federal library or information center; for example, the National Agricultural Library or the Environmental Data System

The Government Printing Office (GPO)

National Technical Information Service (NTIS)

Technical Information Center at Oak Ridge (TIC)

Government Solar-Involved Organizations

Directly from the U.S. Department of Energy

National Solar Heating \& Cooling Information Center

Regional Solar Energy Centers

State Energy or Solar Offices

' Other:

Some other state or local government office or publication

A public utility company
Percentage Responding Yes $\cdots$

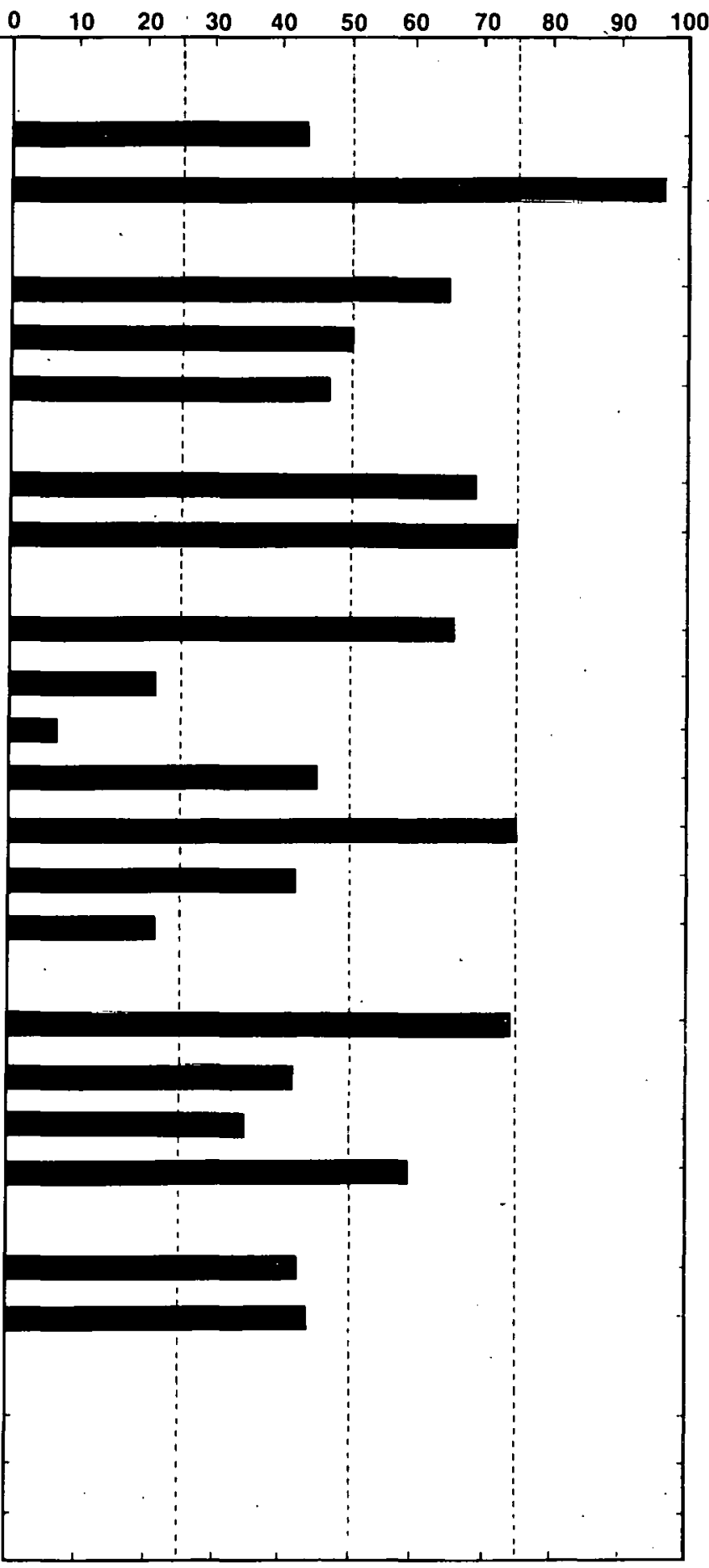

- Services and centers whose primary purpose is to disseminate information

- Some sample irames were questioned about additional information sources which are applicable to their technology. For example. the manutacturers of blutldss currver sion equipment woro alco aeked it they have ohtainert any type of solar information from: "the local or national office of the U.S. Department of Agriculture, including Extension and Fortesliy."

These data are based upon a total of 98 respondents.

Figure 4-6. Use of Selected Information Sources: All Manufacturer Representatives 
had used a Regional Solar Energy Office was particularly surprising. Compared to All Manufacturer Representatives, Passive Manufacturer Representatives mentioned "private solar energy or environmental organizations" significantly ( $P$ 0.05) more often and "a public utility company" significantly ( $P$ 0.05) less of ten.

\subsubsection{Membership in Solar-Interested Organizations}

Six of the 9 Passive Manufacturer Representatives surveyed were members of a professional, technical, or other organization with an interest in solar energy. These organizations (and the number of times mentioned) included:

- Colorado Solar Energy Society,

- International Society of Passive Solar Manufacturers,

- ISES (3),

- New Mexico Solar Energy Association,

- New Mexico Solar Energy Society,

- Producers Council, and

- Roaring Fork Research Center.

Also mentioned were several organizations that could not be verified by the authors. These included "BIA" and "CSI."

\subsubsection{Exposure to Publications on Solar Energy}

During the past 6 months, all 9 of the Passive Manufacturer Representatives had read publications which included information on passive. The publications they could specify (and the number of times mentioned) included:

- American Society of Heating, Refrigerating, and Air Conditioning Engineers (ASHRAE) publications;

- Harrowsmith (Canada);

- Passive Solar Energy Book (by Mazria);,

- Professional Builder;

- Solar Age (5);

- Solar Energy (z);

- Solar Heating and Cooling; and

- Sunworld.

\subsubsection{Use of Special Acquisition Methods}

The respondents were asked whether they had obtained any information (not just passive or solar energy) in the past year by computer terminal, by Computer Output Microform (COM), or by other microform (e.g.; microfiche, microfilm sheets, or rolls). Few Passive 
Manufacturer Representatives appeared accustomed to using these special acquisition methods, a trait common to manufacturers in all technologies surveyed. In the past year, only 3 of the 9 (33\%) used a computer terminal, no one had used COM, and only 2 of the 9 (22\%) had used other microform.

\subsection{SUMMARY AND COMMENTS}

Representatives of nine manufacturers producing passive solar energy systems were interviewed. These respondents were involved in the production of varying types of passive systems and components including greenhouses, collectors, duct work, fiber glass panels, insulated glazing material, hybrid air systems, and movable insulation systems. Their level of involvement, educational level, and length of professional experience was typical of manufacturers interviewed in this study. Their degree of informedness, however, was second lowest of the 10 manufacturer groups surveyed.

The level of interest expressed by Passive Manufacturer Representatives concerning eight technical areas of passive technology was not predominantly high for any one area, but was moderately high (between 5 and 7 of the 9) for seven of the eight areas. Only one area, "landscaping or orientation of the building on the site," received minimal interest ( 2 of the 9 respondents).

When asked to volunteer what information was important for them to obtain on passive solar energy, it was not surprising that Passive Manufacturer Representatives most frequently mentioned marketing data. However, upon providing the respondents with a list and asking them to evaluate 10 types of passive information products and 14 types of passive information categories, the priority for marketing data fell below site-specific information categories, cost information categories, design information products, and descriptive information products.

Representatives of Passive Manufacturers gave the highest priority to receiving information on:

- Climatological data;

- Costs of installing and operating a passive system compared to a conventional system;

- Tax credits, grants, or other economic incentives for passive solar systems;

- Manual methods for sizing and predicting performance or costs of passive solar systems;

- Costs and performance of passive solar systems; and

- Computer models for sizing and predicting performance or costs of passive solar systems,

They gave low ratings to "calendars of passive conferences and programs," "educational institutions," "a bibliography of general readings," and "institutional, social, environmental, and legal aspects."

Representatives of Passive Manufacturers needed three principal things. First, they needed climatological data. Second, they needed all information related to the cost of passive systems including installation costs, cost versus performance, and financial 
incentives. Third, they needed methods for sizing and predicting cost and performance of passive systems.

Representatives of Passive Manufacturers most of ten received solar information through "private solar energy or environmental organizations" and ISES. Other sources frequented included professional contacts ("an installer, builder, (etc.)" and "workshops, (etc.)") and DOE. At least five were members of a local or national solar energy association, with Solar Age also serving as an important information disseminator. Compared to the active solar heating and cooling manufacturers, there was very little use of the RSECs and the State Solar/Energy Offices. 


\section{SECTION 5.0}

\section{PASSIVE ARCHITECTS}

\subsection{DESCRIPTION OF RESPONDENTS}

\subsubsection{Description of Sample}

This section describes the results of a telephone study to determine the needs of architects for information on passive solar technologies. Nine Passive Architects were interviewed.

The sample frame for Passive Architects was constructed from the following four sources: the 1979 Directory of the American Section of the International Solar Energy Society (ISES), passive systems division [10]; the Mid-American Solar Energy Complex (MASEC) "Passive Workshop Attendees" list [1 1]; Solar Heated Buildings of North America [12]; and National Solar Heating and Cooling Commercial Demonstration Program-Key Personnel Directory (KPD) [13]. Names taken from the ISES directory all had been coded as an architect/designer professional. A maximum of 3 were selected from each state. The MASEC passive workshop attendees' occupations were specified as "architect." Names were also obtained from Solar Heated Buildings of North America [12], that listed architects/designers of projects with passive or passive/active buildings. Also used as a source was the Key Personnel Directory (KPD) [13] that listed architects for the Solar Heating and Cooling (SHAC) demonstration projects. Architects from passive and passive/active systems were identified by use of the KPD in conjunction with Solar Heating and Cooling Demonstration Project Summaries [14]. After all adjustments were made, the 9 interview candidates were randomly selected from a sample frame of 137 names.

Respondents. In making the telephone calls to contact the randomly selected interview candidates, it sometimes occurred that the person could not be reached. In this event another randomly selected name was substituted for the original name. When individuals were contacted, it was verified that they really were Passive Architects, and that they would be needing information on passive solar technologies within the next year. If they were not both involved and needing information, they were asked if they could refer the interviewer to someone else in their organization who would be an appropriate respondent. If such a referral was made, a call was then made to this new candidate; if no intraorganizational referral was made, a new candidate was randomly selected from the sample frame. The results of this process may be seen in Table 5-1.

Comparisons. For additional insight into the information needs and the information habits of these Passive Architects, results from this group are compared to the results from Passive Builders and SHAC Architects interviewed in this study. The data for Passive Architects, Passive Builders, and SHAC Architects can be found in Appendix F.

\subsubsection{Current Status of Respondents}

Role. Three of the 9 Passive Architects specifically mentioned that they were working on residential applications of passive. One was working on commercial applications (of 19 th century cooling techniques). One was working on passive solar heating of apartment buildings, one was conducting workshops and providing design information, one was in the stage of reviewing and collecting data on passive solar heating and cooling, one was involved in research, and one mentioned working on passive solar heating projects. 
Table 5-1. COMPLETION OF INTERVIEWS: PASSIVE ARCHITCTS

Event

Number of

Candidates

Interview completed with sample frame candidate

Interview completed with referral candidate

Refusal or candidate termination

Contact attempted: could not reach candidate within three

attempts, or before interviews were completed

Subtotal

6

3

0

6

15

Contact attempted: invalid candidate (inappropriate field of

interest, no telephone)

TOTAI,

16

6

Sample frame error rate ${ }^{a}$ (Percent)

Completion rate ${ }^{\mathrm{b}}$ (Percent)

60

anvalid candidates divided by TOTAL

${ }^{\mathrm{b}}$ Completed interviews divided by Subtotal

Involvement. Four of the 9 (44\%) Passive Architects said that they were "very involved" in passive solar technologies, compared to 5 of the 9 (56\%) of the Passive Builders and 4 of the 9 (44\%) of the SHAC Architects.

Informedness. - Five of the 9 (56\%) Passive Architects considered themselves "very informed," compared to 7 of the 9 (78\%) and 6 of the 9 (67\%) for Passive Builders and SHAC Architects respectively.

Need for Information. All respondents indicated they would need information on passive solar heating and cooling on the job during the next year. Passive Architects and SHAC Builders also responded unanimously to needing information on their respective technologies on the job. Outside the job, however, only 4 of the 9 Passive Architects needed information on passive during the next year. This was slightly lower than the results for Passive Builders, where 6 of the $9(67 \%)$ indicated they would need information on their own technology outside the job. In another comparison, only 3 of the 9 (33\%) of the SHAC Architects indicated they would need information on SHAC outside the job in the next year. Perhaps architects feel they will not need information within the next year because they will not be building a new house within the next year.

\subsubsection{Background of Respondents}

Two of the 9 Passive Architects held doctoral degrees, 5 held bachelor's degrees, and 2 held associate degrees. Four had received degrees in architecture, 3 in engineering, and 2 in design. One received his/her most recent degree over 30 years ago, 3 from 10-20 years ago, 3 from 5-10 years ago, and 2 within the past five years. A comparison of Passive Architects with Passive Builders and SHAC Architects. showed no significant differences in educational level or year of most recent degree. The type of degree earned, however, showed slightly more concentration in engineering and architectural degrees in both Passive Architects (7 of the 9 or $78 \%$ ) and SHAC Architects (9 of the 9) and more miscellaneous type of degrees in the Passive Builder group. 
Only 1 had been in his/her current profession for 2 or fewer years, 3 for 6-10 years, and 5 for over 10 years (lengths of experience similar to SHAC Architects but slightly longer than Passive Builders). Five were architects, 2 were engineers, and 2 were designers. For both Passive Architects and SHAC Architects, the current profession was predominantly in the field of architecture and engineering.

\subsection{INFORMTION NEEDS OP RESPONDENTS}

\subsubsection{Technical Areas}

Passive Architects were asked to choose those areas in which they were "particularly interested in obtaining information" from a list of selected technical areas of passive solar technology. They seemed to be somewhat more interested in "building design" (9 of the $9)$, "collection of heat" (8 of the 9), "storage of heat" (8 of the 9), and "water heating" (8 of the 9 ) than in "space cooling" (6 of the 9). Areas of information interest selected by Passive Builders did not significantly ( $P$ 0.05) differ (see Table 5-2).

Table 5-2. AREAS OF INTEREST: PASSIVE ARCHITECTS AND PASSIVE BUILDERS

\begin{tabular}{|c|c|c|c|c|c|}
\hline \multirow{2}{*}{ Technical Area of Interest } & & \multicolumn{2}{|c|}{ Passive Architects } & \multicolumn{2}{|c|}{ Passive Builders } \\
\hline & & No. & Percent & No. & Percent \\
\hline \multicolumn{2}{|l|}{ Total Respondents } & 9 & 100 & 9 & 100 \\
\hline \multirow{2}{*}{\multicolumn{2}{|c|}{ Building Design }} & 9 & 100 & $\dot{9}$ & 100 \\
\hline & & 8 & 89 & 9 & 100 \\
\hline Storage of Heat & & 8 & 89 & 9 & 100 \\
\hline Water Heating & & 8 & 89 & 5 & 56 \\
\hline \multicolumn{6}{|l|}{ Landscaping or Orientation } \\
\hline of Building on Site & . & 7 & 78 & 5 & 56 \\
\hline Greenhouses & . & 7 & 78 & 9 & 100 \\
\hline \multicolumn{6}{|l|}{ Hybrid Systems (combining } \\
\hline Active and Passive) & & 7 & 78 & 7 & 78 \\
\hline Space Cooling & & 6 & 67 & 7 & 78 \\
\hline
\end{tabular}

One Passive Architect volunteered that he/she was also interested in commercial applications.

\subsubsection{Types of Information}

Passive Architects were asked to name the information about passive solar heating and cooling that was important for them to obtain. All 9 Passive Architects volunteered one or more items of information which they considered important. Three felt system design handbooks were important (design guidelines, general "rule-of-thumb" data, and simple procedures for designing passive solar heating systems), 2 mentioned test results (including data on test rooms and fully instrumented buildings and results from test sites), and 2 mentioned the location of demonstration projects. Other topics included: "the physical 
principles in air movement and ventilation," technical information on evaporation and cooling data for high humidity areas "like New Orleans," data on bacteria build-up in passive storage, night cooling rates, climatological data, performance standards, and "facts and figures on Midwestern buildings."

Four of the 9 Passive Architects stated that there was information they needed but were unable to obtain on passive solar energy. This included climatological data, general physics course information on passive cooling, visual aids, and information on solar installations for small towns. Passive Builders also mentioned climatological data as difficult to obtain.

Choice Between Specific Needs. A list of 11 types of passive information products and 14 types of passive information categories was read to each respondent. Each respondent described the usefulness of each particular item by assigning it a value of "essential," "very useful," "somewhat useful," or "not at all useful." The results are given in Fig. 5-1. For the purpose of comparison, the results for Passive Builders are shown in Section 6.0 and SHAC Architects in Fig. 5-2 of this section.

Passive Architects selected information categories/products directly related to application of passive solar systems as most important. The seven top-rated information categories/products were:

- Climatological data;

- Manual methods for sizing and predicting peformance or costs;

- Costs of installing and operating a passive solar system compared to a conventional system;

- Tax credits, grants, or other economic incentives;

- Design handbooks, installation handbooks, or reference tables;

- Costs and performance of systems; and

- A technical description of how a particular system works.

Passive Architects assigned the lowest relative ratings to:

- Programs, research, industries, and markets outside the United States;

- Computer models for sizing and predicting performance or costs;

- Institutional, social, environmental, and legal aspects;

- A bibliography of general readings;

- Lists of technical experts; and

- A nontechnical description of how a particular system works.

Statistical tests indicated that differences between the ratings for these seven highest and six lowest-rated information items were significant $(P 0.05)$ for Passive Architects. The difference between "manual methods" and "computer models" seems particularly interesting.

It should be noted that these lower-rated items were not necessarily of no worth to the Passive Architects. For example, 3 of the 9 (33\%) thought "a bibliography" was either "essential" or "very useful." Thus, these information categories/products could be useful to some Passive Architects but were of a lower relative priority to the entire group. 
Question \#8. I will read a list of potential information or information products on solar systems. For each, please tell me how useful that information would be to you. Would the following be: essential, very useful, somewhat useful, or not at all useful?

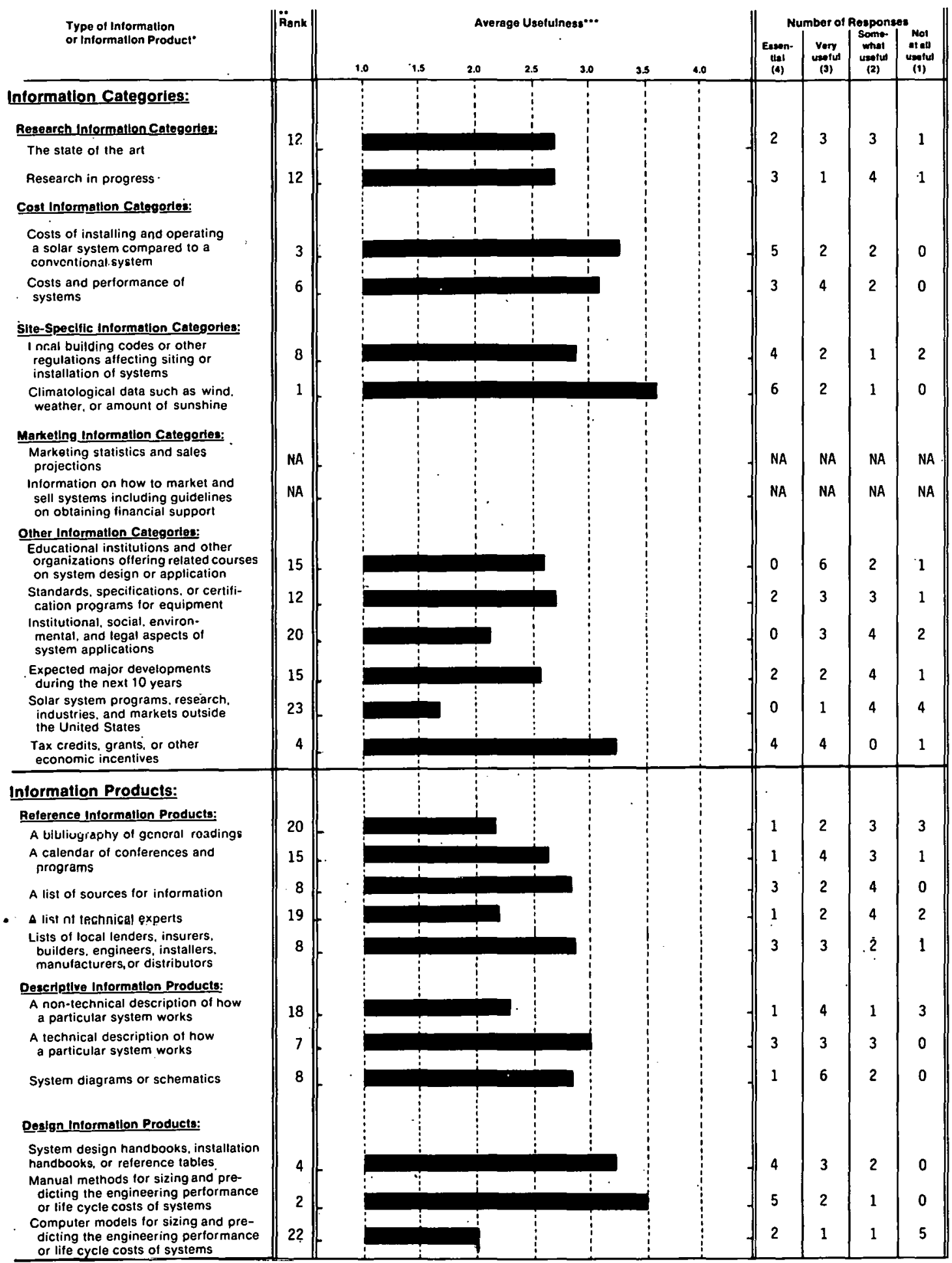

- Each sampte irame ol users was questioned on intormation and intormation products in the context of their specific technology. For example, biomess sample trames were ashed abuiv "a bibliogrophy of goneral roadings on hinmass", "A calender of upcoming biomass conterences and programs ", etc. Rank-Eachinformation product was assigned a rank besed on average usetulness. Thus, the product with the highest average uselutness was assigned ine rank of " " $1 "$; the prudurit with hes lowest average usotuliness would
highest renking was then assigned o "4.

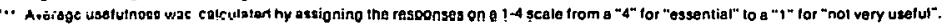

Figure 5-1. Usefulness of Selected Intormation ltems: Passive Architects 
Question \#8. I will read a list of potential information or information products on solar systems. For each, please lell me how useful that information would be to you. Would the following be: essential, very useful, somewhat useful, or not at all useful?

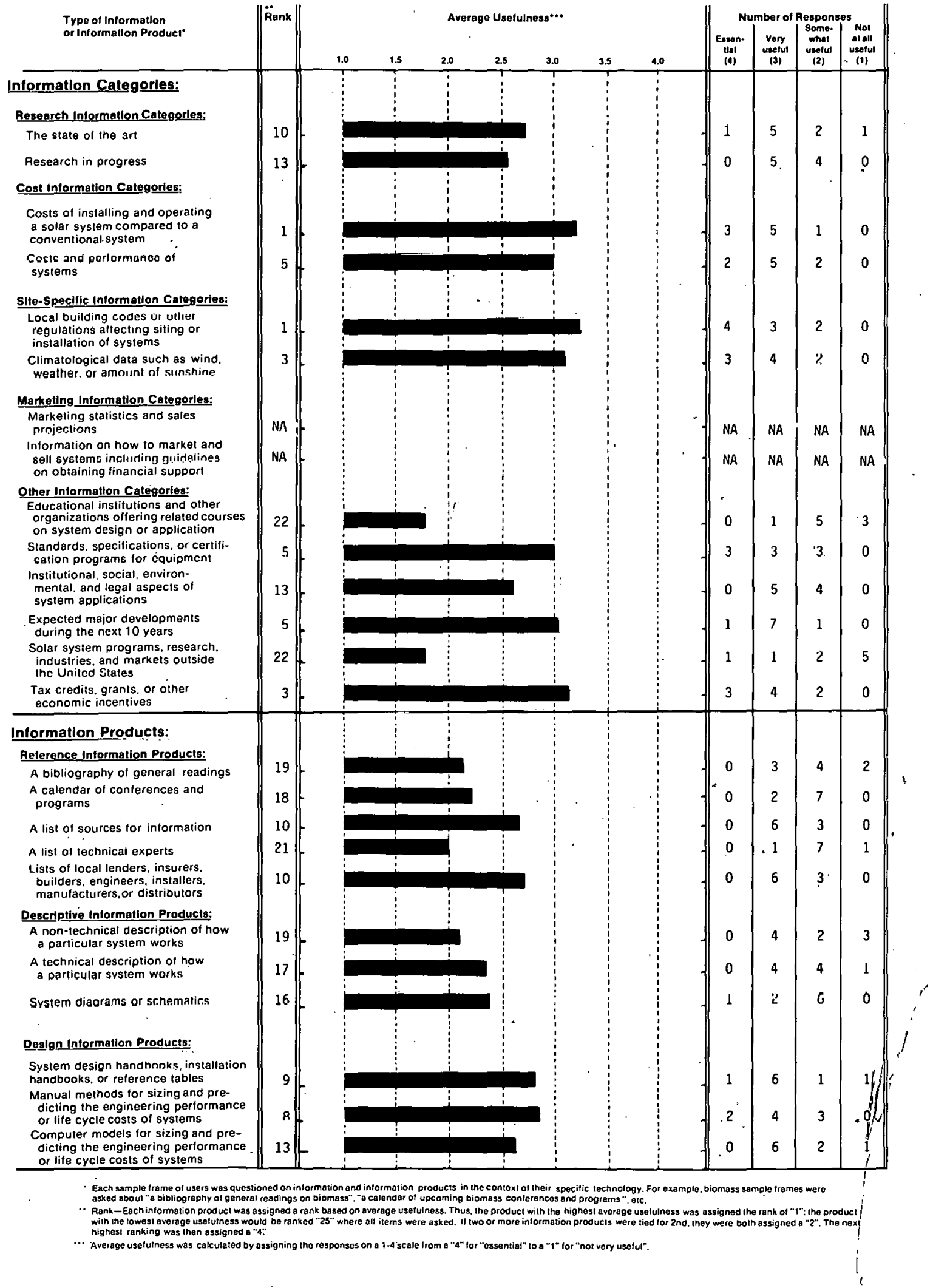

Figure 5-2. Usefulness of Selected Information Items: Active solar Hoating and Cooling Arohitocto 
Statistical tests were alșo used to determine whether the Passive Architects rated any of these information items significantly higher (or lower) than they were rated by the Passive Builders and SHAC Architects. Some groups, however, tended to give higher scores in general than did other groups. To compensate for this effect, these statistical tests compared the "relative rating" given by one group to the "relative rating" given by the other groups. The procedure for calculating the relative rating is described in Appendix E. The average overall rating Passive Architects gave to all items was 2.72; for Passive Builders it was 2.81; and for SHAC Architects, 2.60.

Compared to Passive Builders, the ratings given by Passive Architects did not differ significantly. There did seem to be evidence, however, that the Passive Architects were somewhat more interestëd in "costs of installing," "a technical description," and "systems diagrams or schematics."

Looking at SHAC Architects for another comparison, Passive Architects rated the need for information on "educational institutions" significantly (P 0.05 ) higher and "institutional, ... aspects" significantly ( $P$ 0.05) lower. There also seemed to be some evidence that Passive Architects were more interested in design information and less interested in "local"building codes" and in "standards, (etc.)."

\subsection{ACQUISTION OF INFORMATION BY RESPONDENTS}

\subsubsection{Use of Selected Information Sources}

Passive Architects were asked which of 21 different potential sources of solar information they had used in the past few years. For this question the respondents were not asked if they had obtained information on passive solar technologies, but instead were asked if they had obtained any solar information from each specific source. Thus, the question sought to determine which information sources were the most familiar to the respondents. The results are shown in Fig. 5-3. For the purpose of comparison, the results for Passive Builders are shown in Scetion 6.0 and SHAC Architects in Fig. 5-4 of this section.

The information sourees mentinned most often by Passive Architects were:

- Workshops, conferences, or training sessions;

- Periodicals, newspapers, or magazines;

- Private solar energy or environmental organizations;

- An installer, builder, or manufacturer;

- State energy or solar offices;

- ISES;

- Directly from the U.S. Department of Energy (DOE); and

- National Solar Heating and Cooling Information Center (NSHCIC).

It must be noted, however, that the high frequency of mentions received for ISES may have been impacted by the sampling procedure (see Section 5.1.1). 
Question \#11. In the past few years, have you obtained any type of solar information from any of the following sources?

Information Sources

Public Media:
Radio or TV
Periodicals, newspapers or magazines

\section{Private Solar-Involved Organizations:}

Private solar energy or environmental organizations

The local chapter or national headquarters of Internatinna! Solar Energy Society (ISES). including their publications

The local chapter or Ilational headquarters of Solar Enerqy Industries Assuciation (SEIA). including their publications

\section{Oonlacts will, Prulesslonals}

An installer, builder, designer or manufacturer of solar systems

Workshops, conferences or training sessions

\section{Intormation Services*:}

Your organizational library or a local library

A commercial data base: for example, Lockheed, SDC. BRS

Smithsonian Science Information Exchange (SSIE)

A Federal library or information center; for example, the National Agricultural Library or the Environmental Data System

The Government Printing Office (GPO)

National Technical information Service (NTIS)

Technical Information Center at Oak Ridge (TIC)

Government Solar-Involved Organizations

Directly from the U.S. Department of Energy

National Solar Heating \& Cooling Information Center -

Regional Solar Energy Centers

State Energy or Solar Offices

Other:

Some other state or local government office or publication

A public utility company

Sources fon this spocific cample trame"*:

American Institute of Architects (AIA) or AIA Research Corporation
Percentage Responding Yes ${ }^{* \cdot}$

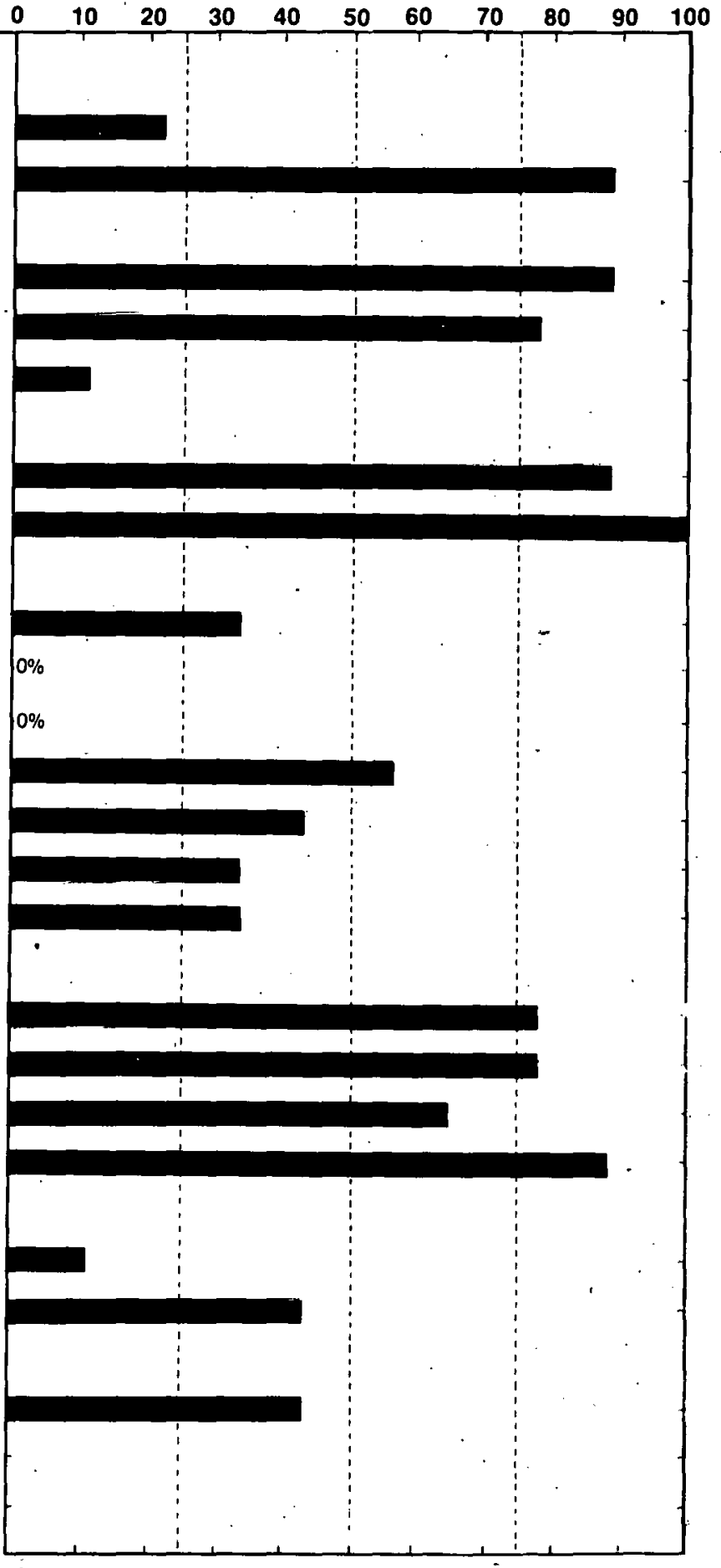

$\therefore$ Services and centers whose primary purpose is to disseminate information.

- Some sample frames were questioned about additional information sources which are applicable to their technology. For example. the manufacturers of biomass conversion equipment were also asked it they have obtained any type of solar information from: "the locat or national office of the U.S. Department of Agriculture. including Extension and Forestry."

... These data are based upon a total of 9 respondents.

Figure 5-3. Use of Selected Information Sources: Passive Architects 
Question \#11. In the past few years, have you obtained any type of solar information from any of the following sources?

Information Sources
Percentage Responding Yes ${ }^{* * *}$

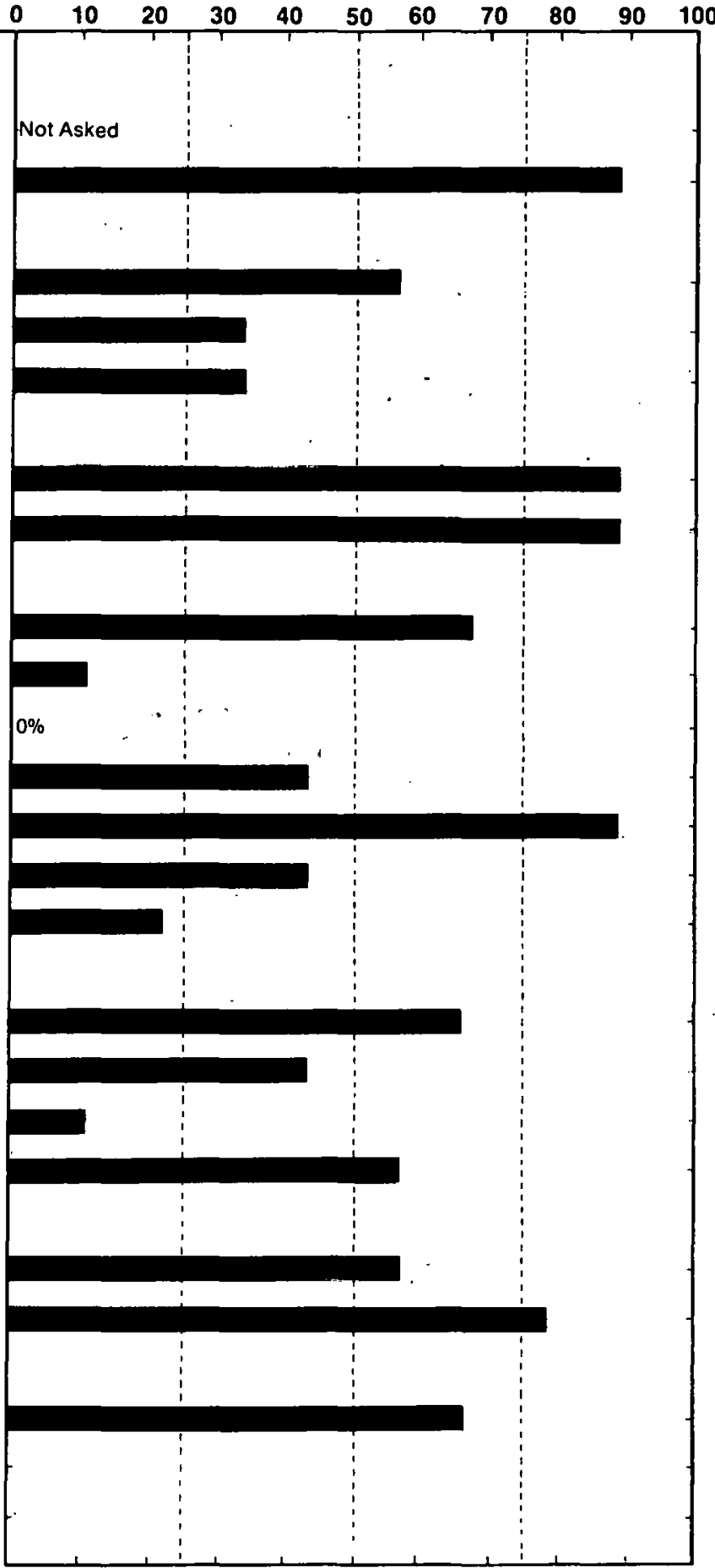

The local chapter or national headquarters of International Solar Energy Society (ISES). including their publications

The local chapter or national headquarters of Solar Energy.

Industries Association (SEIA), including their publications

Contacts with Professionals:

An installer, builder, designer or manufacturer of solar systems

Worksnops, conferences ur lidiling sessiuris

Information Services*:

Your organizational library or a local library

A commercial data base; for example, Lockheed, SDC, BRS

Smithsonian Science Information Exchange (SSIE)

A Federal library or information center; for example. the Nationa Agricultural Library or the Environmental Data System

The Government Printing Office (GPO)

National Technical Information Service (NTIS)

Technical Information Center at Oak Ridge (TIC)

Government Solar-Involved Organizations

Directly from the U.S. Department of Energy

National Solar Heating \& Cooling Information Center

Regional Solar Energy Centers

State Energy or Solar Offices

Other:

Some other state or local government office or publication

A public utility company

Sources for this specific sample frame* *:

American Institute of Architects (AIA) or AIA Research Corporation

- Services and centers whose primary purpose is to disseminate information.

- Some sample frames were questioned about additinnal information sources which are applicable to their technology. For example. the manufacturers of biomass conversion equipment were also asked it they have obtained any type of solar informatıon irom: "the local or national office of the U.S. Department of Agriculture, including Extension and Forestry."

** These data are baser upon a total of 9 respondents.

Figure 5-4. Use of Selected Information Sources: Active Solar Heating and Cooling Architects 
The information sources mentioned least often by Passive Architects were:

- A commercial data base,

- Smithsonian Science Information Exchange (SSIE),

- Solar Energy Industries Association (SEIA),

- Some other state or local government office or publications, and

- Radio or TV.

In comparing the information sources used by Passive Architects to those used by Passive Builders, no statistically significant ( $P$ 0.05) differences were found. Compared to SHAC Architects, however, significantly ( $P$ 0.05) 'more Passive Architects mentioned using the services of the Regional Solar Energy Centers (RSECs). Although the results were not statistically significant, it is interesting to note that Passive Architects seemed more likely than SHAC Architects to use "private solar energy or environmental organizations," ISES, and state energy or solar offices, but less likely to use the Government Printing Office (GPO) and "a public utility company."

\subsubsection{Membership in Solar-Interested Organizations}

Eight of the 9 Passive Architects surveyed were members of a professional, technical, or other organization with an interest in solar energy. The organizations mentioned (and the number of times mentioned) included:

- Alabama Solar Energy Society;

- American Institute of Architects (AIA) (3);

- American Institute of Constructors;

- American Society. of Heating, Refrigerating, and Air Conditioning Engineers (ASHRAE);

- American Society of Mechanical Engineers (ASME);

- Institute of Electrical and Electronics Engineers (IEEE);

- ISES (5); and

- Louisiana Solar Council.

Also mentioned was the "Passive Solar Energy Society," an organization that could not be verified by the authors.

\subsubsection{Exposure to Publications on Solar Energy}

During the past 6 months, all 9 Passive Architects had read publications that included information on passive solar technologies. The publications they could specify (and the number of times mentioned) included:

- AIA publications,

- ISES publications (e.g., reports and newsletters) (2),

- Mother Earth News, 
- Passive solar design manuals,

- Passive Solar Energy Book (by Mazria) (2),

- Progressive Architecture,

- Solar Age (4),

- Solar Engineering (2),

- Solar News,

- Technical publications by the Massachusetts Institute of Technology (MIT); and

- Sun World.

Aiso mentioned were some publications that could not be verified by the authors. These included "Balcomb Notes," "Solar World," "Sunwork," and "trade journals."

\subsubsection{Use of Special Acquisition Methods}

The respondents were asked whether they had obtained any information (not just passive solar energy) in the past year by computer terminal, by Computer Output Microform (COM), or by other microform (e.g.; microfiche, microfilm sheets, or rolls). Few Passive Architects appeared accustomed to using these special acquisition methods, a trait common to architects and builders surveyed in both passive and active SHAC. In the past year, 4 of the 9 had used a computer terminal, and no one had used either COM or other microform. A comparison of Passive Architects with Passive Builders and SHAC Architects showed no statistically significant $(P \quad 0.05)$ differences in the proportion using computer terminals, COM, or other microform.

\subsection{SUMMARY AND COMMENTS}

Nine architects involved in passive solar heating and cooling were interviewed. Six Passive Architects appeared to be actively involved in passive solar projects including residential applications, commercial applications, and apartment buildings. The remaining three were involved in disseminating passive design information, passive solar research, and reviewing and collecting data on passive. Their level of involvement, degree of informedness, and educational level was similar to that of Passive Builders and SHAC Architects.

Passive Architects were most interested in "building design," "collection of heat;" "storage of heat," and "water heating" and least interested in "space cooling." These pref'erences were consistent with those of Passive Builders.

Passive Architects gave the highest priority to receiving information on:

- Climatological data;

- Manual methods for sizing and predicting performance or costs of passive solar systems;

- Costs of installing and operating a passive solar system compared to a conventional system;

- Tax credits, grants, or other economic incentives for passive solar systems; 
- Passive solar system design handbooks, installation handbooks, or reference tables;

- Costs and performance of passive solar systems; and

- A technical description of how a particular passive solar system works.

They gave low ratings to "passive solar energy programs, research, industries, and markets outside the United States," "computer models," "institutional, social, environmental, and legal aspects," "a bibliography of general readings," "lists of technical experts," and "a nontechnical description."

The Passive Architects needed two principal things. First, they needed information for systems design. Within this area it was interesting to note they ranked "manual methods" second and "computer models" as twenty-second. Further, they needed information on installation costs, system costs, system performance, and "tax credits, grants, or other economic incentives."

Passive Architects, similarly to Passive Builders and SHAC Architects, most often received solar information through professional contacts ("workshops, (etc.)" and "an installer, builder, (etc.)") and "periodicals, (ete.)" Passive Architects also mentioned "private solar energy or environmental organizations," "directly from DOE," NSHCIC, and "state energy or solar offices." At least five were members of a local or national solar energy association, with ISES also serving as an important information disseminator and Solar Age as an important information source. (The results for ISES may have been biased due to sampling procedure). 


\section{SECTION 6.0}

\section{PASSIVE BUILDERS}

\subsection{DESCRIPTION OF RESPONDENTS}

\subsubsection{Description of Sample}

This section describes the results of a telephone study to determine the needs of builders/developers for information on passive solar technologies. Nine Passive Builders were interviewed.

The sample frame for Passive Builders was constructed from the following four lists: Residential Solar Data Center Grant Application Reports [15], the Mid-American Solar Energy Complex (MASEC) "Passive Workshop attendees" list [11], Solar Heated Buildings of North America [12], and the National Solar Heating and Cooling Commercial Demonstration Program-Key Personnel Directory (KPD) [13]. Names were taken from the U.S. Department of Housing and Urban Development (HUD) Grant Application Reports [15] that listed builders from passive or hybrid (passive/active) projects. The names selected from the MASEC "Passive Workshop Attendees" list [11] specified their occupation as builder; however, more than one occupation was of ten given. The attendees selected could also have been engineers, educators, homeowners, financiers, real estate people, architects, or researchers. Respondents were selected from Solar Heated Buildings of North America that listed builders of projects with passive or passive/active buildings. Also used as a source was the Key Personnel Directory (KPD) [13] that listed builders for Solar Heating and Cooling (SH $\overline{\mathrm{AC}})$ demonstration projects (DOE-CS). Builders from passive and passive/active demos were identified by use of Solar Heating and Cooling Demonstration Project Summaries [14] in conjunction with the KPD. After all adjustments were made, the 9 interview candidates were randomly selected from a sample frame of 58 names.

Respondents. In making the telephone calls to contact the randomly selected interview candidates, it sometimes occurred that the person could not be reached. In this event another randomly selected name was substituted for the original name. When individuals were contacted it was verified that they really were Passive Builders and that they would be needing information on passive solar heating and cooling within the next year. If they were not both involved and needing information, they were asked if they could refer the interviewer to someone else in their organization who would be an appropriate respondent. If such a referral was made, a call was then made to this new candidate; if no intraorganizational referral was made, a new candidate was randomly selected from the sample frame. The results of this process may be seen in Table 6-l.

Comparisons. For additional insight into the information needs and the information habits of these Passive Builders, results from this group are compared to the results from Passive Architects and SHAC Builders interviewed in this study. The data for Passive Builders, Passive Architects, and SHAC Builders can be found in Appendix F.

\subsubsection{Current Status of Respondents}

Role. Six of the 9 Passive Builders were working on residential applications of passive systems, and 1 was also involved with commercial applications. The remaining 3 respondents were involved in the following: designing and installing passive heating and cooling systems, manufacturing components, and designing and conducting research on passive systems. 
Table 6-1. COMPLETION OF INTERVIEWS: PASSIVE BUILDERS

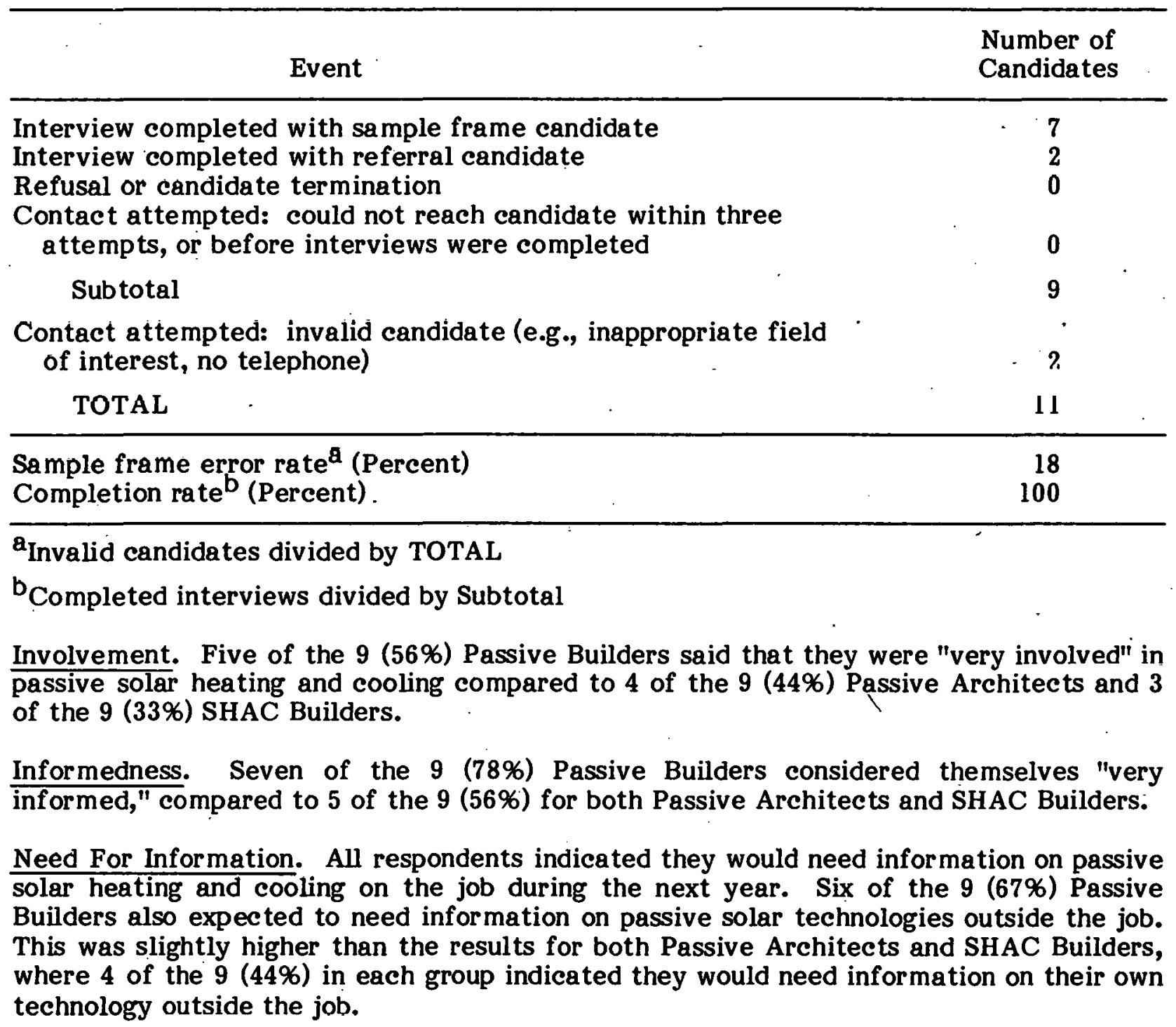

\subsubsection{Background of Respondents}

Five of the 9 Passive Builders held bachelor's degrees and 3 held master's degrees ( 1 did not have a degree). The types of degrces rcccivcd varich widely from 2 in business, 2 in architecture, and 1 each in engineering, economics, education, and psychology. All degrees were received within the past 15 years with 2 received 10-15 years ago, 3 from 5-10 years ago, and 3 within the past 5 years. A comparison of Passive Builders with Passive Architects and SHAC Builders showed no significant difference in educational level or year of most recent degree. The type of degree earned, however, showed slightly more concentration of engineering and architecture degrees in the Passive Architect ( 7 of the 9 or $78 \%$ ) and SHAC Builder (6 of the 9 or 67\%) groups and more miscellaneous type of degrees in the Passive Builder group.

One respondent had been in his/her current profession for 2 or fewer years, 3 for 3-5 years, 2 for 6-10 years, and 3 for over 10 years. This level of professional experience 
was slightly lower than that of Passive Architects and SHAC Builders. When stating their current profession, Passive Architects mentioned the following: builder, architect, executive, manager, home manufacturer, researcher, instructor, and a bookkeeper. In contrast, the majority of Passive Architects and SHAC Builders stated their current profession as either an architect or an engineer.

\subsection{INPORMATION NEEDS OF RESPONDENTS}

\subsubsection{Technical Areas}

- Passive Builders were asked to choose those areas in which they were "particularly interested in obtaining information" from a list of selected technical areas of passive solar heating and cooling. They seemed to be somewhat more interested in "building design" (9 of the 9), "greenhouses" (9 of the 9), "collection of heat" (9 of the 9) and "storage of heat" ( 9 of the 9) than in "landscaping or orientation of building on site" (5 of the 9). The level of interest expressed by Passive Builders in each technical area did not differ significantly ( $P$ 0.05) from Passive Architects. (See Table 6-2.)

\section{Table 6-2. AREAS OF INTEREST: PASSIVE BUILDERS AND PASSIVE ARCHITECTS}

\begin{tabular}{|c|c|c|c|c|}
\hline \multirow{2}{*}{ Technical Area of Interest } & \multicolumn{2}{|c|}{ Passive Builders } & \multicolumn{2}{|c|}{ Passive Architect } \\
\hline & No. & Percent & No. & Percent \\
\hline Total Respondents & 9 & 100 & 9 & 100 \\
\hline Building Design & 9 & 100 & 9 & 100 \\
\hline Greenhouses & 9 & 100 & 7 & 78 \\
\hline Collection of Heat & 9 & 100 & 8 & 89 \\
\hline Storage of Heat & 9 & 100 & 8 & 89 \\
\hline Space Cooling & 7 & 78 & 6 & 67 \\
\hline Hybrid Systems (Combining & & & & \\
\hline Active and Passive) & 7 & 78 & 7 & 78 \\
\hline Landscaping or Orientation & & & & \\
\hline of Building on Site & 5 & 56 & 7 & 78 \\
\hline Water Heating & 5 & 56 & 8 & 89 \\
\hline
\end{tabular}

One Passive Builder volunteered that he/she was also interested in information on thermosyphon systems.

\subsubsection{Types of Information}

Passive Builders were asked to name information about passive solar heating and cooling that was impurtant for them to obtain. All 9 of the Passive Builders volunteered one or more items of information which they considered important. Five named passive solar 
system design/specifications data (including design specifications per U.S. Department of Housing and Urban Development (HUD)-type documents, design ideas, designs for specific geographical areas, and current product development with specifications) and 4 named cost/performance data (including data on how to reduce cost, a comparison of construction cost versus performance, data on prices, and results from monitored buildings) as important. Other topics included climatological data, up-to-date research done by national labs and government projects, urban issues and applications, moisture buildup, commercial applications, data on retrofits, location of passive solar demonstration homes, and data on glass or large glazed areas.

Six of the 9 Passive Builders stated that there was information they needed but were unable to obtain on passive solar energy. This need included climatological data, information on window treatments (including retention of heat and blockage of cold), the cost versus performance of large glazed surfaces, greenhouses, studies on heat transfer in buildings (not computer simulations), overall design of homes for specific geographical areas, and "comparisons of theoretical to actual systems."

Choice Between Specific Needs. A list of 11 types of passive information products and 14 types of passive information categories was read to each respondent. Each respondent described the usefulness of each particular item by assigning it a value of "essential," "very useful," "somewhat useful," or "not at all useful." The results are given in Fig. 6-1. For the purpose of comparison, the results for Passive Architects are shown in Section 5.0 and SHAC Builders in Fig. 6-2 of this section.

Passive Builders selected financial incentives and site-specific information as most important. The six top-rated information categories/products were:

- Tax credits, grants, or other economic incentives;

- Local building codes or other regulations;

- Climatological data;

- Costs and performance of systems;

- Expected major developments during the next 10 years; and

- Manual methods for sizing and predicting performance or costs.

Passive Builders assigned the lowest relative ratings to:

- A nontechnical description of how a particular system works;

- Educational institutions and other organizations offering courses;

- Marketing statisties and sales projections; and

- Solar energy programs, research, industries, and markets outside the United States.

Statistical tests indicated that differences between the ratings for these six highest and four lowest-rated information items were significant ( $P$ 0.05) for Passive Builders.

It should be noted that these lower-rated items were not necessarily of no worth to the Passive Builders. For example, 3 of the 9 (33\%) thought "solar energy programs, research . . .outside the United States" was either "essential" or "very useful." Thus, these information categories/products could be useful to some Passive Builders but were of a lower relative priority to the entire group. 
Question \#8. I will read a list of potential information or information products on solar systems. For each, please tell me how useful that information would be to you. Would the following be: essential, very useful, somewhat uselul, or not at all useful?

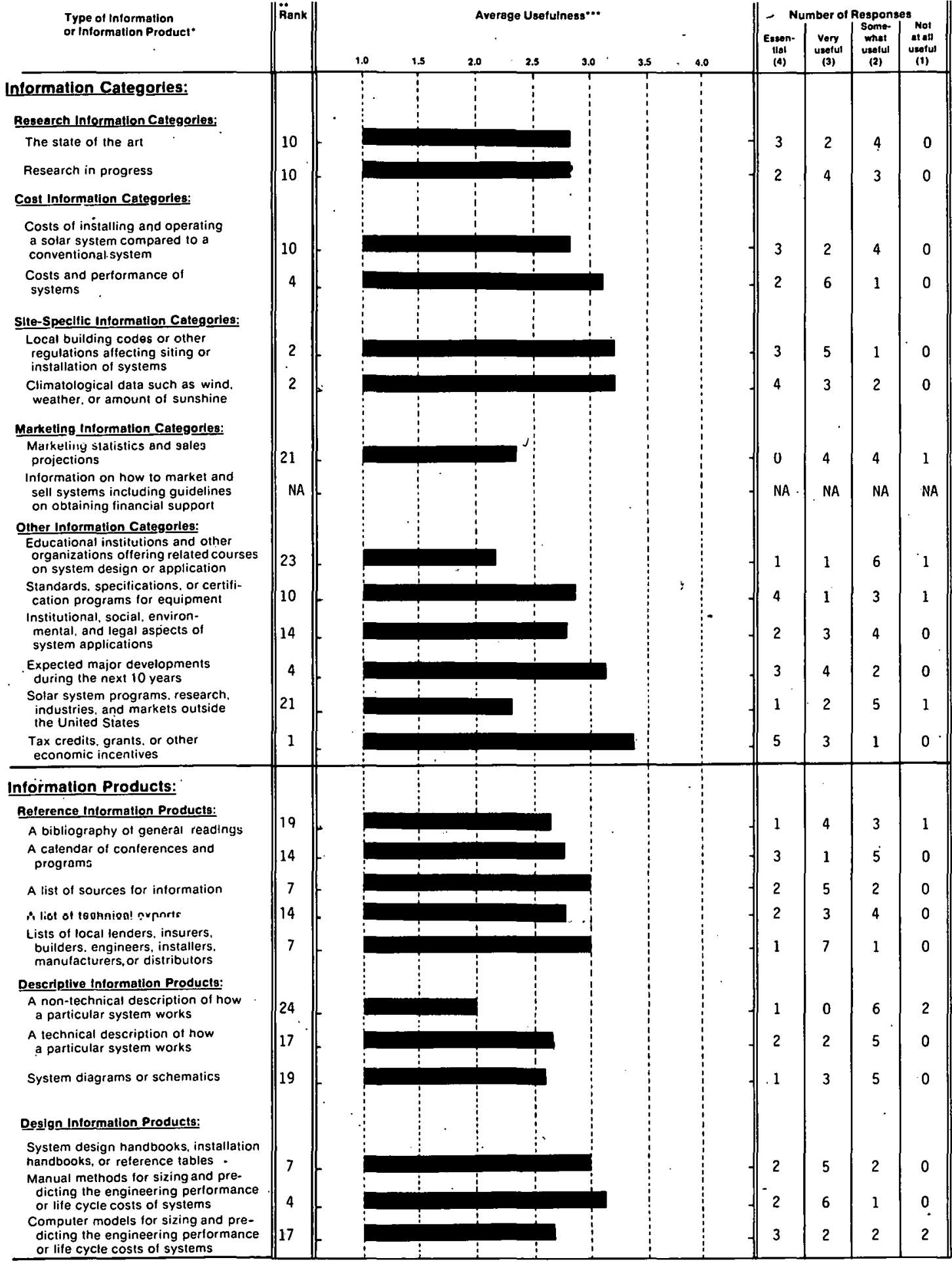

Each samplo trame of users was questioned on information and intormation products in the context of their specific technology. For example, biomass sample lrames were

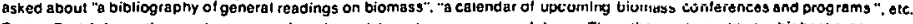

" nighest ranking was then assigned a " 4 "

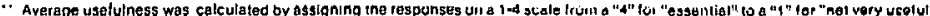

Figure 6-1. Usefulness of Selected Intormation ltems: Passive Builders 
Question \#8. I will read a list of potential intormation or information products on solar systems. For each, please tell me how useful that inlormation would be to you. Would the following be: essential, very useful, somewhat useful, or not at all useful?

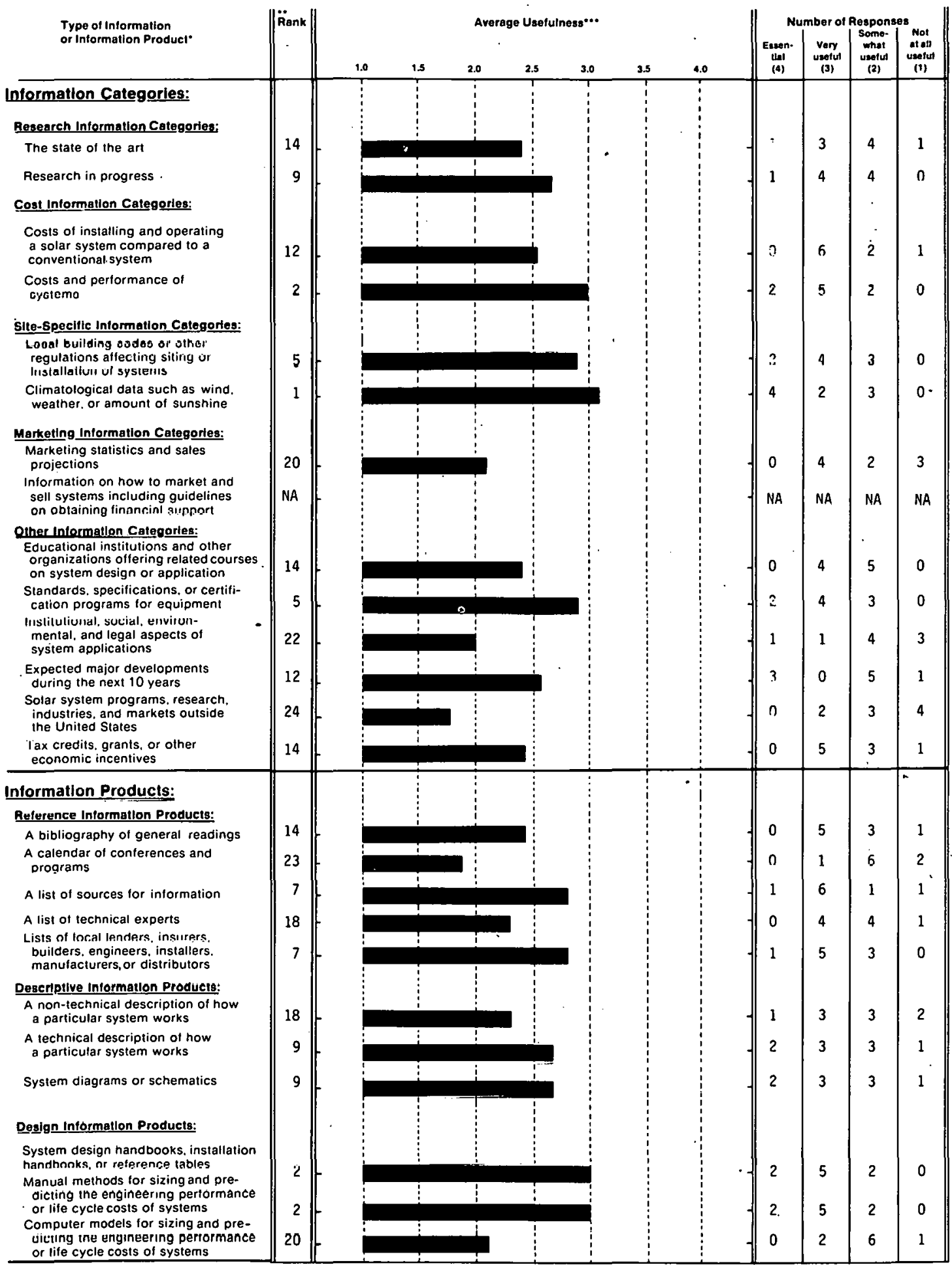

Each sample trame of users was questioned on intormation and intormation procucts in the context of theit specitic technology. For example. biomass sampte tremes were

Rank - Each information producl was assigned a rank based on average usefulness. Thus, the producl with the highest average usetulness was assigned the rank of " $"$ "; the product with the lowest average usefulness would be ranked "25" where all items were asked. II two or more intormation products were tied tor 2nd, they were both assigned a "2". The next nighest canking was then assigned a " 6 "

... Average usetulness was calculated by assigning the responses on a 1.4 seale trom a "a" for "essential" to a "1" tor "not very useful".

Figure 6-2. Usefulness of Selected Information Items: Active Solar. Hoatng and Cooling Bulldere 
Statistical tests were also used to determine whether the Passive Builders rated any of these information items significantly higher (or lower) than they were rated by the Passive Architects or the SHAC Builders. Some groups, however, tended to give higher scores in general than did other groups. To compensate for this effect, these statistical tests compared the "relative rating" given by one group to the "relative rating" given by the other groups. The procedure for calculating the relative rating is described in Appendix E. The average overall rating was slightly higher for Passive Builders (2.81) than it was for Passive Architects (2.72) and for SHAC Builders (2.54). As such, Passive Builders were among the top six groups in the whole study ( 86 groups) in the importance they attached to the information options presented.

Compared to those of Passive Architects, the ratings given by Passive Builders did not differ significantly. There seemed to be some evidence, however, that Passive Builders were less interested in "system diagrams" and "technical descriptions" and more interested in "expected major developments" than were the Passive Architects.

Compared to SHAC Builders, Passive Builders rated the need for information on "tax credits, grants, (etc.)," significantly (P 0.05) higher. Although the test results were not significant, Passive Builders seemed less interested in systems design information "standards" and "technical descriptions" but more interested in "expected developments" than were the SHAC Builders.

\subsection{ACQUISITION OF INFORMATION BY RESPONDENTS}

\subsubsection{Use of Selected Information Sources}

Passive Builders were asked which of 20 different potential sources of solar information they had used in the past few years. For this question the respondents were not asked if they had obtained information on passive solar heating and cooling, but instead were asked if they had obtained any solar information from each specific source. Thus, the question sought to determine which information sources were the most familiar to the respondents. The results are shown in Fig. 6-3. For the purpose of comparison, the results are shown for Passive Architects in Section 5.0 and for SHAC Builders in Fig. 6-4.

The information sources mentioned most often by Passive Builders were:

- Periodicals, newspapers, or magazines;

- Workshops, conferences, or training sessions;

- An installer, builder, designer, or manufacturer;

- Directly from the U.S. Department of Energy (DOE);

- National Solar Heating and Cooling Information Center (NSHCIC);

- Private solar energy or environmental organizations; and

- The Government Printing Office (GPO).

The information sources mentioned least often by Passive Builders were:

- Smithsonian Sclence Information Exchange (SSIE),

- Technical Information Center (TIC), 
Question \#11. In the past few years, have you obtained any type of solar information from any of the following sources?

Information Sources

Percentage Responding Yes "*

Public Media:

Radio or TV

Periodicals, newspapers or magazines

Private Solar-Involved Organizations:

Private solar energy or environmental organizations

The local chapter or national headquarters of International Solar tnergy Society (I'SES). including their publications

The local chapter or national headquarters of Solar Energy Industries Association (SEIA), including their publications

Contacls with Professlonals:

An installer, builder. designer or manufacturer of solar systems

Workshops, conterences or training sessions

Information Services*:

Your organizational library or a local library

A commercial data base: for example. Lockheed. SDC. BRS

Smithsonian Science Information Exchange (SSIE)

A Federal library or information center: for example. the National Agricultural Library or the Environmental Data System

The Government Printing Office (GPO)

National Technical Information Service (NTIS)

Technical Information Center at Oak Ridge (TIC)

Government Solar-Involved Organizations

Directly from'the U.S. Department of Energy

National Solar Heating \& Cooling Information Center

Regional Solar Energy Centers

State Energy or Solar Otfices

Other:

Some other state or local government office or publication

A public utility company

Sources for this snerifie sample framo**;

National Association of Home Builders

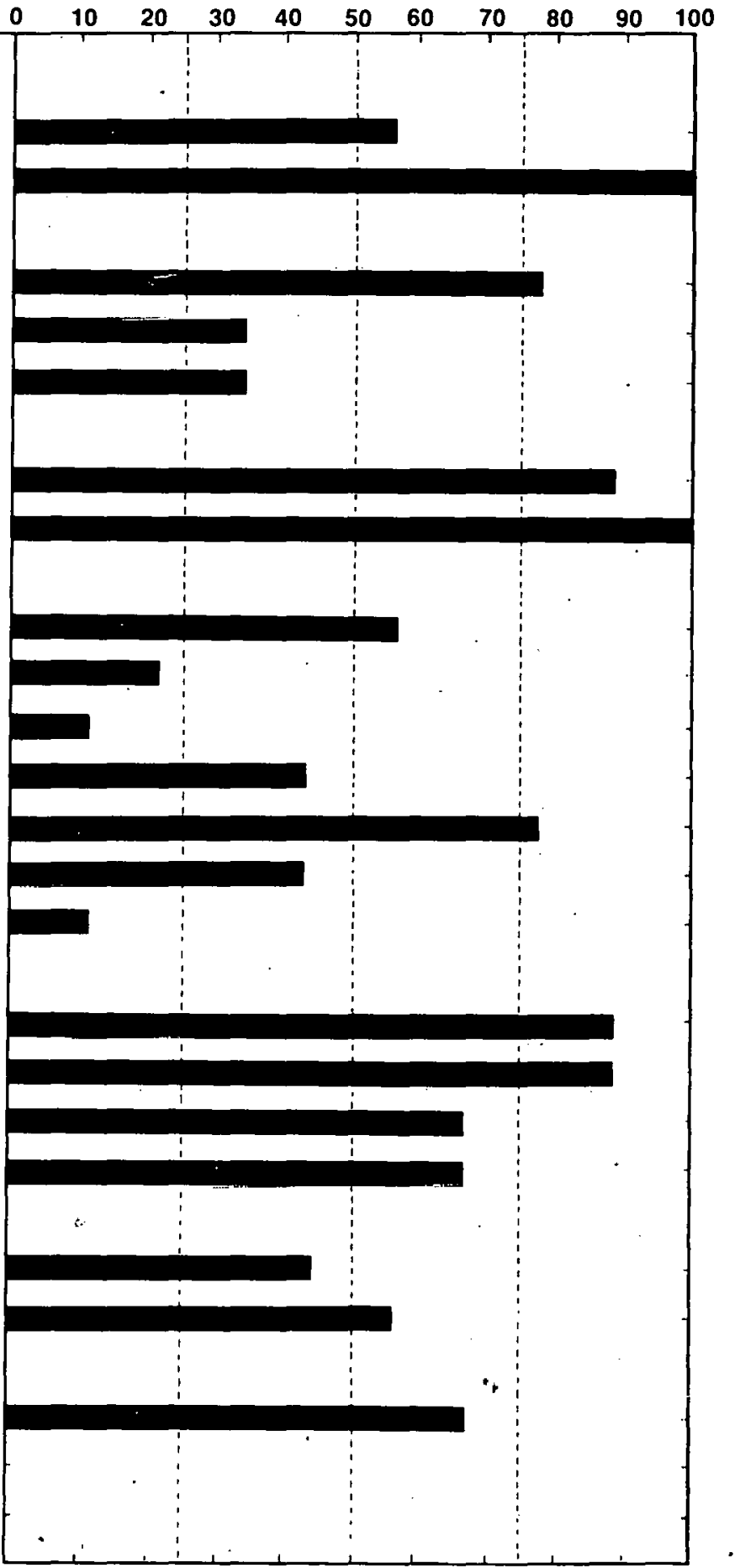

- Services and centers whose primary purpose is to disseminate information.
Some sample irames were questioned about additional information sources which are applicable to their technology. For example. the manufacturers of biomass conversion equipment were also asked if they have obtained any type of solar information from: "the local or . national office of the U.S. Department of Agriculture. including Extension and Forestry."

... These data are based upon a total of 9 respondents.

Figure 6-3. Use of Selected Information Sources: Passive Builders 
Question \#11. In the past few years, have you obtained any type of solar information from any of the following sources?

Information Sources

Percentage Responding Yes $\cdots$

Public Media:
Radio or TV
Periodicals. newspapers or magazines
Private Solar-Involved Organizations:
Private solar energy or environmental organizations
The local chapter or national headquarters of International
Solar Energy Society (ISES). including their publications
The local chapter or national headquarters of Solar Energy
Industries Association (SEIA). including their publications
Contacts with Professionals:

An installer, builder. designer or manufacturer of solar systems

Workshops. conferences or training sessions

Information Services*:

Your organizational library or a local library

A commercial data base; for example. Lockheed, SDC, BRS

Smithsonian Science Information Exchange (SSIE)

A Federal library or information center; for example, the National Agricultural Library or the Environmental Data System

The Government Printing Office (GPO)

National Technical Information Service (NTIS)

Technical Information Center at Oak Ridge (TIC)

Government Solar-Involved Organizations

Directly from the U.S. Department of Energy

National Solar Heating \& Cooling Information Centẹ

Regional Solar Energy Centers

State Energy or. Solar Offices

Other:

Some other state or local government office or publication

A public utility company

Sources for this specific sample frame**:

National Association of Home Builders

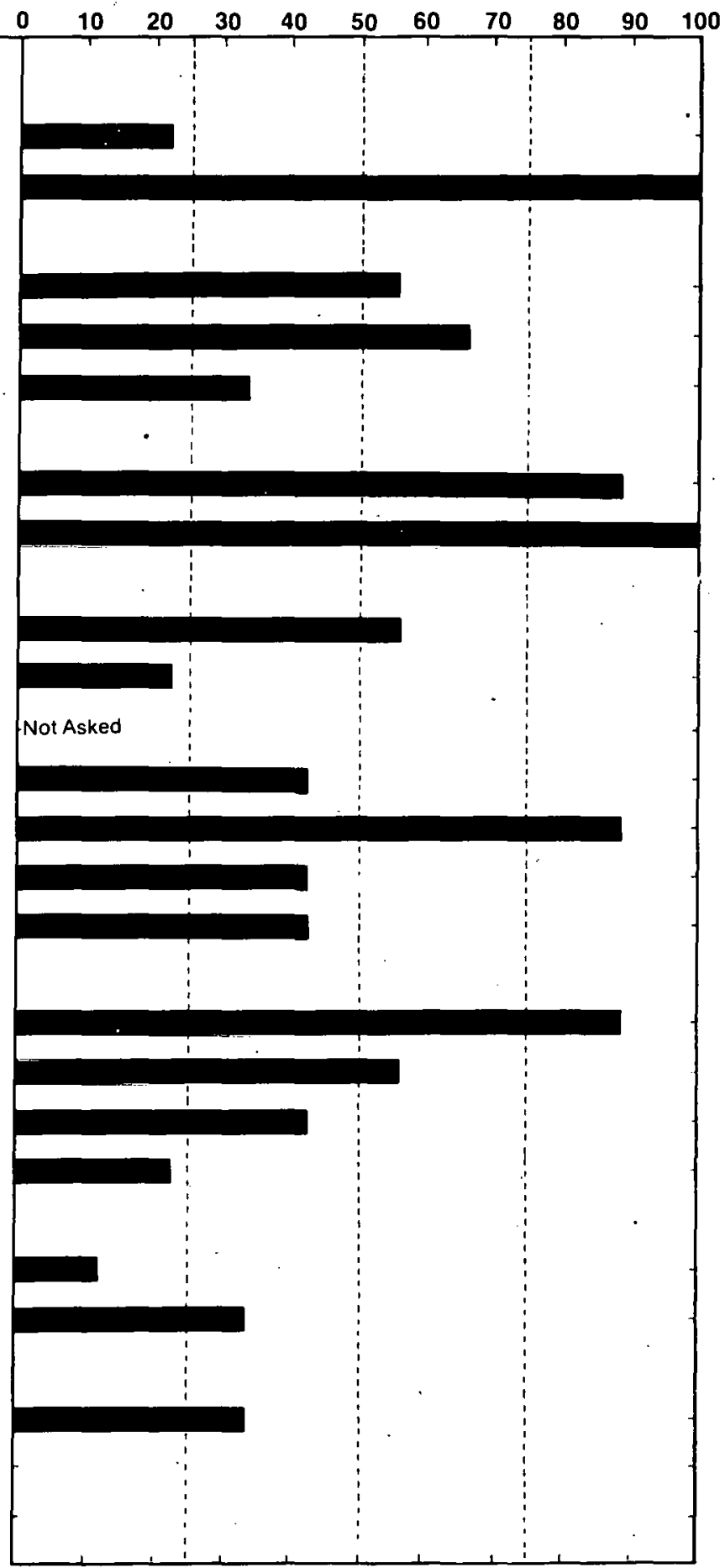

- Services and centers whose primary purpose is to disserrirlate information.

- Some sample frames were questioned about additional information sources which are applicable to their technology. For example. the manufacturers of biomass conversion equipment were also asked it they have obtained any type of solar information trom: "the local or naliorlal ullice ul the U.S. Department of Agrioulturc. including Extension and Fntestry"

... These data are based upon a total of 9 respondents.

Figure 6-4. Use of Selected Information Sources: Active Solar Heating and Cooling Bullders 
- A commercial data base,

- International Solar Energy Society (ISES), and

- Solar Energy Industries Association (SEIA).

In comparing the information sources used by Passive Builders to those used by Passive Architects and to SHAC Builders, although Passive Builders appeared to use more information sources, no statistically significant $(P \quad 0.05)$ differences were found.

\subsubsection{Membership in Solar-Interested Organizations}

Five of the 9 Passive Builders surveyed were members of a professional, technical, or other organization with an interest in solar energy. These organizations (and the number of times mentioned) included:

- American Institute of Architects (AIA);

- American Society of Heating, Refrigerating and Air Conditioning Engineers (ASHRAE) (2);

- Capital Hill Alliance of Planners and Architects;

- ISES;

- MASEC;

- National Association of Home Builders;

- Nebraska International Solar Energy Society;

- Solar Energy Exchange Program, University of Colorado; and

- SEIA.

Also mentioned were some organizations that could not be verified by the authors. These included "MIES," "MEA," "SPI," and "Boulder County Community Design Center."

\subsubsection{Exposure to Publications on Solar Energy}

During the past 6 months, all 9 Passive Builders had read publications which included information on passive solar heating and cooling. The publications they could specify (and the number of times mentioned) included:

- Air Conditioning and Refrigeration Business,

- Better Homes and Gardens,

- Builder (National Home Builders Association) (3),

- DOE pamphlets on system design,

- Government publications (e.g., solar monthly pamphlets),

- Housing (2),

- HUD documents,

- Passive Solar Design: A Survey of Monitored Buildings,

- Passive Solar Energy Book (by Mazria), 
- Proceedings of the passive conferences,

- Professional Builder (2),

- Solar Age (2), and

- Solar Engineering.

Also mentioned were some publications that could not be verified by the authors. These included "Building Management," "solar publications" (2), and "trade journals or publications (3)."

\subsubsection{Use of Special Acquisition Methods}

The respondents were asked whether they had obtained any information (not just passive or solar energy) in the past year by computer terminal, by Computer Output Microform (COM), or by other microform (e.g.; microfiche, microfilm sheets, or rolls). Few Passive Builders appeared accustomed to using these special acquisition methods, a trait common to builders and architects surveyed in both passive and active SHAC. In the past year, only 3 of the 9 (33\%) had used a computer terminal, and no one had used either COM or other microform. A comparison of Passive Builders with Passive Architects and SHAC Builders showed no statistically significant $(P \quad 0.05)$ differences in the proportion using computer terminals, COM, or other microforms.

\subsection{SUMMARY AND COMMENTS}

Nine builders involved in passive solar were interviewed. Six of the nine were working on residential applications of passive, and the other three were involved in design (2), component manufacturing, and research. Their level of involvement and degree of informedness appeared to be slightly higher than that of SHAC Builders. The three groups were similar in educational level, but Passive Builders had slightly fewer years of professional experience. Passive Builders also differed by having more miscellaneous types of degrees and current professions as compared to the predominantly architect and engineer types of degrees and professions for both Passive Architects and SHAC Builders.

All nine Passive Builders were interested in "building design," "greenhouses," "collection of heat," and "storage of heat." The least interest (mentioned by 5 of the 9 respondents) was for "landscaping or orientation of building on site." These preferences were consistent with those of Passive Architects.

Passive Builders gave the highest priority to receiving information on:

- Tax credits, grants, or other economic incentives for passive solar systems;

- Local building codes or other regulations affecting passive solar systems;

- Climatological data;

- Costs and performance of passive solar systems;

- Expected major developments in passive solar technology during the next 10 years; and

- Manual methods for sizing and predicting performance or costs of passive solar systems. 
They gave low ratings to "a nontechnical description," "educational institutions," "marketing statistics," and "solar energy programs ... outside the United States."

The resulting picture of the Passive Builder is quite similar to that of the Passive Architect and somewhat similar to that of the SHAC Builder. All three groups placed a high priority on site-specific information ("local building codes" and "climatological data"), "costs and performance," and "manual methods." Other noted similarities identified "design handbooks" ranked within the top eight and "lists of sources" and "lists of local lenders, (etc.)," ranked either seventh or eighth by each group. Passive Builders' first priority ("tax credits"), however, was rated significantly lower (ranked 14th of the 24 information items) by SHAC Builders. One possible explanation is that SHAC tax credits were well-defined and well-known, while tax credits for passive seemed to be bottled up by the IRS.

Passive Builders most often received information through professional contacts ("workshops" and "an installer, builder"), "periodicals, (etc.)," "private solar energy or environmental organizations," ISES, and government solar-involved organizations. At least four were members of a local or national solar energy association. Builder-oriented periodicals seemed to provide a good deal of their information on passive solar technologies. 


\section{SECTION 7.0}

\section{PASSIVE EDUCATORS}

\subsection{DESCRIPTION OF RESPONDENTS}

\subsubsection{Description of Sample}

This section describes the results of a telephone study to determine the needs of educators for information on passive solar technologies. Nine Passive Educators were interviewed.

The sample frame for Passive Educators was constructed by searching the Solar Energy Information Data Base (SEIDB) Education Data Base [16]. Over 200 schools that had courses, including information on passive solar technologies, were listed in the data base. - Instructors of advanced-level courses were selected when possible. Instructors who also appeared in Educator sample frames for other technologies were eliminated. In many cases, course descriptions named several technologies, and it was necessary to make some arbitrary decisions about the sample frame in which to place the course instructor. After all adjustments were made, the 9 interview candidates were randomly selected from a sample frame of 120 names.

Respondents. In making the telephone calls to contact the randomly selected interview candidates, it sometimes occurred that the person could not be reached. In this event another randomly selected name was substituted for the original name. When individuals were contacted it was verified that they really had been teaching passive solar technology and that they would be needing information on passive within the next year. (No attempt was made to determine if the respondent was currently teaching a course on passive solar.) If they were not both involved and needing information, they were asked if they could refer the interviewer to someone else in their organization who would be an appropriate respondent. If such a referral was made, a call was then made to this new candidate; if no intraorganizational referral was made, a new candidate was randomly selected from the sample frame. The results of this process may be seen in Table 7-1.

Table 7-1. COMPLETION OF INTER VIEWS: PASSIVE EDUCATORS

Event

Number of

Candidates

Interview completed with sample frame candidate

Interview completed with referral candidate

Refusal or candidate termination

Contact attempted: could not reach candidate within three

attempts, or before interviews were completed

Subtotal

Contact attempted: invalid candidate (e.g., inappropriate field of interest, no telephone)

Sample frame error rate $^{a}$ (Percent)

anvalid candidates divided by TOTAL

${ }^{\mathrm{b}}$ Completed interviews divided by Subtotal 
Comparisons. For additional insight into the information needs and the information habits of these Passive Educators, results from this group are compared to the results from SHAC (Active Solar Heating and Cooling) Educators and to the results from all of the educators interviewed in this study (All Educators). In addition to passive solar heating and cooling, the technologies included in All Educators were solar thermal electric power, active solar heating and cooling, photovoltaics, biomass, wind, and solar industrial process heat. In performing any statistical comparisons, the totals for Passive Educators have been subtracted from the totals for All Educators. The data for Passive Educators, for SHAC Educators, and for All Educators can be found in Appendix F.

\subsubsection{Current Status of Respondents}

Role. Seven of the 9 Passive Educators were on the faculties of 4-year colleges or universities, and 2 taught at community colleges. They taught courses in the Physics, Mechanical Engineering, Architecture, and Industrial Education and Technology Departments. All taught courses at the senior or graduate level. At least 7 of the 9 taught courses that covered heat and energy transfer, solar collector evaluation and design, solar system design, domestic water heating, and/or space heating. Other topics frequently included (by 4 or more) were alternate energy sources, energy conservation, energy conversion, energy storage, solar system components, and solar home construction. One of the 9 appeared to be involved with research as well as teaching. Two mentioned having passive solar in their own homes. One mentioned being involved with design, and another was doing consulting. Specific topics that were mentioned (and are assumed to be major emphases of their courses) included: passive design of houses and factories, solar conversion, conservation and passive solar energy in existing buildings, passive solar energy in mobile homes, solar collector analysis, window heating units, and alternate energy. One mentioned attending a DOE conference for high-school teachers.

Involvement. Two of the 9 (22\%) Passive Educators said that they were "very involved" in passive solar technologies compared to 5 of the 9 (56\%) SHAC Educators and 27 of the 63 (43\%) All Educators who said they were "very involved" with their respective solar technologies. However, the proportion who considered themselves at least "moderately involved" was the same for Passive Educators (78\%) as for All Educators. In comparison, all 9 of the SHAC Educators were at least "moderately involved."

Informedness. Only two of the 9 (22\%) Passive Educators considered themselves "very informed," compared to 6 of the 9 (67\%) SHAC Educators and 31 of the 63 (49\%) All Educators. All of the other 6 groups of Educators gave themselves higher marks for informedness than did the Passive Educators.

Need for Information. All respondents indicated they would need information on passive on the job during the next year. Seven of the 9 (78\%) Passive Educators also expected to need information on passive solar technologies outside the job. This compares to the 31 of the 45 (69\%) All Educators who expected to need off-the-job information on their respective solar technologies. The Passive Educators were more likely than any of the other passive groups (Researchers, Builders, Architects, Manufacturers, or County Agents) to need off-the-job information on passive solar technologies. Thus, it might be speculated that more than the 2 who presently have passive solar energy in their own homes may be interested in using passive technologies in the future (or, alternatively, that they are involved with other avocational interests requiring passive solar information). 


\subsubsection{Background of Respandents}

Six of the 9 Passive Educators held a PhD, and 2 held master's degrees. The percentage holding advanced degrees (beyond bachelor's) was about the same for both Passive and SHAC Educators (89\%) and for All Educators (90\%). Seven of the 9 Passive Educators had received their most recent degree within the past 15 years, 2 of them within the past 5 years. Three Passive Educators had received their most recent degree in physics. Other degree fields were: education (including vocational technology and industrial), mechanical engineering, city planning, and cooling and air conditioning.

Six of the 9 Passive Educators had been in their present profession (not necessarily teaching) for over 10 years, 2 for 6-10 years, and 1 for less than 5 years. Six of the 9 described their present profession as educator or professor. Other professional descriptions included administrator, mechanical engineer, and physicist.

\subsection{INFORMATION NEEDS OF RESPONDENTS}

\subsubsection{Technical Areas}

Passive Educators were asked to choose those areas in which they were "particularly interested in obtaining information" from a list of selected technical areas of passive solar technologies. They seemed to be somewhat more interested in "building design," "collection of heat," "storage of heat," and "hybrid systems" (all of the 9 were interested) than in "landscaping or orientation of buildings" ( 6 of the 9). Eight were interested in "greenhouses" and "water heating" and 7 in "space cooling."

Some Passive Educators volunteered that they were also interested in interactive effects of daylighting, greenhouse heat storage, phase-change storage, and the use of concrete blocks with phase-change materials.

\subsubsection{Types of Information}

Passive Educators were asked to name the information about passive solar technologies that was important for them to obtain. All of the 9 volunteered one or more items of information that they considered important. One respondent referred to three booklets from the National Solar Heating and Cooling Information Center (NSHCIC) as being important. Other important information included: background for building heating and cooling study courses, formal education programs, health impact of passive solar techniques, construction needs, window insulation techniques, computer modeling, correlation between performance of real systems and physical models, quantitative design criteria, methods for quantifying variables, time lags and storage, results of implementation tests, new designs, cost effectiveness (especially in the Northeast), research on thermal storage, and "all general information on solar heating and cooling."

Three of the Passive Educators volunteered that there was information they needed but were unable to obtain. Included were transient responses of various elements, costeffectiveness of passive in the Northeast, and window insulation techniques.

Choice Between Specific Needs. A list of 11 types of passive information products $\backslash$ and 14 types of passive information categories was read to each respondent. Each respondent 
described the usefulness of each particular item by assigning it a value of "essential," "very useful," "somewhat useful," or "not at all useful." The results are given in Fig. 7-1. For the purpose of comparison, results for SHAC Educators are in Fig. 7-2, and those for All Educators are in Fig. 7-3.

Passive Educators assigned high ratings to the cost and the system design items. Many of the items received quite high ratings. The seven top-rated information categories/products were:

- Costs and performance of systems;

- A technical description of how a particular system works;

- Design handbooks, installution hanabooks, or reference tables;

- Costs of installing and oporating a passive systern compared to a conventional system;

- Educational institutions and other organizations offering courses;

- Expected major developments during the next 10 years; and

- Manual methods for sizing and predicting performance or costs.

Passive Educators assigned the lowest relative ratings to six items, including both items in the marketing category:

- How to market and sell solar systems;

- Marketing statistics and sales projections;

- Calendars of conferences and programs;

- Solar energy programs, research, industries, and markets outside the United States;

- Lists of local lenders, insurers, builders, engineers, installers, manufacturers, or distributors; and

- Standards, specifications, or certification programs.

Statistical tests indicated that ratings for the seven highest- and six lowest-rated items differed significantly (P $\mathbf{0 . 0 5}$ ) for Passive Educators. It appeared that although the Passive Educators were interested in (formal) programs of fered by educational and other institutions, they were less interested in more informal programs or conferences.

It should be noted that these lower-rated items were not necessarily of no worth to the Passive Educators. For example, 3 of the 9 (3j\%) thought "standards, (etc.)" and "lists of local lenders, (etc.)" were either "essential" or "very useful." Thus, these information categories/products could be useful to some Passive Educators but were of a lower relative priority to the entire group.

Statistical tests were used to determine whether the Passive Educators rated any of these information items significantly higher (or lower) than they were rated by the SHAC Educators or by All Educators. Some groups, however, tended to give higher scores in general than did other groups. To compensate for this effect, these statistical tests compared the "relative rating" given by one group to the "relative rating" given by the other groups. The procedure for calculating the relative rating is described in 
Question \#8. I will read a list of polential information or information products on solar systems. For each, please tell me how useful that information would be to you. Would the following be: essential, very useful, somewhat useful, or not at all useful?

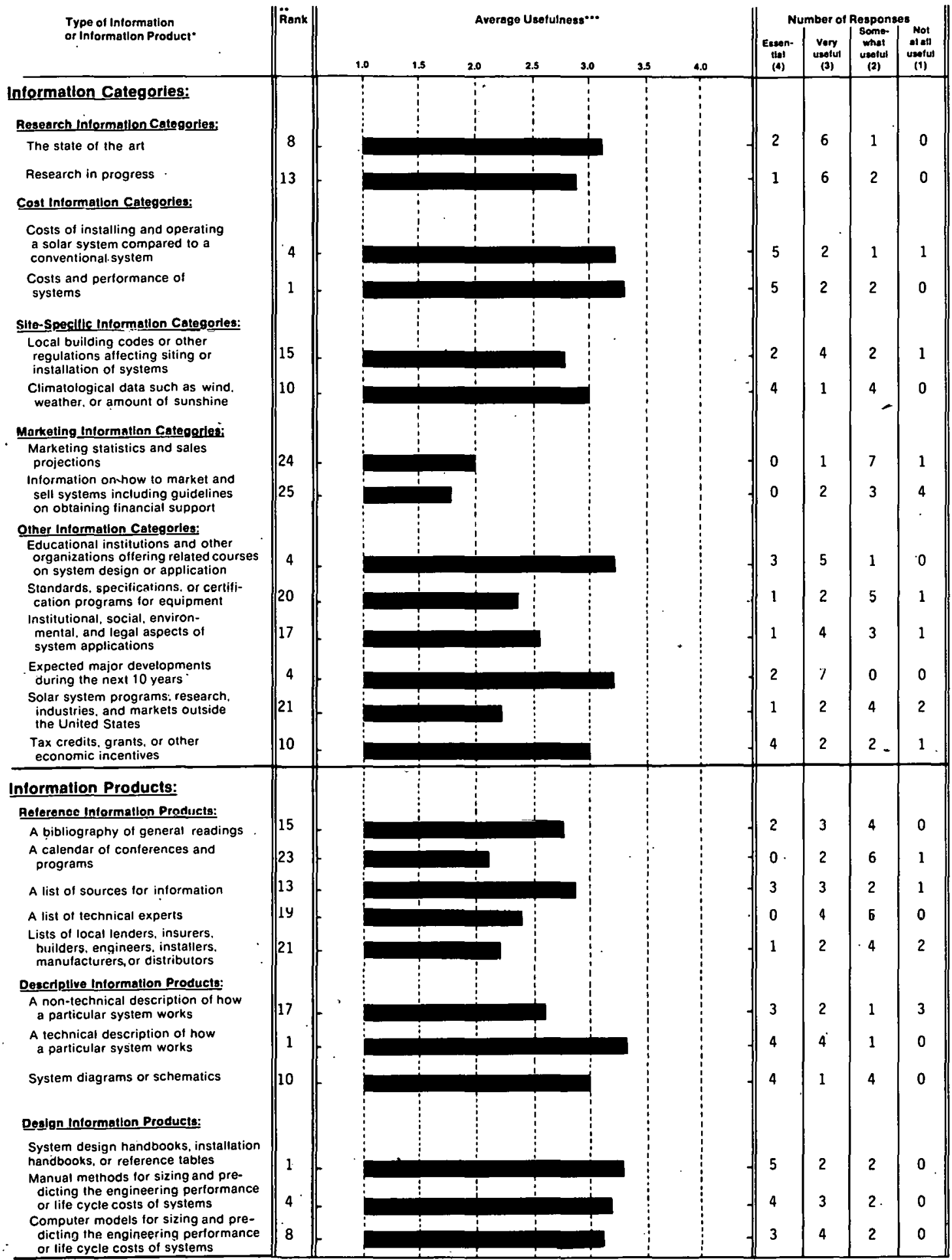

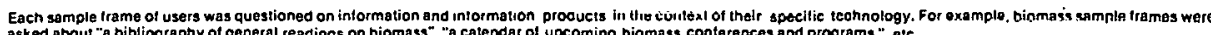
asked about "a bibliography of genteral readings on biomass". "A caiendar or upcoming biomass conterences and programs ", atc. Rank Average usefulness was calcutated by assigning the responses on a i-4 seale trom a "4" lor "essenial" io a "1" tor "nut very useful".

FIgure 7-1. Usefulness of Selected Information Items: Passive Educators 
Question \#8. I will read a list of polential information or information products on solar systems. For each, please tell me how useful that information would be to you. Would the following be: essential, very useful, somewhat useful, or not at all useful?

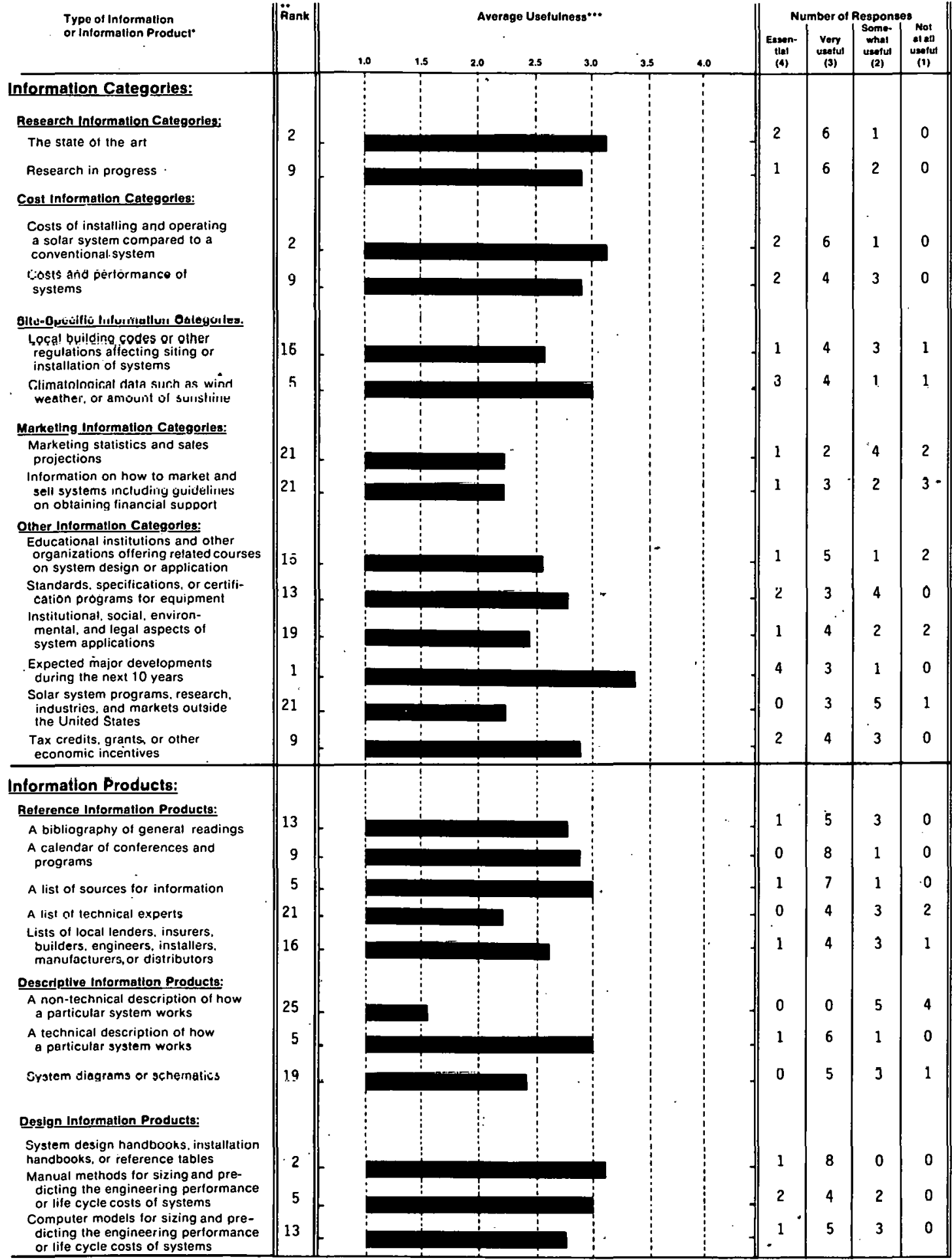

Each sampte Irame of users was questioned on inlormation and information products in the context of their specific technotogy. For example, biomass sample trames were asked about "a bibliography of general readings on biomass", "a calencar of upcoming biomass conterences and programs". etc.

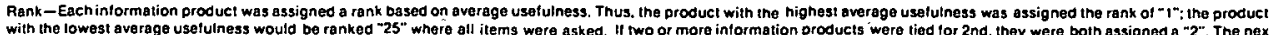
nighest ranking was then assigned a "4:

Averago usefulness was catculated by assigning the responies on a 1-4 scale from a " 4 " for "essential" to "1" tor "not very useful".

Figure 7-2. Usefulness of Selected Information Items: Wive Solar Hathing and Cooling Edicatore 
Question \#8. I will read a list of potential information or information products on solar systems. For each, please tell me how useful that information would be to you. Would the following be: essential, very useful, somewhat useful, or not at all useful?

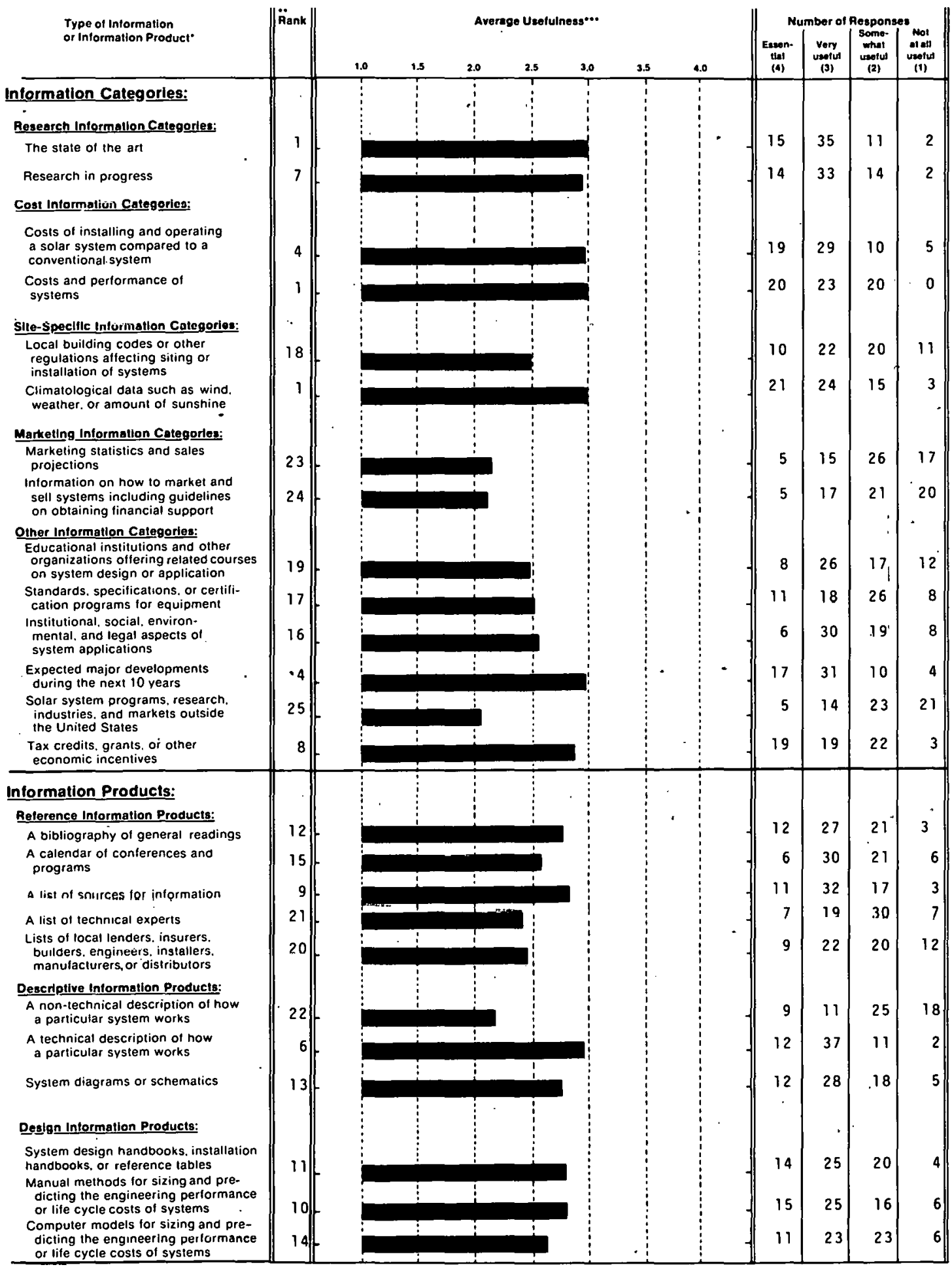

Each sample frame of users was questioned on intur mation and information products in the context of their spocitic technology. For example, blomass sample irs mes ware bioliography of general reading on

Rank - Each intormation produet was assigned a rank based on average usetulness. Thus. the product with the highest average usetulness was assigned the rank of "1": the product

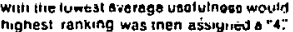

".. Average uselulness was calculated by assigning the responses on a 1.4 scale from a "4" tor "essential" 108 " 1 - tor "nol very usetul".

Figure 7- 3. Usefulness of Selected Information Items: All Educators 
Appendix E. The average overall rating was higher for both Passive Educators (2.79) and SHAC Educators (2.70) than it was for All Educators (2.64).

In comparing the results for Passive Educators to the results for SHAC Educators, both rated "costs of installing," "expected major developments," and "design handbooks, (etc.)" relatively high. Items that Passive Educators found useful that the SHAC Researchers did not find as useful were "costs and performance," "educational institutions," "a technical description," and "manual methods." Statistical tests showed that the differences between SHAC and Passive Educators' ratings were significant only for "calendars of conf erences," which the Passive Researchers rated lower.

In comparing the results for Passive Educators to the results for All Educators, similarities were found in high ratings for both cost items and "expected major developments," coupled with low ratings for marketing information and "passive programs . . . outside the United States." Passive Educators rated "calendars" significantly (P $\mathbf{0 . 0 5})$ lower than did All Educators, but "educational institutions" significantly ( $P \quad 0.05)$ higher. It is interesting to note that Passive Educators were one of only two of the seven groups of Educators who rated "educational ... courses" higher than they rated "calendars of conferences and programs."

\subsection{ACQUISITION OF INPORMATION BY RESONDENTS}

\subsubsection{Use of Selected Information Sources}

Passive Educators were asked which of 20 different potential sources of solar information they had used in the past few years. For this question the respondents were not asked if they had obtained information about passive technologies, but instead were asked if they had obtained any solar information from each specific source. Thus, the question sought to determine which information sources were the most familiar to the respondents. The results for Passive Educators are shown in Fig. 7-4. For comparison, those for SHAC Educators are provided in Fig. 7-5, and All Educators in Fig. 7-6.

The information sources mentioned most of ten by Passive Educators were:

- Periodicals, newspapers, or magazines;

- An installer, builder, designer, or manufacturer;

- State energy or solar offices;

- An organizational library or a local library;

- Directly froin the U.S. Department of Energy (DOE);

- Workshops, conferences, or training sessions;

- Government Printing Office (GPO);

- NSHCIC; and

- A public utility company.

The first three sources listed above had been used by all of the Passive Educators. There were no significant differences between SHAC Educators and Passive Educators in the number who had used each source. However, a significantly ( $P$ 0.05) larger percentage 
Question \#11. In the past few years, have you obtained any type of solar information from any of the following sources?

Information Sources

Public Media:
Radio or TV
Periodicals, newspapers or magazines

Private Solar-Involved Organizations:

Private solar energy or environmental organizations

The local chapter or national headquarters of International Solar Energy Society (ISES). including their publications

The local chapter or national headquarters of Solar Energy Industries Association (SEIA), Including their publications

\section{Confacts with Professionals:}

An installer, builder, designer or manufacturer of solar systems

Workshops, conferences or training sessions

Information Services*:

Your organizational library or a local library

A commercial data base; for example, Lockheed, SDC. BRS

Smithsonian Science Information Exchange (SSIE)

A Federal library or information center; for example, the National Agricultural Library or the Environmental Data System

The Government Printing Office (GPO)

National Technical Information Service (NTIS)

Technical Information Center at Oak Ridge (TIC)

Government Solar-Involved Organizations

Directly from the U.S. Department of Engergy

National Solar Heating \& Cooling Informatiorı Centel

Reginnal Snolar Energy C̣enters

State Energy or Solar Offices

Other:

Some other state or local government office or publication

A public utility company
Percentage Responding Yes ${ }^{\cdots}$

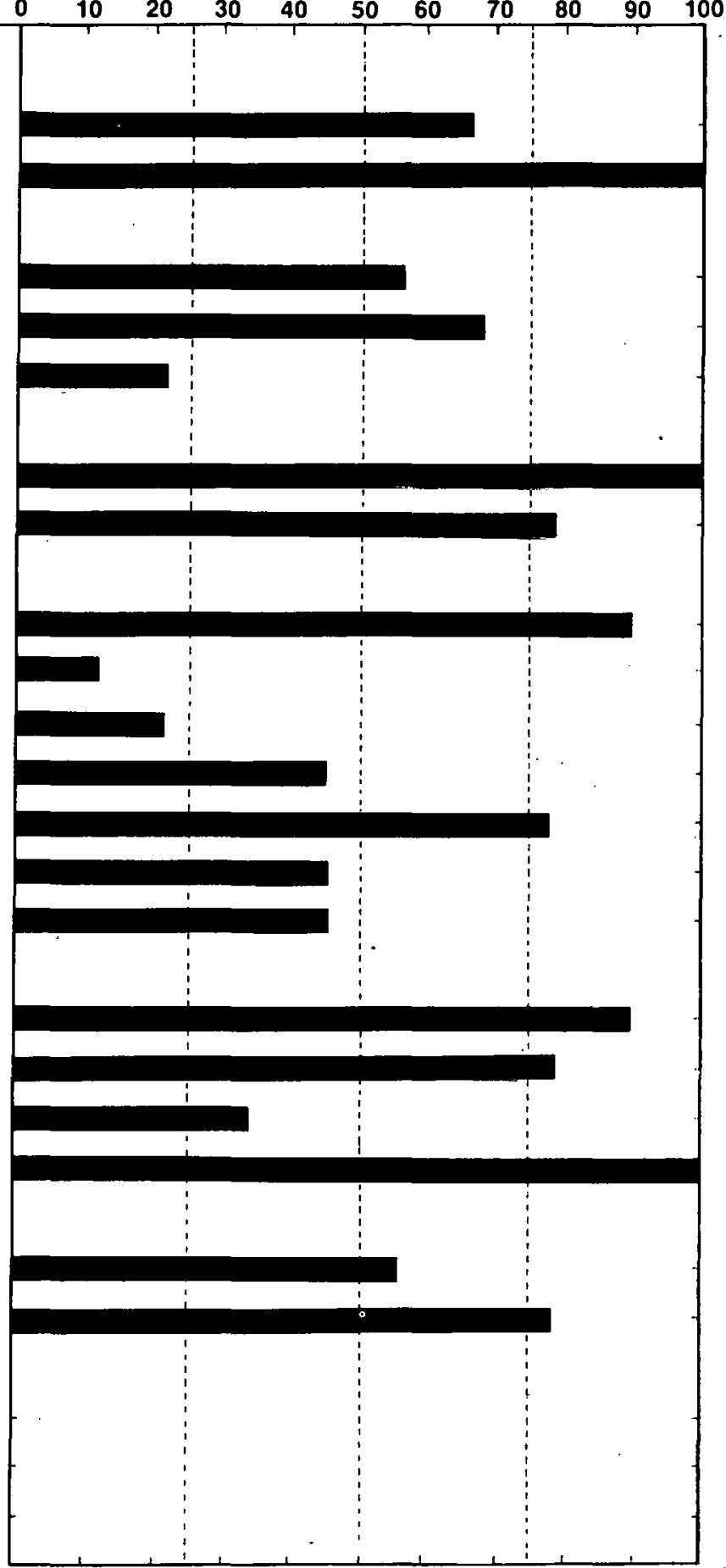

- Services and centers whose primary purpose is to disseminate information.

- Some sample frames were questioned about additional information sources which are applicable to their technology. For example. the iliailiffacturcrs of biomass conversinn equipment were also asked it they have obtained any type of solar information from: "the local or nationat office of the U.S. Departmenl of Agriculture. including Extension and Furtesly."

... Thiese data arc based upon a total of 9 respondents.

Figure 7-4. Use of Selected Information Sources: Passive Educators 
Question \#11. In the past few years, have you obtained any type of solar information from any of the following sources?

Information Sources

Percentage Responding Yes $\cdots$

Public Media:
Radio or TV
Periodicals. newspapers or magazines

Private Solar-Involved Organizations:

Private solar energy or environmental organizations

The local chapter or national headnut!arters of Intornationa Solar Energy Society (ISES), including their publications

The lucal chapter or national headquarters of Solar Enerav

lıdusli ies AssuciatIon (SEIA). including their publications Conlacts with proféssionals:

An installer, builder, deslgner or manufacturer of solar systerris

Workshops. conferences or training sessions

Information Services*:

Your organizational library or a local library

A commercial data base: for example. Lockheed. SDC. BRS

Smithsonian Science Information Exchange (SSIE)

A Federal library or information center: for example. the National Agricultural Library or the Environmental Data System

The Government Printing Office (GPO)

National Technical Information Service (NTIS)

Technical Information Center at Oak Ridge (TIC)

Government Solar-Involved Organizations

Directly trom the U.S. Department of Energy

National Solar Heating \& Cooling Information Cente!

Regional Solar Energy Centers

State Energy or Solar Otfices

Other:

Some other state or local government office or publication

A public utility rompany

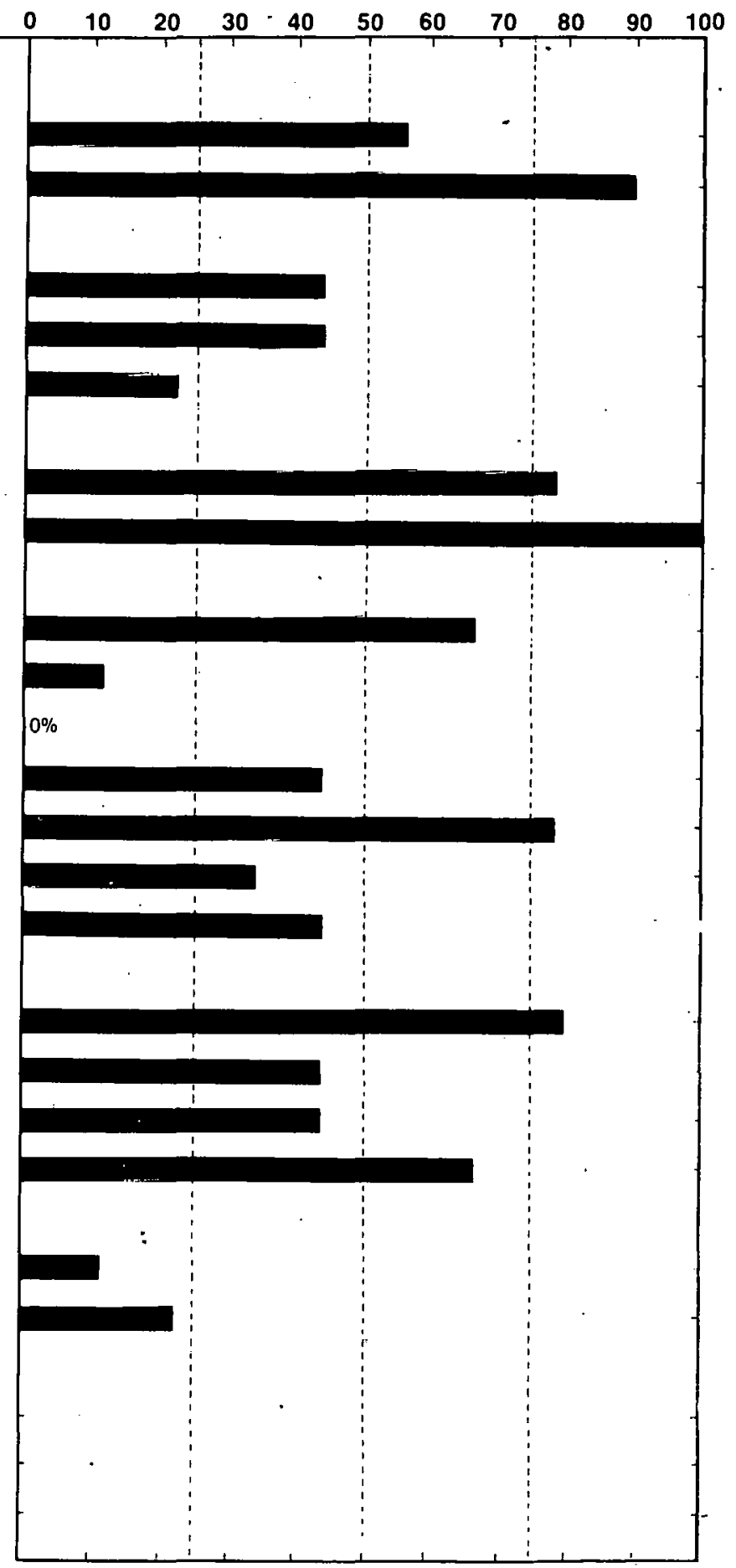

- Services and centers whose primary purpose is to disseminate information.

- Some sample frames were questioned about additional information sources which are applicable to their technology. For example. the manufacturers of biomass conversion equipment were also asked it they have obtained any type of solar information from: "the local or national office of the U.S. Department of Agriculture. including Extension and Forestry."

... These data are based upon a total of 9 respondents.

Figure 7-5. Use of Sẻlected Information Sources: Active Solar Heating and Cooling Educators 
Question \#11. In the past few years, have you obtained any type of solar information from any of the following sources?

Information Sources

Public Media:
Radio or TV
Periodicals, newspapers or magazines
Private Solar-Involved Organizations:
Private solar energy or environmental organizations
The local chapter or national headquarters of International
Solar Energy Society (ISES). including their publications
The local chapter or riational headquarters of Solar Energy
Industries Association (SEIA). including their publications
Contacts with Professionals:

An installer, builder, designer or manufacturer of solar systems

Workshops, conferences or training sessions

Information Services*:

Your organizational library or a local library

A commercial data base; for example, Lockheed. SDC. BRS

Smithsonian Science Information Exchange (SSIE)

A Federal library or information center; for example. the National Agricultural Library or the Environmental Data System

The Government Printing Office (GPO)

National Technical Information Service (NTIS)

Technical Information Center at Oak Ridge (TIC)

Government Solar-Involved Organizations

Directly from the U.S. Department of Energy

National Solar Heating \& Cooling Information Center

Regional Solar Energy Cênters

State Energy or Solar Offices

Other:

Some other state or local government office or publication

A public utility company
Percentage Responding Yes $\cdots$

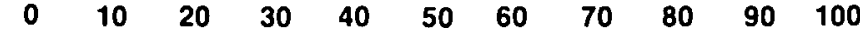

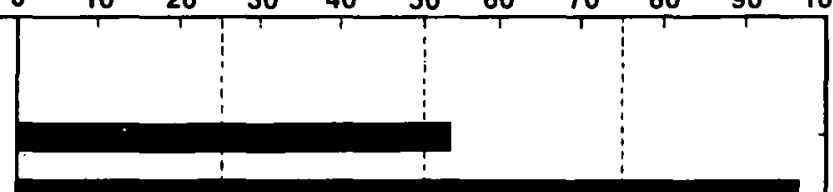
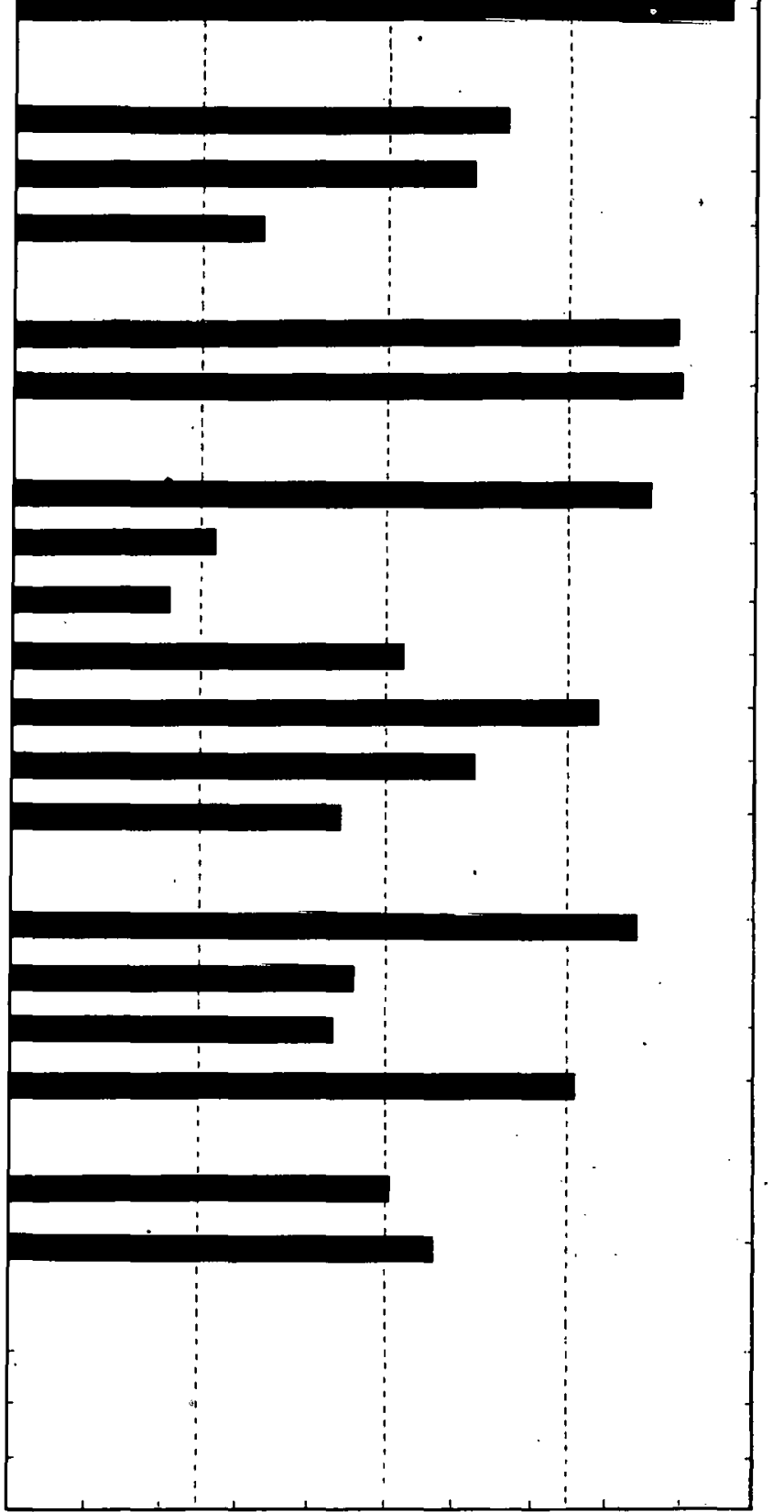

- Services and centers whose primary purpose is to disseminate information

Somc sample ir ames were questioned about additional information sources which are applicable to their technology. For example. the manufacturers of biumass conversion cquipment were alsn asked il they havc obtainod any type nf snlar information from: "the local or national office of the U.S. Department of Agriculture. including Extension and Forestry:"

... These data are based upon a total of 63 respondents.

Figure 7-6. Use of Selected Information Sources: All Educators 
of Passive Educators than of All Educators had used NSHCIC. Passive Educators also seemed more likely to use "state energy or solar offices" or "a public utility company" than were SHAC Educators or All Educators.

The information sources mentioned least often by Passive Educators were:

- A commercial data base,

- Solar Energy Industries Association (SEIA),

- Smithsonian Science Information Exchange (SSIE), and

- Regional Solar Energy Centers (RSECs).

All of these information sources except SSIE were more popular with All Educators, although all of these least-named sources for Passive Educators were also among the five least-named by All Educators.

\subsubsection{Membership in Solar-Interested Organizations}

Eight of the 9 Passive Educators surveyed were members of a professional, technical or other organization with an interest in solar energy. These organizations (and the number of times mentioned) included:

- American Association for the Advancement of Science (AAAS) (2),

- American Industrial Arts Association,

- American Physical Society,

- American Society of Mechanical Engineers (ASME),

- East New York Energy Society,

- Georgia Solar Energy Society,

- International Solar Energy Society (ISES) (3),

- Northern Illinois Solar Energy Association,

- Refrigeration Service Engineers Society, and

- Society for the Advancement of Education.

The ISES was the most popular organization, with 3 of the 9 claiming membership, and 3 mentioned membership in local solar energy organizations. The AAAS was named by 2 respondents.

\subsubsection{Exposure to Publications on Solar Energy}

During the past 6 months, all 9 Passive Educatore had read publications that included information on passive solar heating and cooling. The publications they could specify (and the number of times mentioned) included:

- American Institute of Architects (AIA) publications;

- Earth Sheltered Housing Design (by the Underground Space Center); 
- Government solar test project information;

- Heating, Air Conditioning and Refrigeration;

- Heating, Piping and Air Conditioning;

- Homeowner's Guide to Solar Heating (by Foster);

- Refrigeration;

- Refrigeration Service and Contracting;

- Solar Energy Research Institute (SERI) publications (on solar heating);

- Solar Age (4);

- Solar Decision Book (by Montgomery) (1);

- Solar Energy (4);

- Solar Engineering (2);

- Solar Greenhouse Digest;

- Solar Heating and Cooling;

- Solar Home Book (by Anderson) (2); and

- Sunworld.

Also mentioned was "Ashbery" literature, "Solar Primer by Wright" and "trade journals," publications that could not be verified or further specified by the authors. Solar-specific publications appear to be the primary items read. Heating and refrigerating journals are also popular. Interestingly, no general interest publications were mentioned, which was unusual for any group surveyed in this study.

\subsubsection{Use of Special Acquisition Methods}

The respondents were asked whether they had obtained any information (not just passive or solar energy) in the past year by computer terminal, by Computer Output Microform (COM), or by other microform (e.g.; microfiche, microfilm sheets, or rolls). Few of the Passive Educators appeared accustomed to using these special acquisition methods. In the past year, only 1 of the 9 (11\%) Passive Educators had used computer terminals, $\mathrm{COM}$, or other microforms to obtain information. The proportion who had used each of the three methods was lower for this group than it was for All Educators, except for COM. Twenty-two percent (14 of the 63) of All Educators had used computer terminals, $6 \%$ (4 of the 63) COM, and 33\% (21 of the 63) other microforms. None of the SHAC Educators had used any of the three forms. Both SHAC Educators and Passive Educators made less use of microforms (other than COM) than did other groups of Educators.

\subsection{SUMMARY AND. COMMENTS}

Nine post secondary educators, each teaching courses covering passive solar heating and cooling, were interviewed. All of these Passive Educators taught at a college or university, generally in a physics, mechanical engineering, or architecture department. Their level of involvement, degree of informedness, and educational level were typical of educators interviewed in this study. 
Passive Educators assigned the greatest utility to information on:

- Costs and performance of passive solar systems;

- Costs of installing and operating a passive solar system compared to a conventional system;

- A technical description of how a particular passive solar system works;

- Passive solar system design handbooks, installation handbooks, or reference tables;

- Manual methods for sizing and predicting performance or costs of passive solar systems;

- Educational institutions and otlier organizations offering courses in passive solar technology; and

- Expected major develnpments in passive sular lechnology during the next 10 years.

They gave low ratings to marketing information, "calendars of passive conferences and programs," passive programs outside the United States, "lists of local lenders, insurers, builders, (etc.)," and "standards, specifications, or certification programs for passive solar systems."

The fact that Passive Educators were quite similar to SHAC Educators was to be expected, since in many cases both sets of instructors were teaching courses which included both of these technologies. The low level of interest in conferences, however, was unusual for Educators, as was the high level of interest in educational institutions off ering passive coursework.

Like most Educator groups, Passive Educators used a large number of different sources from which to obtain solar information. All Passive Educators received solar information through "periodicals, (etc.)," state energy or solar offices, and "an installer, builder, designer, or manufacturer." DOE and organizational or local libraries were also popular sources. Both solar organizations and scientific or technical societies were additional sources of solar information for many. Solar-specific publications (books, technical reports, and periodicals) were also mentioned as solar information sources by all respondents. 


\section{COUNTY AGENTS, COOPERATIVE EXTENSION SERVICE}

\subsection{DESCRIPTION OF RESPONDENTS}

\subsubsection{Description of Sample}

This section describes the results of a telephone study to determine the needs of county agricultural agents in the Cooperative Extension Service (CES) for information on passive solar heating and cooling. Nine Passive County Agents were interviewed.

The sample frame for Passive County Agents was selected from the County Agents Directory [17] that lists CES staff members by state and county. In order to eliminate urban counties, the County and City Data Book [18] was consulted. From this source, any counties which had $35 \%$ or less of total land area in farms were eliminated from consideration. The 2,160 remaining rural counties were reduced to 300 by randomly selecting every seventh county. (Counties were, listed in alphabetical order within states, which were also in alphabetical order.) Every fifth county was then selected as a candidate for the survey.* Senior Agricultural Agents (rather than Home Economics Agents, 4-H Agents, or Youth Agents) were identified for each county. The 9 interview candidates were randomly selected from a sample frame of 60 names.

Respondents. In making the telephone calls to contact the randomly selected interview candidates, it sometimes occurred that the person could not be reached. In this event another randomly selected name was substituted for the original name. When individuals were contacted, it was verified that they really had some experience with passive solar technology and that they would be needing information on passive within the next year. If they were not both involved and needing information, they were asked if they could refer the interviewer to someone else in their organization who would be an appropriate respondent. If such a refereal was made, a call was then made to this new candidate; if no intraorganizational referral was made, a new candidate was randomly selected from the sample frame. The results of this process may be seen in Table 8-1.

Comparisons. For additional insight into the information needs and the information habits of these Passive County Agents, results from this group are compared to the results from SHAC (Active Solar Heating and Cooling) County Agents, from all of the CES county agricultural agents interviewed in this study (All County Agents), and from statelevel CES specialists in agriculture and information (All State Specialists). Other technologies included in All :County Agents were active SHAC, wind, biomass, and agricultural process heat. In performing any statistical comparisons, the totals for Passive County Agents have been subtracted from the totals for All County Agents. The data for Passive County Agents, SHAC County Agents, All County Agents, and All State Specialists can be found in Appendix F.

*The remaining counties were divided into similar groups, and surveys were conducted on wind energy, active solar heating and cooling, biomass energy, and agricultural process heat. The results of these surveys are reported in other volumes. 


\section{Table 8-1. COMPLETION OF INTERVIEWS: PASSIVE COUNTY AGENTS}

Event

Number

of Candidates

Interview completed with sample frame candidate

Interview completed with referral candidate

Refusal or candidate termination

Contact attempted: could not reach candidate within three

attempts, or before interviews were completed

Subtotal

7

2

0

4

13

Contact attempted: invalid candidate (e.g., inappropriate

field of interst, no telephone)

TOTAL

Sample Frame Error Rate ${ }^{\mathbf{a}}$ (Percent)

Completion Rate ${ }^{b}$ (Percent)

19

69

Invalid candidates divided by TOTAL

${ }^{b}$ Completed interviews divided by Subtotal

\subsubsection{Current Status of Respondents}

Respondents represented counties in the following nine states:

- Alabama,

- Georgia,

- Indiana,

- Kentucky,

- Mínnesota,

- Nebraska,

- North Carolina,

- South Dakota, and

- Tennessee.

Thus the South was heuvily represented, as were three states in middle America. It will be noted that no Western or Northeastern states were sampled. All County Agents accounted for 24 states, providing somewhat more representation of the West and Middle Atlantic. Similarly, State Specialists were not interviewed in New England nor the far West. (Geographic distribution by state of respnndents in.cach of the County Agents' and State Spccialists' yroups are shown in Appendix B, Table B-1).

Role. Five of the 9 Passive County Agents were primarily involved with collecting and

$\therefore$ disseminating information. Two stated they were not presently doing anything relative to passive solar technology. Others mentioned that the passive activities in which they were currently involved included heating of barns, research, and weather factors. One mentioned "grain drying," which is usually classified as agricultural process heat. 
Involvement. Eight of the 9 (89\%) Passive County Agents said that they were only "slightly involved" in passive solar technology. Only 1 (11\%) was "moderately involved" and none were "very involved." This compares to 5 of the 9 (55\%) SHAC County Agents who were at least "moderately involved" (reflecting the highest level of involvement of any of the five groups of County Agents). Significantly ( $P$ 0.05) fewer Passive County Agents than All State Specialists (13 of the 18 or 72\%) stated that they were "moderately involved" or "very involved." This difference may be accounted for by the fact that State Specialists were asked about involvement in solar technologies generally, rather than just about passive solar technology. Twenty-nine percent (13 of the 45) of All County Agents were at least "moderately involved." Involvement levels of County Agents in other technologies were not significantly different from that of Passive County Agents, tending to support the conclusion that greater involvement was characteristic for CES respondents who were asked about solar energy in general.

Informedness. Eight of the 9 (89\%) Passive County Agents said that they were only "slightly informed" about passive. Only 1 (11\%) was "moderately informed." This compares to 5 of the $9(56 \%)$ SHAC County Agents who were at least "moderately involved." All County Agents were similarly not very well informed about their respective solar technologies (10 of the 45 were at least "moderately informed"), while State Specialists (15 of the 18 were at least "moderately informed") were significantly (P 0.05$)$ more informed than were Passive County Agents. Again, the difference in responses of County Agents and State Specialists may be explained by the more specific question which was addressed to County Agents.

Need for Information. All respondents indicated they would need passive information either on the job or outside the job during the next year. Eight needed information on passive on the job while only 4 (44\%) needed information on passive outside the job. This was about the same level of off-the-job information need that was found for All County Agents (21 of the 45 or 47\%). Six of the 9 (67\%) SHAC County Agents expected to need off-the-job SHAC information. Seven of the 18 (38\%) All State Specialists needed solar information outside of their jobs.

\subsubsection{Background of Respondents}

Six of the Passive County Agents held master's degrees; the remainder held bachelor's degrees. Eight had received their most recent degree in agriculture or in the related fields of animal science and agronomy. One held a degree in adult education. Two of the 9 had received their most recent degrees 10-20 years ago, 2 from 5-10 years ago, and 2 within the past 3 years.

Six Passive County Agents had been in their current profession for over 10 years and 2 for less than 2 years. Although their current profession was assumed to be "county agricultural agent," professional statements included educator, administrator, and agricultural worker, as well as Extension Agent.

\subsection{INFORMATION NEEDS OF RESPONDENTS}

\subsubsection{Technical Areas}

Passive County Agents were asked to choose those areas in which they were "particularly interested in obtaining information" from a list of selected technical areas of passive 
solar heating and cooling. All 9 respondents were interested in "collection of heat," "storage of heat," "space cooling," "water heating," and "hybrid systems." The topics of lowest interest (7 of the 9) were "landscaping or orientation of buildings" and "greenhouses." Eight were interested in "building design."

\subsubsection{Types of Information}

Passive County Agents were asked to name the information about passive solar technologies that was important for them to obtain. All of the 9 volunteered one or more items of information that they considered important. Five felt that information on cost, savings, economics, or economic feasibility were most important. Two stated that all passive information was important. Other topics includer research updates, information sources, basic plans, crop drying, a heating center in a farm building, and livestock facilities (including a pig nursery).

Five Passlve County Agents volunteered that there was information they needed but were unable to obtain. This information included "everything," cost estimates for housing, economies, and designs and plans for houses (including blueprints).

Choice Between Specific Needs. A list of 11 types of passive information products and 14 types of passive information categories was read to each respondent. Each respondent described the usefulness of each particular item by assigning it a value of "essential," "very useful," "somewhat useful," or "not at all useful." The results are given in Fig. 8-1. For the purpose of comparison, results for SHAC County Agents are shown in Fig. 8-2, those for All County Agents in Fig. 8-3, and those for All State Specialists in Fig. 8-4.

Passive County Agents selected the 2 items in the cost class as the most important. The five top-rated information categories/products were:

- Costs of installing and nperating a passive system compared to a conventional system;

- Costs and performance of systems;

- System diagrams or schematics;

- Climatological data; and

- Tax credits, grants, or other economic incentives.

These choices are in line with the information that they volunteered as being important and are even closer to those items they stated they were unable to obtain. "Nontechnical descriptions," "expected major developments," and information sources also were ranked high.

Passive County Agents assigned the lowest relative ratings to:

- Computer models for sizing and predicting performance or costs;

- Institutional, social, environmental, and legal aspects;

- Calendars of conferences and programs; and

- A technical description of how a particular system works. 
Question \#8. I will read a list of potential information or intormation products on solar systems. For each, please tell me how useful that information would be to you. Would the following be: essential, very useful, somewhat useful, or not at all useful?

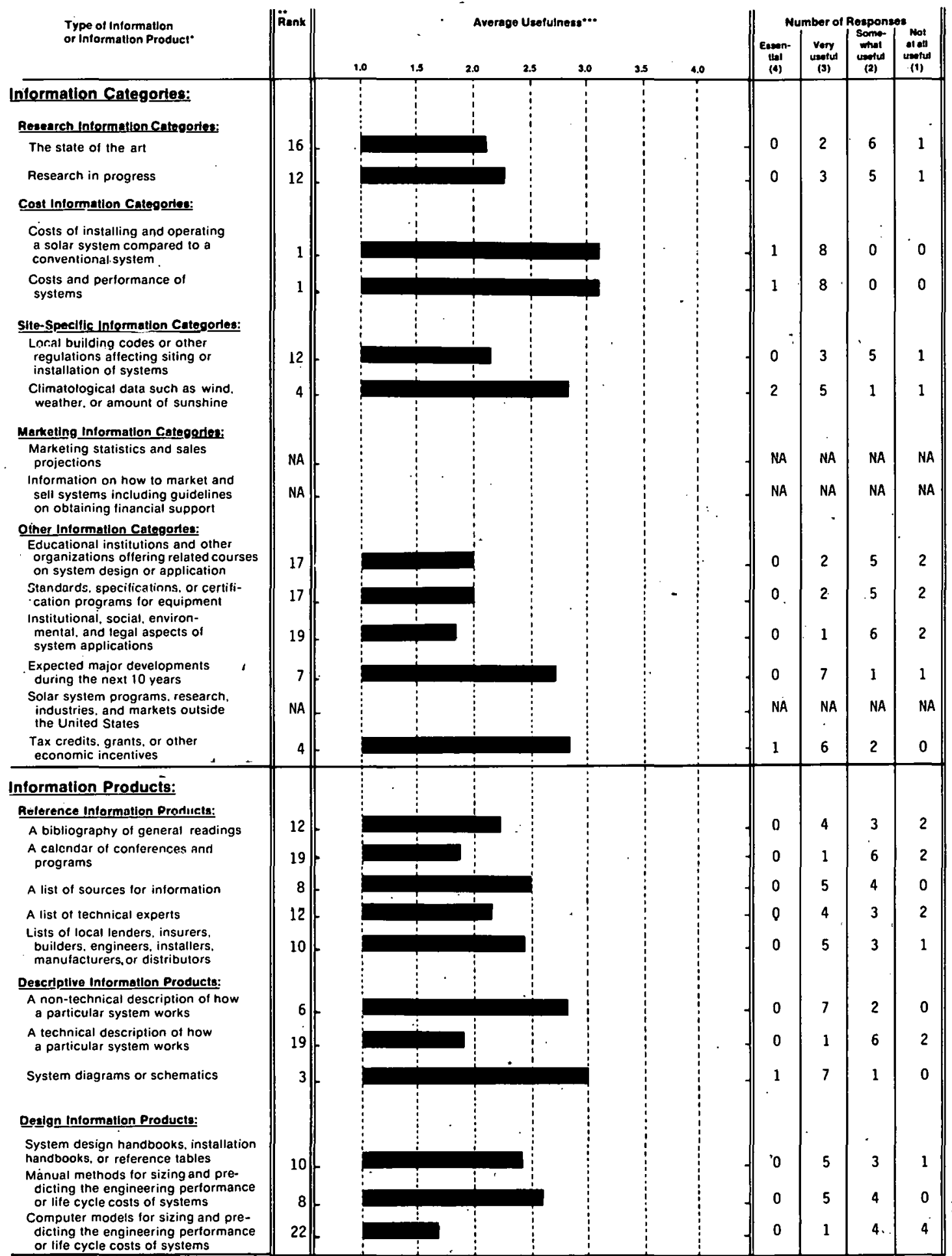

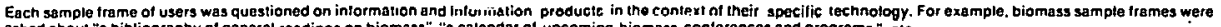

asked abovi "a oibliography of general reacings on biomass", "a calondar of upcoming biomass conterences and programs". etc.

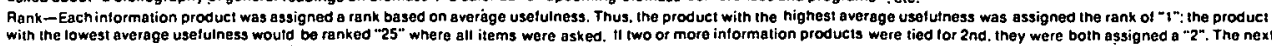

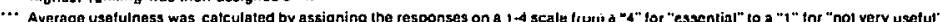

Figure 8-1. Usefuiness of Selected Information Items: Passive Cooperative Extension Service 
Question \#8. I will read a list of potential information or information products on solar systems. For each, please tell me how useful that information would be to you. Would the following be: essential, very useful, somewhat useful, or not at all useful?

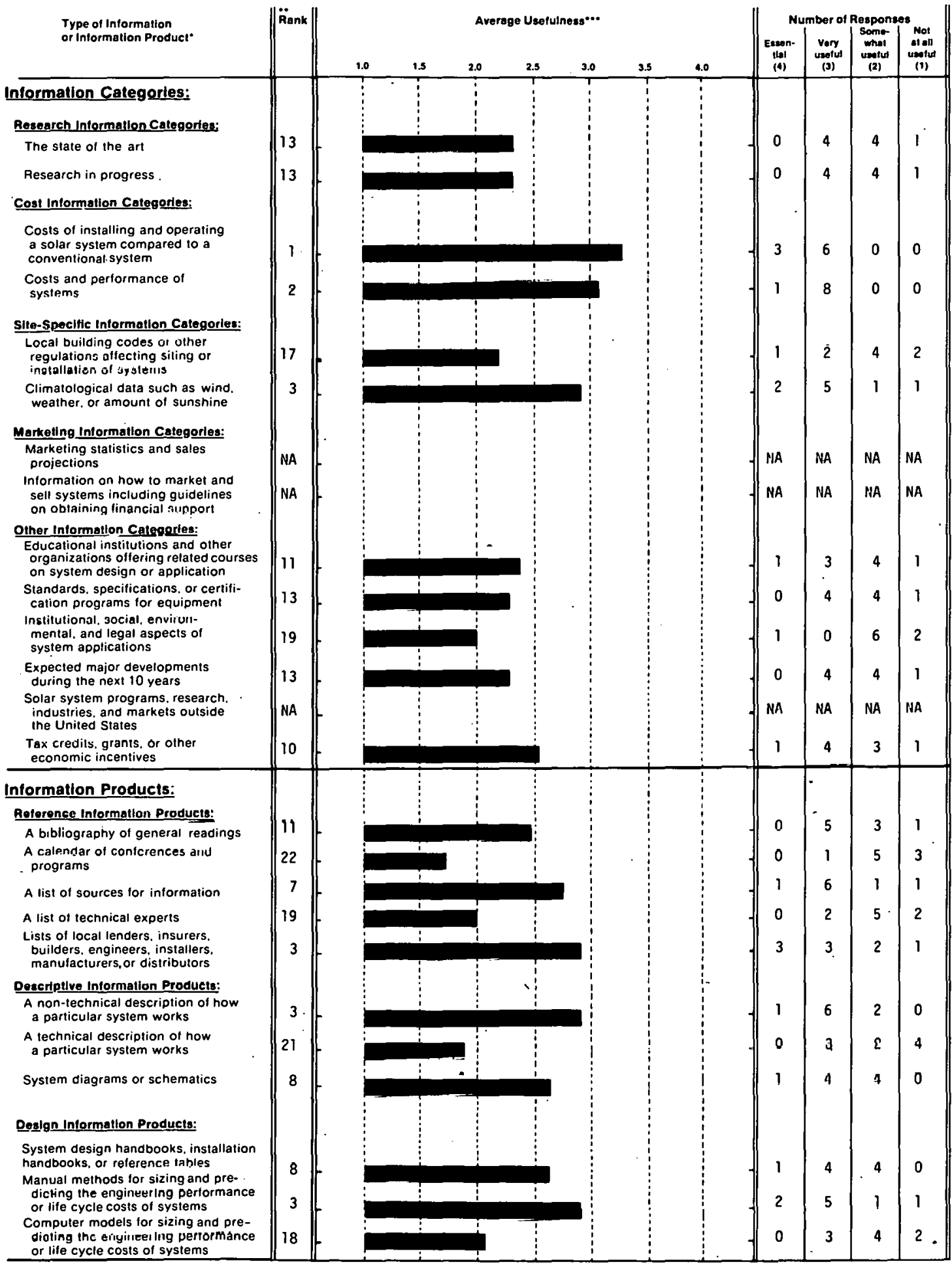

Each sample lrame of users was questioned on information and information products in the context of their specific technology. For example, biomass sample trames were

Rank-Each information producl was assigned a rank based on average useturness. Thus. the procuct with the highest avergge usefulness was assigned the renk of "1": Ihe product nignest ranking was inen assigned a -4 :"

Average usetulness was calculated by assigning the responses on a 1 -4 scate from a "4" tor "essential" to a " 1 " for "not very usefut".

Figure 8-2. Usidulives of Eolected Information Items: Active Solar Heating and Cooling Cooperative Extension Service County Agënts 
Question \#8. I will read a list of potential information or information products on solar systems. For each, please tell me how useful that information would be to you: Would the following be: essential, very useful, somewhat uselul, or not at all useful?

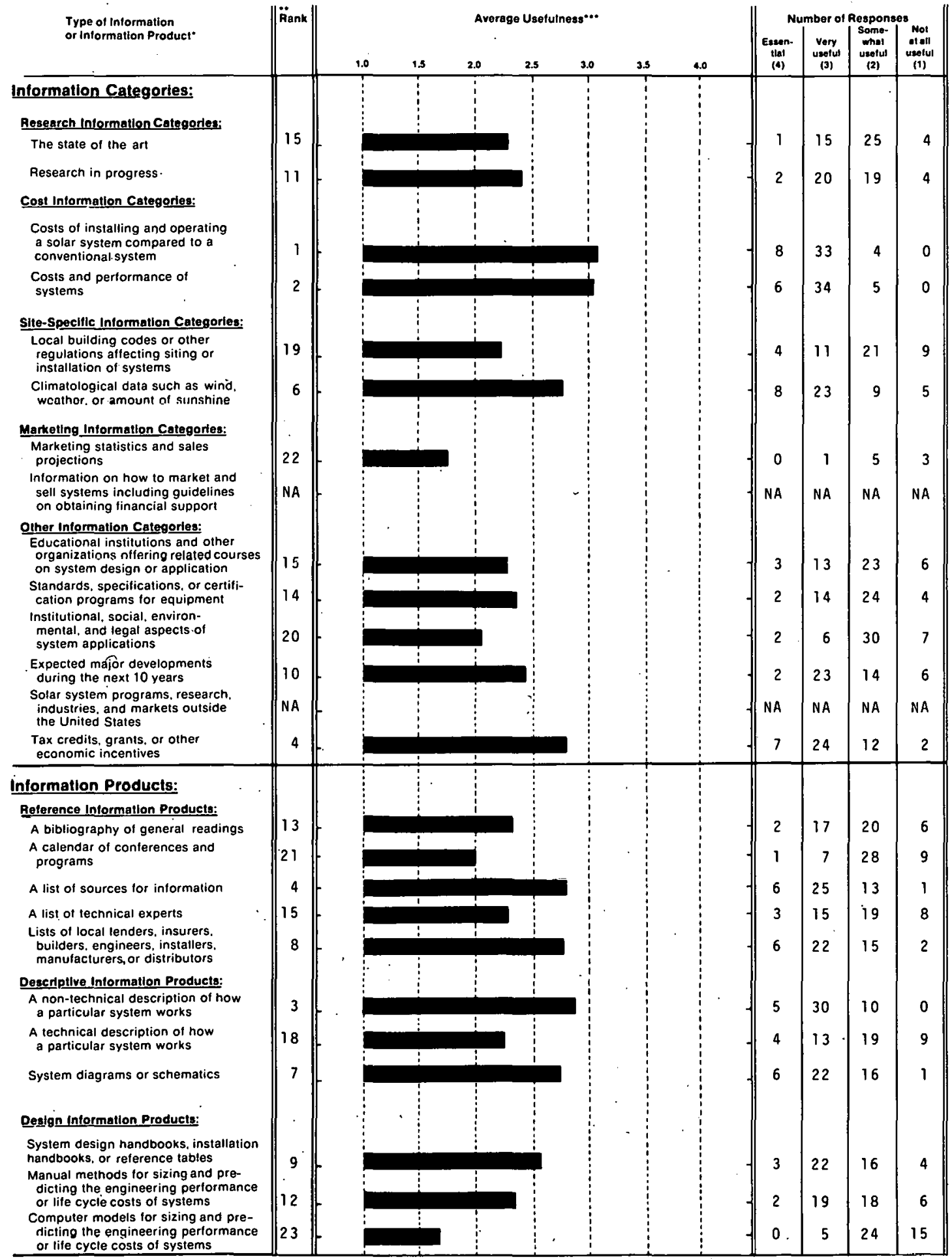

Each sample frame ol users was questioned on information and information products in the context of theit specilic technology. For example, biomass sample trames were

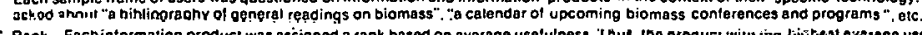

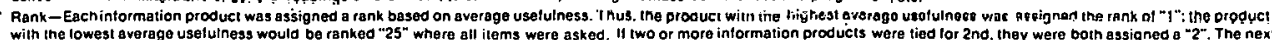
with thest lanking wag then asgigned a "A"

... Average usefutness was calculated by assigning the responses on a 1-4 scala trom a "4" tor "essential" to " "1" tor "not very usolul".

Figure 8-3. Usefulness of Selected Information Items: All Cooperative. Extension Service County Agents 
Question \#8. I will read a list of potential information or information products on solar systems. For each, please tell me how useful that information would be to you. Would the following be: essential, very useful, somewhat useful, or not at all useful?

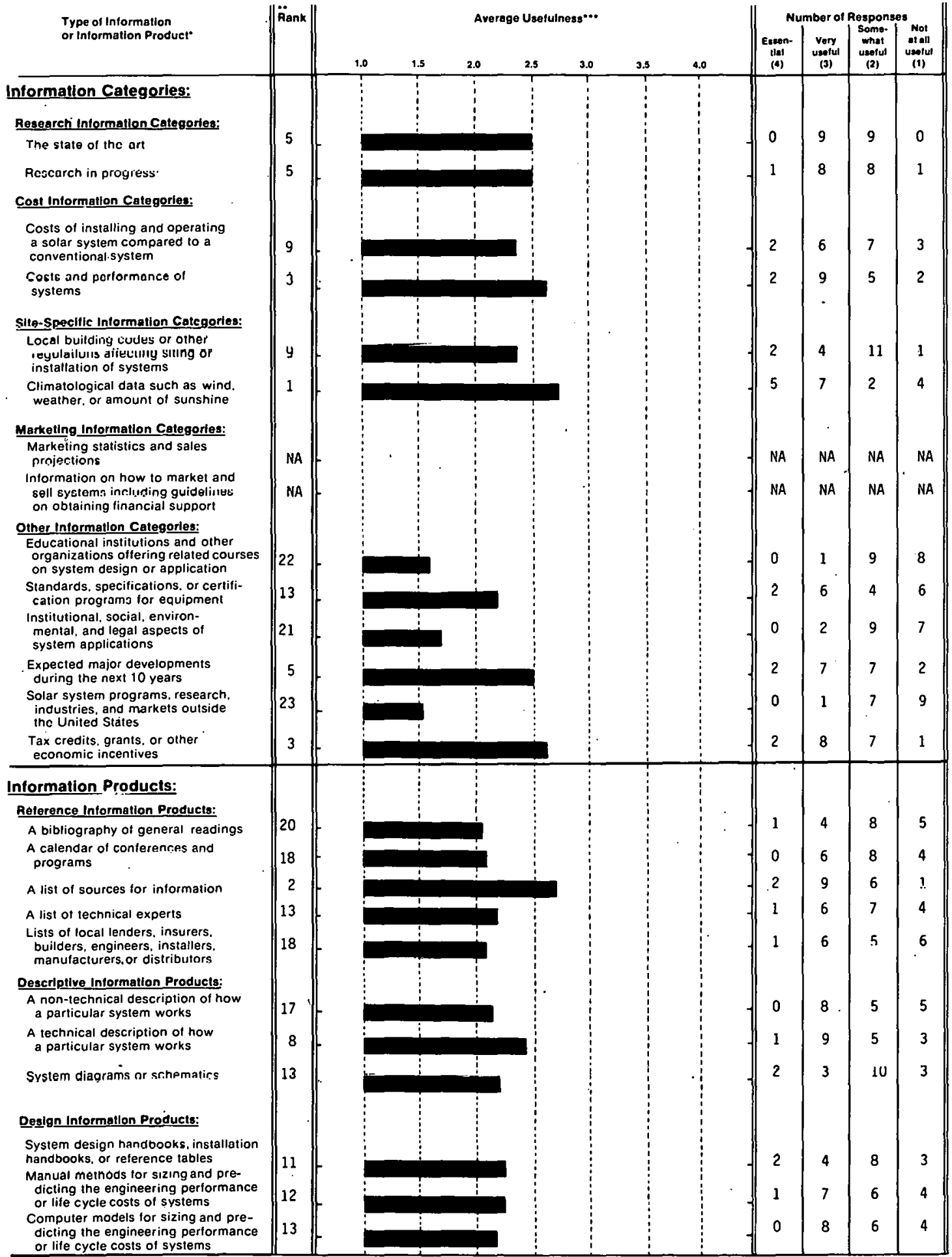

- Each somple lrame of users was questioned on information and intormation products in the context of their specific technology. For example, biomass sample trames were asked about "a bibliography of general readings an biomass"." "a calencar of upcoming biomass conterences and programs". etc. ".

Rank-Eachintormation product was assigned a rank based on average usetulness. Thus. The product with the highest average usefulness was assigned the rank of "1": Ihe product with the lowest avera

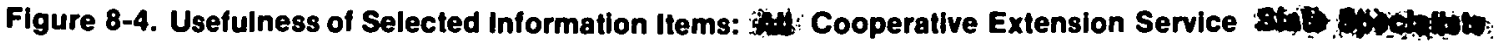


Statistical tests indicated all five of the top categories/products were rated significantly (P 0.05) higher than were the four lowest-rated items. The contrast of high ratings for "system diagrams or schematics" and low ratings for "a technical description" was interesting, especially when "a nontechnical description" was rated significantly (P 0.05$)$ higher than was "a technical description."

It should be noted that these lower-rated items were not necessarily of no worth to the Passive County Agents. For example, 7 of them thought "calendars" were either "somewhat useful" or "very useful." Thus, these information categories/products could be useful to some of the Passive County Agents but were of a lower relative priority to the entire group.

Statistical tests were used to determine whether the Passive County Agents rated any of these information items significantly higher (or lower) than they were rated by SHAC County Agents, by All County Agents, or by All State Specialists. Some groups, however, tended to give higher scores in general than did other groups. To compensate for this effect, these statistical tests compared the "relative rating" given by one group to the "relative rating" given by the other groups. The procedure for calculating the relative rating is described in Appendix E. Average ratings across all information items were somewhat higher for All County Agents (2.47) than for Passive County Agents (2.40), while both results were lower than results for SHAC County Agents (2.49) and higher than results for All State Specialists (2.27).

In comparing the results for Passive County Agents to the results for SHAC County Agents and for All County Agents, ratings were very similar. Statistical tests indicated no significant differences existed between ratings by Passive County Agents and those by SHAC County Agents or by All County Agents for any of these information items. It seemed likely, however, that Passive County Agents were more interested in "tax credits, (etc.)" and less interested in "lists of local lenders, (etc.)" and "manual methods" than were the SHAC County Agents.

In comparing Passive County Agents to All State Specialists, the Passive County Agents rated "system diagrams" and "costs of installing" as significantly ( $P$ ( 0.05$)$ more useful and " a technical description," "computer models," and "the state of the art" as significantly less useful. It also seems possible that Passive County Agents were more interested in "nontechnical descriptions" and less interested in "research in progress" than were All State Specialists.

\subsection{ACQUISTION OF INFORMATION BY RESPONDENTS}

\subsubsection{Use of Selected Information Sources}

Passive County Agents were asked which of 20 different potential sources of solar information they had used in the past few years. For this question the respondents were not asked if they had obtained information on passive solar heating and cooling, but instead were asked if they had obtained any solar information from each specific source. Thus, the question sought to determine which information sources were the most familiar to the respondents. The results are shown in Fig. 8-5. For comparison, those for SHAC Counly Agents are in Fig. 8-6 and those for All County Agents and All State Specialists are in Figs. 8-7 and 8-8. 
Question \#11. In the past few years, have you obtained any type of solar information from any of the following sources?

\section{Information Sources}

Percentage Responding Yes $\cdots$

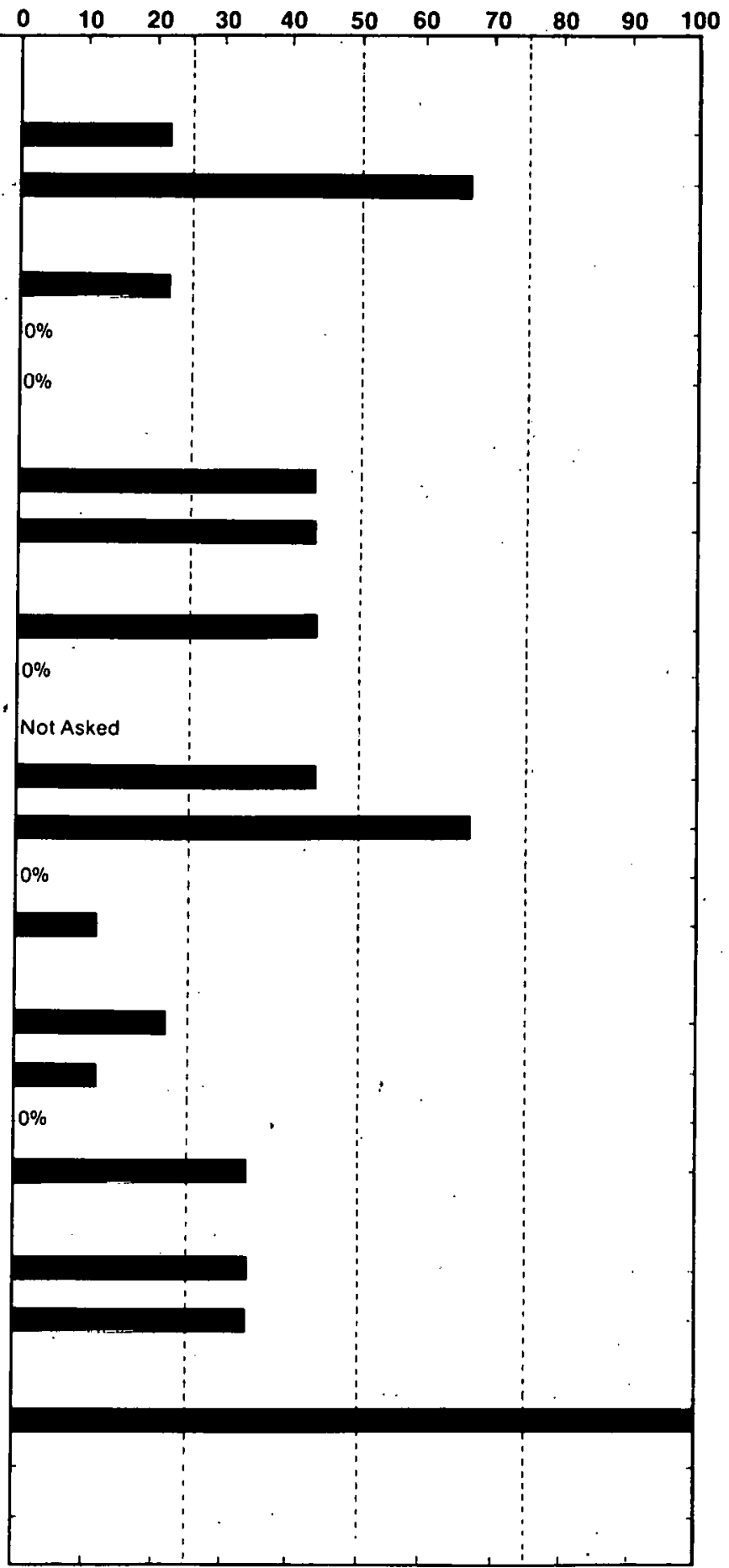

Some other state or local government office or publication

A public utility company

Sources for this specific sample frame**:

USDA, including the Cooperative Extension Service

An installer, builder, designer or manufacturer of solar systems

Workshops. conferences or training sessions

Intormation Services*:

Your organizational library or a local library

A commercial data base; for example. Lockheed. SDC. BRS

Smithsonian Science Information Exchange (SSIE)

A Federal library or information center: for example. the National Agricultural Library or the Environmental Data System

The Government Printing Office (GPO)

The

National Technical Information Service (NTIS)

Technical Information Center at Oak Ridge (TIC)

Government Solar-Involved Organizations

- Directly from the U.S. Department of Energy

National Solar Heating \& Cooling Information Center

Regional Solar Energy Centers

State Energy or Solar Offices

Other:

$+$


Question \#11. In the past few years, have you obtained any type of solar information from any of the following sources?

Information Sources

Percentage Responding Yes ".*

Public Media:
Radio or TV
Periodicals. newspapers or magazines

Private Solar-Involved Organizations:

Private solar energy or environmental organizations

The local chapter or national headquarters of Internationa

Solar Energy Society (ISES). including their publications

The local chapter or national headquarters of Solar Energy

Industries Association (SE|A). including their publications

Contacts with Professionals:

An installer, builder. designer or manufacturer of solar systems

Workshops, conferences or training sessions

Intormation Services":

Your organizational library or a local library

A commercial data base: for example, Lockheed, SDC, BRS

Smithsonian Science Information Exchange (SSIE)

A Federal library or information center; for example, the National Agricultural Library or the Environmental Data System

The Government Printing Office (GPO)

National Technical Information Service (NTIS)

Technical Information Center at Oak Ridge (TIC)

Government Solar-Involved Organizations

Directly from the U.S. Department of Energy

National Solar Heating \& Cooling Information Center

Regionál Solar Érteryy Ceuıleıs

State Energy or Solar Offices

Other:

Some other state or local government office or publication

A public utility company

Sources for this specific sample frame**:

USDA, including the Cooperative Extension Service

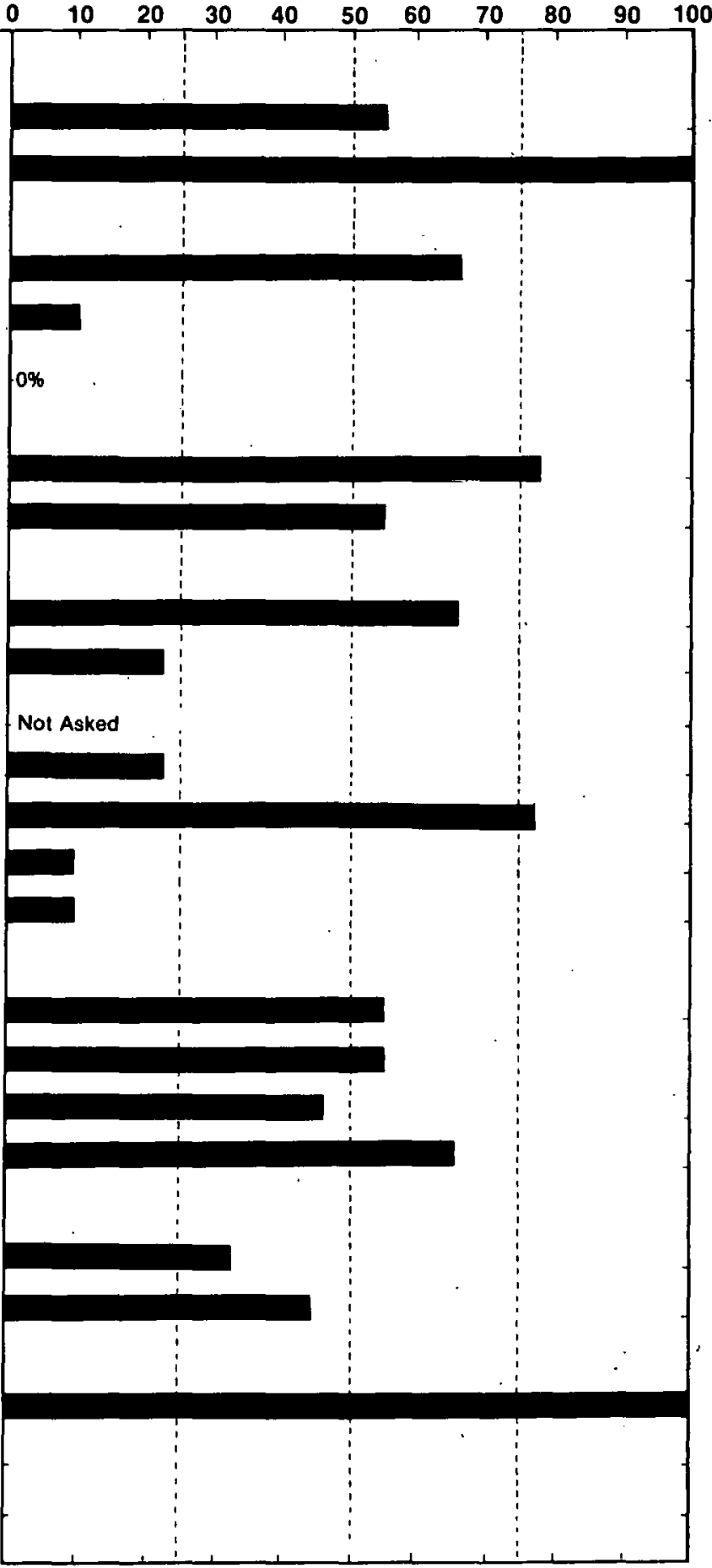

- Services and centers whose primary purpose is to disseminate information.

- Some sample irames were questioned about additional information sources which are applicable to their technology. For example. the manufacluiers of biomass conversion equinment wele also asked it thoy have obtainer any type of solar information from: "the local or national office of the U.S. Department of Agriculture. including Extension and Forestry:"

... These data are based upon a total of $\dot{y}$ respondents.

Figure 8-6. Use of Selected Information Sources: Active Solar Heating and Cooling Cooperative Extension Service County Agents 
Question \#11. In the past few years, have you obtained any type of solar information from any of the following sources?

Information Sources

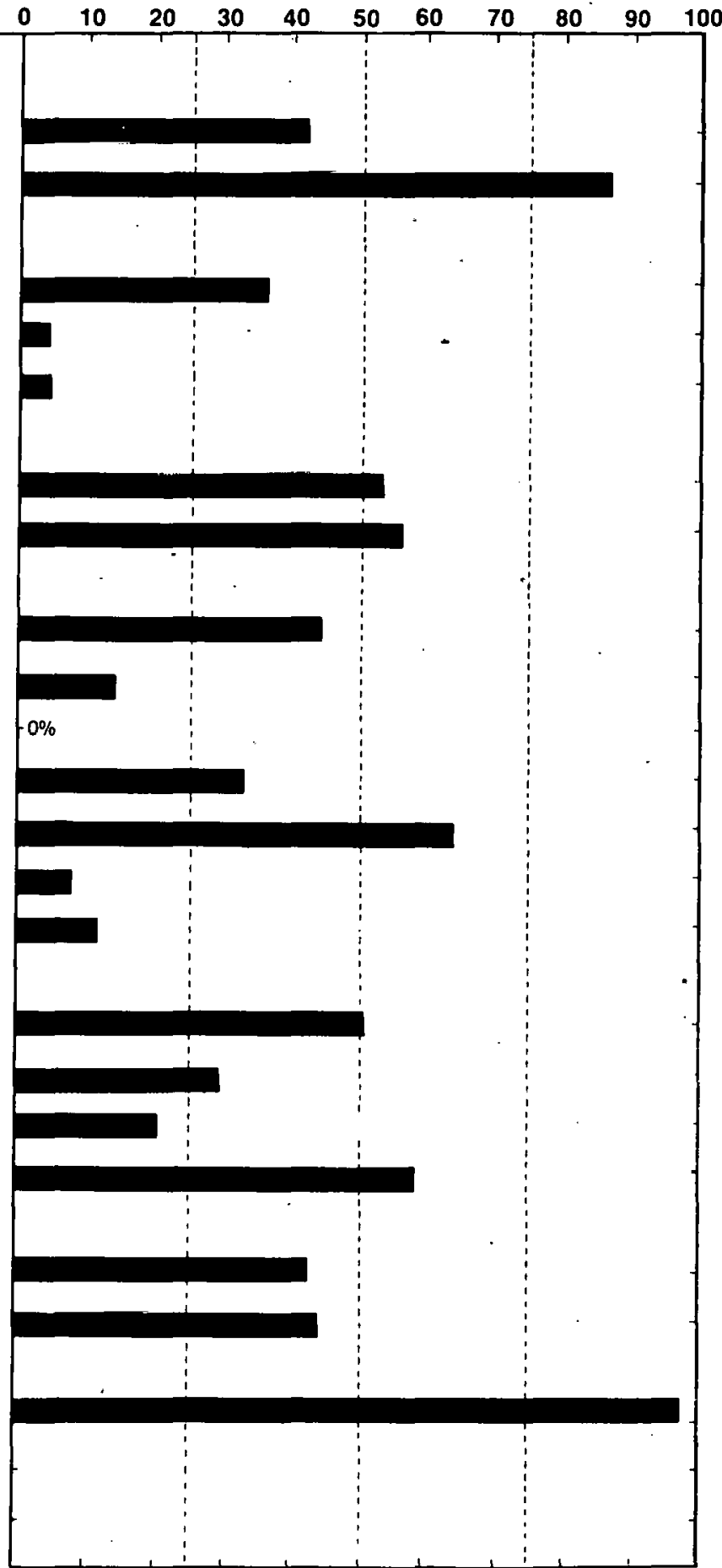

Percentage Responding Yes $\cdots$

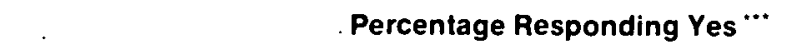

Private solar energy or environmental organizations

The local chapter or national headquarters of Intornational Solar Energy Society (ISES), including their publications

The local chapter or national headquarters of Solar Energy Industries Association (SEIA). inc.luding their publications

\section{Contacis with protessionals:}

An installer, builder. designer nr manufacturer of snlar systems

Workshops. conferences or training sessions

Information Services*:

Your organizational library or a local library

A commercial data base: for example. Lockheed, SDC. BRS

Smithsonian Science Information Exchange (SSIE)

A Federal library or information center; for example, the National Agricultural Library or the Environmental Data System

The Government Printing Office (GPO)

National Technical Information Service (NTIS)

Technical Information Center at Oak Ridge (TIC)

Government Solar-Involved Organizations

Direcily from the U S. Department of Energy

National Solar Heating \& Cooling Information Cente

Regional Solar Energy Centers

State Energy or Solar Offices

Other:

Some other state or local government office or publication

A public utility company

Sourooo for this apecifii, sallpuly framet:

USDA, including the Cooperative Extension Service 
Question \#11. In the past few years, have you obtained any type of solar information from any of the following sources?

Information Sources

Percentage Responding Yes ${ }^{*}$

\section{Public Media:}

Radio or TV

Periodicals, newspapers or mayaziries

Private Solar-Involved Organizations:

Private solar energy or environmental organizations

The local chapter or national headquarters of international Solar Energy Society (ISES), including their publications

The local chapter or national headquarters of Solar Energy

Industries Association (SE|A). including their publications

Contacts with Protessionals:

An installer, builder, designer or manufacturer of solar systems

Workshops. conferences or training sessions

Information Services*:

Your organizational library or a local library

A commercial data base: for example: Lockheed, SDC, BRS

Smithsonian Science Information Exchange (SSIE)

A Federal library or information center; for example. the National Agricultural Library or the Environmental Data System

The Government Printing Office (GPO)

National Technical Information Service (NTIS)

Technical Information Center at Oak Ridge (TIC)

Government Solar-Involved Organizations

Directly from the U.S. Department of Energy

National Solar Heating \& Cooling Information Center

Acgional Solar Energy rẹnters.

State Energy or Solar Offices

Other:

Some other state or local government office or publication

A public utility company

Sources for this specific sample frame**:

USDA, including the Cooperative Extension Service

$\begin{array}{lllllllllll}0 & 10 & 20 & 30 & 40 & 50 & 60 & 70 & 80 & 90 & 100\end{array}$


The information sources mentioned most of ten by Passive County Agents were:

- U.S. Department of Agriculture (USDA);

- Periodicals, newspapers, or magazines; and

- The Government Printing Office (GPO).

The information sources mentioned least of ten by Passive County Agents (none of the 9 had used them) were:

- International Solar Energy Society (ISES),

- Solar Energy Industries Association (SEIA),

- A commercial data base,

- National Toohnical Information Bervice (NTIB), und

- Regional Solar Energy Centers (RSECs).

Passive County Agents apparently rely directly on USDA for solar information. This is dramatized by the fact that although they rated "periodicals, newspapers, or magazines" among their top three solar information sources, they were only able to name four publications (see Section 8.3.3) as ones in which they had seen solar information in the past 6 months. None of these publications were specifically solar or energy oriented. (In addition, none were USDA publications or GPO documents.) Use of most information sources other than the top three was fairly low. Of the 86 groups surveyed in this study, only 5 had respondents indicating a lower familiarity with the various information sources than did the Passive Agents.

This information acquisition pattern seemed to be fairly typical for county level Extension Agents, but differs from that of state level Agents. SHAC County Agents, however, seemed somewhat more familiar with the various information sources than did the Passive County Agents; they were more familiar with most of the sources than were the Passive County Agents.

In reviewing Figs. 9-5 through 9-8, all four single and combined groups most frequently named USDA and "periodicals." All County Agents named "periodicals" and DOE significantly (P 0.05) more frequently than did Passive County Agents. State Specialists were significantly ( $P$ 0.05) more likely to name DOE, NTIS, and the "state energy or solar offices" as solar information sources they had used.

\subsubsection{Membership in Solar-Interested Organizations}

Three of the 9 Passive County Agents surveyed were members of a professional, technical, or other organization with an interest in solar energy. The organizations (and the number of times mentioned) included:

- Minnesota Extension Association,

- National Association of County Agricultural Agents (2), and

- National Association of Extension 4-H·Agents.

Passive County Agents mentioned only extension associations and no solar energy or other organizations. This was fairly typical of County Agents, although two solar 
organizations were mentioned by. SHAC County Agents. Two solar organizations were also mentioned by State Specialists.

\subsubsection{Exposure to Publications on Solar Energy}

During the past 6 months, 8 of the 9 Passive County Agents had read publications that included information on passive solar technologies. The publications they could specify (each mentioned by only one respondent) included:

- House Beautiful,

- Popular Science,

- Southeast Farm Press publications, and

- Time.

With one exception, these are all general interest, rather than technical or solar publications. No SHAC County Agents mentioned solar specific publications, although some County Agents in other technologies did. State Specialists, however, mentioned quite a few solar publications.

\subsubsection{Use of Special Acquisition Methods}

The respondents were asked whether they had obtained any information (not just passive or solar energy) in the past year by computer terminal, by Computer Output Microform (COM), or by other microform (e.g.; microfiche, microfilm sheet, or rolls). Few of the Passive County Agents appeared accustomed to using special acquisition methods, a trait common to All County Agents. In the past year, only l of the 9 (11\%) had used computer terminals, COM, or other microf orms. About the same proportions of All County Agents had used computer terminals ( 7 of the 45 or $16 \%$ ), COM ( 3 of the 45 or $7 \%$ ), and other microf orms ( 4 of the 45 of $9 \%$ ). Somewhat larger proportions of All State Specialists had used each of the three forms (computer terminals, 8 of the 18, 44\%; COM, 5 of the 18 .or $28 \%$; and other microf orms, 6 of the 18 or $33 \%$ ), but the differences were not significant.

\subsection{SUMMARY AND COMMENTS}

Nine senior agricultural agents in county CES offices were interviewed. Most had only slight involvement with passive solar technologies, mostly in agricultural applications and information dissemination.

Passive County Agents were interested in a variety of agricultural-related topics. They assigned the greatest utility to information on:

- Costs of installing and operating a passive solar system compared to a conventional system;

- Costs and performance of passive solar systems;

- Passive solar system diagrams or schematics;

- Climatological data; and

- Tax credits, grants, or other economic incentives for passive solar systems. 
They gave low ratings to "computer models for sizing and predicting performance or costs of passive solar systems," "institutional, social, environmental, and legal aspects affecting passive solar installations," "calendars of passive conferences and programs," and "a technical description of how a particular passive solar system works."

Despite their expressed need for information, the Passive County Agents were not using very many sources to obtain information. The USDA was clearly the most important information source for Passive County Agents, with "periodicals" and GPO also popular. Organizational membership appeared to be limited to extension associations. Thus, expanding the solar knowledge of Passive County Agents (and other County Agents as well) was done principally through the USDA-it's publications, announcements, and memoranda. 


\section{SECTION 9.0}

\section{PASSIVE HOMEOWNERS}

\subsection{DESCRIPTION OF RESPONDENTS}

\subsubsection{Description of Sample}

This section describes the results of a telephone study to determine the needs of potential owners of passive homes for information on passive solar heating and cooling. A total of 9 Passive Homeowners were interviewed. The purpose of studying this group was to determine the sources each respondent used to obtain information for acquiring a passive system and to determine in retrospect which types of information would have been the most useful. By learning the information needs and the sources used, we can determine the information needs and information habits of potential residential purchasers of passive solar heating and cooling systems.

The sample frame for Passive Homeowners was constructed from two sources: the National Solar Heating and Cooling Information Center (NSHCIC) "Selected Solar Buildings in (State); Private Residences" lists [19] and Solar Heated Buildings of North America [12]. Names listed as owners of passive or passive/active systems were selected from both sources as potential respondents. Respondents listed on both this and other sample frames were eliminated. After all adjustments were made, the 9 interview candidates were randomly selected from a sample frame of $\mathbf{4 0}$ names.

Respondents. In making the telephone calls to contact the randomly selected interview candidates, it sometimes occurred that the person could not be reached. In this event, another randomly selected name was substituted for the original name. When individuals were contacted, it was verified that they really were owners of passive or passive/active homes. If they were not a passive homeowner, they were asked if they could refer the interviewer to someone using passive solar technologies who would be an appropriate respondent. If such a referral was made, a call was then made to this new candidate; if no referral was made, a new candidate was randomly selected from the sample frame. The results of this prnpess may he seen in Table 9-1.

Comparisons. For additional insight into the information needs and the information habits of these Passive Homeowners, results from this group are compared to the results from Total SHAC Homeowners interviewed in this study, which included owners of SHAC heating and cooling systems and SHAC hot water systems. The data for Passive Homeowners and Total SHAC Homeowners can be found in Appendix F.

\subsubsection{Current Status of Respondents}

Six of the 9 Passive Homeowners stated that their house was originally built as a passive heated house, 2 that the changes were made later, and 1 a combination of both. Six of the 9 respondents had been the owner of a solar system for over 3 years (including years when system was under construction), and 3 had been owners for 1-3 years. 
Table 9-1. COMPLETION OF INTERVIEW': PASSIVE HOMEOWNERS

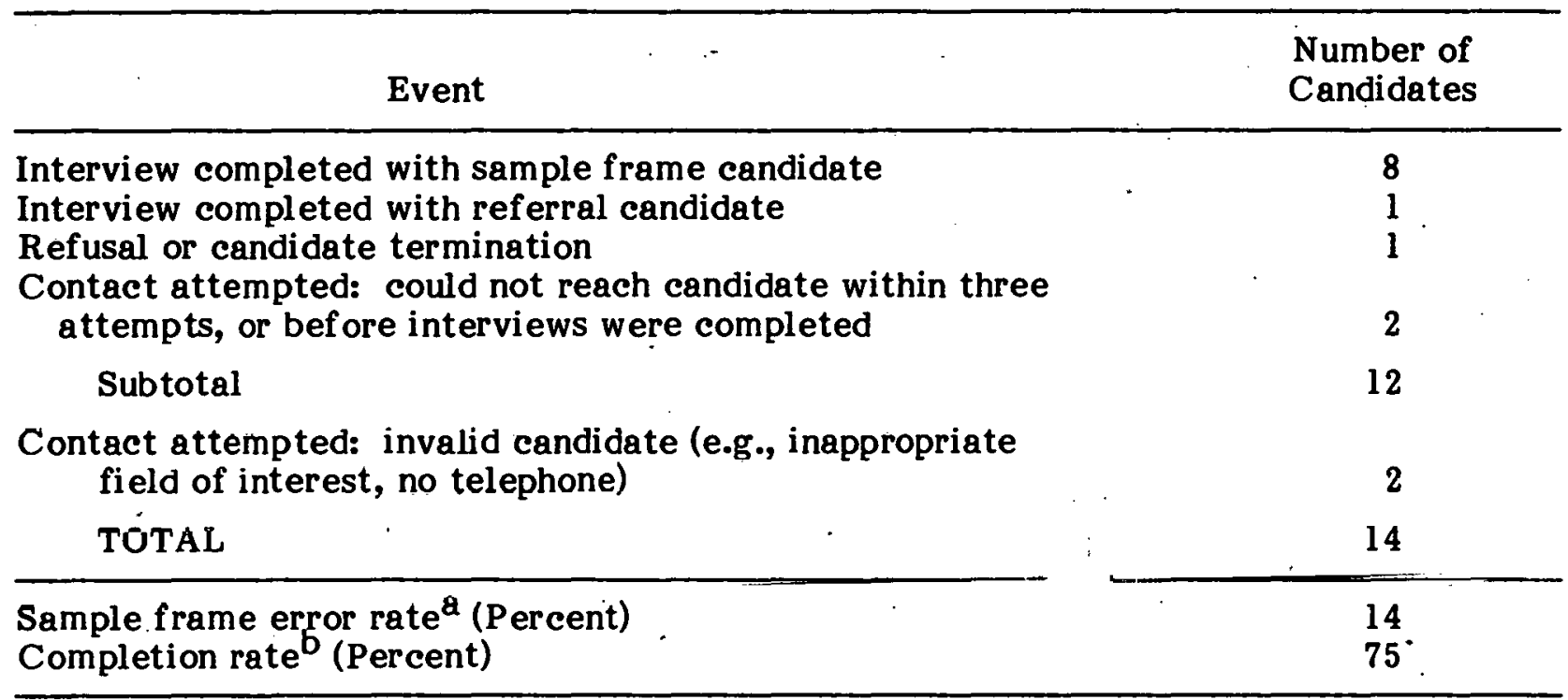

${ }^{\text {anvalid candidates divided by TOTAL }}$

${ }^{\mathrm{b}}$ Completed interviews divided by Subtotal

\subsubsection{Background of Respondents}

Five of 9 Passive Hom eowners had bachelor's degrees; two had no degree; and the other 2 had a master's degree and a PhD. Types of degrees received varied widely with 2 in English, 2 in engineering, and the remaining 3 in art, mathematics, and fine arts. Two had received their most recent degree within the past 10 years, 1 from 10-15 years ago, 3 from 20-40 years ago, and 1 received his/hers 50 years ago. The educational level and years of most recent degrees for Passive Homeowners did not differ significantly from those of Total SHAC Homeowners. Similar to Passive Homeowners, the types of degrees earned by the SHAC group also varied widely. Professions represented by the Passive Hom eowner's group included engineer (2), designer, designer/writer, student, housewife, educator, and "natural foods."

\subsection{INPORMATION NEEDS OF RESPONDENTS}

Even though the Passive Hom eowners had already built and currently owned a passive or passive/active home, 5 of the 9 (56\%) Passive Homeowners indicated they would need additional information on passive on the job and 4 of the 9 (44\%) outside the job during the next year. Comparatively, this was slightly lower than the interest expressed by Total SHAC Homeowners for information on the job (13 of the 18 or $72 \%$ ); however, similar levels of interest were expressed for information outside the job ( 8 of the 18 or 44\%). Four of the 9 (44\%) Passive Homeowners did not expect to need information on passive solar energy during the next year (either on the job or outside the job) compared to 5 of the $18(28 \%)$ Total SHAC Hom eowners. 


\subsubsection{Technical Areas}

The one application incorporated by all 9 Passive Homeowners was "landscaping or orientation of building on the site." "Heat storage in a wall" was mentioned by 6 of the 9 and "greenhouses" by 5 of the 9 respondents. None of the Passive Homeowners mentioned using "solar ponds." "Atriums or solariums" and "solar cooling" were not used very frequently (see Table 9-2).

Table 9-2. TYPES OF SYSTEMS USED BY PASSIVE HOMEOWNERS

\begin{tabular}{llc}
\hline \multicolumn{1}{c}{ Technical Area } & No. & Percent \\
\hline Landscaping or Orientation of Building & & 100 \\
on the Site & 9 & 67 \\
Heat Storage in Wall & 6 & 56 \\
Greenhouse & 5 & 44 \\
Rock Storage of Heat & 4 & 33 \\
Other Water Storage of Heat, such as Barrels & 3 & 33 \\
Clerestory Windows & 3 & 22 \\
Atrium or Solarium & 2 & 22 \\
Solar Cooling & 2 & 0 \\
Solar Pond & 0 & \\
\hline
\end{tabular}

Passive Homeowners volunteered that they also used other passive devices including insulating shutters, massive brick floors (tile over 3-inch concrete), underground construction, north-south glazing, "open collectors," solar hot-water preheaters, and passive solar collectors.

\subsubsection{Types of Information}

Passive Homeowners were asked to name the information about passive solar heating and cooling that they would want to have if they were starting over again and first considering the installation of a passive system. All 9 Passive Homeowners volunteered one or more items of information which they considered important. Information on solar greenhouses (2) and cost of passive systems (2) was considered important. Other topics included insulation, "Dynamic Insulation (trademark)," heat bin designs, skylighting, insulating systems, architectural information, siting information, use of staircases for heat storage, insolation data by geographical area, performance, basic weather data, glazing, thermal storage products, and caulking.

Passive Homeowners were asked if there was passive information that they needed but could not obtain when they were considering the purchase of a solar energy system. This retrospective question elicited responses from 4 respondents including information on the cost and operation of smaller solar homes on modest incomes, "everything," and basic performance data for varying approaches to passive designs.

Choice Between Specific Needs. A list of 11 types of passive solar energy information products and 14 types of passive solar energy information categories was read to each respondent. Each respondent described the retrospective usefulness of each particular item by assigning it a value of "essential," "very useful," "somewhat useful," or "not at all 
useful." The results are given in Fig. 9-1. For the purpose of comparison, the results for Total SHAC Hom eowners are shown in Fig. 9-2.

Passive Homeowners selected information related to system application as most important. The five top-rated information categories/products were:

- Climatological data,

- Manual methods for sizing and predicting performance or costs,

- Research in progress,

- Costs and performance of systems, and

- A technical description of how a particular system works.

The high ratings given to "research in prngress" and "the stato of the art" were surpirising. It is also interesting to note that Passive Homeowners did not give very high ratings to "computer models" (ranked 17th) or to "a nontechnicol description" (ranked 18th).

Passive Hom eowners assigned the lowest ratings to:

- Marketing statistics and sales projections;

- Calendars of conferences and programs;

- Standards, specifications, or certification programs; and

- Expected major developments during the next 10 years.

Statistical tests indicated that differences between the ratings for these five highest and four lowest-rated information items were significant ( $P \quad \mathbf{0 . 0 5})$ for Passive Homeowners.

It should be noted that these lower-rated items were not necessarily of no worth to the Passive Homeowners. For example, 3 of the 9 (33\%) thought "expected major developments" was either "essential" or "very useful." Thus, these information categories/ products could be useful to some Passive Homeowners but were of a lower relative priority to the entire group.

Statistical tests were also used to determine whether the Passive Homeowners rated any of these information items significantly higher (or lower) than they were rated by the Total SHAC Homeowners. Some groups, however, tended to give higher scores in general than did other groups. To compensate for this effect, these statistical tests compared the "relative rating" given by one group to the "relative rating" given by the other groups. The procedure for calculating the relative rating is described in Appendix $\mathrm{E}$. The average overall rating was slightly higher for Passive Homeowners (2.85) than it was for Total SHAC Homeowners (2.71). Passive Homeowners' average overall ratings were the highest of the 86 groups surveyed.

A comparison of Passive Homeowners to Total SHAC Homeowners showed the passive group was significantly ( $P$ 0.05) more interested in "manual methods," "research in progress," "educational institutions," and "institutional, social, environmental, and legal aspects" and significantly ( $P \cdot 0.05)$ less interested in "lists of local lenders, insurers, (etc.)." The data also indicated that Passive Homeowners were probably more interested in "the state of the art" and "a technical description" and less interested in installation costs, "standards," "tax credits," "lists of local lenders, (etc.)," and "system diagrams" than the SHAC Homeowners were. 
Question \#8. I will read a list of potential information or information products on solar systems. For each, please tell me how useful that information would be to you. Would the following be: essential, very useful, somewhat useful, or not at all useful?

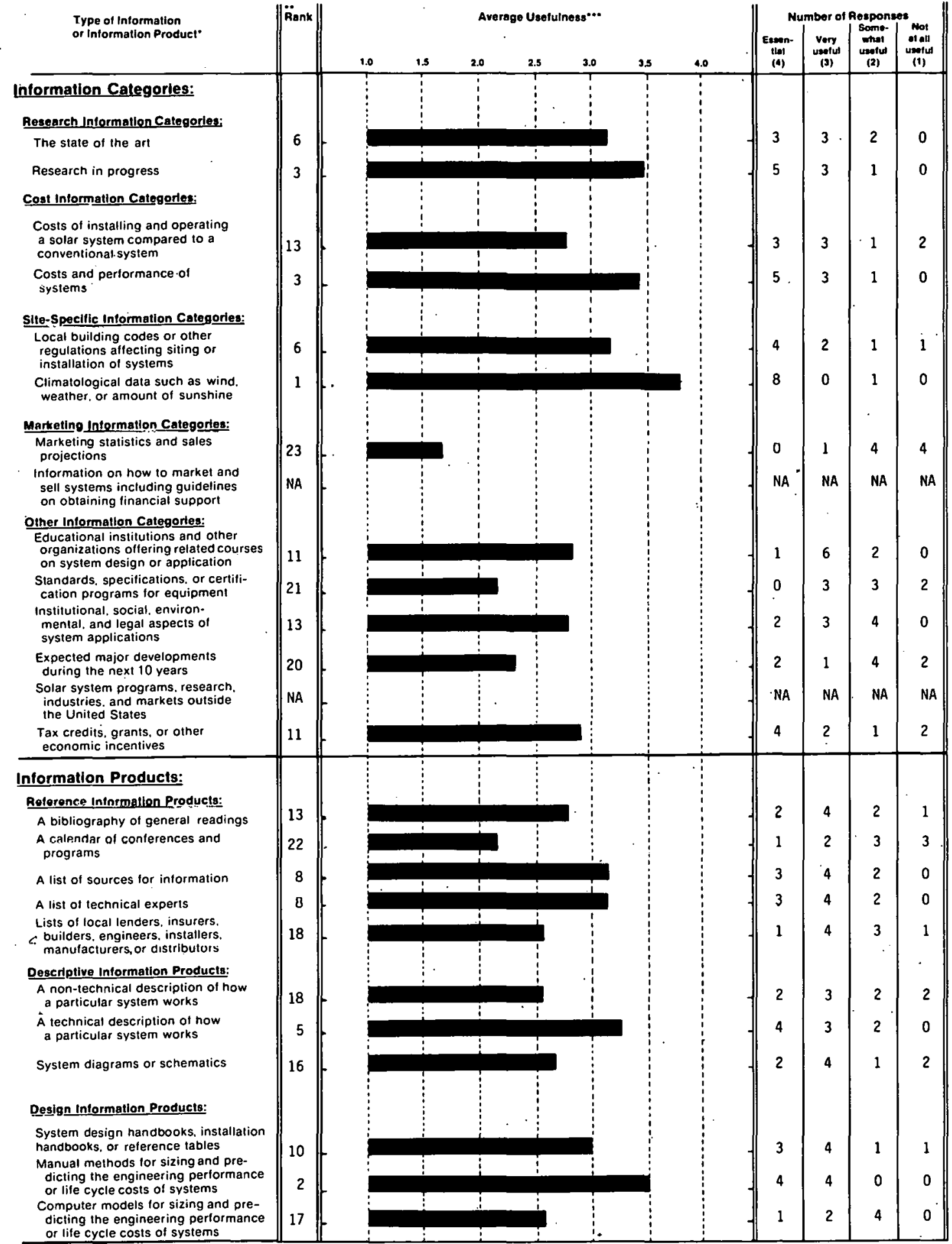

Each șampte trame of users was questioned on infuntialion ond information products in the rentext of their specitic technology. For example. biomass sample trames wore asked about "a bibliography of genetal reacings ur liumass", "a calondar of upcoming bicmass conlerences and programs ", etc. Rank-Each intormation product was assigned a rank based on average usetulness. Thus. the product with the highest average usetufiness was assigned the rank of " " ": the product

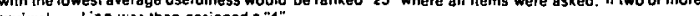

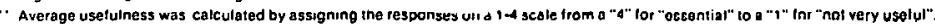

FIgure 9-1. Usefulness of Selected Information Items: Passive Homeowners 
Question \#8. I will read a list of potential information or information products on solar systems. For each, please tell me how useful that information would be to you. Would the following be: essential, very useful, somewhat useful, or not at all useful?

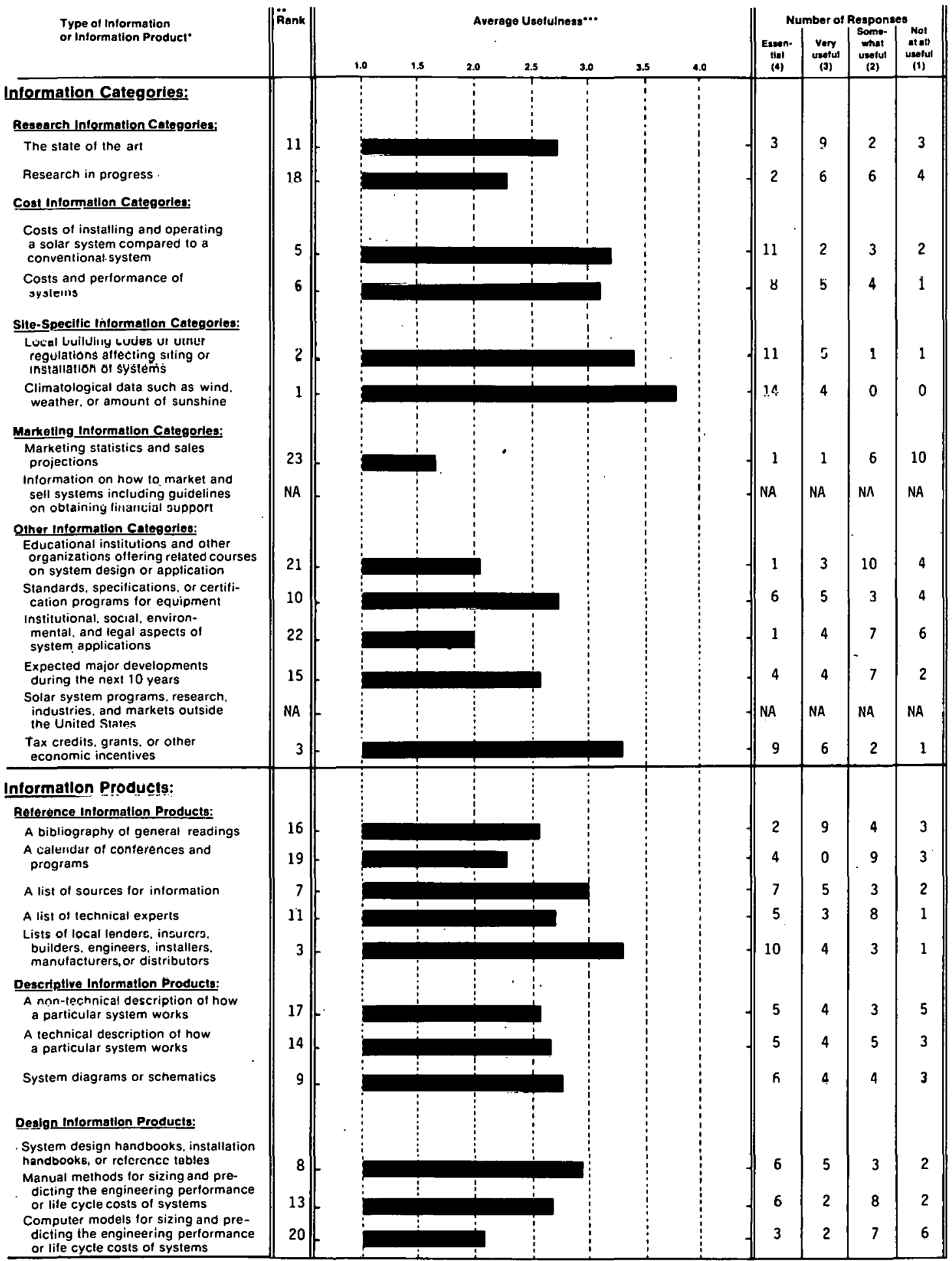
- Each sample trame of users was questioned on intormation and intormation products in the contexs of their spocitic technology. For example, biomass sample lrames were
asked aboul "a bibliograghy ol general readings on biomass"." a calendar of upceming biomass conferences and programs ". etc. Rank - Each intormation product was assigned a ranik based on average usefulness. Thus, the product with the highest average usefuiness was assigned the rank of " " " the producl with the lowest aversge usefulness woutd be renked "25" where all items were asked. II two of more intormation products were tied tor 2nd. they were both assigned " "2". The nex

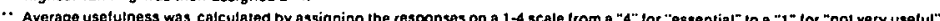

Figure 9-2. Usefuiness of Selected Information Items: Total Active Solar Heating and Cooling Homeowners 


\subsection{ACQUISTION OF INPORMATION BY RPSPONDENTS}

\subsubsection{Initial Information Sources}

Although the Passive Homeowners had already gone through the data gathering process, they were asked in retrospect what would be the first thing they would do to obtain information about passive solar heating and cooling. The types of information sources mentioned varied widely, with 2 mentioning books (Solar Greenhouse and Solar Home), 2 mentioning magazines (Solar Age and Popular Science), and 2 mentioning NSHCIC. Other sources included: colleagues (at their college), a solar energy association (Taos), magazines, reference books, the library, the government, the weather bureau, Total Environmental Action, the "All Solar House Pamplet,". and "Solar Heating Basic."

\subsubsection{Use of Selected Information Sources}

Passive Homeowners were asked which of 20 different potential sources of solar information they had used in the past few years. For this question the respondents were not asked if they had obtained information on passive but instead were asked if they had obtained any solar information from each specific source. Thus, the question sought to determine which information sources were the most familiar to the respondents. The results are shown in Fig. 9-3. For the purpose of comparison, the results for Total SHAC Homeowners are shown in Fig. 9-4.

The information sources mentioned most of ten by Passive Homeowners were:

- Periodicals, newspapers, or magazines;

- Private solar energy or environmental organizations;

- An installer, builder, designer, or manufacturer; and

- Workshops, conferences, or training sessions.

As the above list indicates; the respondents relied frequently on contacts with professionals. The SHAC Homeowners were quite similar as to which information sources were. the most familiar.

The information sources mentioned least of ten by Passive Homeowners were:

- Smithsonian Science Information Exchange (SSIE),

- Solar Energy Industries Association (SEIA),

- A commercial data base,

- $\Lambda$ fcderal library or information center,

- A public utility company,

- National Technical Information Service (NTIS), and

- Regional Solar Energy Centers (RSECs).

None of the above-mentioned sources had been used by more than 3 of the 9 Passive Homeowners. Similar responses were also given by Total SHAC Homeowners, with no more than $39 \%$ mentioning any of the above sources. 
Question \#11. In the past few years, have you obtained any type of solar information from any of the following sources?

Information Sources

Percentage Responding Yes “.

Public Media:
Radio or TV
Periodicals. newspapers or magazines
Private Solar-Involved Organizations:
Private solar energy or environmental organizations
The local chapter or national headquarters of International
Solar Energy Society (ISES), including their publications
The local chapter or national headquarters of Solar Energv
Industries Association (SEIA), including thcir publications
Contacts with Professionals:

An installer, buitder, designer or manufacturer of solar systems

Workshops, conferences or training sessions

Information Services::

Your organizational library or a local library

A commercial data base: for example. Lockheed, SDC, BRS

Smithsonian Science Information Exchange (SSIE)

A Federal library or information center; for example, the National Agricultural Library or the Environmental Data System

The Government Printing Office (GPO)

National Technical Intormation Service (NTIS)

Technical Information Center at Oak Ridge (TIC)

Government Solar-Involved Organizations

Directly from the U.S. Department of Energy

National Solar Heating \& Cooling Information Cente

Regional Solar Energy Centers

State Energy or Solar Offices

Other:

Some other state or local government office or publication

A public utility company

Sources for this specific sample frame**:

Your State Solar Society or Association

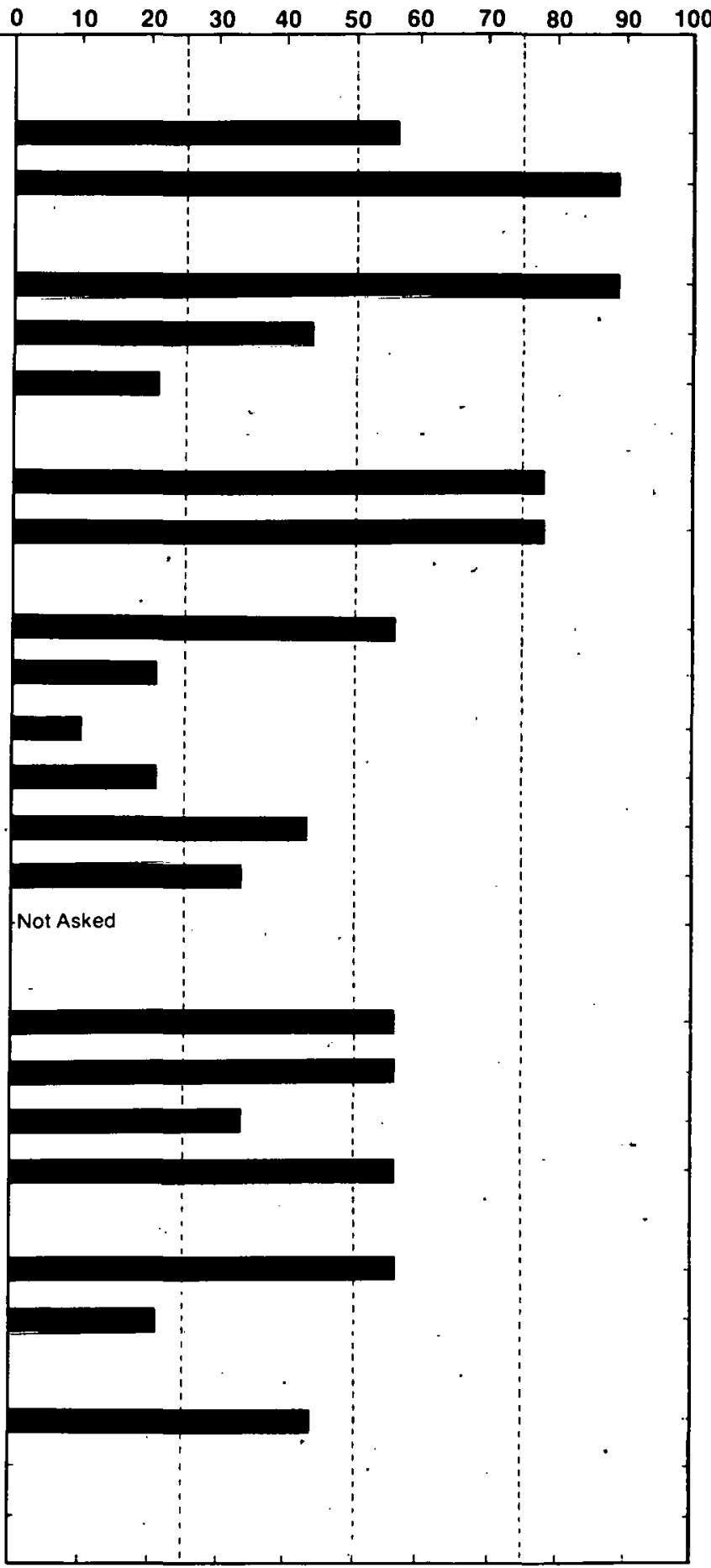

- Services and centers whose primary purpose is to disseminate information.

Some sample frames were questioned about additional information sources which are applicable to their technology. For example. the manufacturers of biomass conversion equipment were also asked it they have obtained any type of solar information from: "the local or national office of the U.S. Department of Agriculture, including Extension and Forestry."

... These data are based upon a total of 9 respondents.

Figure 9-3. Use of Selected Information Sources: Passive Homeowners 
Question \#11. In the past few years, have you obtained any type of solar information from any of the following sources?

, Information Sources

Public Media:

Radio or TV

Periodicals, newspapers or magazines

Private Solar-Involved Organizations:

Private solar energy or environmental organizations

The local chapter or national headquarters of International

Solar Energy Society (ISES). including their publications

The local chapler or national headquarters of Solar Fnergy

Industries Association (SEIA). including their puhlications

\section{Contacts with Professionals:}

An installer, builder, designer or manufacturer of solar systems

Workshops, conferences or training sessions

Information Services*:

Your organizational library or a local library

A commercial data base: for example. Lockheed, SDC. BRS

Smithsonian Science Information Exchange (SSIE)

A Federal library or information center: for example, the National

Agricultura! Library or the Environmental Data System

The Government Printing Office (GPO)

National Technical Information Service (NTIS)

Technical Information Center at Oak Ridge (TIC)

Government Solar-Involved Organizations

Directly from the U.S. Department of Energy

National Solar Heating \& Cooling Information Center

Hegional Solar Energy Centers

State Energy or Solar Offices

Other:

Some other state or local government office or publication

A public utility company

Sources for this specific sample frame**:

Ynur State Solar Soçiẹty or Association

Percentäge Responding Yes “"
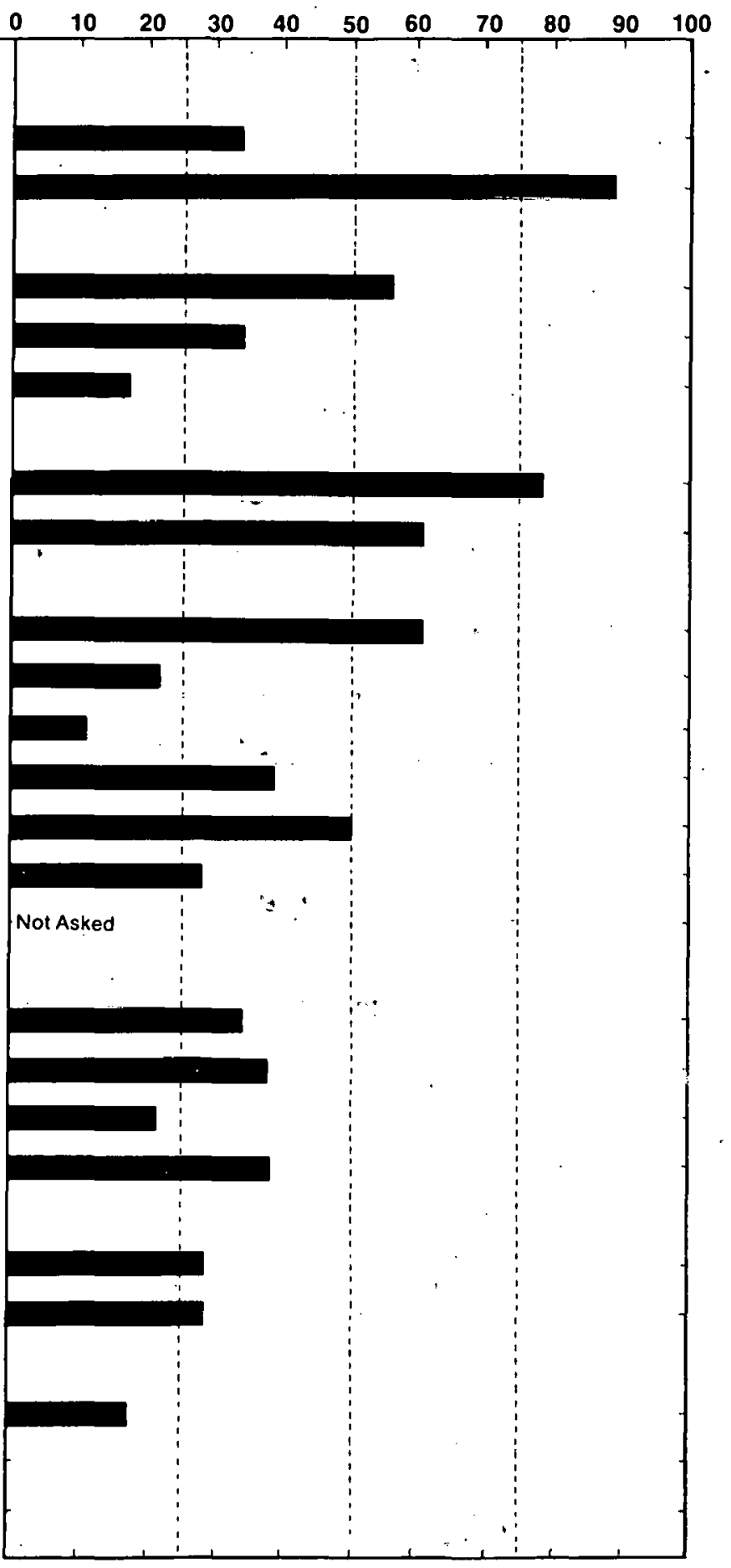

- Services and centers whose primary purpose is to disseminate information.

. Some sample frames were questioned about additional information sources which are applicable to their technology. For example. the manufacturers of biomass. conversion equipment were aiso dsked il they have obtaincd any type of solar intormation from: "the local or national nftice of the U.S. Department of Agriculture, including Extension and Forestry:"

... These data are based upon a total of 18 respondents.

Figure 9-4. Use of Selected Information Sources: Total Active Solar Heating and Cooling Homeowners 


\subsubsection{Membership in Solar-Interested Organizations}

Only 2 of the 9 Passive Homeowners surveyed were members of a professional, technical, or other organization with an interest in solar energy. These organizations (and the number of times mentioned) included:

- American Wind Energy Association (AWEA),

- British AWEA,

- International Solar Energy Society (ISES) (2),

- New England Solar Energy Association, and

- Western Meeting Messachusetts Bay.

Also mentioned was the "SAVE," an organization that the authors could not verify.

\subsubsection{Exposure to Publications on Solar. Energy}

During the past 6 months, all 9 Passive Homeowners had read publications that included information on passive. The publications they could specify (and the number of times mentioned) included:

- Alternative Sources of Energy;

- Better Homes and Gardens;

- Electronic Products;

- ISES publications;

- In the Bank or Up the Chimney;

- Mother Earth News;

- National Brick Institute article, Washington, D.C.;

- Optical Spectra;

- Organic Gardening (2);

- Other Homes and Garbage;

- Popular Mechanics;

- Popular Science (3);

- Solar Age (5);

- Solar Engineering (2);

- Taos News (newspaper);

- Wind Energy Digest; and

- Woman's Day.

Also mentioned were several publications that the authors could not verify. These included "Earth Covered Shelters," "Mendle's book," "Passive Solar Handbook," and trade journals. 


\subsection{SUMMARY AND COMMENTS}

Nine owners of passive or passive/active homes were interviewed. Six of the 9 stated that their homes were originally built as passive heated homes, 2 were retrofitted, and 1 was a combination of the two. Their educational level was similar to that of Total SHAC Homeowners.

Since six of the 9 respondents had been the owner of a solar system for over three years, it seems likely that most of this group were "early innovators [3]." As such, their needs may have been atypical.

The one application of passive incorporated by all 9 Passive Homeowners was "landscaping or orientation of building on site." The next most popular applications were "heat storage in wall" and "greenhouse"; no one had solar ponds. Four of the 9 respondents had experienced difficulty in obtaining information they needed when they were in the evaluation phase of the innovation adoption process model [3]. Information needed included information on the cost and operation of smaller solar homes on modest incomes, "everything," and basic performance data for varying approaches to passive designs.

Passive Homeowners gave the highest priority to receiving information on: .

- Climatological data,

- Manual methods for sizing and predicting performance or costs of passive solar systems,

- Passive solar research in progress,

- Costs and performance of passive solar systems, and

- A technical description of how a particular passive solar system works.

They gave low ratings to "marketing statistics," "calendars of passive conferences and programs," "standards, specifications, or certification programs," and "expected major develoments."

The resulting picture of the Passive Homeowner was a person who desired to keep up to date even af ter incorporating a passive solar system. This group indicated a need for additional information both on the job ( 5 of the 9 or 56\%) and outside the job ( 4 of the 9 or 44\%) during the next year.

Passive Homeowners most of ten received solar information through "periodicals," "private solar energy or environmental organizations," and through professional contacts such as "an installer, builder, (etc.)," and "workshops, etc." Solar Age also appeared to be an important information disseminator for this group.

It was interesting to note that, although both groups used the same information sources, Passive Homeowners and SHAC Homeowners had very different information needs. Both groups gave high ratings to:

- Climatological data, and

- Cost and performance of systems. 
Passive Homeowners were relatively more interested in:

- Research in progress;

- The state of the art;

- Manual methods for sizing and predicting engineering performance or life cycle costs;

- Technical descriptions;

- Educational institutions off ering related courses; and

- Institutional, social, environmental, and legal aspects.

SHAC Homeowners were relatively more interested in:

- Lists of local lenders, etc.;

- Tax credits, grants, or incentives;

- Installation and operating costs;

- System diagrams or schematics; and

- Standards, specifications, or certification programs. 
SECTION 10.0

REPERENCES

1. Belew, William W.; Wood, Barbara L. Solar Information User Priority Study. - SERI/ TR-75 1-472. Golden, CO: May, 1980 .

2. Belew, W. W.; Wood, B. L.; Marle, T. L.; Reinhardt, C. L. 1981. General Solar Information User Study. SERI/TR-751-753. Golden, CO: Solar Energy Research Institute.

3. Rogers, Everett M. Diffusion of Innovations. New York, NY: The Free Press. 1962.

4. Solar Heating and Cooling Research and Development Project Summaries. DOE/CS0010 . Washington, DC: Department of Energy. May, 1978.

5. RIP, Energy Research in Progress (Data Base). DOE/RECON: File 15. Washington, DC: Department of Energy. Spring/Summer, 1979.

6. CRIS, Current Research Information System (Data Base). USDA Lockheed: File 60. Washington, DC: United States Department of Agriculture. 75-79/MAY.

7. SSIE, Smithsonian Science Information Exchange (Data Base). Lockheed: File 65. Washington, DC: The Smithsonian Institution. 75-79/MAR.

8. Manufacturers Data Base. Solar Energy Information Data Bank (SEIDB). Golden, CO: Solar Energy Research Institute. Spring/Summer, 1979.

9. "Manufacturers of Passive Design Products." Rockville, MD: National Solar Heating and Cooling Information Center (NSHCIC). January 15, 1979.

10. 1979 Directory of the American Section of the International Solar Energy Society, Inc. Kileen, TX: American Section of the International Solar Energy Society, Inc. American Techuological University. Fehruary, 1979.

11. "Passive Workshop Attendees." Bloomington, MN: Mid-American Solar Energy Complex.

12. Shurcliff, William. Solar Heated Buildings of North America: 120 Outstanding Examples. Harrisville, NH: Brick House Publishing Company. 1978.

13. National Solar Heating and Cooling Commercial Demonstration Program - Key Personnel Directory. DOE-CS, 0038. Washington, DC: Department of Energy. June, 1978.

14. Solar Heating and Cooling Demonstration Project Summaries. DOE-CS, 0038-2. Washington, DC: Department of Energy. January, 1977.

15. Residential Solar Data Center Grant Application Reports. Washington, DC: Department of Housing and Urban Development (HUD). September, 1978. 
16. Education Data Base. Solar. Energy Information Data Bank (SEIDB). Golden, CO: Solar Energy Research Institute (SERI). Spring/Summer, 1979. Also available in hard copy as the National Solar Energy Education Directory. SERI/SP-42-141. Golden, CO: Solar Energy Research Institute. January, 1979.

17. County Agents Directory. 63rd Edition. Flossmor, IL: C.L. Mast, Jr. 1978.

18. County and City Data Book; 1977 (A Statistical Abstract Supplement). Washington, DC: U.S. Department of Commerce, Bureau of the Census. U.S. Government Printing Office.

19. "Selected Solar Buildings (in Various States); Private Residences." Philadelphia, PA: National Solar Heating and Cooling Information Center (NSHCIC). 
SEP

TR -746

APPENDIX A

GROUPS INCLUDED IN STUDY

113 


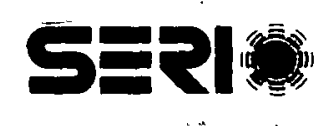




\section{APPENDIX A}

\section{GROUPS INCLUDED IN STUDY}

The following table (Table A-1) lists the 86 groups included in this study of solar information users. Major headings are the same as those of individual reports. Ten separate reports analyzing the study results by technology will be issued.

In general, results for each group are reported in only one volume, although comparisons to similar groups in other technologies are of ten part of the analysis. There are two exceptions: the results for Concentrating Collector Manufacturers are discussed in both the Solar Thermal Electric Power and the Industrial and Agricultural Process Heat reports; the results for Nonconcentrating Collector Manufacturers are discussed in both the Active Solar Heating and Cooling and the Industrial and Agricultural Process Heat reports.

Table A-1. GROUPS STUDIED

\section{A. PhOTOVOLtaics}

1. DOE-Funded Researchers

2. Non-DOE-Funded Researchers

3. Researcher Manufacturers

4. Manufacturers

5. Electric Power Engineers

6. Utilities

7. Educators

\section{B. PASSIVE SOLAR HEATING AND COOLING}

1. Federally Funded Researchers

2. Manufacturers

3. Architects

4. Builders

5. Educators

6. Cooperative Extension Service (CES) County Agents

7. Homeowners with Passive Systems

\section{ACTIVE SOLAR HEATING AND COOLING}

1. DOE-Funded Researchers

2. Non-DOE-Funded Researchers

3. Heating and Cooling System Manufacturers

4. Water Heating System Manufacturers

5. Nonconcentrating Collector Manufacturers (see also Industrial and Agricultural Process Heat)

6. Other Comonent Manufacturers

7. Distributors 
Table A-1. GROUPS STUDIED (continued)
8. Installers
9. Architects
10. Builders
11. Planners
12. Heating, Ventilating, and Air Conditioning Engineers
13. Industrial Engineers
14. Utilities
15. Educators
16. CES County Agents
17. Hom eowners with Space Heating Systems
18. Homeowners with Water Heating Systems
19. . Owners/Managers of Buildings (with SHAC Systems)

\section{BIOMASS ENERGY}

1. Federally Funded Researchers in Production and Collection

2. Federally Funded Researchers in Conversion

3. Nonfederally Funded Researchers in Production and Collection

4. Nonfederally Funded Researchers in Conversion

5. Production and Collection Equipment Manufacturers

6. Conversion Equipm ent Manuf acturers

7. State Forestry Offices

8. Private Foresters

9. Forest Products Engineers and Consultants

10. Educa tors

11. CES County Agents

12. Owners/Managers of Biomass Systems

\section{E SOLAR THERMAL ELECTRIC POWER}

1. DOE-Funded Researchers

2. Non-DOE-Funded Researchers

3. Concentrating Collector Manufacturers (see also Industrial and Agricultural Process Heat)

4. Electric Power Engineers

5. Utilities

6. Educators

\section{F. INDUSTRIAL AND AGRICULTURAL PROCESS HEAT}

1. Industrial Process Heat (IPH) Researchers

2. Agricultural Process Heat (APH) Researchers

3. Concentrating Collector Manufacturers (see also Solar Thermal Electric Power)

4. Nonconcentrating Collector Manufacturers (see also Active Solar Heating and Cooling)

5. Plant Engineers (IPH)

6. Industrial Engineers (IPH) 
Table A-1. GROUPS STUDIRD (concluded)
7. Private Agricultural Engineers (IPH)
8. Educa tors (IPH)
9. State Agricultural Offices (APH)
10. CES County Agents (APH)

\section{G. WIND ENERGY}

1. DOE-Funded Researchers

2. Non-DOE-Funded Researchers

3. Manufacturers

4. Distributors

5. Wind Engineers

6. Electr ic Power Engineers

7. Utilities

8. Educators

9. CES County Agents

10. Small Wind Energy System Owners

\section{H. OCEAN ENERGY SYSTEMS}

1. DOE-Funded Researchers

2. Non-DOE-Funded Researchers

\section{ADVANCED ENERGY STORAGE}

1. DOE-Funded Researchers

2. Non-DOE-Funded Researchers

\section{J. GEN RRAL SOLAR}

1. Loan Officers

2. Real Estate Appraisers

3. Tax Assessors

4. Insurers

5. Lawyers

6. Nonsolar Utilities

7. Public Interest Groups

8. CES State Agricultural Specialists

9. CES State Information Specialists

10. State Energy/Solar Offices (Western SUN states)

11. State Energy/Solar Offices (MASEC states)

12. State Energy/Solar Offlces (NESEC states)

13. State Energy/Solar Offices (SSEC states) 


\section{SE귀*}


APPENDIX B

STUDY DEVELOPMENT AND PROCEDURE 


\section{SEPI}




\section{APPENDIX B}

\section{STODY DEVELOPMENT AND PROCEDURE}

This Appendix describes several aspects of the way in which the studies were developed and conducted.

\section{FACTORS IN STUDY DESIGN}

Surveys of 86 groups, each interested either in one of nine specific solar technologies or in solar energy in general, provided an extremely broad view of the information needs of the solar community. Although the sample size of nine respondents per group was small, the data still proved to be quite adequate for planning purposes. It was possible to determine which information was the most important to the respondents and what was the best channel for disseminating that information. There were a number of valid statist ical tests that could be made, both to compare the priorities a group gave to different information items and to compare the priorities different groups gave to the same item.

Several major factors resulted in the decision to conduct a study with these characteristics. First, there were very few data available on the information needs and information-acquiring activities of the various segments of the solar community, and those data that did exist were related almost exclusively to the area of active solar heating and cooling. Many people had strong opinions as to which information products should be developed first, but data obtained directly from the information users was virtually nonexistent. Due to this general lack of information, most of the potential users of the findings of these studies could not define highly specific questions that they needed to have answered by these studies. Instead, baseline data was needed: it did not make sense to ask a researcher detailed questions on whether he needed a calendar of solar events to be up dated monthly or updated quarterly, when no one knew whether he even needed calendars at all. Thus, the lack of baseline data dictated that most of the potential users of study findings framed their questions at the level of "What information do you need the most?" For such a level of questions there was obviously no great need to use large sample sizes to obtain extremely precise, quantitative answers. Since qualitative data would be quite adequate, there was no need for a large sample size.

Further, there was a need to obtain this baseline data as rapidly as possible so that realtime programmatic decisions about development of information products and data bases could be based upon data rather than conjecture. As a result, the decision was made to conduct the studies by telephone in an attempt to speed up the data collection process. Interviewing by telephone also had the result of improving the response rates (over those using a mail questionnaire).

Thus, these factors dictated the final study design: a broad-based study (the final number of groups included, 86 , was determined primarily by the number of meaningful sample frames that could be constructed) to collect qualitative data by obtaining completed telephone interviews, with approximately 9 randomly selected respondents from each of the 86 groups being interviewed.

\section{Impect on Questionnaires}

As a result of using telephone interviews to conduct the studies, it was necessary to limit the number of questions to be asked. Telephone interviews had to be kept relatively 
short (preferably under twenty minutes) to keep the respondents from prematurely termina ting the interview. Even if a respondent did not hang up before completing the questionnaire, his attention span could be tried severely by lengthy interviews; respondents would then answer questions without much thought in order to terminate the interview as rapidly as possible. In the final study the interviews took an average of about eighteen minutes to complete (with a range from ten minutes to fifty minutes) and incorporated very simple question formats, sometimes open-ended questions. For each of the 86 studies a separate and distinct sample frame; letter of introduction, and questionnaire was developed and separa te computer runs and analyses were performed.

Perhaps a more important effect of deciding to do a telephone study was the necessity of using interviewers without solar backgrounds to conduct the study. With almost 800 interviews to be conducted, each requiring an average of 35 to 40 minutes to complete an 18 minute interview (due to callbacks, referrals, busy signals, wrong numbers, etc.), there was too much effort required to conduct the interviews using internal staff. Thus, the eff ort had to be contracted. The choice was whether to conduct the interviews by contracting solar experts (who would not know anything about interviewing teclinlques) or by contracting a professional telephone interview firm (whose interviewers would not know anything about solar energy). Due to the significantly lower cost and to the significantly reduced chance of biasing the responses, it was decided to use a professional telephone interview firm.

As a consequence of this decision, there were some problems caused by using nonsolar interviewers to pose questions of solar experts. If a respondent asked for a question to be clarified, the interviewer could not assist. Instead, the interviewer could only repeat the question. The biggest problem involved the open-ended questions. Sometimes the interviewer simply did not understand what the respondents were talking about. Interviewers were briefed in solar terminology and instructed to ask respondents to spell out words the interviewers did not understand. Nevertheless, some of the verbatims (i.e., quotes from the respondents that were copied down verbatim by the interviewers) were not intelligible. For example, one interviewer recorded "small square train feeders" when the respondent really said "small-scale terrain features," another recorded "nel lenses" instead of "Fresnel lenses." To minimize errors in translation, all of the questionable verbatim items listed in this report were reviewed and verified by SERI technical experts. However, based upon listening to live interviews and comparing the results to the verbatims, usually the interviewers were able to transcribe the salient points of the responses.

\section{Impact on Statistical Characteristics}

The sample size of nine respondents per group was limiting for the analyst. To illustratu thr. lack of precision in the results, if five of the nine respondents answered "yes" to a particular question, there was a $95 \%$ chance that the true proportion saying "yes" was between 0.212 and 0.862 . Obviously this was an extremely wide confidence interval. For such a small sample size, it was not feasible to make national estimates (e.g.; the number of Federally funded passive researchers in the country who need bibliographies); it was not meaningful to construct 'cross-classification tables (e.g.; "type of information needed" versus "degree of informedness"). Because of these small sample sizes, the authors were sometimes for ced to propose hypotheses rather than dra $w$ conclusions.

Nonetheless, the results were extremely useful when taken as qualitative, baseline results. Certain statistical tests could still be performed (see Appendix E). One could 
test whether passive researchers wanted "state-of-the-art" information significantly more than they wanted "marketing statistics." Several tests could be made comparing one group with another. Thus, one could test whether Passive Architects wanted cost da ta significantly more than did Solar Heating and Cooling (SHAC) Architects. This type of a comparison usually highlighted basic differences between technologies. One could also test whether Passive Researchers responded differently from All Researchers.

Comparisons of this type were valuable for several reasons. First, they allowed the comparison of the information needs of a relatively unknown group against those of a more familiar group. For example, the information needs of Wind Manufacturers were easier to understand when compared to the more familiar information needs of SHAC Manufacturers.

Second, if one can establish basic similarities in infor mation habits and the types of information needed, it will eventually become possible to use the results of other information science studies. For example, many studies have detailed the types of information researchers need and the ways of getting information to them. Thus, if Passive Researchers were quite similar in needs to All Researchers, it was an indication that many of the well-known findings for researchers in genéral may also apply for Passive Researchers.

\section{STUDY DEVELOPMENT}

There were several tasks which had to be completed before the studies could be conducted. These tasks are described in the following subsection.

\section{Development of Sample Frames}

Sample frame development was the single most difficult, most time-consuming task in the entire study. As discussed in Section 2.2, the initial attempt was to obtain lists of the names, addresses, and phone numbers of members of as many meaningful groups as possible. A total of about 86 such sample frames was the maximum that could be developed adequately within a reasonable amount of time.

The services of reference and research librarians were used in this process, much of it on a subcontractor basis. Over 200 documentary sources (printed, published, and unpublished sources, and data bases) were consulted. Staff searched the Solar Energy Information Center and Denver-area public and academic libraries to examine directories, catalogs, periodicals, and da ta bases. Directories of professionals, organizations and associations, and solar-related individuals and groups were examined, both to obtain sample frames and to obtain individual names. Periodicals were searched both to identify associations whose members might be eligible for sample frames and to identify authors who could be contacted because they represented certain target groups. Various data bases were identifed which contained names of individuals categorized by sample frame categories (e.g.; educa tors, resear chers, manuf acturers). Lists of conference attendees were accumulated. Sample frames were also constructed by establishing numerous personal contacts with professional, technical, and special interest organizations, with authors of solar articles, technical staff at the Solar Energy Research Institute (SERI), federal offices, publishers, solar groups, at least thirty sta te solar and state energy offices, etc.

Both the Mid-American Solar Energy Complex (MASEC) and the Northeast Solar Energy Center were subcontracted to provide additional names and addresses. Western SUN also 
provided many names on a voluntary basis. The Southern Solar Energy Center was asked to participate on either a contractual or a voluntary basis, but declined. Additionally, the Technical Information Dissemination (TID) program subcontracted a consulting firm to develop lists of members of the solar community. Although the resulting lists were significantly smaller than had been anticipated, they provided valuable backup information for some sample frames. The National Solar Heating and Cooling Information Center (NSHCIC) provided several of the data bases and other lists used.

It sometimes occurred that the person contacted was not in the presumed field: for example, an installer was no longer involved with solar energy. The proportion of the time that this or a similar sample-frame error occurred has been calculated for each group and is included in the section documenting the results for the group. Sample frame error included such factors as no known telephone number, individual not in the specified field or specified employment sector, etc. Averaging over all groups, 20\%-25\% of the candidates in the sample frames were no longer valid.

\section{Pilot Testing}

In August 1979 Market Opinion Research (MOR) conduc ted a pilot test by doing telephone studies of $10 \mathrm{groups}$ (9 respondents for each). The groups were:

- Wind: Engineers,

- Wind: County Extension Agents,

- Active SHAC: DOE-Funded Researchers,

- Active SHAC: Installers,

- Active SHAC: Utilities,

- Active SHAC: Educators,

- Active SHAC: Commercial Building Owners,

- Passive SHAC: Equipment Manufacturers,

- Solar Industrial Process Heat: Industrial Engineers, and

- General Solar Energy: Lawyers.

These groups were selected specifically to test a range of questionnaires, the peculiarities of selected sample frames, and the receptiveness of certain target groups to telephone interviews on solar energy. The persons contacted in the pilot were not contacted in the full study.

The pilot test proved very useful. There were no major revisions resulting, but several refinements improved the interview procedure and the questionnaire content and format. The interviews were completed within a reasonable time, an average of about 18 minutes per interview. The most important finding of the pilot test was the enthusiasm of the respondents for solar energy. Most respondents were very cooperative and were excited about receiving solar information. Because of this attitude, interviewers had no difficulty in getting respondents through long lists of infor mation products and sources, or in keeping respondents on the telephone to fin ish the interview.

SERI personnel visited MOR while the pilot test was being conducted, personally participating in monitoring interviews, reviewing tape recordings of previously conducted inter- 
views, and debriefing interviewers. Based upon these inputs, several changes were made in the basic questionnaire concept, resulting in changes for each of the 86 distinct questionnaires. Among these changes were: addition of a question designed to defuse the respondent by allowing expression of the respondent's individual concerns; deleting two questions which were not working; changing the sequence of a few questions; making a few small wording changes to sharpen questions, and changing MOR's suggested questionnaire format in order to minimize interviewer errors.

Upon realizing that there was more sample frame error than had been anticipated, the screening procedure was revised to a double screening procedure. Only people who said they needed solar infor mation within the next year, and who were truly in the proper group (e.g., "an architect doing work in passive solar heating and cooling") were to be interviewed. The rules for handling referrals were revised to allow interviews with intraorganizational referrals only.

Perhaps the most important change was in the interviewer training procedure. More specific instructions were developed for each question so that the interviewers would know the real point of the question, would ask the question properly, and would know what to emphasize. Lists of words being mispronounced by the interviewers were developed. Specific interviewers with pronunciation problems were singled out for additional coaching. Because of the interviewers' lack of familiarity with solar energy terminology, glossaries and other background infor mation on solar energy were provided to interviewers.

\section{Interviewer Training and Monitoring}

The MOR interviewers used for these studies were all experienced interviewers. They went through three separate training sessions: a pilot test briefing, a pilot test debriefing (with question and reaction session), and a full study briefing. The full study briefing was held in four separate sessions so that the interviewers could be trained in small groups. SERI representatives were present for and assisted with the second two sessions.

These training sessions covered the purpose of the study, question wording, recording procedures, the screening procedure, and pronunciation of unfamiliar words. The training was built around the use of an annotated briefing questionnaire. Notes concerning each question were written on a questionnaire, which the interviewer studied during the briefing. Additional written materials covered included a list of solar energy terms, a list of common solar acronyms, and a list of words for pronunciation reminders.

\section{Randomized Selection of Respondents}

Once the sample frames were developed for each group, a random sample of 30 to 40 potential respondents was drawn by systematic sampling. (If the sample frame for a group only had 30 to 40 names in the beginning, this step was omitted.) These reduced sample frames were then forwarded to MOR. At MOR, these randomly selected names were put through a second randomization process which assigned the order in which these names were to be called. The MOR process used systematic sampling to identify the first nine candidates for interviewing; the total number of potential candidates was divided by nine to obtain "i," the "skip interval." Starting from a random point (R), every $i^{\text {th }}$ name then became one of the first nine candidates.

An initial call and up to two callbacks (at different times of day on different days of the week) were made, attempting to reach each designated respondent. If an interview was 
not completed after three attempts, the interviewer took the questionnaire to the interviewing supervisor. The supervisor then designated the next person in the sequence as the substitute candidate: if the $(R+i)^{\text {th }}$ person could not be reached, the $(R+i+1)^{\text {th }}$ became the replacement candidate. If after three attempts to reach the substitute, no interview was completed, this process was repeated. (This time the $(R+i+2)^{\text {th }}$ person would become the candidate, etc.) For the entire study, 54\% of the completed interviews were with the originally designated respondent and $26 \%$ were with the first substitute. The remainder were completed with a sec ond or higher substitute.

There is evidence that for some sample frames MOR did not use a random starting point to commence the skip interval, but instead used the sequence of $1^{s t},(1+i)^{\text {th }},(1+2 i)^{\text {th }}$, etc. names for initial candidates. Such a practice clearly does not conform to professional standards. This practice was not critical in those of the sample frames with a large initial size or no particular order since SERI did a valid random subsampling to reduce the sample size to 30 or 40 . In small sample frames or in frames with a definite pattern, however, this procedure could have caused biases. All seven of the Cooperative Extension Service sample frames were arranged in a state-by-state order. As a rcoult of not randomly changing the starting point, there was a strong tendency towards sampling from the same states for these sample frames. The final distribution of CES respondents by state is shown in Table B-1. Some clustering did occur for some states. Thus, for these groups, results were geographically biased.

\section{STUDY PROCEDURE}

The procedure was the same for each study. Each of the potential respondents was sent a letter of introduction one to three weeks before they were telephoned (see Appendix C). This letter explained that the person was selected as a candidate and may be called by MOR, that MOR was calling for SERI, the purpose of the call, the type of infor mation being sought, and that the respondent's identity would be kept confidential.

The telephone interviews were conducted in one of MOR's two telephone rooms, with each individual interviewer in an acoustically. insulated booth. Throughout the study, interviews were monitored by MOR's phone room supervisors. They were responsible for randomly listening to interviews to determine whether the operators were conducting the interviews correctly. If $\mathrm{m}$ istakes were being made, the supervisor explained the proper procedure to the interviewer. The supervisors were able to monitor calls without the interviewers knowing they were being monitored.

Candidates were telephoned during business hours (except for homeowners who were called during the early evening and weekends). If the interview candidate could not be contacted in the initial call, as many as two additional callbacks were mare. These callbucks were made at different times of the day and on different days of the week. If no interview was completed after three attempts, a substitute candidate replaced the initial candida te and the process started over. If a secretary indicated the candidate would be in later at a specified time and day, the callback was scheduled correspondingly. If a candida te was too busy to talk when initially contacted, an appointment was made to call back at a specified time. Only $3 \%$ of the candidates contacted refused to be interviewed or terminated the interview before it was completed. Once a candidate was contacted, a screening procedure was used to verify that the respondents being interviewed actually represented the group to which they ostensibly belonged. For example, a respondent who was presumably an educator teaching courses in passive solar technologies was read the following statement at the beginning of the interview: 
Table B-1. COOPERATIVE EXTENSION SERVICE (CES) STATES REPRESENTED IN SAMPLES* (Number of Respondents)

\begin{tabular}{|c|c|c|c|c|c|c|c|c|c|c|}
\hline \multirow{2}{*}{ State } & \multicolumn{6}{|c|}{ County Agents } & \multicolumn{4}{|c|}{ State Specialists } \\
\hline & $\begin{array}{l}\text { Bio- } \\
\text { mass }\end{array}$ & Wind & $\mathrm{APH}$ & $\begin{array}{l}\text { Pas- } \\
\text { sive }\end{array}$ & $\begin{array}{l}\text { Ac- } \\
\text { tive }\end{array}$ & Total & $\begin{array}{l}\text { Infor- } \\
\text { mation }\end{array}$ & $\begin{array}{l}\text { Agricul- } \\
\text { tural }\end{array}$ & Total & $\begin{array}{c}\text { All } \\
\text { CES }\end{array}$ \\
\hline Alabama & - & 1 & - & 1 & - & 2 & - & - & - & 2 \\
\hline California & - & 1 & - & - & - & 1 & - & - & 一 & 1 \\
\hline Colorado & - & 1 & - & - & 1 & 2 & - & - & - & 2 \\
\hline Connecticut & - & - & - & - & - & - & 1 & - & - & 1 \\
\hline Delaware & - & - & - & - & - & - & - & 1 & 1 & 1 \\
\hline Georgia & - & - & - & 1 & - & 1 & - & - & - & 1 \\
\hline Idaho & - & - & 1 & - & - & 1 & 1 & 1 & 2 & 3 \\
\hline nlinois & - & 1 & - & - & - & 1 & - & - & - & 1 \\
\hline Indiana & 2 & 1 & - & 1 & 1 & 5 & 一 & - & 一 & 5 \\
\hline Iowa & - & 1 & - & - & - & 1 & 一 & - & - & 1 \\
\hline Kansas & - & - & 2 & - & 1 & 3 & 一 & - & - & 3 \\
\hline Kentucky & - & 1 & - & 1 & - & 2 & 1 & 1 & 2 & 4 \\
\hline Louisiana & - & - & - & - & - & - & 1 & 一 & 1 & 1 \\
\hline Maryland & 1 & - & - & - & - & 1 & - & - & - & 1 \\
\hline Michig an & - & 1 & - & - & - & 1 & 1 & 1 & 2 & 3 \\
\hline Minnesota & - & - & - & 1 & 1 & 2 & - & - & - & 2 \\
\hline Missouri & - & 1 & - & - & - & 1 & - & - & - & 1 \\
\hline Montana & 1 & - & - & - & 1 & 2 & - & - & - & 2 \\
\hline Nebraska & - & - & 1 & 1 & 1 & 3 & 1 & 1 & 2 & 5 \\
\hline New Mexico & 1 & - & - & - & - & 1 & - & - & - & 1 \\
\hline New York & 一 & 一 & - & - & - & - & 1 & 1 & 2 & 2 \\
\hline N. Carolina & - & $\cdot \quad-$ & 1 & 1 & 一 & 2 & - & - & - & 2 \\
\hline Ohio & 1. & - & - & 一 & 1 & 2 & 一 & - & - & 2 \\
\hline Oklahoma & 一 & 一 & l & - & - & 1 & 1 & - & 1 & 2 \\
\hline Oregon & 1 & - & 一 & - & 一 & 1 & - & - & 一 & 1 \\
\hline S. Carolina & - & - & 一 & - & 一 & 一 & - & 1 & 1 & 1 \\
\hline S. Dakota & 一 & - & 1 & 1 & 1 & 3 & 1 & 一 & 1 & 4 \\
\hline Tennessee & 1 & - & 1 & 1 & - & 3 & $=$ & - & $\ldots \cdots$ & 3 \\
\hline Texas & 1 & - & 1 & - & 1 & 3. & - & 1 & 1 & 4 \\
\hline $\begin{array}{l}\text { W. Virginia } \\
\text { Sample Size }\end{array}$ & - & - & - & - & - & - & - & 1 & 1 & 1 \\
\hline $\begin{array}{l}\text { Sample Size } \\
\text { by Technology }\end{array}$ & 9 & 9 & 9 & .9 & 9 & 45 & 9 & 9 & 18 & 63 \\
\hline Total States & & & & & & & & & & \\
\hline Represented & 8 & 9 & 8 & 9 & 9 & 24 & 9 & 9 & 13 & $30 *$ \\
\hline
\end{tabular}

*States not represented in any CES samples are: Arizona, Arkansas, Florida, Maine, Massachusetts, Mississippi,.. Nevada, New Hampshire, New Jersey, North Dakota, Pennsylvania, Rhode Island, Utah, Vermont, Virginia, Washington, Wisconsin, and Wyoming. Alaska and Hawaii were not included in the sample frame. 
Hello (respondent's name). This is (interviewer's name) of Market Opinion Research. A week or so ago you were sent a letter from the Solar Energy Research Institute describing a survey of solar energy information needs and request ing your participation.

Your name has been provided to us as someone who has been teaching courses rela ted to passive solar technologies. Is that correct?

If the respondent answered "yes," the interview continued. If the respondent answered "no," then the respondent was not interviewed but instead was asked if there was another person within the same university who was teaching courses related to passive solar technologies. If the initial candida te could give the name of another person, the referral person (or "referral") was called as a substitute for the initial candidate. If no intraorganizational referral was given, another candidate was telephoned.

A second screen was used to eliminate those people who did not feel they would be needing information in the near future. For example, passive respondents were askor the folluwing two quest fons:

- In the next year do you expect to need information on passive solar systems for your job?

- In the next year do you expect to need infor mation on passive solar systems outside your job?

For all respondents other than Passive Homeowners, these questions were asked at the beginning of the interview and if the answer to both questions was "no," the interview was terminated and a substitute candidate telephoned. No request for a referral was made.

Once an interview was completed, the questionnaire was reviewed for completeness by the phone room supervisor. Incomplete questionnaires were returned to interviewers to recall the respondents.

Completed questionnaires were forwarded from the phone rooms to the Coding Department where they were checked in and assigned a unique identification number. They were subsequently sent to the Data Entry Department where they were keyed directly in to computer data files. Since no computerized editing system could prevent the incorrect entry of a data value that was within the proper range (e.g., entering a " 3 " when the correct number was a "2," but where the numbêrs "1," "2," "3," and "4" are all valid numbers), SERI did a random sample of supposedly correct values to verify that they were correct. Out of 225 allowable values reviewed, only 1 had been incorrectly entered. Once the data were entered on the computer file, data tables were printed and analyzed.

Nonuniform Group Sample Size The study was originally designed to sample nine respondents from each group. For most groups this was done correctly. Upon analysis of the completed questionnaires, however, it was sometimes apparent that a respondent obviously belonged in a group other than the one in which or iginally sampled. This was generally due to two simultaneous errors: a sample frame error and a screening error.

First, the person was included on the wrong sample frame. For example, a person listed as doing non-DOE-funded research could have received DOE funding af ter the sample frames were completed. Second, the screening process did not successfully remove this 
person from the Non-DOE-Funded Researchers; instead the interview was completed. During the interview the respondent mentioned that he was receiving DOE funds for his research. As a result, the analyst received eight interviews completed with Non-DOEFunded Researchers and one completed with a DOE-Funded Researcher.

For such cases, the dissimilar interview was removed from the original group (in the example above, the Non-DOE-Funded Researchers). If there was another group into which that interview naturally fit (above, the DOE-Funded Researchers), the interview was included with the interviews for the second group. Although the added interview did not have exactly the same probability of selection as did the original interviews, the resulting inaccuracy was minimal given the qualitative nature of the data. 


\section{SE尺I*}


SEPI — TR -746

APPENDIX C

LETTER OF INTRODUCTION

131 


\section{Sइㄹ*}


APPENDIX C

\section{LETTER OF INTRODUCTION}

All potential respondents from the initial sample frames were sent the following letter (see Fig. C-1) from one to three weeks prior to being contacted by telephone. There are three phrases (underlined in this example) which were changed to describe the group and the solar technology. For example, "a researcher" was changed to read "a manufacturer" or "an educator," etc., as appropriate for the specific sample frame. Similarly, "passive solar heating and cooling" read "photovoltaics" or "wind energy systems," etc., according to the technology about which this potential respondent was to be interviewed. About 3,500 such letters were mailed over a period of several weeks. Less than 100 were returned as undeliverable.

It should be noted that in cases where the actual respondent was a referral, the respondent had not necessarily received this letter.

There were numerous telephone calls to the Solar Energy Research Institute (SERI) from people who had received this letter. Most volunteered they were eager to participate (and concerned that they had not yet been called) or that they wanted study results. A few volunteered referrals or gave the best times for them to be called. 
September, 1979

Dear Colleague:

The Solar Energy Research Institute (SERI) is currently developing a Solar Energy Information Data Bank (SEIDB). The SEIDB is designed to include many categories of solar information and will serve the needs of a variety of groups: among them, researchers, manuf acturers, architects, builders, lawyers, and homeowners. Services provided to you by the SEIDB may include an inquiry response service, computer access to models or large sets of data and free brochures, handbooks, etc.

The U.S. Department of Energy has defined solar energy as encompassing technologies which involve both direct and indirect uses" of sunlight; information for all of the following technologies will be included in the SEIDB:

Solar heating and cooling (active)

Solar heating and cooling (passive)

Solar agricultural process heat

Solar industrial process heat

Wind energy conversion systems

Biomass energy systems

Photovoltaics (direct conversion of sunlight to electricity)

Ocean energy systems

Solar thermal electric power

Solar energy storage

So that this data bank can be developed to meet your present or future solar infor mation needs, SERI is surveying information users like yourself. You have been selected as a candidate for this interview because you are a researcher with an active or potential interest in passive solar heating and cooling.

We believe your participation in this survey will be beneficial to you and to the country. If called, you will have an opportunity to express your opinions and to define your solar information needs. This will help us ensure that the data bank will be responsive to the needs of researchers as well as those of other groups.

Market Opinion Research of Detroit, Michigan, has been chosen to conduct this survey for SERI. A trained interviewer may contact you within two weeks to interview you. The telephone interview will last no more than 20 minutes. You can be assured that your responses to this survey are strictly confidential. No names will be used in reporting the results.

If you have questions about this survey, its purpose, or the interview methods to be used, please feel free to contact me at (303) 231-1155. Thank you for your assistance.

Sincerely,

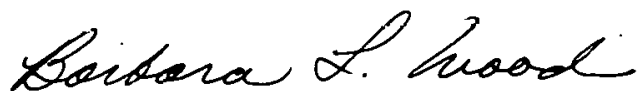

Barbara L. Wood,

Staff Market Research Infor mation Specialist, Inf orm ation Disse mination Branch,

Inf ormation Systems Division 
APPENDIX D

STUDY QUESTIONNAIRE 


\section{SEP}




\section{APPENDIX D}

\section{STODY QUESTIONNAIRE}

A different questionnaire was developed for each distinct group in this study. These questionnaires were very similar, however, in that the same type of information was being sought from each of the groups. The individual questionnaires were developed by constructing a core quest ionnaire, then making appropriate revisions, additions, and deletions to produce a distinctly tailored questionnaire for each group.

Two sample questionnaires are provided in this appendix. A version of the first (Fig. D-1) was used for all samples except for users of solar systems (homeowners, building and plant owners/managers.) The second (Fig. D-2) was used only for users. The basic difference is that phraseology was changed for users so that their queries were related to information about the period of time their system was being considered for purchase or was under construction. The question numbering system for the user questionnaires follows that of the standard core questionnaire, although the sequence does not. For example, que stion $\mathrm{Bl}-6 \mathrm{a}$ of the user questionnaire is similiar to question $6 \mathrm{a}$ of the standard core quest ionnaire.

The questionnaires used in the passive solar technology studies were very similar to those used for the other studies. The two instruments which follow (see Figs. D-l and D-2) contain references to passive technologies in Questions 1 through 9. Questionnaires that were used for respondents from other technologies substituted references to their appropriate technologies instead of to passive technologies.

Certain variations were made in the passive technology questionnaires for different passive technology groups in Questions $8 \mathrm{a}, 8 \mathrm{~b}$, and 11 , in that certain items were not asked of groups if the item seemed inappropriate. For example, Passive Manufacturers were not asked Question 8a (5) about "a non-technical description," and Passive Cooperative Extension Service (CES) County Agents were not asked Question 11 (7) about Smithsonian Science Infor mation Exchange (SSIE). While it would have been less complicated to have all que stions asked of all respondents, concern over questionnaire length and the desire to avoid asking questions that were not relevant to the group led to deleting questions wherever possible. Questions that were not asked of each group may be noted in the data tables (Appendix F) whenever an individual group shows no entries for that item. (Variations for user questionnaires are addressed below.)

Slight variations in wording were made on the questionnaire of each individual group. For example, in Question 11(18), which asked if information had been obtained from "some other state or local govern ment office or publication," the phrase "other than your own" was inserted for Passive CES County Agents.

\section{Standard Core Questionnaire}

Question 5. This question asked, "What is the most important information that could be provided to you about passive solar heating and cooling?" This question allowed respondents to volunteer the information need that came to mind spontaneously, without reflecting any of the biases of the questionnaire designers as to what was the most im-

portant. Most of the time, however, it did not result in an answer which could be compared to another respondent's answer; for nine respondents, there were typically seven or 
Cd 1

1. In the next year do you expect to need information on passive solar systems.... (a) For your job? Yes. . . . . I No.......2 Don't know. . . . 8 NA. . . . . . 9

(b) Outside of your job?
Yes. ...... $1^{-}$

No. ...... 2

Don't know. . . .8

NA. . . . . . 9
(IF "YES"

TO EITHER,

CONTINUE.

OTHERWISE,

TERMINATE)

31

Very involved. ........4

Moderately involved or ...... 3

Slight ly illvulved. . . . . . . . 2

Not at all involved: (VOLUNTEERED) 1

Don't know. ......... 8

NA. ............ 9

3. What are you doing in the field of passive solar heating and cooling? (ASK AS OPEN END)

Verb

4. How well informed would you say you are about passive'solar heating and cooling? Would you say you are:
Very informed. . . . . . . 4 Moderately informed or ...... 3 . Sl ight ly informed. . . . . . . 2 Nht at all informed (VOLUNTEERCD) , 1 Don't know. .......... . 8

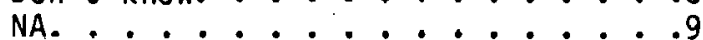

5. What is the most important information that could be provided to you about passive solar heating and cooling? (INTERVIEWER: THIS INCLUDES INFORMATION WHICH COULD BE PROVIDED BY AN INFORMATION CENTER)

lst mention

- $\quad$ 2nd mention 
6. For which of the following areas of passive solar heating and cooling

Cd 2

$$
1-10 \text { as } 1
$$

$11-75$ B1k

are you particularly interested in obtaining information? [READ LIST.
CIRCLE ONE RESPONSE PER ITEM.]
DOn't

$$
\text { Don't }
$$

$76 \mathrm{Cd} \#$ $77-80 \cdot$ Job \#

(1) Building design

$$
\text { Yes No }
$$

Know NA

$\mathrm{Cd} 3$

$1-10$ as 1

(2) Landscaping or orientation of building on site

.(3) Greenhouses

(4) Collection of heat

(5) Storage of heat

(6) Space cooling

(7) Water heating

(8) Hybrid systems, combining active and passive

$\begin{array}{lllll}1 & 2 & 8 & 9 & 11 \\ 1 & 2 & 8 & 9 & 12 \\ 1 & 2 & 8 & 9 & 13 \\ 1 & 2 & 8 & 9 & 14 \\ 1 & 2 & 8 & 9 & 15 \\ 1 & 2 & 8 & 9 & 16 \\ 1 & 2 & 8 & 9 & 17 \\ 1 & 2 & 8 & 9 . & . \\ 18\end{array}$

Are there any other areas of passive solar heating and cooling for which you are especially interested in obtaining information?

(SPECIFY)

(1st Mention)

(2nd Mention)

7. What publications have you read in the None. . . . . . . . 001 past six months that include information on passive solar heating and cooling?

Read, but can't remember titles .002 (VOLUNTESRED)

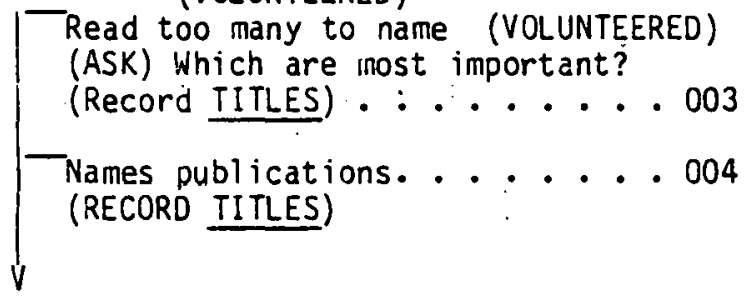

1st Mention

2nd Mention

3rd Mention 
8a. I will read a list of potential information products on passive solar heating and cooling. For each, please tell me how useful that information would be to you. Would the following be: essential, very useful, somewhat useful, or not at all useful? (READ LIST. ROTATE. CIRCLE ONE RESPONSE PER ITEM)

$\underline{\text { Essential Useful }} \begin{gathered}\begin{array}{c}\text { Very } \\ \text { Useful Useful Know }\end{array} \text { NA } \\ \underline{4}\end{gathered}$

(1) A bibliography of general readings on passive solar design. . ... 4

(2) A list of sources for information on passive solar heating and cooling. . 4

(3) A calendar of upcoining passive heating and cooling conferences and programs. . .

4

(4) Diagrams or schematics of a passive solar system. . .

4

(5) A non-technical description of how a particular passive. solar heating and cooling system works...... 4

(6) A technical description of how a particular passive solar system works....

2

1

8943

Lists of local lenders, insurers, builders, engineers, installers or distributors for passive solar design ......

(8) Passive solar design handbooks, installation handbooks or reference tables. .

4

3

2

1

$8 \quad 9 \quad 47$

9) A list of technical experts in passive solar design... .

4

3

(10) Manual methods for sizing and predicting the perforinance of passive solar heating and cooling systems. . 4

(11) Computer models for sizing and predicting the performance. .....

4

3

2

1

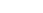


Cd $1 \quad 54$ B

8b. I will next read a list of types of information on passive solar heating and cooling: for each, piease tell me how useful information of that type would be to you. Would the following be: essential, very useful, somewhat useful or not at all useful?

(READ LIST. ROTATE. CIRCLE ONE RESPONSE PER ITEM).

Essential Useful $\begin{gathered}\text { Very } \\ \text { Useful At All Don't } \\ \text { Useful Know NA }\end{gathered}$

(1) Educational institutions and other organizations offering courses on passive solar design. . . 4

(2) Passive solar heating and cooling research currently in progress. . .

(3) The state-of-the-art in passive solar heating and cooling...

4.

(4) Costs and performance of passive solar installations...

(5) Costs of installing and operating a passive solar heating and cooling system compared to a conventional system. . .

(6) Local building codes or other regulations affecting siting or installation of passive solar systems. . . . 4

(7) Tax credits, grants, or other economic incentives for passive solar applications ...

(8) Standards, specifications, or certification programs for passive solar equipment and installations... 4

3

2

1.

$\begin{array}{lll}8 & 9 & 62\end{array}$

(9) Marketing statistics and sales prujections for passive solar equipment. 4

$$
2
$$

1

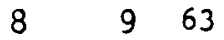

(10) Passive solar heating and cooling programs, research and markets outside the United States. . . . 4

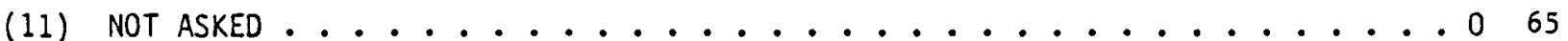

(12) Institutional, social, environmental, and legal aspects of passive solar applications. .

$\begin{array}{lllllll}4 & 3 & 2 & 1 & 8 & 9 & 66\end{array}$

(13) Expected major developments in passive solar heating and cooling during the next ten years.... 4

4 3

Climatological data such as wind, weather, or amount of sunshine. . 4 3

$\begin{array}{lllll}2 & 1 & 8 & 9 & 68\end{array}$




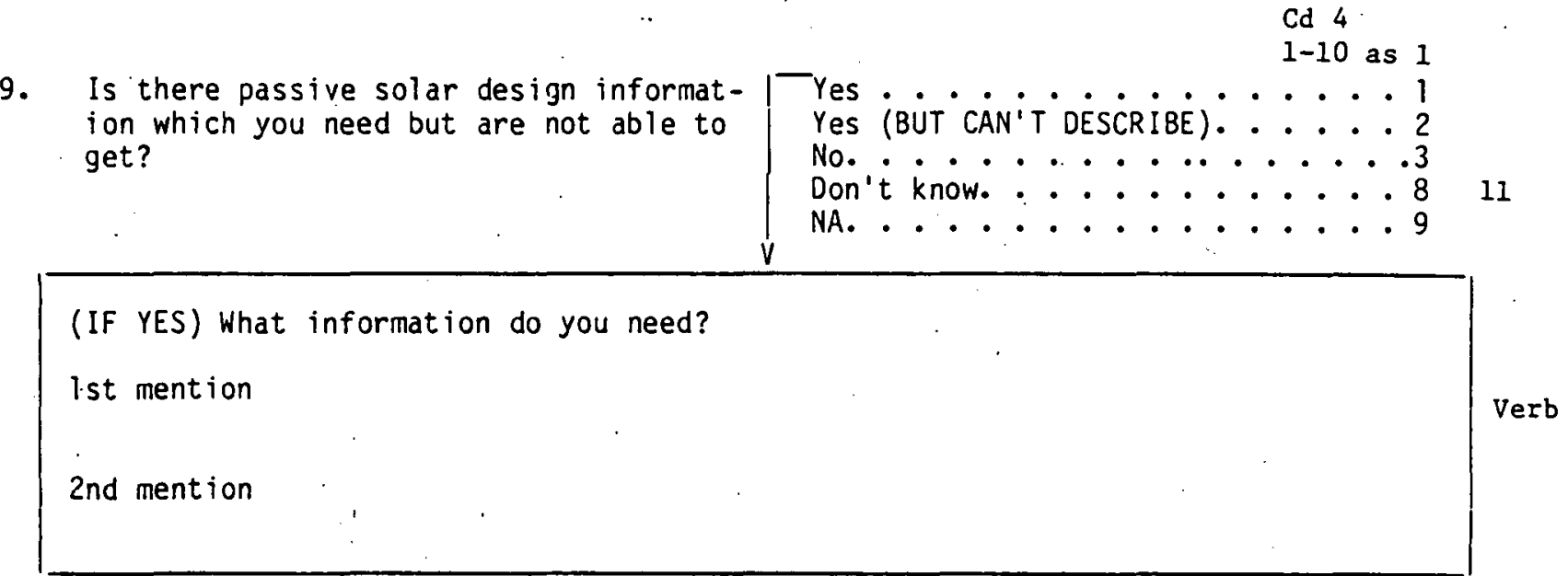

10. In the past year have you obtained any information, not just solar, in the following forms? (READ LIST. CIRCLE ONE RESPONSE PER ITEM)

$\begin{array}{cccc}\text { Yes } & \text { No } & \begin{array}{c}\text { Don't } \\ \text { Know }\end{array} & \frac{N A}{N} \\ 1 & 2 & 8 & 9 \\ 1 & 2 & 8 & 9 \\ 1 . & 2 & 8 & 9\end{array}$
(b) Microform from a computer, sometimes referred to as $\mathrm{C}-0-\mathrm{M}$
(c) Other microforms, for example, micro-
fiche, microfilm sheets or rolls
(c) Other microforms, for example, micro-
fiche, microfilm sheets or rolls
(a) On-line access to a central data bank via computer terminal (n) 
11. Solar information reférs to information about any solar technology, and factors which may relate to its use such as weather, econonics; legislation, architecture, environment, etc. In the past few years, have you obtained any type of solar information from any of the following sources? (READ LIST.

CIRCLE ONE RESPONSE PER ITEM.]

(1) Your organizational library or a local library. . Yes No Know NA

(2) A public utility company...

$\begin{array}{lllll}1 & 2 & 8 & 9 & 17\end{array}$

(3) An installer, builder, designer or manufacturer of solar. systems.......

(4) Workshops, conferences or training sessions...

(5) A comercial data base, for example, Lockheed, SDC, BRS. .

(6) A federal library or information center, for example, the National Agricultural Library or the Environmental Data System. .....

(7) Smithsonian Science Information Exchange (SSIE) . .

(8) The Government Printing Office (GPO) . •

How would you evaluate the service you received from GPO?

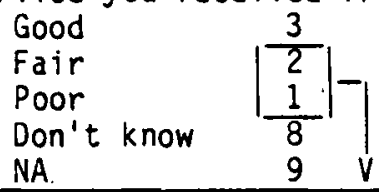

lst Mention

2nd Mention

(9) National Technical Information Service (NTIS). . •

\begin{tabular}{|l}
\hline How would you evaluate the service you received from NTIS? \\
Good \\
Fair \\
Poor \\
Don't know \\
NA
\end{tabular} \mid


(10) Technical Information Center at Oak Ridge (TIC) ...

$\frac{\text { Yes }}{T_{V}^{T}}$ No

$\mathrm{Cd} 4$

Don't

know $\mathrm{NA}$

89

How would you evaluate the service you received from TIC?

\begin{tabular}{l|l} 
Good & $\frac{3}{2}$ \\
Fair & $\mid \begin{array}{l}\frac{1}{1} \\
\text { Poor } \\
\text { Don't know }\end{array}$ \\
NA & $\frac{9}{8}$
\end{tabular}

What are some of the reasons yuu do not consider their service "good"?

lst Mention

2nd Mention

(11) National Solar Heating and Cooling Information Center. .

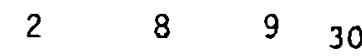

How would you evaluate the service you received from the Center?
Good
Fair
Poor
Don't know $\left|\frac{3}{2}\right|$
NA

What are some of the reasons you do not consider their service "good"?

lst Mention

2ind Mention

(12) Regional Solar Energy Centers. ....

How would you evaluate the service you received from the regional center?

$\begin{aligned} & \text { Good } \\ & \text { Fair } \\ & \text { Poor } \\ & \text { Nan know }\end{aligned}\left|\begin{array}{c|c}\frac{3}{2} \\ \frac{1}{8}\end{array}\right|-\mid$

What are some of the reasons you do not consider their service "good"?

ist Mention

2nd Mention

Figure D-1. Questionnaire (continued) 
(13) Directly froin the U. S. Department of Energy. .

Cọ 4

(14) Radio or TV . . . . .

(15) Periodicals, newspapers or inagazines. . . .

(10) Private solar energy or environinental organizations . . 1

(17) State Eneriy or Solar Offices... Yes No Know NA

(18) Some other state or local government office or publication 1

(19) The local chapter or national headquarters of the International Solar Energy Society (ISES), including their publications. .....

(20) The local chapter or national headquarters of the Solar Energy Industries Association (SEIA), including their publications. ....

(21) Your State Solar Socịety or Association . . . . $\quad 1 \quad 2 \quad 8 \quad 942$

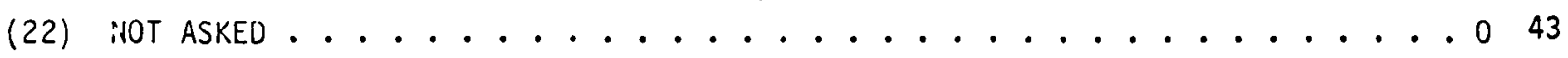

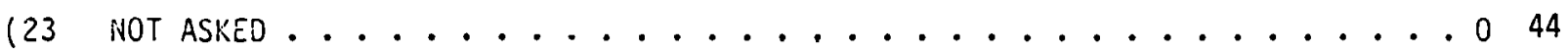

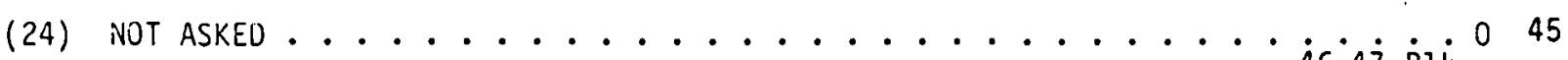

39-7. What publications have you read in the past six months that include information on passive solar heating and cooling? None. ........... 001

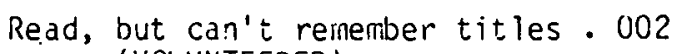
(VOLUNTEERED)

1st Viention

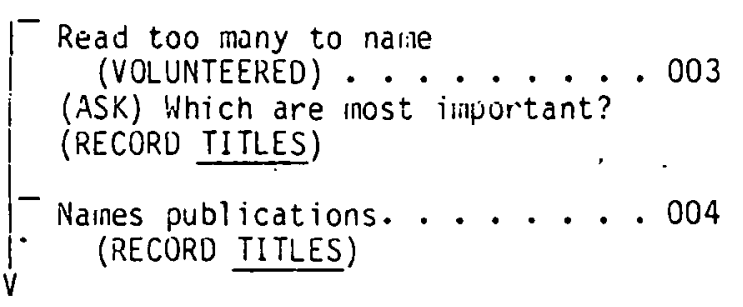

2nd ilention 
In conclusion, I would like to ask you some questions about yourself. Your ansivers will be kept completely confidential.

Dla. What is the highest level of education you have completed? (DO NOT READ) 8th grade or less....... 01

Solne high school ....... 02

High school graduate. ..... 03

Post high school vocational/

Technical........ 04

Attended college/University:

No degree. ....... 05

Associate (2 year junior/

Community college) .... 06

Bachelors. .......07 07

Macters. ......... 08

Ph.0/Doctorate....... 09

JD/LLD .......... 10

Other

11

Don't know ...........98

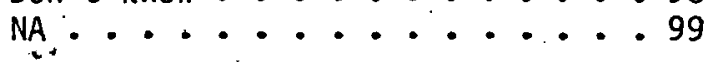

01b. In what field is your most recent degree?

Dic. In what year did you get that degree?

02a. Please describe your present profession by completing the following statenent: "Based on my total education and experience, I now regard myself professionally as a (an) POSSIBLE). ." (AVDID USING JOB TITLE IF

D2b. How many years have you been in this profession? (CIRCLE CODE)

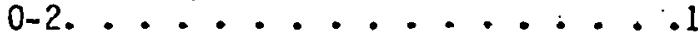
$3-5 \ldots . . . . . . .2$

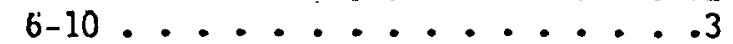

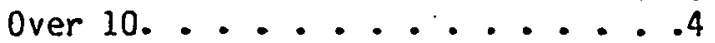
NA .............. 9

\section{Figure D-1. Questionnaire (continued)}


$\therefore$

Cd 4

D3. Do you belony to any professional, technical, or other organizations which have an interest in solar?

Yes. . . . . . . . . . .

Yes (BUT CAN'T NAME) ......

No ............. . .

Don't know........... 8

NA.............. 9

a. What organizations?

1st Mention

2nd Hention

3rd Mention

4th Mention

:

.

Thank you very much for your time.

54-69 BIk

Figure D-1. Questionnaire (concluded) 
Cd 2

$1-10$ as 1

$11-75$ Blk

B1-6a. What type of solar system do you have? Does your system incorporate. . 76 Cd \# [READ LIST. CIRCLE ONE RESPONSE PER ITEM.]

(1) Landscaping or passive orientation of the building on the site.

(2) Greenhouse

(3) Atrium or solarium

(4) Solar pond

(5) Other water storage of heat such as . harrels

(6) Rock storage of heat

(7) Storaye of heat in a wall

(8) Solar coolino

(9) Clerestory ("CLEAR STORY") windows

Yes Ho Know $\frac{\text { Non't }}{\star}$

$\frac{77-80 \mathrm{Job} \#}{\mathrm{Cd} 3}$

Does your system incorporate any other passive devices?

$1-10$ as 1

$11-43$ Blk

Does your systen incorporate any other passive devices?

(1st Mention)

$\begin{array}{lllll}1 & 2 & 8 & 9 & 55\end{array}$

$\begin{array}{lllll}1 & 2 & 8 & 9 & 56\end{array}$

$\begin{array}{lllll}1 & 2 & 8 & 9 & 57 \\ 1 & 2 & 8 & 9 & 58\end{array}$

$\begin{array}{lllll}1 & 2 & 8 & 9 & 59\end{array}$

$\begin{array}{lllll}1 & 2 & 8 & 9 & 60\end{array}$

$\begin{array}{lllll}1 & 2 & 8 & 9 & 61\end{array}$

$\begin{array}{lllll}1 & 2 & 8 & 9 & 62 \\ 1 & 2 & 8 & 9 & 63\end{array}$

(2nd Mention)

B1-6b. Was your house built originally as a

Originally passive. . . . . 1

passively heated house or were changes

Later chaniges . . . . . . 2

made later?

Some of both (VOLUNTEERED)... 3

Uon't know. ........ 8

$64-75$ B $k$

$76 \mathrm{Cd} \#$

$77-80$ Job \#

$44 \mathrm{C}+\mathrm{V}$

45-51 B $1 k$

NA. ............ 9

Figure D-2. Questionnaire 
Cd 1

B2-13. How many years have you been the owner of a solar system?

(INCLUDE YEARS WHEN SYSTEM WAS

UNDER CONSTRUCTION.)

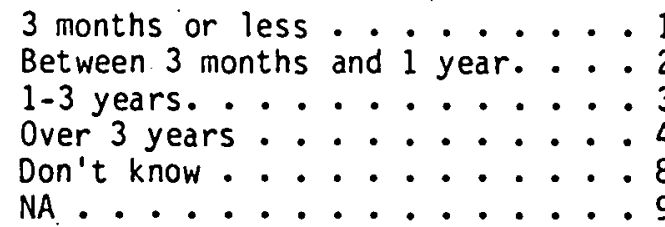

B3-5. Knowing what you now know, in terms of obtaining information about passive solar heating and cooling systems, please answer the following questions as if you were starting over again and first considering the installation of a passive solar heating and cooling system.

What would be the most important information product or service about passive solar heating and cooling that you would want to have? (PROBE FOR TWO MENTIUNS)

lst Mention

$35 \mathrm{C}+\mathrm{V}$

2nd Mention

B4-14. What is the first thing you would do to obtain information about passive solar heating and cooling? That is, where would you go or who would you contact to get the information you needed? (PROBE FOR TWO MENTIONS)

1st Mention

2nd Mention 
Cd 1

B5-8a.. I will read a list of potential information products on passive solar heating and cooling. For each, please tell ine how useful that information would be to you if you were obtaining a new system. Would the following be: essential, very useful, sornewhat useful, or not at all useful? [READ LIST. ROTATE. CIRCLE UNE RESPONSE PER ITEM.]

$$
\begin{aligned}
& \text { Very Somewhat At All Don't } \\
& \text { Essential Useful Useful Useful Know NA }
\end{aligned}
$$

(1) A bibliography of jeneral readings on passive solar heating and cooling 4

$\begin{array}{llllll}3 & 2 & 1 & 8 & 9 & 43 \\ 3 & 2 & 1 & 8 & 9 & 44 \\ 3 & 2 & 1 & 8 & 9 & 45 \\ 3 & 2 & 1 & 8 & 9.46\end{array}$

(4) Diagrans or schematics of a passive. solar systen......

(5) A non-technical description of how a particular passive solar heating and cooling systein works.....4

(6) A technical description of how a particular passive solar system works. .... heating or cooling.....

4

3

2

2

(1)

1

89
(7) Lists of local lenders, insurers, builders, engineers, installers or distributors for passive solar

4
(8) Passive solar design handbooks, installation handbooks, or reference tables......

$\begin{array}{lllllll}4 & 3 & 2 & 1 & 8 & 9 & 50\end{array}$

(9) A list of technical experts in passive design......

4

3

2

1

$8 \quad 951$

(10) Manual methods for sizing and predicting the perforinance of passsive solar heating and cooling systeins. . 4

(11) Computer models for sizing and predicting the performance. .... 4

$\begin{array}{llllll}3 & 2 & 1 & 8 & 9 & 52 \\ 3 & 2 & 1 & 8 & 9 & 53\end{array}$

\section{Figure D-2. Questionnaire (continued)}


Cd 1

36-8b. I will next read a list of types of information on passive solar heating and cuoling. For each, please tell me how useful information of that type would be to you if you were obtaining a new system. Would the following be: essential, very useful, somewhat useful or not at all useful? [READ LIST. ROTATE. CIRCLE ONE RESPONISE PER ITEM.]

Not

54 B1k

Very Solnewhat At All Don't

Essential Useful Useful Useful Know NA

(1) Educational institutions and other oryanizations offering courses on passive solar design. . .... 4

(2) Passive solar heating and cooling research currently in progress. .

(3) The state-of-the-art in passive solar heating and cooling...

4

$4-3$

(4) Costs and performance of passive solar installations. . .

2

1

$\begin{array}{lll}8 & 9 & 58\end{array}$

(5) Costs of installing and operating a passive solar heating and cooling system compared to a conventional systeri. ......

(6) Local building codes or other regulations affecting siting or installation of passive solar heating and cooling systems. .....

\section{4}

3

2

1

8960

(7) Tax credits, grants, or other economic inceritives for passive solar applications...

(8) Standards, specifications, or certification prograins for passive solar equipment and installations. . . 4

$\begin{array}{lllllll}3 & 2 & 1 & 8 & 9 & 62\end{array}$

(9) Marketing statistics and sales pro-

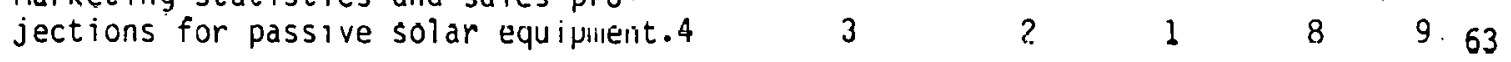$$
\text { ................ } 064
$$

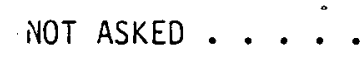

(12) Institutional, social, environinental, and legal aspects of passive solar applications. .....

4

[xpected major developtient.s in pass
solar heating and cooling during

the next ten years. . . . 4

4

(14) Clinatological data such as wind,

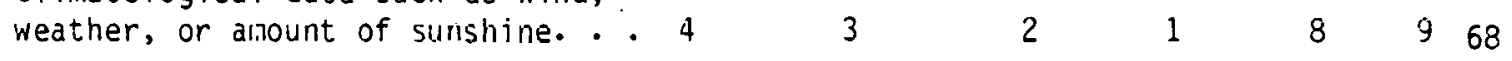


B7-9. When your current solar systein was being considered for purchase, was there passive solar heating and cooling information which you needed but were not able to yet?

(IF YES) What passive solar heating and cooling information couldn't you get?

1st Mention

2nd Mention

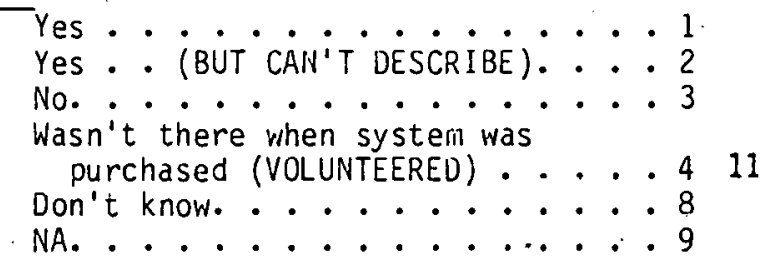

V

Figure D-2. Questionnaire (continued) 
88-11. Solar information refers to information about any solar technology, and factors which may relate to its use such as weather, economics, legislation, architecture, environinent, etc. In the past few years, have you obtained any type of solar information from any of the following sources? [READ LIST. CIRCLE ONE RESPUNSE PER ITEM.]

(1) Your organizational library or a local library. . Don't

(2) A public utility company. Yes No Know NA

(3) An installer, builder, designer or inanufacturer of solar systems. . .

(4) Workshops, conferences or training sessions. . $\begin{array}{lllll}1 & 2 & 8 & 9 & 17\end{array}$ $\begin{array}{lllll}1 & 2 & 8 & 9 & 18\end{array}$

(5) A commercial data base, for example, Lockheed, SDC, BRS. . $1 \quad 2 \quad 2 \quad 8 \quad 921$

(6) A Federal library or information center, for exanple, the ivational Agricultural Library or the Environmental Data Systen. . - $\quad 1 \quad \begin{array}{lllll}2 & 8 & 9 & 22\end{array}$

(7) Smithsonian Science Information Exchange (SSIE) . . . $\quad 1 \quad 2 \quad 2 \quad 3 \quad 923$

(8) The Government Printing Office (GPO) . . .

How would you evaluate the service you received from GP0?

Good
Fair
Poor
Don't know $\frac{3}{2}\left|\begin{array}{l}\frac{3}{8} \\ \text { NA }\end{array}\right|$

What are soine of the reasuns you do not consider their service "yood"?

1st Mention

2nd Mention

(9) National Technical Information Service (NTIS). .

2

How would you evaluate the service you received froin ATIS?
cood
$\begin{gathered}\text { Fair } \\ \text { Poor } \\ \text { Don't know } \\ \text { NA }\end{gathered}$




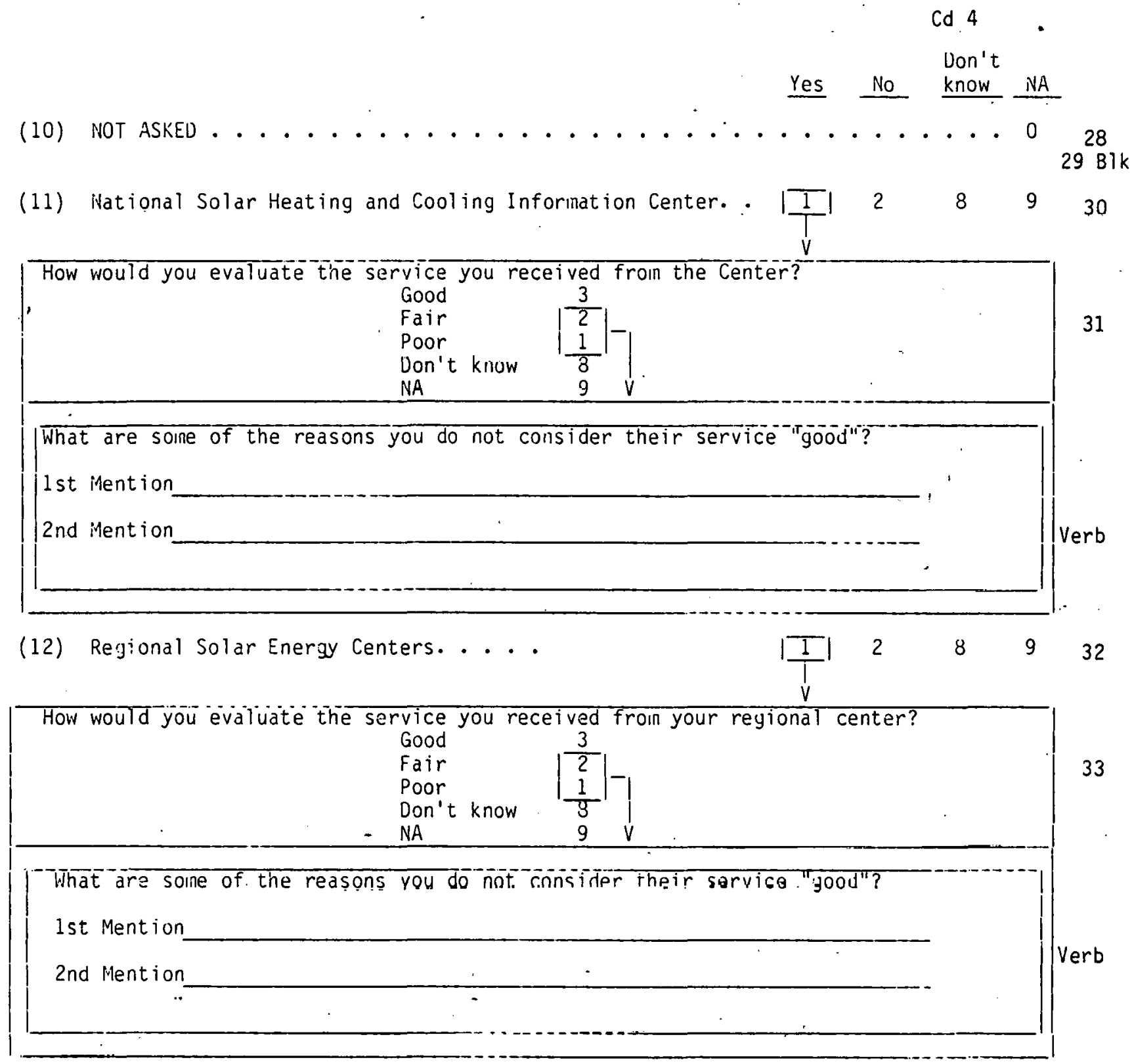

Figure D-2. Questionnaire (continued) 


\begin{abstract}
Cd 4 Don't Yes No Know NA

(13) Directly from the U. S. Department of Energy. . . $\quad 1 \quad 1 \quad 2 \quad 8 \quad 934$

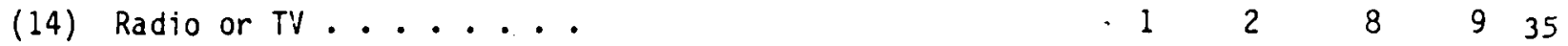

(15) Periodicals, newspapers or magazines. ..... $4 \begin{array}{llll} & 2 & 8 & 9\end{array}$

(16) Private solar energy or environmental organizations . . . $1 \quad 202 \quad 8 \quad 937$

(17) State Energy or Solar Offices . . . $\quad 1 \quad 38$

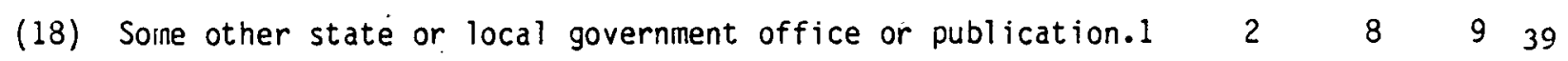

(19) The local chapter or national headquarters of the International Solar Energy Society (ISES), including their publications.... $1,2 \quad 8 \quad 940$

(20) The local chapter or national headquarters of the Solar Energy Industries Association (SEIA), including their publications.....

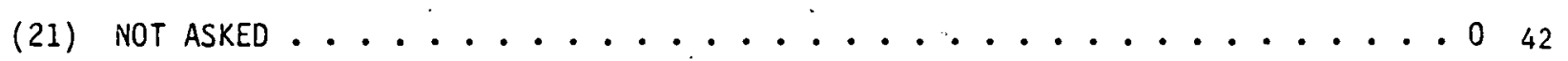

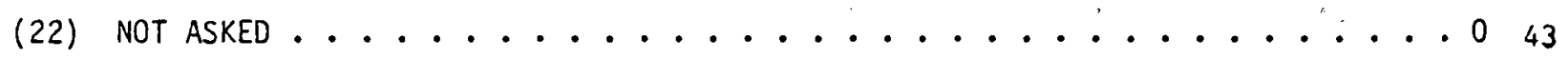

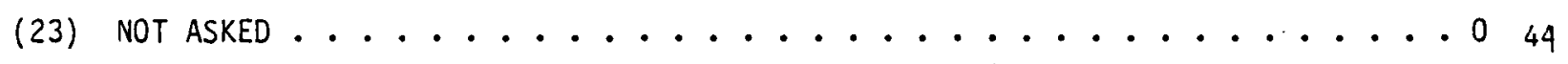

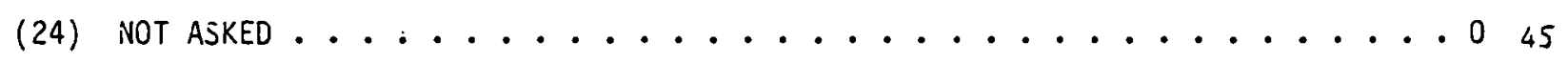


In conclusion, I would like to ask you some questions about yourself. Your answers will be kept completely confidential.

Dla. What is the highest level of education you have coinpleted? (DO NOT READ) 8th grade or less....... 01

Some high school ....... 02

High school graduate...... 03

Post high school vocational/

Technical........ 04

Attended college/University:

No degree. ....... 05

- Associate (2 year junior/

Comnunity college)....06

Bachelors. ...... 07

Masters. ......... 08

Ph.D/Doctorate...... 09

JD/LLD ....... 10

Other

11

Don't know .......... 98

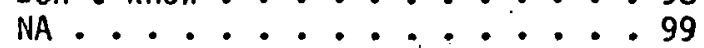

D1b. In what field is your most recent degree?

Dlc. In what year did you get that degree?

(RECURD) Verb

B10-1. In the next year do you expect to need additional passive solar heating and cooling information.....

(a) On your job?

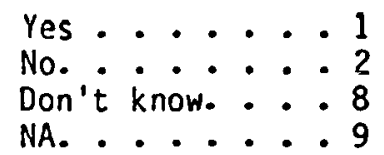

(b) Outside of your job?
Yes: ..... 1

No. ..... 2

Don't know. . 8

NA. ...... 9

02a. Please describe your present profession by completing the following statement: "Based on firy total education and experience, I now regard hiyself professionaliy as a (an) ." (AVOId USING J08 TITLE IF PUSSIBLE). 
Cd 4

D3. Do you belong to any professional, technical, or other organizations which have an interest in solar?

a. What organizations?

lst Mention

CL

2nd Mention

3rd ilention

4 th ilention

Thank you very much for your tirne.

Figure D-2. Questionnaire (concluded) 
eight distinct answers given. Since each respondent did not rate these items, it was impossible to determine which of these information needs was the most important. Afforded a second thought, respondents of ten gave items they had mentioned as "most important" in Question 5 a lower rating in Question 8 than they gave to items that they had not even mentioned in Question 5. As a result, the data from Question 5 could not provide a valid measurement of the most important information items which could be provided to the respondent. Therefore, this report refers to the responses to Question 5 as "infor mation which was important for the respondents to obtain."

Question 6. In this question, a list of different passive solar heating and cooling applications was read to the respondent, and the respondent was asked which application he was particularly interested in obtaining information for. After this was completed, respondents werc asked "Ale there any other areas of passive solar heating and cooling for which you are particularly interested in obtaining information?" Responses to this question fell into one of two areas: additional passive applications of interest or speoific types of information wanted. The former were discussed with other results from Question 6; the latter were included with the responses from Question 5.

Question 8. In this question a list of up to 25 specific information products or types of infor mation was read to the respondent. The respondent rated each item as "essential," "very useful," "somewhat useful," or "not at all useful" as it applied to himself. In contrast to Question 5, this question assessed each respondent's ratings for each of a set of items that the study designers thought might be important to the respondents. Question 8 did not allow respondents to add and rate items not already on the list. To reduce the possibility of introducing blas due to item order within Question 8, the interviewers rotated their starting point by randomly selecting which item would be read to the respondent first. Items in Question 8 a were rotated separately from those in Question 8 b.

Question 9. This question asked, "Is there any passive solar information which you need but are not able to get?" Unfortunately, this question just did not work. Answering Questions $8 \mathrm{a}$ and $8 \mathrm{~b}$ required the respondent to assign a rating to each of $23-25$ information items. By the time the respondents had completed Question 8 they were usually starting to get fatigued with the interview. As a result many did not answer Question 9 at all.

Question 11. In this question respondents were not asked if they had obtained solar information from the Solar Energy Research Institute (SERI). The principal reason was the probability of obtaining biased responses. All respondents had received a letter describing the Solar Energy Information Data Bank (SEIDB) and introducing SERI. It was felt that many respondents would attempt to encourage information flows from SERI by responding positively when asked whether they had used SERI as an information sourcewhether or not they actually received infor mation directly from SERI. Since explaining the nature of SERI and the SEIDB was necessary to promote a good response rate, no questions about SERI were included.

In Question 11, items 21-23 require some explanation: they are shown as "NOT ASKED" on the sample questionnaire (readers may note that data for items 21-23 does occur on the tables in Appendix F for some groups). These ite ms were left open for the inclusion of specific organizations which seemed most appropriate for each group. Table D-1 lists the organizations, the respondent groups and the question numbers for each item used for the groups covered in this report. 


\section{User Questionnaire}

Bl-6a. Users were asked about their present system, rather than areas of interest; the list differs somewhat from Question 6 of the standard questionnaire.

$\mathrm{Bl}-6 \mathrm{~b}$ and B2-13. Asked only of users.

B3-5 and B4-14. These questions differ from the standard Question 5 in that the user respondent is asked about information and information sources that would be sought out if the system were currently being considered for purchase or construction .

B5-8a and B5-8b. These items listed are the same as those on Questions $8 \mathrm{a}$ and $8 \mathrm{~b}$ in the standard questionnaire, except that users are asked the qualifying "if you were obtaining a new system."

B7-9. The standard Question 9 is altered by referring to "when your current system was being considered."

B10-1. The standard Question 1 is altered by asking about "additional" passive solar heating and cooling inf ormation. 
Table D-1. SELECTED ORGANIZATIONS ABOUT WHICH PASSIVE RESPONDENTS WBRE ASKED

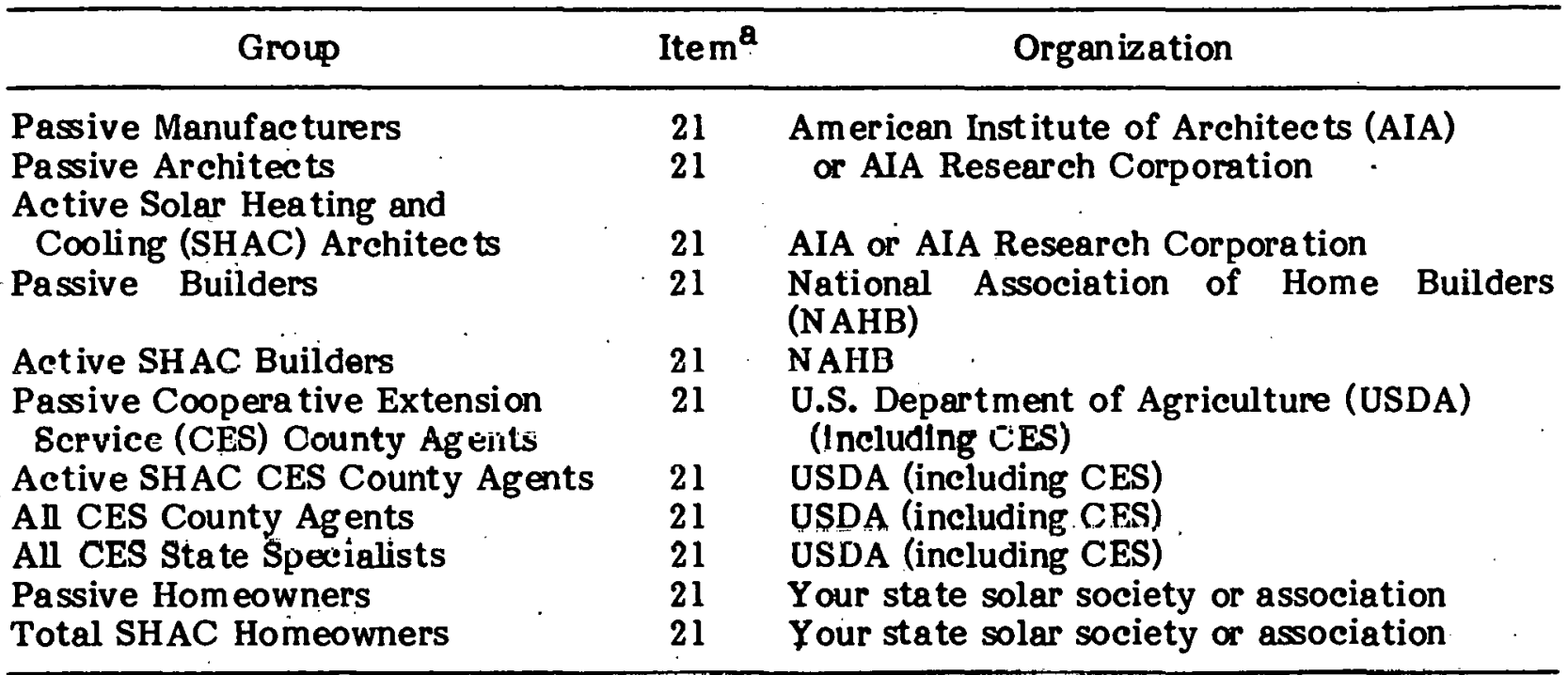

aThe number of the item in which the group was asked about the particular organization. For example, 21 is Item 21 of Question 11 . 
APPENDIX E

STATISTICAL TESTING 


\section{SERI}




\section{APPBNDIX E}

\section{STATISTICAL TESTING}

Despite the small sample sizes, selected statistical tests could be used. All of these tests used a $5 \%$ rejection region unless otherwise noted. Thus, if a test result indicated that a difference between two means was statistically significant $(P \quad 0.05)$, it meant that there was only a one-out-of-twenty chance that the two means were not different. Actual calculations were made with the Statistical Package for the Social Sciences (SPSS) software and other computer packages.

The tests conducted fell into three main types: tests of proportions between two groups, $\mathrm{t}$-Tests between two groups, and Paired t-Tests within a group. Each of these are discussed below.

For all except Question 8, tests of proportions were used. For example, the proportion of Passive Architects using computer terminals was compared to the proportion of Passive Builders using computer terminals. If the sample sizes were small, Exact Binomial Tests were used. When the sample sizes were larger (e.g., a comparison of Passive Researchers to All Researchers), Chi-Square Tests were used.

For analysis of the results from Question 8, t-Tests were used. In Question 8 each respondent was asked to describe the usefulness of up to 25 information products/ categories as either "essential," "very useful," "somewhat useful," or "not at all useful." The "average usefulness" rating that the group assigned an ite $m$ was then calculated by assigning the responses a "4" for "essential," a "3" for "very useful," a "2" for "somewhat useful," and a "1" for "not very useful," then calculating the average for the entire group. A t-Test was used to determine whether group A rated a specific information ite $m$ significantly higher (or lower) than it was rated by group B. Some groups, however, tended to give higher scores in general than did other groups. To compensate for this effect, these statistical tests compared the "relative rating" given by one group to the "relative rating" given by the other groups. The relative rating given by a group to a particular item was calculated as follows: take the average usefulness rating the group gave that item (for example, suppose "a bibliog raphy" received a 3.15 rating), then subtract the average overall rating this group gave to all items (suppose the average rating the group gave all items was 2.75); the difference was the relative rating (for this example $3.15-2.75=+0.40)$. The $t-T e s t$ then was used for the comparison of the relative rating group A gave to the item to the relative rating group $B$ gave the item.

For the tests of proportions (or the t-Tests involving Question 8), if group A was being compared to group B and group A was a subset of group B (e.g., a comparison of Passive Researchers to All Researchers), the totals for group A were subtracted from the totals for group B and the proportions (or the relative ratings) for group B were recalculated from the adjusted totals.

For Question 8 it sometimes occurred that the researcher wanted to compare the rating a group gave one item to the rating they gave another item. For example, did Passive Manuf acturer Representatives rate "lists of sources for infor mation" significantly higher (or lower) than they rated "lists of technical experts?" This test was conducted using a Paired $\mathrm{t}$-Test. 


\section{SEPI*}




\section{APPENDIX $\mathbf{F}$}

PASSIVE SOLAR HRATING AND COOLNG DATA TABLES 


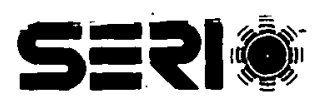

$\therefore$ 


\section{APPENDIX F}

\section{PASSIVE SOLAR HEATING AND COOLING DATA TABLES}

In the following passive data tables, each table entry shows counts and percentages displayed in the for mat (\%\#), where $\%$ is the column percentage for each group, and \# is the number of respondents in each group who gave the response shown in the row title. Each column shows the results for an individual group or for a combination of groups.

Table F-l lists the groups and combinations for which data are shown in the data tables. Table F-2 shows which groups are included in each of the combination groups listed in Table F-1. Table F-3 lists the data tables and Fig. F-1 contains the data tables the mselves. 
Table F-1. GROUPS AND COMBN ATION GROUPS WITH DATA INCLUDED IN APPENDIX F.

\begin{tabular}{|c|c|c|}
\hline Group & Report & Section \\
\hline \multicolumn{3}{|l|}{ DOE-Funded Solar Heating and Cooling (SHAC) } \\
\hline Researchers (SHAC DOE-FUND RES) & SHAC & 3.0 \\
\hline Non-DOE-Funded SHAC Researchers & & \\
\hline (SHAC NDOE-FUND RES) & SHAC & 3.0 \\
\hline Total SHAC Researchers (TOTAL SHAC RES) & SHAC & 3.0 \\
\hline Federally Funded Passive Researchers (PASS RES) & Passive & 3.0 \\
\hline All Researchers (ALL RES) & SHAC, Passive & $3.0,3.0$ \\
\hline \multicolumn{3}{|l|}{ SHAC Heating and Cooling System Manufacturer } \\
\hline Representatives (SHAC SPACE HEAT MANUF) & SHAC & 4.0 \\
\hline \multicolumn{2}{|l|}{$\begin{array}{l}\text { SHAC Water Heating System Manufao turor Representälives } \\
\text { (SHAC WATER HEAT MANUF) }\end{array}$} & 4.0 \\
\hline \multicolumn{3}{|l|}{ SHAC Nonconcentrating Collector Manufacturer } \\
\hline Representatives (SHAC N CONC COLL MANUF) & SHAC & 4.0 \\
\hline \multicolumn{3}{|l|}{ Total SHAC Collector Manufacturer Representatives } \\
\hline \\
\hline (SHAC OTHER COMP MANUF) & SHAC & 4.0 \\
\hline \multicolumn{3}{|l|}{ Total SHAC Manufacturer Representatives } \\
\hline \multicolumn{3}{|l|}{ Passive Equipm ent Manuf acturer Representatives } \\
\hline (PASS EQUIP MANUF) & Passive & 4.0 \\
\hline All Manufacturer Representatives (ALL MANUF) & SHAC, Passive & $4.0,4.0$ \\
\hline SHAC Architec ts (SHAC ARCH) & SHAC & 7.0 \\
\hline Passive Architects (PASS ARCH) & Passive & 5.0 \\
\hline SHAC Builders (SHAC BULD) & SHAC & 8.0 \\
\hline Passive Builders (PASS BUILD) & Passive & 6.0 \\
\hline SHAC Educators (SHAC EDUC) & SHAC & 13.0 \\
\hline Passive Educators (PASS EDUC) & Passive & 7.0 \\
\hline All Educators (ALL EDUC) & SHAC, Passive & $13.0,7.0$ \\
\hline \multicolumn{3}{|l|}{ SHAC Cooperative Extension Service (CES) County } \\
\hline Agents (SHAC CES CO AGENT) & SHAC & 14.0 \\
\hline Passive CES County Agents (PASS CES CO AGENT) & Passive & 8.0 \\
\hline All CES County Agents (ALL CES CO AGENT) & SHAC, Passive & $14.0,8.0$ \\
\hline All CES State Specialists (ALL CES STATE SPEC) & SHAC, Passive & $14.0,8.0$ \\
\hline Passive Homeowners (PASS HOMEOWNER) & SHAC, Passive & $15.0,9.0$ \\
\hline \multicolumn{3}{|l|}{ SHAC Space Heating Hom eowners (SHAC SPACE } \\
\hline HOMEOWNER) & SHAC & 15.0 \\
\hline \multicolumn{3}{|l|}{ SHAC Water Heating Homeowners (SHAC WATER } \\
\hline HOMEOWNER) & SHAC & 15.0 \\
\hline Total SHAC Hom eowners (TOTAL SHAC HOMEOWNER) & Passive & 9.0 \\
\hline \multicolumn{3}{|l|}{ SHAC Building Owners/Managers (SHAC BLDG } \\
\hline OWNER/MNGR) & SHAC & 15.0 \\
\hline \multicolumn{3}{|l|}{ Total SHAC Owners/Managers (TOTAL SHAC } \\
\hline OWNER/MNGR) & SHAC & 15.0 \\
\hline
\end{tabular}


Table F-2. COMBN ATION GROUPS

Total Solar Heating and Cooling (SHAC) Researchers (TOTAL SHAC RES)

DOE-Funded SHAC Researchers

Non-DOE-Funded SHAC Researchers

All Researchers (ALL RES)

Photovoltaics DOE-Funded Researchers

Photovoltaics Non-DOE-Funded Researchers

Photovoltaics Researcher Manufacturers

Biomass Federally Funded Researchers in Production and Collection

Biomass Federally Funded Researchers in Conversion

Biomass Nonfederally Funded Researchers in Production and Collection

Biomass Nonfederally Funded Researchers in Conversion

Wind DOE-Funded Resear chers

Wind Non-DOE-Funded Researchers

Solar Thermal Electric Power DOE-Funded Researchers

Solar Ther mal Electric Power Non-DOE-Funded Researchers

Ocean Energy DOE-Funded Researchers

Ocean Energy Non-DOE-Funded Researchers

Solar Energy Storage DOE-Funded Researchers

Solar Energy Storage Non-DOE-Funded Researchers

Active Solar Heating and Cooling (SHAC) DOE-Funded Researchers

SHAC Non-DOE-Funded Researchers

Passive Federally Funded Researchers

Industrial Process Heat (IPH) Researchers

Agricultural Process Heat (APH) Researchers

Total SHAC Collector Manufäcturer Representatives (TOTAL SHAC COLL MANUF)

SHAC Heating and Cooling System Manufacturer Representatives

SHAC Water Heating System Manufacturer Representatives

SH AC Nonconcentrating Collec tor Manuf acturer Representatives

Total SHAC Manufacturer Representatives (TOTAL SHAC MANUF)

SHAC Heating and Cooling System Manufacturer Representatives

SHAC Water Heating System Manufacturer Ropresentatives

SH AC Nonconcentrating Collector Manufacturer Representatives

SHAC Other Component Manufacturer Representatives

All Manufacturer Representatives (ALL MANUF)

Photovoltaics Manufacturer Representatives

Biomass Production and Collection Equipment Manufacturer Representatives

Biomass Conversion Equipment Manuf acturer Representatives

Wind Manufacturer Representatives

Solar Thermal and IPH Concentrating Collector Manufacturer Representatives

SHAC Heating/Cooling Syste ms Manufacturer Representatives

SH AC Water Heating Systems Manufacturer Representatives

SHAC Nonconcentrating Collector Manufacturer Representatives

SH AC Other Component Manuf acturer Representatives

Passive Manufacturer Representatives 
Table F-2. COMBINATION GROOPS (concluded)

All Educators (ALL EDUC)

Photovoltaics Educa tors

Biomass Educators

Wind Educa tors

Solar Ther mal Electric Power Educators

SH AC Educa tors

Passive Solar Heating and Cooling Educators

IPH Educa tors

All Coopera tive Extension Service (CES) County Agents ( $A L L$ CES CO AGENT)

Passive Solar Heating and Cooling County Agents

SHAC County Agents

Biomass Energy ronunty Agonto

Agricultural Process Heat County Agents

Wind County Ag ents

All CES State Specialists (ALL CES STATE SPEC)

Sta te CES Agricultu ral Specialists

State CES Infor mation Specialists

Total SHAC Hom eowners (TOTAL SHAC HOMEOWNER)

SHAC Space Heating Systems Homeowners

SHAC Water Heating Systems Hom eowners

Total SHAC Owners/Managers (TOTAL SHAC OWNER/MNGR)

SHAC Space Heating Homeowners

' SHAC Water Heating Homeowners

SHAC Building Owners/Managers 
Table F-3. LIST OF PASSIVE SOLAR HEATING AND COOLING DATA TABLES

Question

Number ${ }^{\mathrm{a}}$

Table Title

Page

Nonuser Questionnaire

Question 1 Need for Information On the Job and Outside the Job $\ldots \ldots \ldots$

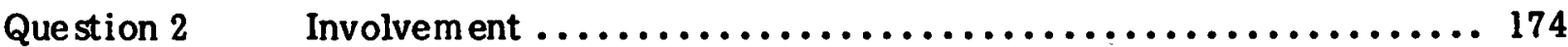

Question $3 \quad$ Infor medness .............................. 176

Question $6 \quad$ Interest in Specified Passive Areas . .................. 178

Question 8A Usefulness of Specified Infor mation Items $\ldots \ldots \ldots \ldots \ldots \ldots \ldots \ldots 182$

Question 8B Usefulness of Specified Inf ormation Items . . . . . . . . . . . 194

Question $10 \quad$ Use of Special Acquisition Methods ................... 208

Question 11 Use of Selected Solar Information Sources .............. 210

Question D2 Years in Current Profession ........................ 224

Question D3 Membership in Solar-Interested Organizations ............. 226

User Questionnaire

Question $1 \quad$ Need for Infor mation On the Job and Outside the Job ........ 228

Question Bl-6a Specified Types of Passive System Used ................ 229

Question 8A Usefulness of Specified Information Items $\ldots \ldots \ldots \ldots \ldots \ldots \ldots . \ldots 232$

Question 8B Usefulness of Specified Inf ormation Items .............. 238

Question 11 Use of Selected Solar Infor mation Sources ................ 245

Question D3 Membership in Solar-Interested Organizations . . . . . . . . . . . 252

Question Bl-6B Inclusion of Solar Energy $\ldots \ldots \ldots \ldots \ldots \ldots \ldots \ldots \ldots \ldots \ldots \ldots \ldots$

Question B2-13 Number of Years ............................ 254

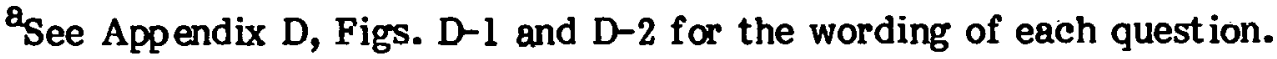




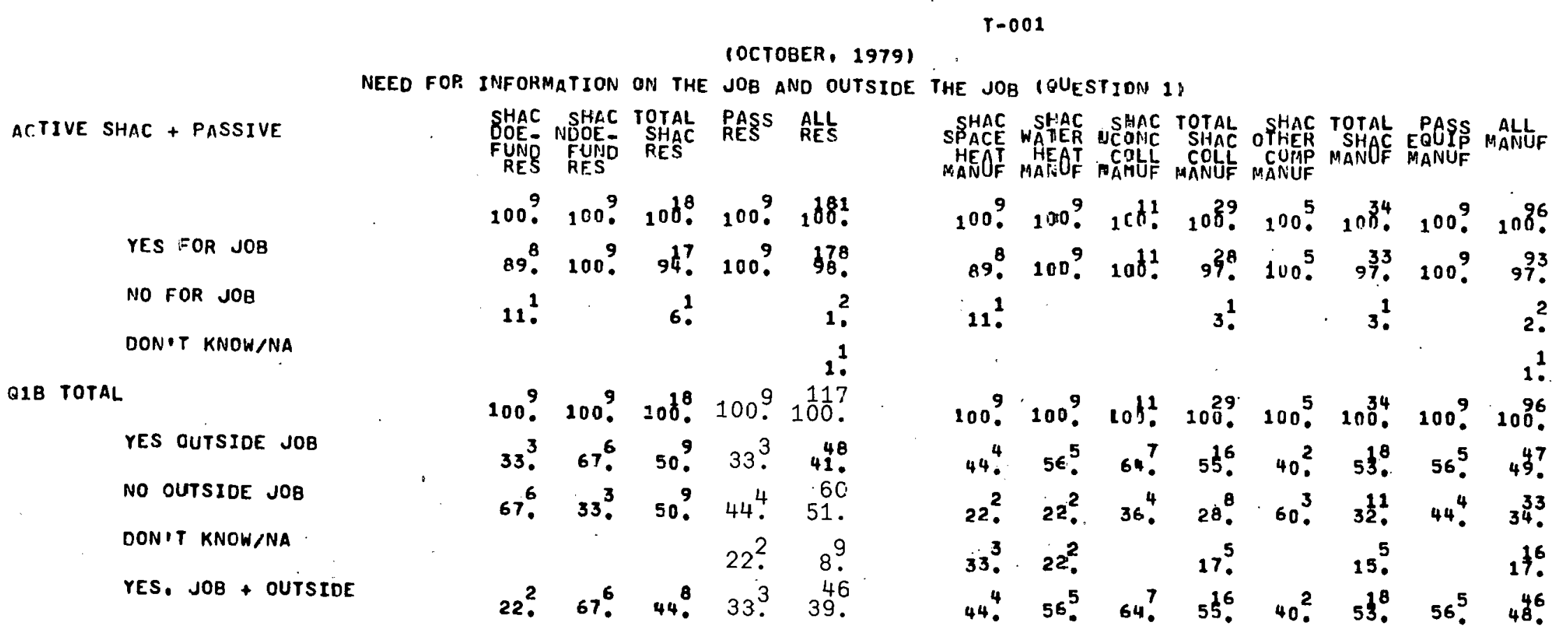

Figure F-1. Passive Solar Heating and Cooling Dáta Tables 


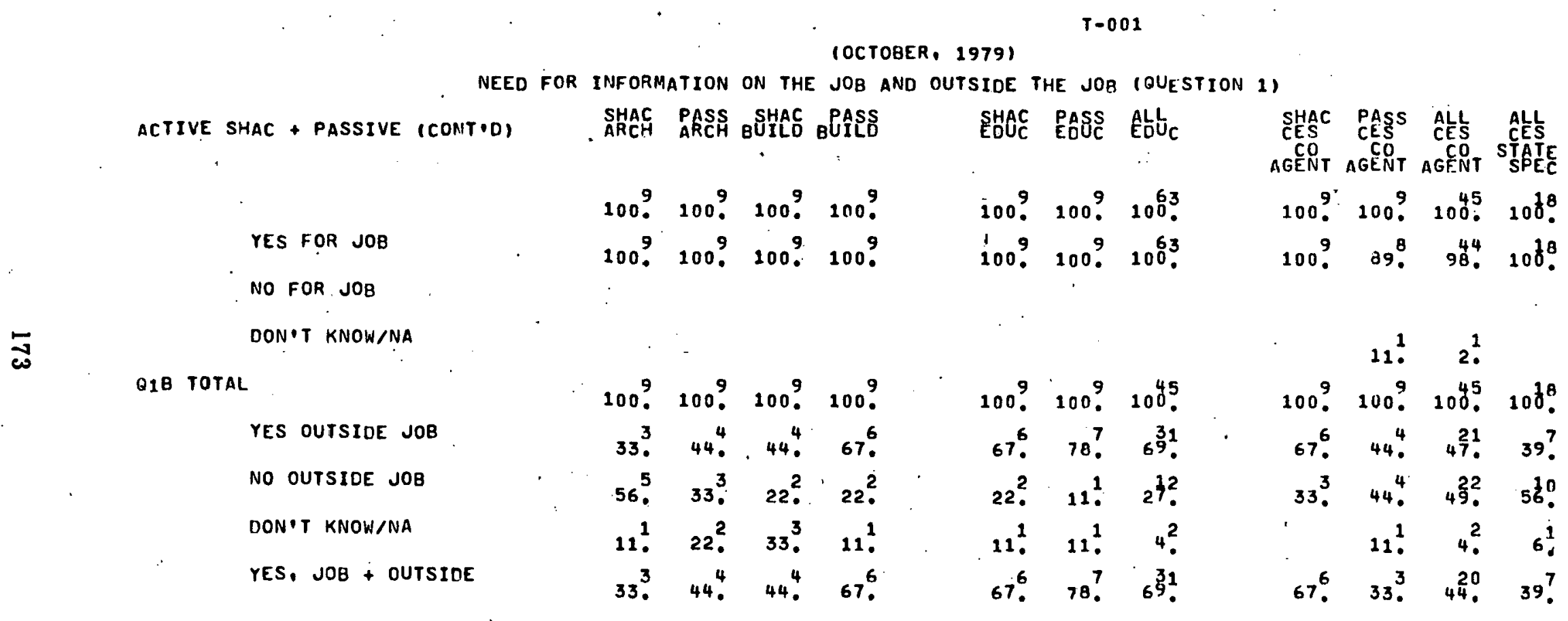

Figure F-1. Passive Solar Heating and Cooling Data Tables (continued) 


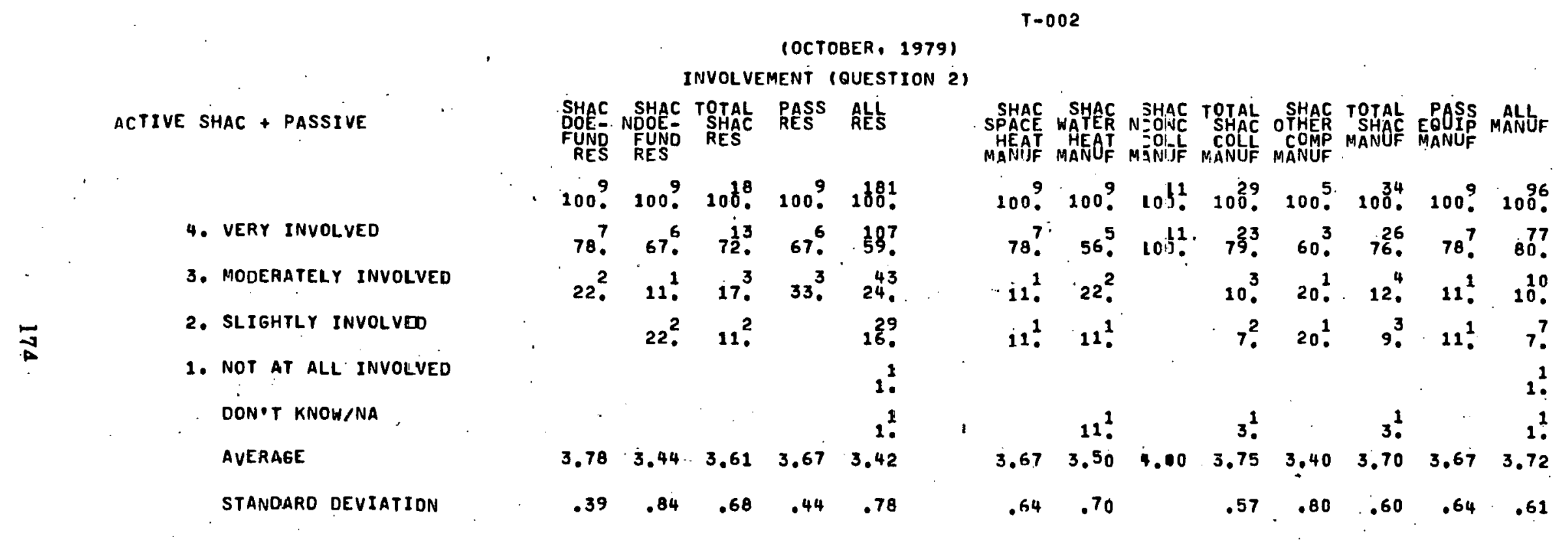

Figure F-1. Passive Solar Heating and Cooling Data Tables (continued) 


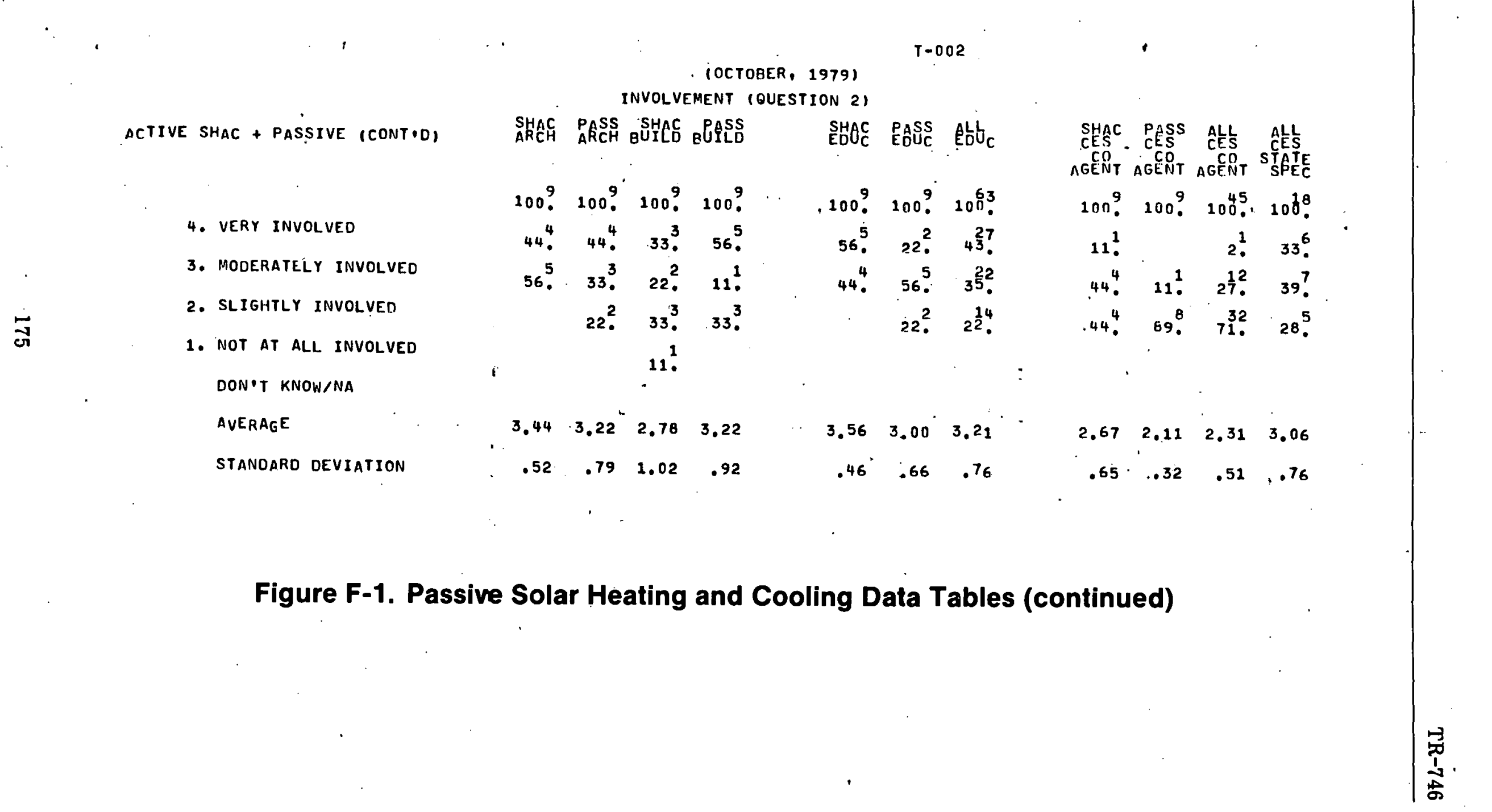




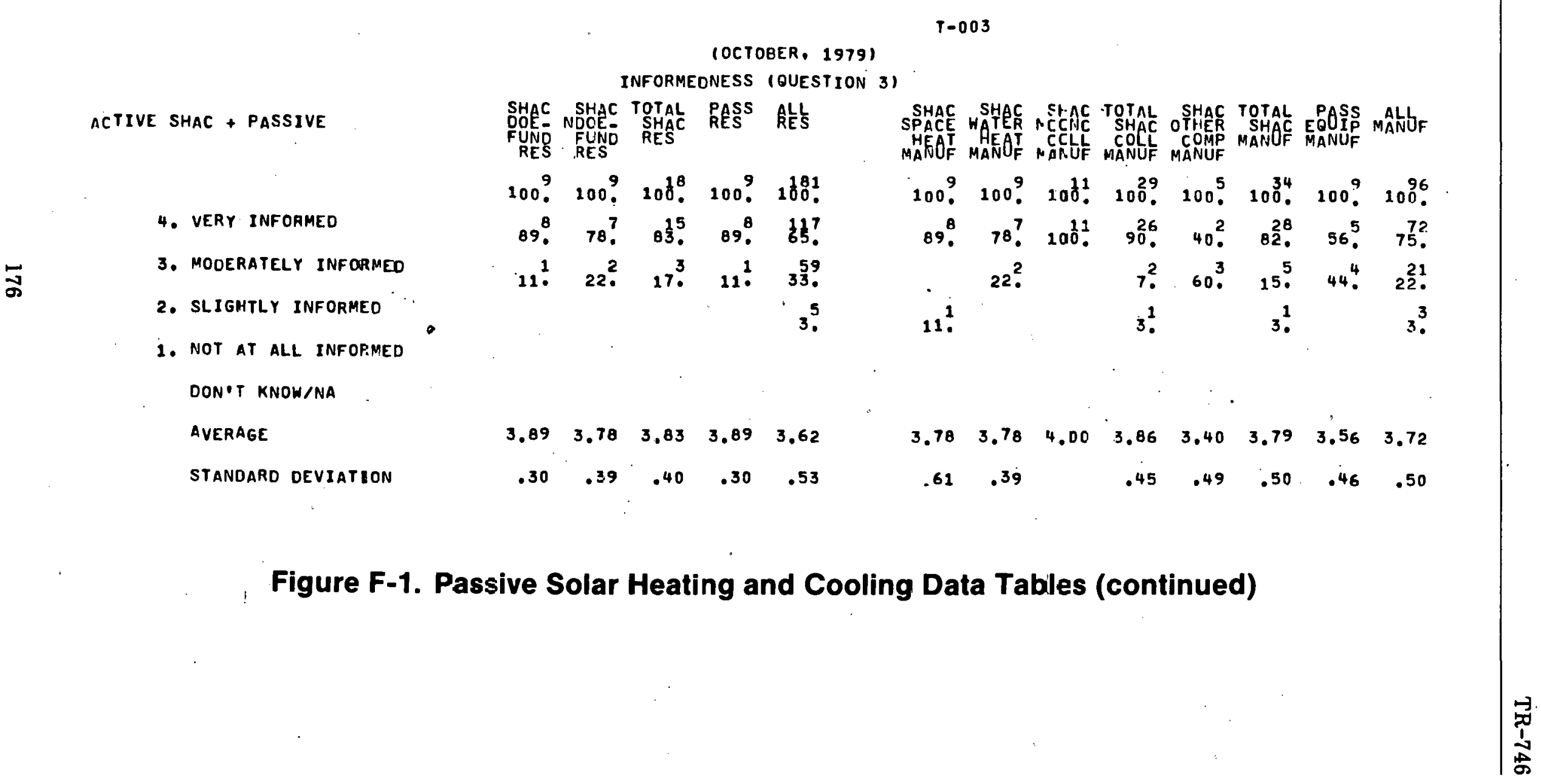




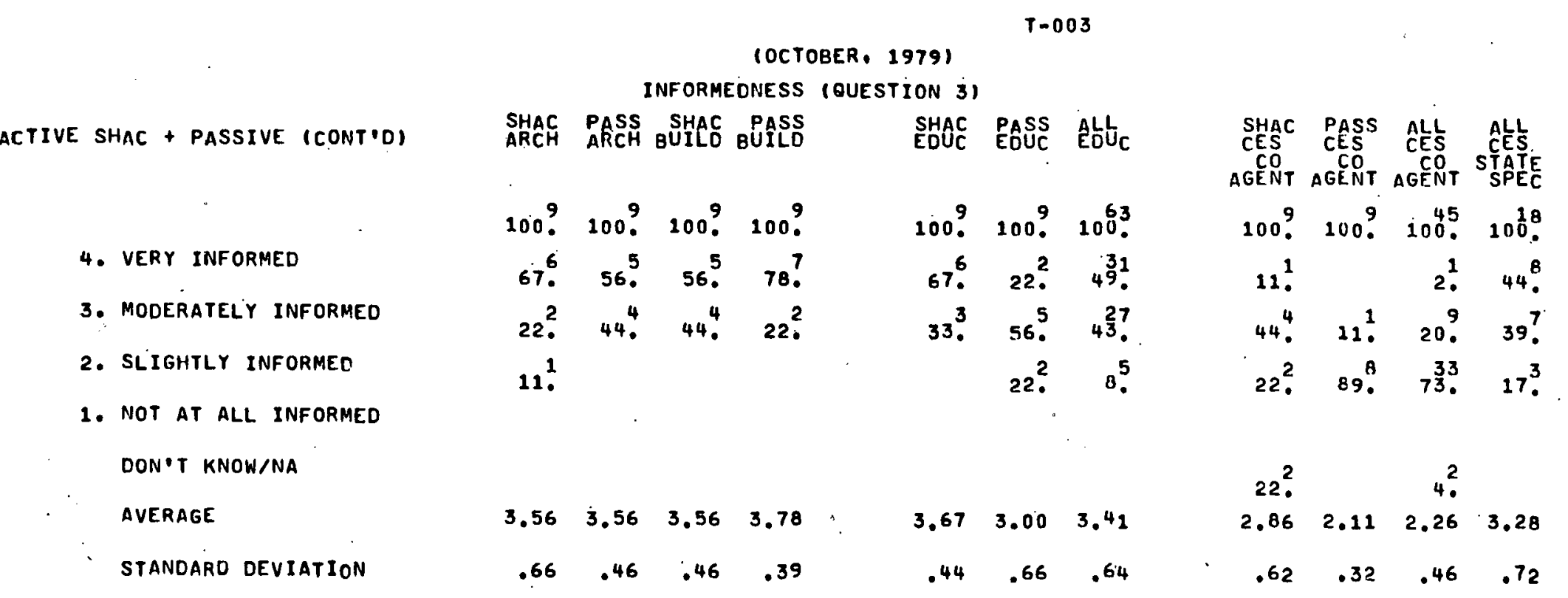

Figure F-1. Passive Solar Heating and Cooling Data Tables (continued) 


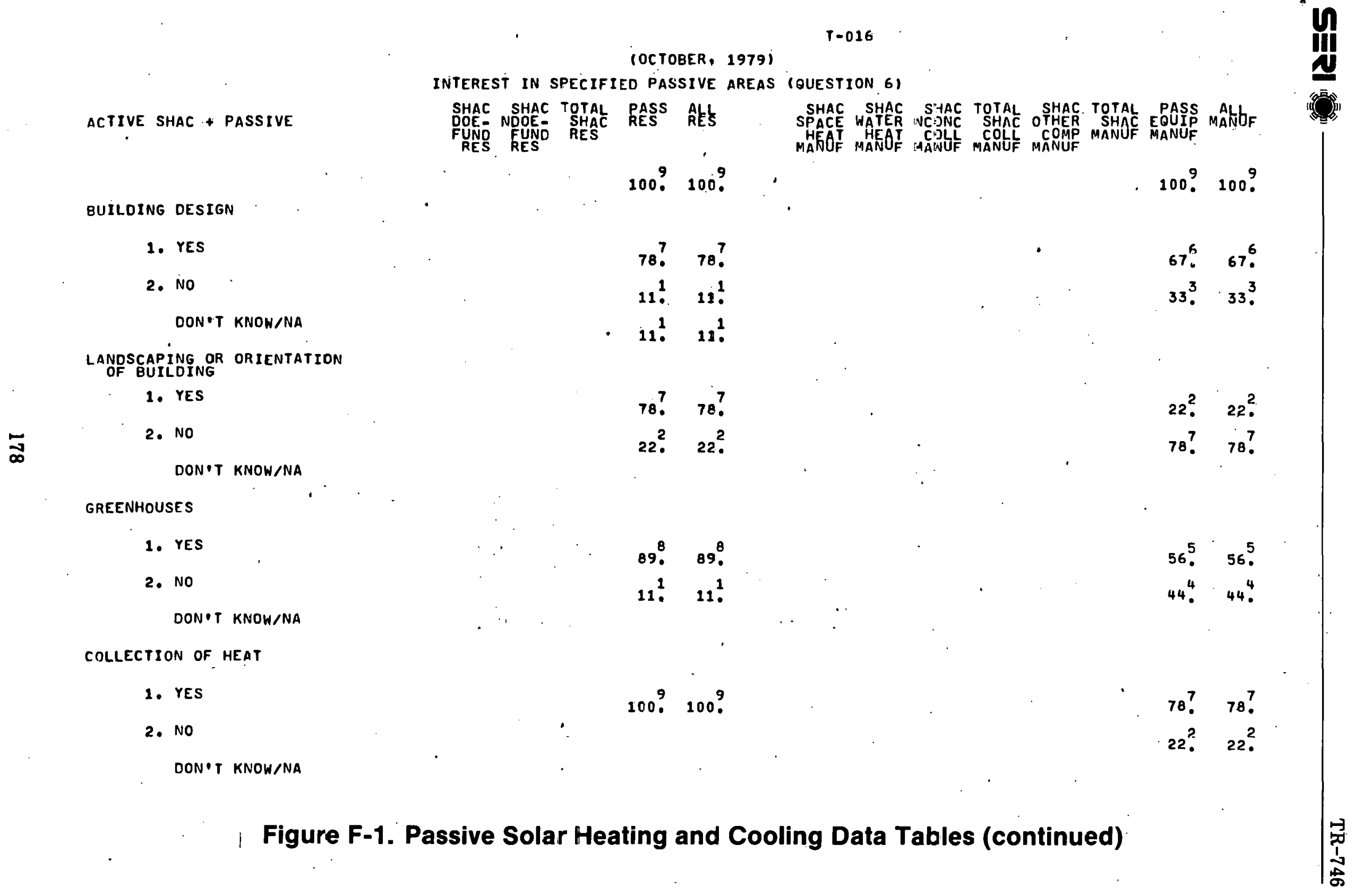


T-016

(OCTOBER, 1979 )

INTEREST IN SPECIFIEO PASSIVE AREAS (OUESTION 6)

ACTIVE SHAC + PASSIVE (CONTID)

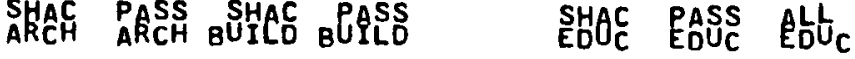

BUILDING DESIGN

$1009 \quad 1009$ 1 $200^{9} 1009$

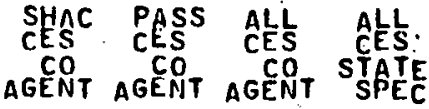
100 . 100 .

$100^{9}$.

100 .

1009.1009

$89^{8} . \quad 89.8$

$111^{1} \quad 11^{1}$

DON T KNOH/NA

LANDSCAPING OR ORIENTATION

1. YES

2. NO

DON'T KNOW/NA

$78^{7}$

$56^{5}$

$22^{2} .44^{4}$.

67. $67^{6}$.

$33^{3} .33^{3}$.

$78^{7} \quad 78^{7}$

$22^{2} . \quad 22^{2}$

GREENHOUSES

1. YES

2. NO

DON'T KNOW/NA

$78^{7} .100^{9}$

89. $89^{8}$

$78^{7} \cdot 78^{7}$

$22^{2}$

$11^{1} 11^{1}$

$22^{2} .22^{2}$

COLLECTION OF HEAT
1. YES
2. NO

DON'T KNOW/NA

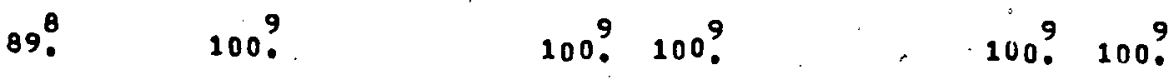

Figure F-1. Passive Solar Heating and Cooling Data Tables (continued) 


\section{$T-017$}

(OCTOBER. 1979)

INTEREST IN SPECIFJED PASSIVE AREAS - CONTINUED (OUEST:OH 6)

ACTIVE SHAC + PASSIVE

STORAGE OF HEAT

1. YES

2. NO

DON T KNOW/NA

SPACE COOLING

1. YES

嗐

2. NO

DON T KNOW/NA

WATER . HEATING
1. YES
2. NO

DON T KNOW/NA

HYBRID SYSTEMS
1. YES

2. NO

DON T KNOW/NA SHAC SHAC TOTAL PASS ALL
DOE- NDOE- SHAC RES RES
FUND FUNC RES

$100 ?$ ? $100 ?$

$100 ? 100 ?$ SHAC SHAC SHAC TOTAL SHAC TOTAL PASS MALL MANOF MANOF MANUF WANUF MANUF

1009.1009

$56^{5} .56^{5}$

44. 44.

$67^{6} \cdot 67^{6}$

$33^{3} .33^{3}$

44. 44.4

$67^{6} .67^{6}$.

33. $33^{3}$

$67^{6} \cdot 67^{6}$

$33^{3} .33^{3}$

$78^{7} \quad 78^{7}$

11. $11^{1}$

11: $11^{1}$. 
(OCTOBER, 1979)

INTEREST IN SPECIFIED PASSIVE AREAS - CONTINUED (OUESTION 6)

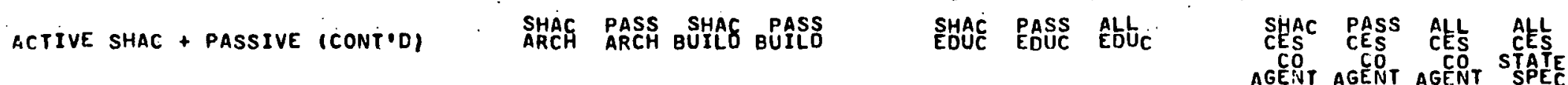

STORAGE OF HEAT
1. YES
2. NO
DON.T KNOW/NA

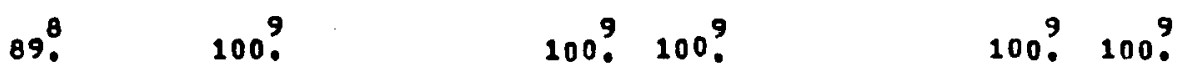
11 .

$1000^{9} \quad 1000^{9} \quad \cdots .100$ ? 100 ?

100 ? 100 ?

SPACE COOLING

$\stackrel{\infty}{\infty}$
1. YES

2. NO

DON T KNOW/NA

$\begin{array}{rrrr}67^{6} & 78^{7} & 78^{7} & 78^{7} \\ 33^{3} & 22^{2} & 22^{2} & 22^{2}\end{array}$

$100 ? 100 ?$

WATER HEATING
1. YES

2. NO

DON'T KNOW/NA

\begin{tabular}{|c|c|c|}
\hline $89^{8}$. & $56^{5}$ & $89^{\circ}$ \\
\hline 1. & $44^{4}$ & i1. \\
\hline
\end{tabular}

$100 \% 100 ?$

HYBRIO SYSTEMS
1. YES
2. NO

$\begin{array}{rr}78^{7} & 78 ? \\ 22^{2} & 22^{2}\end{array}$
$100^{9} 100^{9}$
1009.1009
DON'T KNOW/NA

Figure F-1. Passive Solar Heating and Cooling Data Tables (continued) 


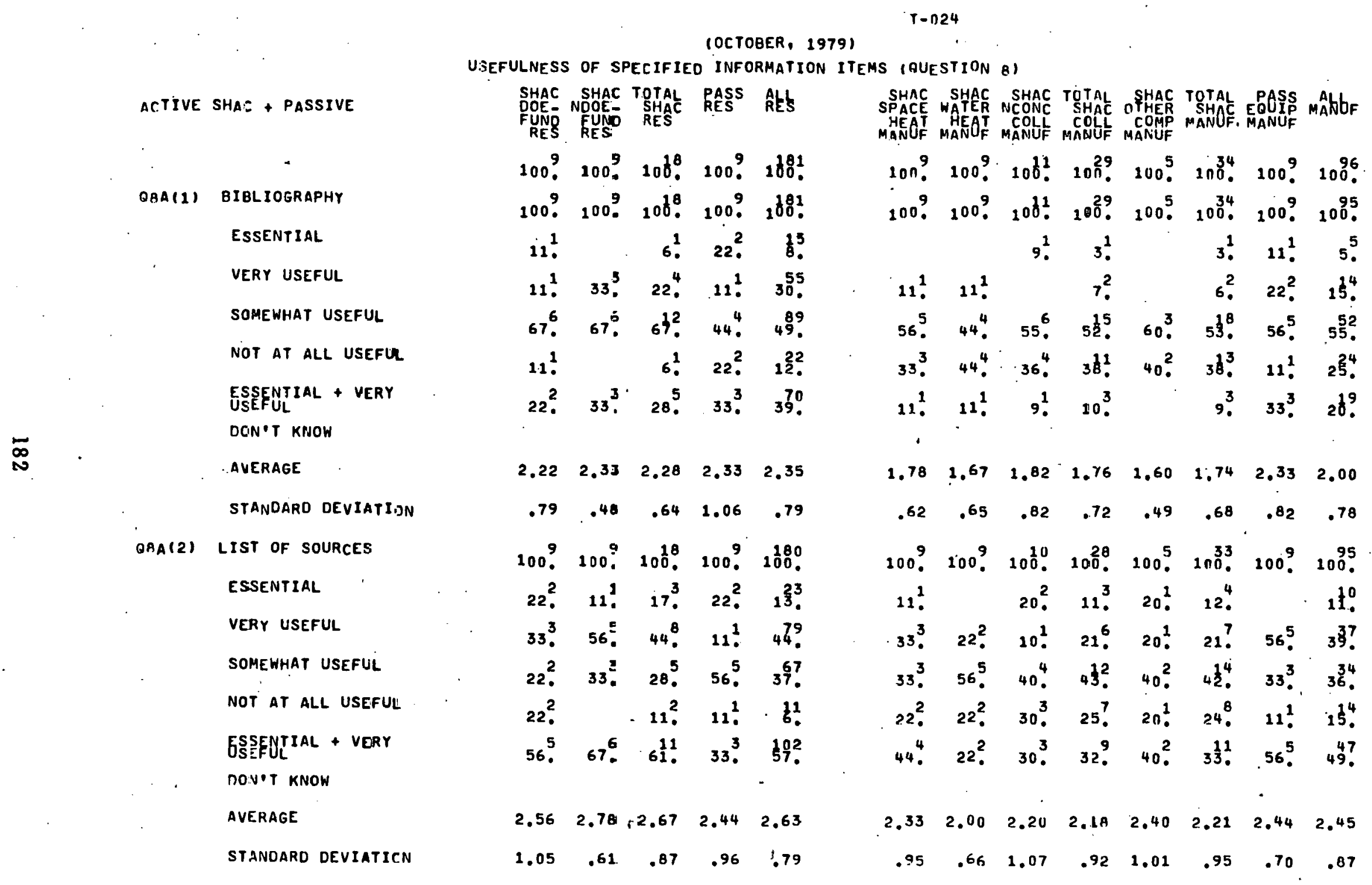

SCALE: ESSENTIAL $=4$, VERY USEFUL $=3$, SOMEWHAT USEFUL $=2$, NOT $A T$ ALL USEFUL $=1$

Figure F-1. Passive Solar Heating and Cooling Data Tables (continued) 


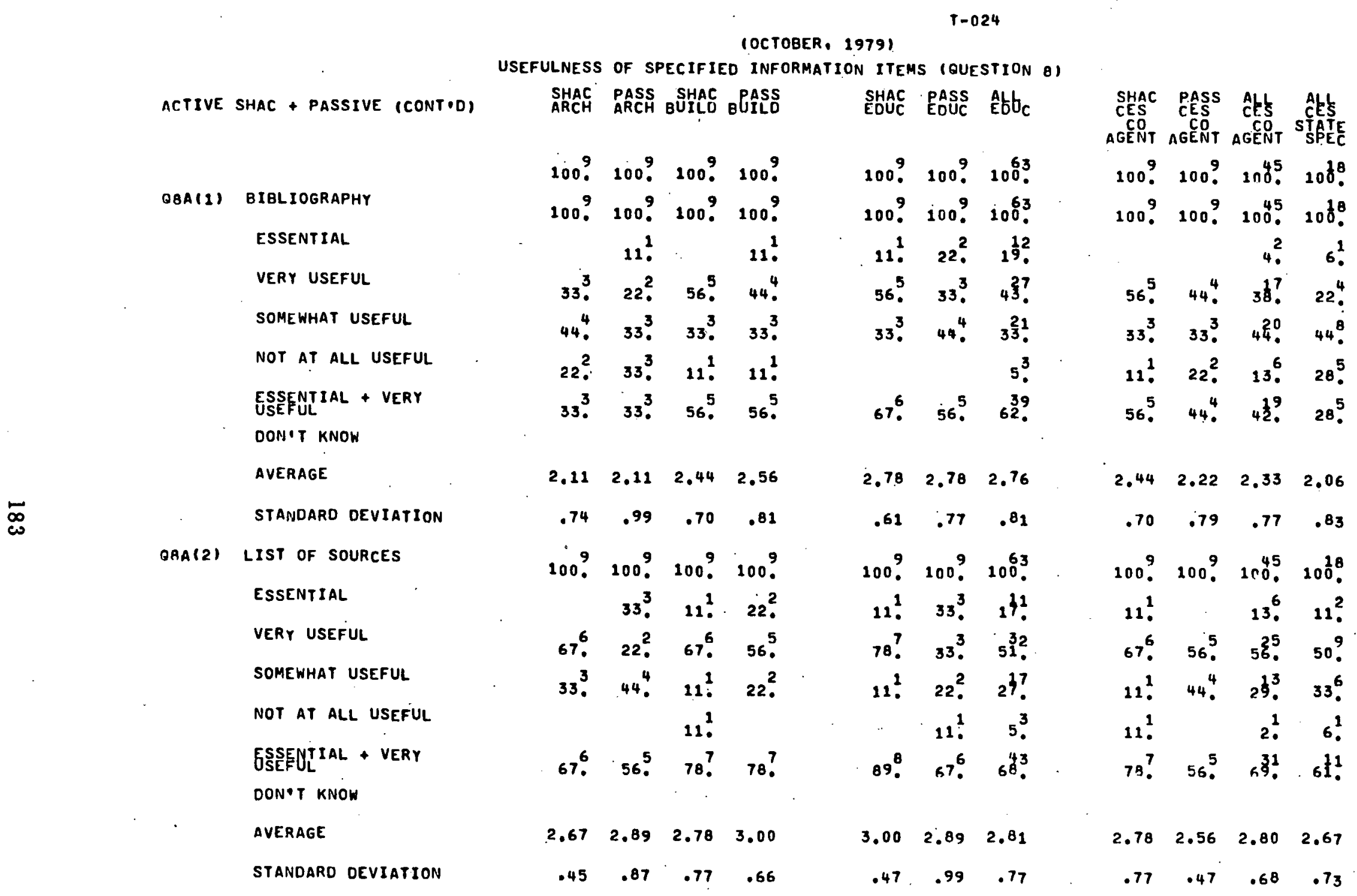

SCALE: ESSENTIAL $=4$, VERY USEFUL $=3$, SOMEWHAT USEFUL $=2$, NOT AT ALL USEFUL $=1$

Figure F-1. Passive Solar Heating and Cooling Data Tables (continued) 
(OCTOBER, 1979 )

USEFULNESS OF SPECIFIED INFORMATION ITEMS - CONTINUED (QUESTION B)

ACTIVE SHAC + PASSIVE

OQA PROGRA CALENDAR-CONFERENCES/ ESSENTIAL

VERY USEFUL

SOMEWHAT USEFIJL

NOT AT ALL USEFL

ESSEENTIAL + VERY DCN T KNOW

AVERAGE SHAC SHAC TOTAL PASS ALL FUND FUNS

100 . 100 ? 10 t. $^{8} 100$ ? 1680 . 100 . 100 . $100^{18}$. 100 . 100 . $33^{3} 22^{2} \cdot 28.211^{1} \quad 10^{19}$. $11^{1} \quad 44^{4} .28 .533^{3} \quad 38^{69}$. 44. $33^{3} . \quad 39$. $33^{3} . \quad 39^{7}$. 11. $\quad 62022^{2} .22$ 44. $67^{6} .56^{10}, \quad 44^{4} .49^{80}$.

$2.67 \cdot 2.89 \quad 2.78 \quad 2.33 \quad 2.47$

$\begin{array}{lllll}1.04 & .73 & .90 & .95 & .83\end{array}$

100 . 1009. 100 . 100 , 100 ? $22^{2} .111^{1} \quad 17^{3} .111^{1}$. b. $^{4}$ $222^{2} \quad 67^{6} .44^{8}$. $44^{4}$. $35^{62}$. $22^{2} \cdot \quad 11^{1} \cdot 17^{3} \cdot 222^{2} \quad 44^{79}$ 33. $11^{1} \cdot 22^{4} .222^{2} .14^{25}$ $44^{4} .78^{7} \quad 61^{11} \quad 56 . \quad 42^{76}$.

$\begin{array}{lllll}2.33 & 2.78 & 2.56 & 2.44 & 2.36\end{array}$

$\begin{array}{lllll}1.16 & .77 & 1.00 & .96 & .82\end{array}$
SHAC SHAC SHAC TOTAL SHAC TOTAL PASS ALL
SOACE WATER NCONC SHAC OTHER SHAC EOIP MANUF MAEAT MEEAT CCLE COE COMP MANOF MANU

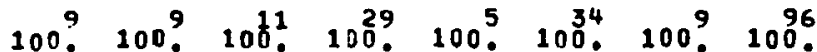
100 . 100 ? $100^{10} \cdot 100^{28}, 100^{5}, 1033.1009 .1005$

$\quad 10^{1} \quad 4^{1} \cdot 13^{1} \quad 3^{10}$.

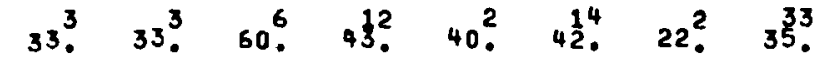

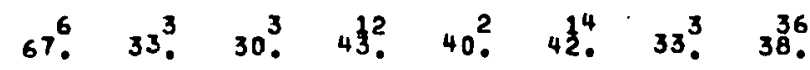

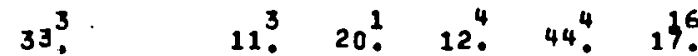
33. $33^{3} .400^{7} \quad 46^{3} .40^{2}$. $45^{5} .422^{2} \quad 45^{3}$.

$\begin{array}{llllllll}2.33 & 2.00 & 2.00 & 2.39 & 2.20 & 2.36 & 1.78 & 2.39\end{array}$ $\begin{array}{llllllll}.48^{\circ} & .81 & .60 & .73 & .74 & .74 & .78 & .88\end{array}$ $100^{9}, 100^{9}, 100^{10}, 100^{28}, 1000^{5} 100^{33}, 1009.100^{9}$. $11.0 \quad 4^{1} \quad 3^{1} .11^{1} 5^{5}$.

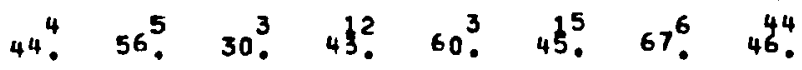

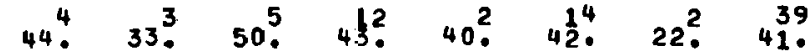
$11^{2}-20^{2}, \quad 11^{3}, \quad 93$.

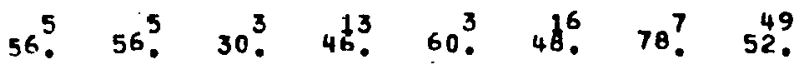
$\begin{array}{llllllll}2.67 & 2.44 & 2.10 & 2.39 & 2.60 & 2.42 & 2.89 & 2.49\end{array}$ $\begin{array}{llllllll}.65 & .70 & .70 & .73 & .49 & .71 & .56 & .72\end{array}$

SCALE: ESSEMTIAL $=4$, VLRY USEFUL $=3$, SOMEWHAT USEFUL $=2$, NOT AT ALL USEFUL $=1$

Figure F-1. Passive Solar Heating and Cooling Data Tables (continued) 


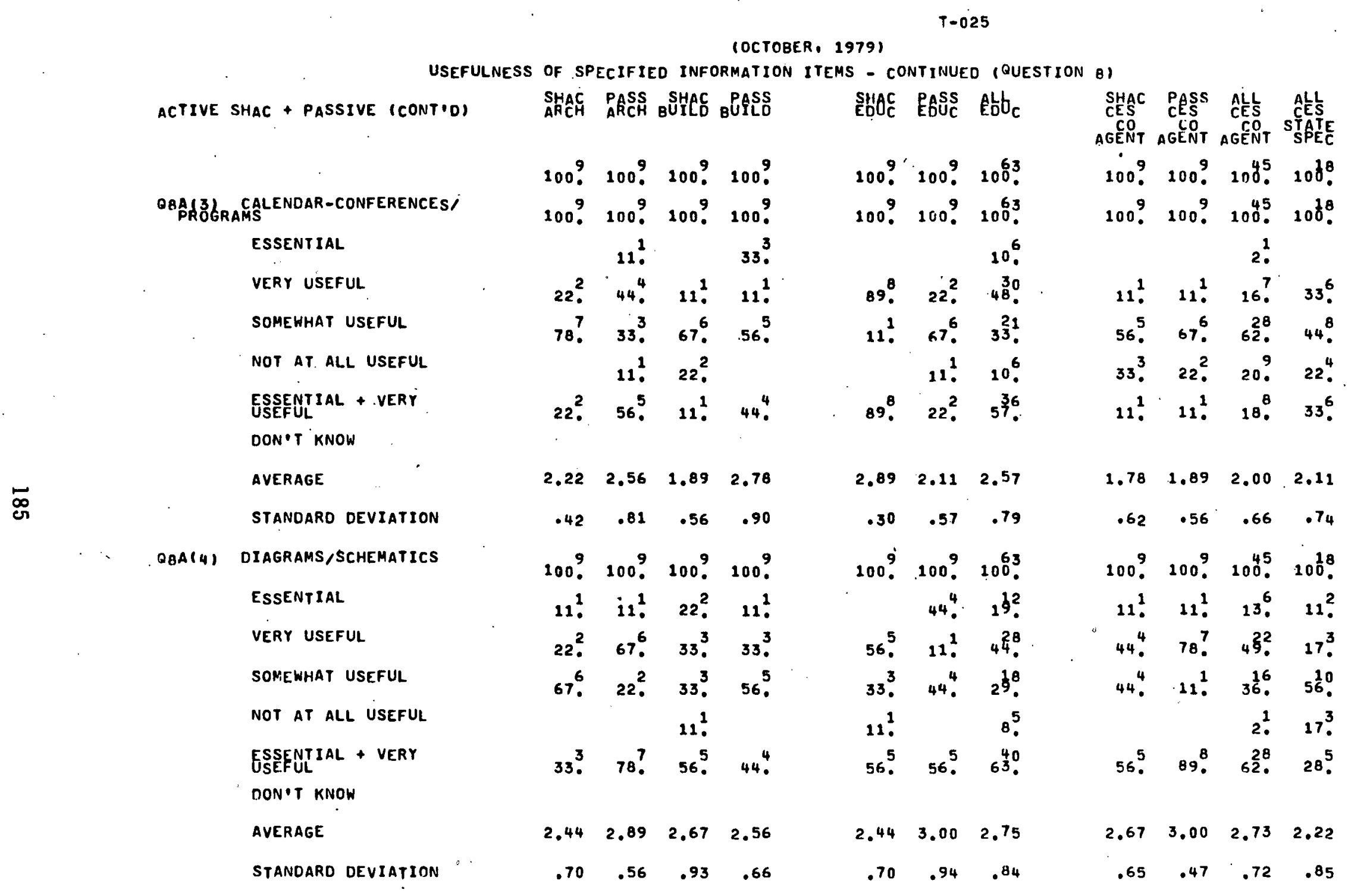

SCALE: ESSENTIAL $=4$, VERY USEFUL $=3$, SOMEWHAT USEFUL $=2$, NOT AT ALL USEFUL $=1$

Figure F-1. Passive Solar Heating and Cooling Data Tables (continued) 


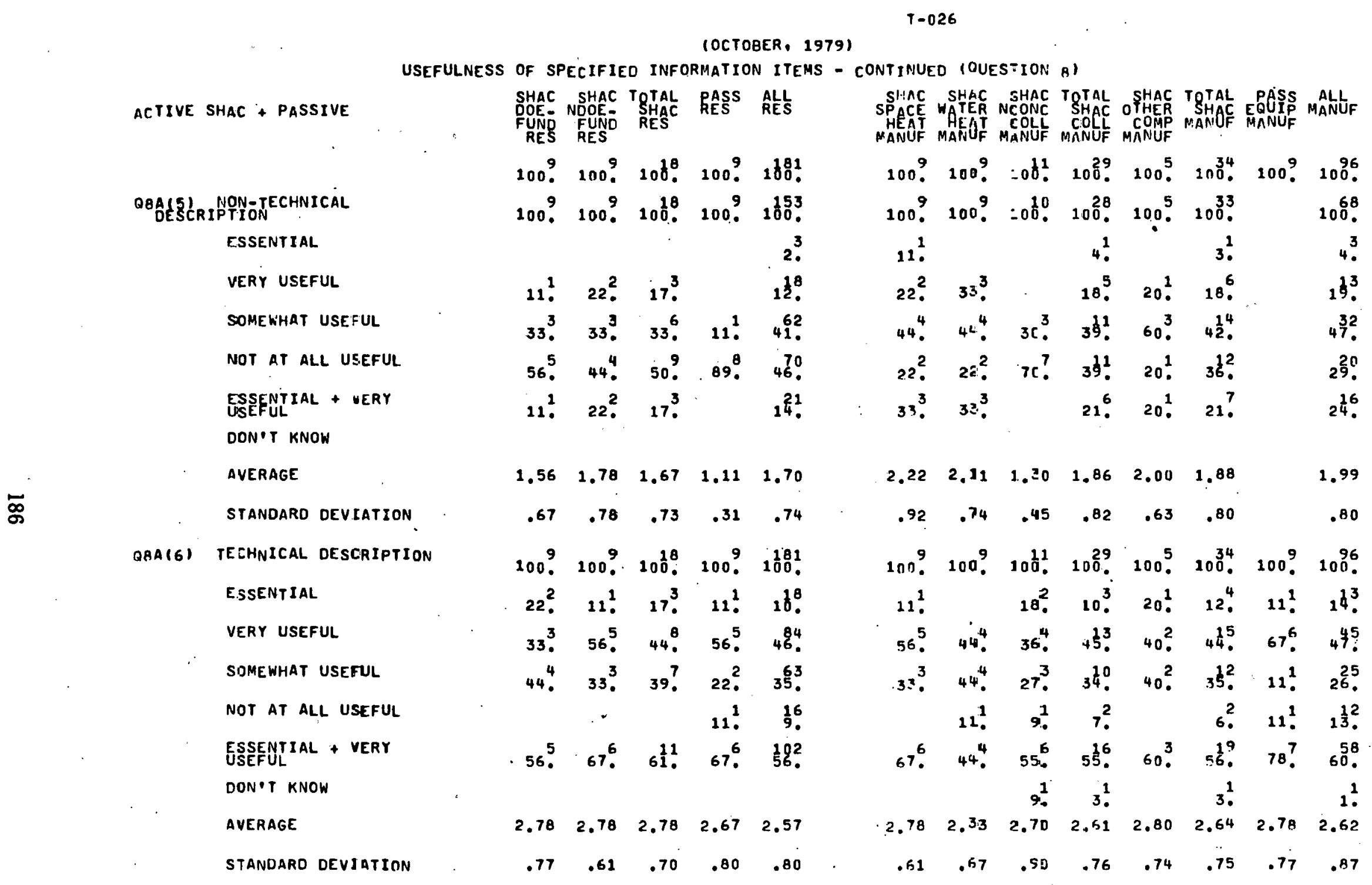

SCALE: ESSENTIAL $=4$, VERY USEFUL $=3$, SOMEWHAT JSEFUL $=2$, NOT AT ALL USEFUL $=1$

Figure F-1. Passive Solar Heating and Cooling Data Tables (continued) 
(OCTOBER, 19791

USEFULNESS OF SPECIFIED INFORMATION ITEMS - CONTINUED (QUESTION Q)

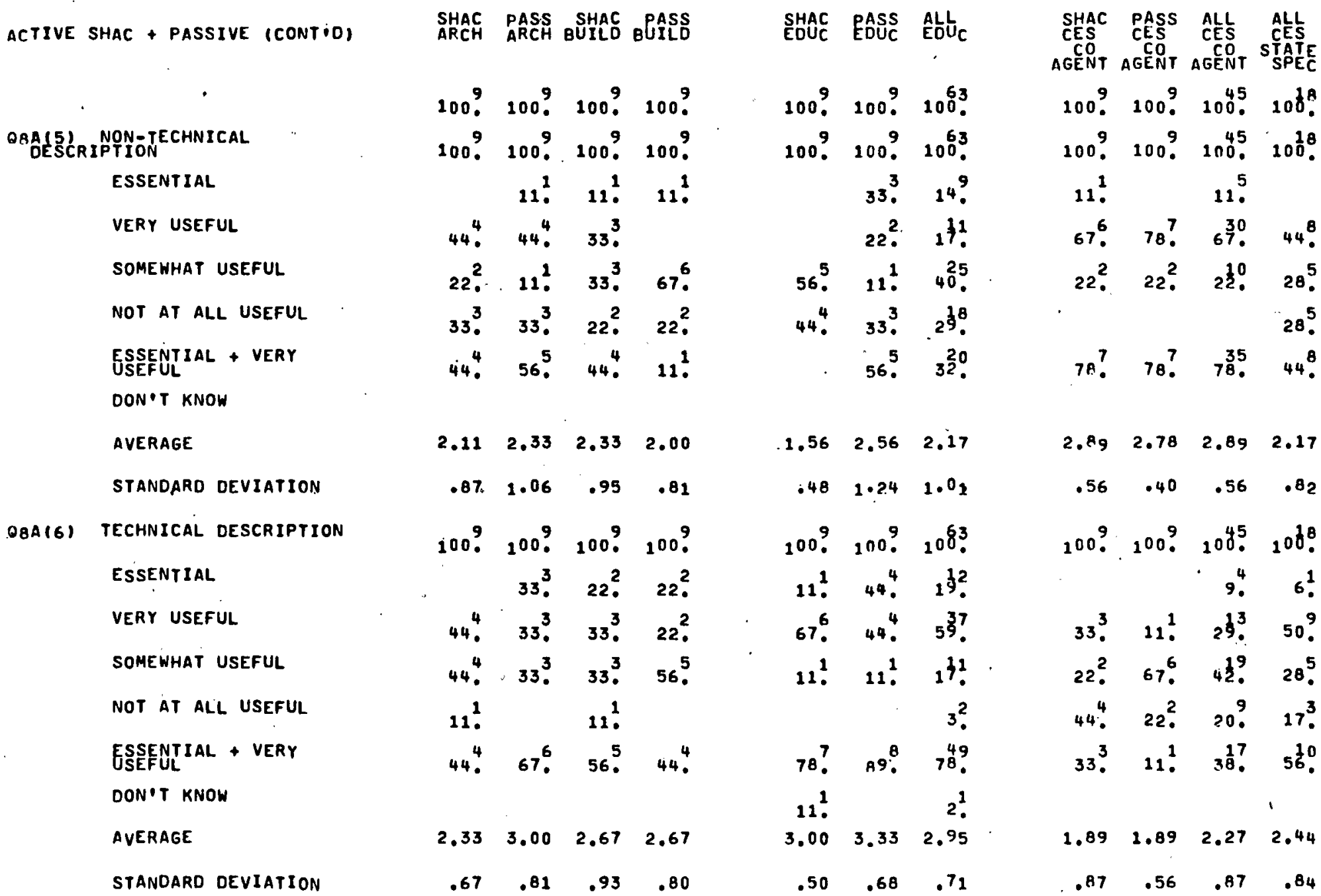

SCALE: ESSENTIAL $=4$, VERY USEFUL $=3$, SOMEWHAT USEFUL $=2$, NOT AT ALL USEFUL $=1$

Figure F-1. Passive Solar Heating and Cooling Data Tables (continued) 
(OCTOBER, 1979 )

USEFULNESS OF SPECIFIED INFORMATION ITEMS - CONTINUED (QUESTION B)

ACTIVE SHAC + PASSIVE

DQA (T) LISTS OF SUPPLIERS

ESSENTIAL

VERY USEFUL

SOMEWHAT USEFUL

NOT AT ALL USEFUL

ESSENTIAL + VERY

DON'T KNOW

STANDARD DEVIATION

QBA(8) HANDBOOKS/TABLES

ESSENTI AL

VERY USEFUL

SOMEWHAT USEFIL

NOT AT ALL USEFUL

ESSENTIAL + VERY

DON'T KNOW

AVERAGE

STANDARD DEVIATION

SHAC SHAC TRTAL RASS ALL FUND FUND RES

100 ? 100? $100^{8}$. 100 ? 1001 .

100 . 100? $100^{8} .100$ ? 100 .

$11^{1} 6^{1} \quad 11^{1}$ के

$56.566^{5}, 56^{10} . \quad 2^{39}$.

$22^{2} \quad 11^{1} \quad 17^{3} \quad 56^{5} \quad 38^{5}$.

$22^{2} \quad 22^{2} \quad 22^{4}, 33^{3}, 27^{39}$

56. $67^{6} \cdot 61^{11}$. $11^{1}$. 35 .

$2.33 \quad 2.56 \quad 2.44 \quad 1.89 \quad 2.16$

$\begin{array}{lllll}.82 & .94 & .90^{-} & .87 & .92\end{array}$

$100^{9} .100^{9} .100^{18}, 100^{9} \cdot 10^{181}$.

33. $11^{3} \cdot 22^{4} \cdot 22^{2}$. $9^{7}$.

$44^{4} .56 .520^{9}, 22^{2} . \quad 37^{67}$.

11. $33^{3} .222^{4}$. $44^{4} .36^{6}$.

11. $\quad$ 6. $11^{1} \cdot 17$.

$78^{7} \cdot \quad 67^{6} \cdot \quad 72^{13} \cdot 44^{4} \cdot 46^{84}$.

1.

$\begin{array}{lllll}3.00 & 2.78 & 2.89 & 2.56 & 2.39\end{array}$

$\begin{array}{lllllllll}.94 & .61 & .80 & .94 & .87\end{array}$
SHAC SHAC SHAC TOIAL SHAC TBTAL PASS ALL MAFAT MENOT MANUF MNWUF MANUF MANUF MANUF

\begin{tabular}{|c|c|c|c|c|c|c|c|}
\hline $100 \%$ & $100^{9}$ & $108^{1}$ & $100^{29}$ & $100^{5}$ & $108^{4}$ & $100^{9}$ & $100^{96}$ \\
\hline $100^{9}$ & $100^{9}$ & $100^{11}$ & $100^{29}$ & $100^{5}$ & $100^{34}$ & $100{ }^{9}$ & 1096 \\
\hline $22^{2}$ & $11^{1}$ & $27^{3}$ & $21^{6}$ & $40^{2}$ & $24^{8}$ & $22^{2}$ & $20^{19}$ \\
\hline $67^{6}$ & & 36. & $48^{14}$. & $20^{1}$ & $44^{25}$ & $22^{2}$ & $\begin{array}{r}36 \\
38\end{array}$ \\
\hline & $3,3^{3}$ & ! & $14^{4}$. & $40^{2}$ & $18^{6}$ & $33^{3}$ & 28 \\
\hline $11^{1}$ & $11^{1}$ & $27^{3}$ & $17^{5}$ & & 15 . & $22^{2}$ & 14 \\
\hline $89^{8}$ & $55^{5}$ & 64. & 620 & $60^{3}$ & 62.3 & $44^{4}$. & 57. \\
\hline & & & & & & & \\
\hline 3.00 & 2,36 & 2.64 & 2,72 & 3.00 & 2.76 & 2.44 & 2.64 \\
\hline .91 & .81 & 1.14 & .99 & .89 & .98 & 1.07 & .95 \\
\hline $10 n^{9}$ & 10 & $100^{11}$ & $100^{29}$ & $100^{5}$ & $100^{34}$ & $100^{9}$ & 1096. \\
\hline & $11^{1}$ & & $3^{1}$ & $40^{2}$ & $9^{3}$. & $22^{2}$. & \\
\hline $56^{5}$ & $33^{3}$ & $45^{5}$ & $45^{3}$ & $20^{1}$ & $41^{4}$ & $33^{3}$ & 420 \\
\hline $33^{3}$ & $22^{2}$ & $36^{4}$ & 31 ? & $20^{1}$ & $29^{\circ}$ & $33^{3}$ & 343 \\
\hline $11^{1}$ & $33^{3}$ & $18^{2}$ & $21^{6}$ & $20^{1}$ & ?21 & $11^{1}$ & $1 \frac{124}{5}$ \\
\hline $56^{5}$ & $44^{4}$. & $45^{5}$. & $48^{4}$ & $60^{3}$ & $50^{17}$ & $56^{5}$ & 5 \\
\hline & & & & & & & \\
\hline 2.44 & 2.22 & 2.27 & 2.31 & 2.80 & 2.38 & 2.67 & 2.46 \\
\hline • & 1.03 & 75 & .83 & 1.16 & .91 & .93 & .84 \\
\hline
\end{tabular}

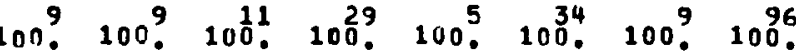
$22^{2} \quad 11^{1} \cdot 27^{3} \cdot 21^{6} \quad 40_{0}^{2} \quad 24^{8} \quad 22^{2} \quad 20^{19}$ 5 


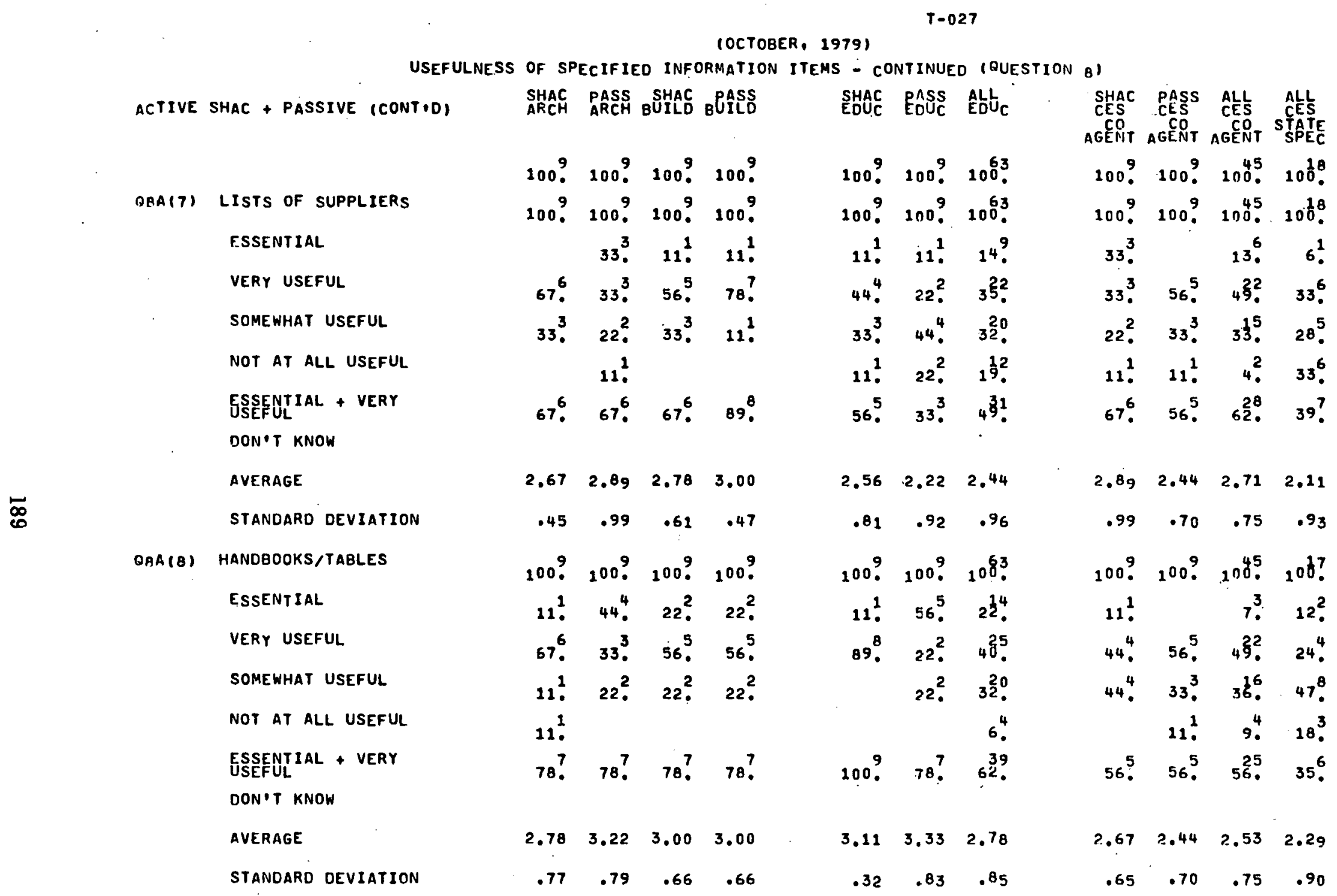

SCALE: ESSENTIAL $=4$, VERY USEFUL $=3$, SOMEWHAT USEFUL $=2, \cdot$ NOT AT ALL USEFUL $=1$

Figure F-1. Passive Solar Heating and Cooling Data Tables (continued) 
(OCTOBER, 1979 )

USEFULNESS OF SPECIFIED INFORMATION ITEMS - CONTINUED IOUESIIIJI BI

ACTIVE SHAC + PASSIVE SHAC SHAC TRTAL RASS ALL
DOE- NDOE. 'SHAC RES RES
FUNO FUND RES

100 ? 100 ? $108^{8}$. 100 ? 168 ?

QAA(9) TECHNICAL EXPERTS LIST ESSENTIAL

VERY USEFUL

SOMEWHAT USEFUL

NOT AT ALL USEFUL

GSSENTIAL + MERT

DON'T KNOW

A'JERAGE

STANDARD DEVIATION

DAA(10) MANUAL METHOOS

ESSENTIAL

VERY USEFUL

SOMEWHAT USEFUL

NOT AT ALL USEFU

ESSENTIAL + VERY

DCN'T KNOW

AVERAGE

STANDARD DEVIATION
100 . 100 ? $100^{8} .200$. $108 \%$.

11 . 16

$44^{4} .33^{3}, \quad 399^{7} \quad 22.236^{2}$.

$44^{4} .56^{5} .500^{9} .44^{4} . \quad 40^{72}$.

11 . $111^{1}$ 11. 22. $12^{2}$.

$44^{4}, \quad 33^{3} . \quad 39^{7}, \quad 33^{3}, \quad 45^{2}$.

$2.33 \quad 2.22 \quad 2.28 \quad 2.22 \quad 2.39$

$\begin{array}{lllll}.67 & .63 & .64 & .92 & .85\end{array}$

1009.1009 .100 .100 .91001

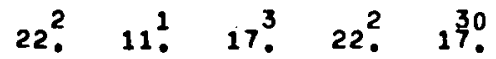

$56.544^{4} .50 .933^{3} .36$.

$111^{1} .22 .217^{3} \cdot 33^{3} \cdot 29$.

$11^{1} \quad 22^{2} \cdot 17^{3} \cdot 11^{1} \cdot 10^{33}$.

$78^{7} \quad 56.53^{2} \cdot 56^{5}, \quad 52^{95}$.

$\begin{array}{lllll}2.89 & 2.44 & 2.67 & 2.67 & 2.51\end{array}$

$\begin{array}{lllll}.87 & .96 & .93 & .93 & .96\end{array}$
SHAC SHAC SH.NC TOTAL SHAC TOTAL PASS ALL HENT HEOT OOLL COLL CUMP MANUF MANUF

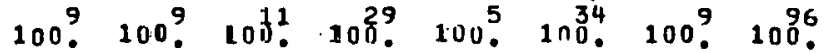

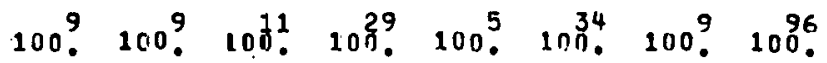
$40^{2} \quad 6^{2}, 22^{2}, 11^{11}$ $33^{3} \quad 36^{4} \quad 24^{7} \quad 21^{7} \quad 33^{3} \quad 31^{30}$ $55^{5} \quad 67^{6} \quad 27^{3} \cdot \quad 48^{4} \cdot 20^{1} \quad 44^{5} \cdot 44^{4} \cdot 36^{36}$. 11. $33^{3} \cdot 36^{4} \quad 28^{8} \cdot 40^{2}$. $29^{\circ}$. $33^{3} \quad 36^{4} \cdot 24^{7} \cdot 40^{2} \quad 26^{9} \cdot 56^{5} \quad 4 \frac{41}{3}$

\begin{tabular}{|c|c|c|c|c|c|c|c|}
\hline 2.22 & 1.67 & $\approx .00$ & 1.97 & 2.40 & 2.03 & 2.78 & 2.34 \\
\hline .63 & .45 & .85 & .70 & $1 \cdot 35$ & .85 & .77 & \\
\hline $1000^{9}$ & $100^{9}$. & . 100. & $130^{28}$ & $100^{5}$ & 100. & $100^{\circ}$ & 10 \\
\hline $11 !$ & $11^{1}$ & & $7^{2}$ & $40^{2}$ & $12^{4}$. & 4 & 2 \\
\hline $22^{2}$. & $44^{4}$. & $50 !$. & $39 !$ & & $33^{1}$. & $22^{2}$ & 3 \\
\hline $55^{5}$. & $11^{1}$ & $30^{3}$ & 32 . & $60^{3}$. & $36^{2}$ & $33^{3}$ & \\
\hline $11^{1}$ & $33^{3}$ & $20 ?$ & $21^{6}$ & & $18^{6}$. & • & \\
\hline $33^{3}$ & $56^{5}$ & 50 ? & $4 b^{13}$. & $40^{2}$. & $45^{15}$. & $67^{6}$ & \\
\hline 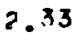 & 33 & 2.33 & 2.32 & 2.80 & 2.39 & 3.11 & 2.59 \\
\hline & & & . 89 & .97 & 2 & .87 & \\
\hline
\end{tabular}

SCALE: ESSENTIAL $=4$, VERY USEFUL $=3$, SOMEWHAT USEFUL $=2$, NOT AT ALL USEFUL $=1$

Figure F-1. Passive Solar Heating and Cooling Data Tables (continued) 
(OCTOBER, 1979)

USEFULNESS OF SPECIFIED INFORMATION ITEMS - CONTINUED (OUESTION B)

\begin{tabular}{|c|c|c|c|c|c|c|c|c|c|c|c|c|}
\hline \multirow[t]{2}{*}{ ACTIVE } & SHAC + PASSIVE (CONTDO) & $\begin{array}{l}\text { SHAC } \\
\text { ARCH }\end{array}$ & $\begin{array}{l}\text { PASS } \\
\text { ARCH }\end{array}$ & $\begin{array}{l}\text { SHAC } \\
\text { BUILO }\end{array}$ & $\begin{array}{l}\text { PASS } \\
\text { BUILD }\end{array}$ & $\begin{array}{l}\text { SHAC } \\
\text { EDUC }\end{array}$ & $\begin{array}{l}\text { PASS } \\
\text { EOUC }\end{array}$ & ALL ${ }^{A} U_{C}$ & $\begin{array}{l}\text { SHAC } \\
\text { CES } \\
\text { CO } \\
\text { AGEMT. }\end{array}$ & $\begin{array}{l}\text { PASS } \\
\text { CES } \\
\text { CD } \\
\text { AGENT }\end{array}$ & $\begin{array}{c}\text { ALL } \\
\text { CES } \\
\text { Cod } \\
\text { AG.NT }\end{array}$ & $\begin{array}{l}\text { ALL } \\
\text { ALES } \\
\text { STATE } \\
\text { SPEC }\end{array}$ \\
\hline & & 100 . & 100 ? & 1009 & $100 ?$ & 100 . & 1009 & $100^{63}$ & 1009 & 100 ? & $100^{45}$ & 108 \\
\hline \multirow[t]{8}{*}{$\operatorname{BaA}(9)$} & TECHNICAL EXPERTS LIST & 100 ? & 100 ? & 100 ? & 1009 & 100 . & 100 . & $100^{63}$ & 100 . & $100{ }^{9}$ & $100^{45}$ & . \\
\hline & ESSENTIAL & & 11. & & $22^{2}$. & & & $11 ?$ & & & $7^{3}$ & \\
\hline & VERY USEFUL & 11 & $22^{2}$ & $44^{4}$ & $33^{3}$ & $44^{4}$. & $44^{4}$. & 30. & $22^{2}$ & $44^{4}$. & $33^{5}$ & \\
\hline & SOMEWHAT USEFUL & $78 ?^{7}$ & $44^{4}$ & $44^{4}$. & $44^{4}$. & $33^{3}$ & 55. & 480 & 56. & $33^{3}$ & $4 \frac{19}{2}$. & \\
\hline & NOT AT ALL USEFUL & 11 & $22^{2}$ & $11 !$ & & $22^{2}$ & & $11 ?$ & $22^{2}$ & $22^{2}$ & $188^{8}$ & \\
\hline & $\begin{array}{l}\text { ESSENTIAL + VERY } \\
\text { USEFUL } \\
\text { DON'T KNOW }\end{array}$ & $11 !$ & $33^{3}$ & $44^{4}$. & 56. & $44^{4}$. & $44^{4}$. & 416 & $22^{2}$ & $44^{4}$ & ${ }_{4} 0^{8}$ & \\
\hline & AVERAGE & 2.00 & 2.22 & 2.33 & 2.78 & 2.22 & 2.44 & 2.41 & 2.00 & 2.22 & 2.29 & \\
\hline & STANDARD DEVIATION & .47 & .92 & .67 & .77 & .79 & .51 & .83 & .66 & .79 & .83 & \\
\hline \multirow[t]{8}{*}{ QRA(10) } & MANUAL METHODS & 100 . & 100 . & 1009 & 100 ? & 1009 & 1009 & $100^{63}$ & 1009 & $100^{9}$. & $100^{45}$ & $100^{\frac{1}{8}}$. \\
\hline & ESSENTIAL & $22^{2}$ & 56. & $22^{2}$ & $22^{2}$ & $22^{2}$ & $44^{4}$ & $24^{15}$ & $22^{2}$ & & $4^{2}$ & \\
\hline & VERY USEFUL & $44^{4}$. & $22^{2}$ & $56^{5}:$ & $67^{6}$. & $44^{4}$. & $33^{3}$ & 40.5 & 56. & $56^{5}$ & $4 \frac{19}{2}$ & \\
\hline & SOMEWHAT USEFUL & $33^{3}$. & 11 . & $22^{\dot{2}}$ & 111 & $22^{2}$ & $22^{2}$ & $25^{16}$ & $11 !$ & $44^{4}$. & $40^{18}$. & \\
\hline & NOT AT ALL USEFUL & & & & & & & $10^{6}$. & $11 !$ & & $13^{6}$. & \\
\hline & $\begin{array}{l}\text { ESSENTIAL + VERY } \\
\text { OSEFUL } \\
\text { DONPT KNOW }\end{array}$ & $67^{6}$. & $\begin{array}{l}78 ? \\
11 !\end{array}$ & $78 ?$ & 89. & 67. & $78 ?$ & $\begin{array}{r}4 \frac{40}{3} \\
2 !\end{array}$ & $78 ?$ & 56. & 431. & \\
\hline & AVERAGE & 2.89 & 3.50 & 3.00 & 3.11 & 3.00 & 3.22 & 2.79 & 2.89 & 2.56 & 2.38 & 2. \\
\hline & STANDARD DEVIATION & .73 & .70 & .66 & .57 & 70 & 79 & .91 & .87 & .47 & 76. & \\
\hline
\end{tabular}

SCALE: ESSENTIIAL $=4$, VERY USEFUL $=3$, SOMEWHAT USEFUL $=2$, NOT AT ALL USEFUL $=1$

Figure F-1. Passive Solar Heating and Cooling Data Tables (continued) 


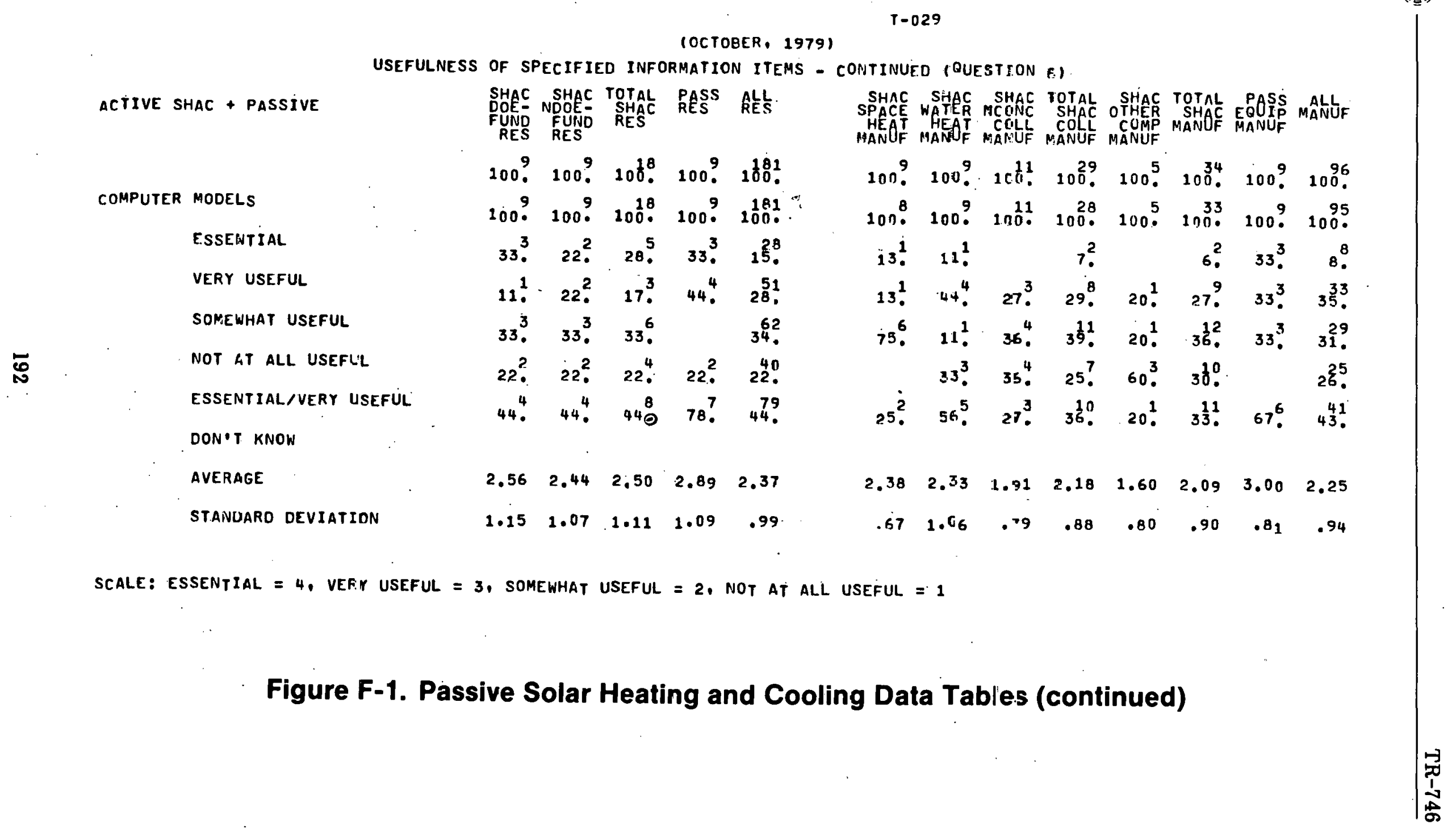




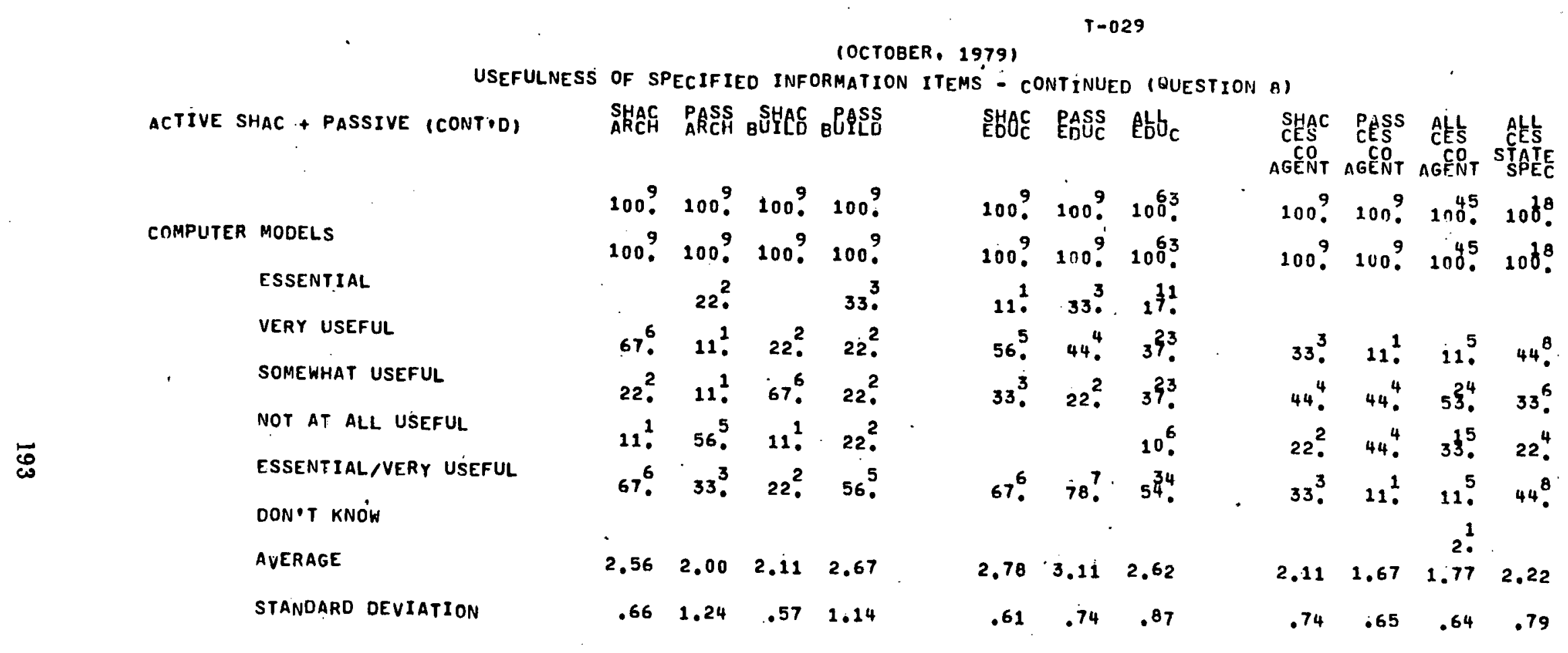

SCALE: ESSENTIAL $=4$, VERY USEFUL $=3$, SOMEWHAT USEFUL $=2$, NOT AT ALL USEFUL $=1$

Figure F-1. Passive Solar Heating and Cooling Data Tables (continued) 
(OCTOBER, 1979)

USEFULAESS OF SPECIFIED INFORMATION ITEMS - CONTINUFD (DUESTION : 8 )

ACTIVE SHAC + PASSIVE

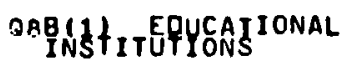

ESSENTIAL

VERY USEFUL

SOMEWHAT USEFUL

NOT AT ALL USEFUL

ESSENTLIAL + NER

DON'T KNOW
SHAC SHAC TRTAL RASS ALL
DOE NOOE
FUND FUND RES RES RES

100 . 100 ? $100^{8} .100$. $1800^{81}$ 100 . 100 . $107^{8}, 100$. 1001

1.

$22^{2} \cdot 22^{2} \cdot 22^{4} \cdot 11^{1} \cdot 1^{26}$.

$56.546^{5} .50 .944^{4} .559$.

$22^{2} . \quad 33^{3} . \quad 28.244^{4}, \quad 30^{54}$.

$22^{2}, 22^{2}, 222^{4}, 111^{1}, 15^{2}$ ?

$\begin{array}{lllll}2.00 & 1.89 & 1.94 & 1.67 & 1.86\end{array}$

$\begin{array}{llllll}.66 & .73 & .71 & .65 & .65\end{array}$

$100.900 . \quad 100.100 . \quad 100$.

$11^{1} \quad 22^{2}, \quad 17^{3}, \quad 11^{1}, 1^{33}$.

$67.56 .51^{6} . \quad 67^{6} . \quad 58^{2}$.

$22^{2} .222^{2} \quad 22^{4}, 111^{1}$ 22.

NOT AT ALL USEFLL

ESSEEYLTAL + VERT

DON'T KNOW

AVERAGE

STANOARD DEVIATION

78 . 78 ? $78^{4}, \quad 78^{7} \quad \frac{135}{75}$

$2.89 \quad 3.00 \quad 2.94 \quad 2.78 \quad 2.89$

$\begin{array}{lllll}.56 & .66 & .64 & .77 & .73\end{array}$
SPHAC SHAC SHAC TGTAL SHAC TQTAL PPASS MALL HENT MENT MOLL COLL COMP MANOF MANUF

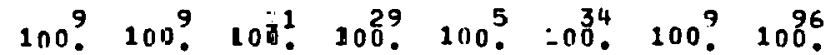
$100^{9} .100^{9} .100^{2} .100^{29}, 100^{-5}=00^{34} . \quad 100.9100^{6}$

$40^{2} .6_{0}^{2} \quad 11^{2} .8^{3}$.

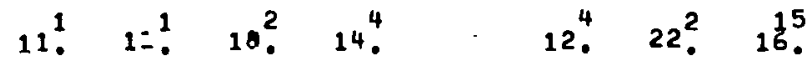

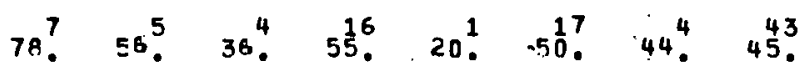

$11^{1} \quad 33^{3} \cdot 45^{5} \quad 31^{9} \cdot 40^{2} \quad 3^{12} \cdot 22^{2}$. $31^{30}$.

$11^{1} \quad 11^{1} \cdot \quad 2 \varepsilon_{0}^{2} \quad 14^{4} \cdot \quad 40_{0}^{2} \quad 188^{6} \quad 33^{3} \cdot 2^{23} \cdot$

$\begin{array}{llllllll}2.00 & 1.78 & =.73 & 1.83 & 2.40 & 1.91 & 2.22 & 2.01\end{array}$

$\begin{array}{llllllll}.47 & .62 & .74 & .64 & 1.35 & .82 & .92 & .89\end{array}$

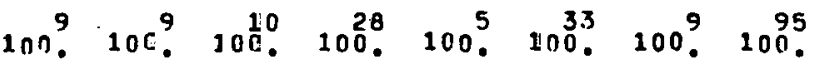

$22^{2} .11^{1} \cdot 10^{1} \cdot 14^{4} \cdot 40^{2} \cdot 18^{6} \cdot 44^{4} .23^{2}$.

$56^{5}, 44^{4}, \quad 30^{3}, 43^{2}, \quad 36^{2} . \quad 40^{3}$.

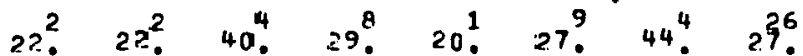

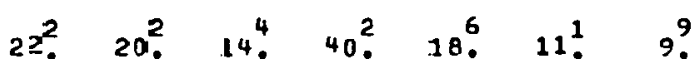

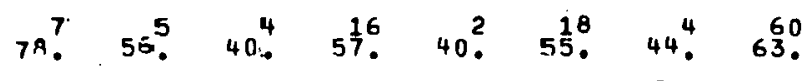

Figure F-1. Passive Solar Heating and Cooling Data Tables (continued) 


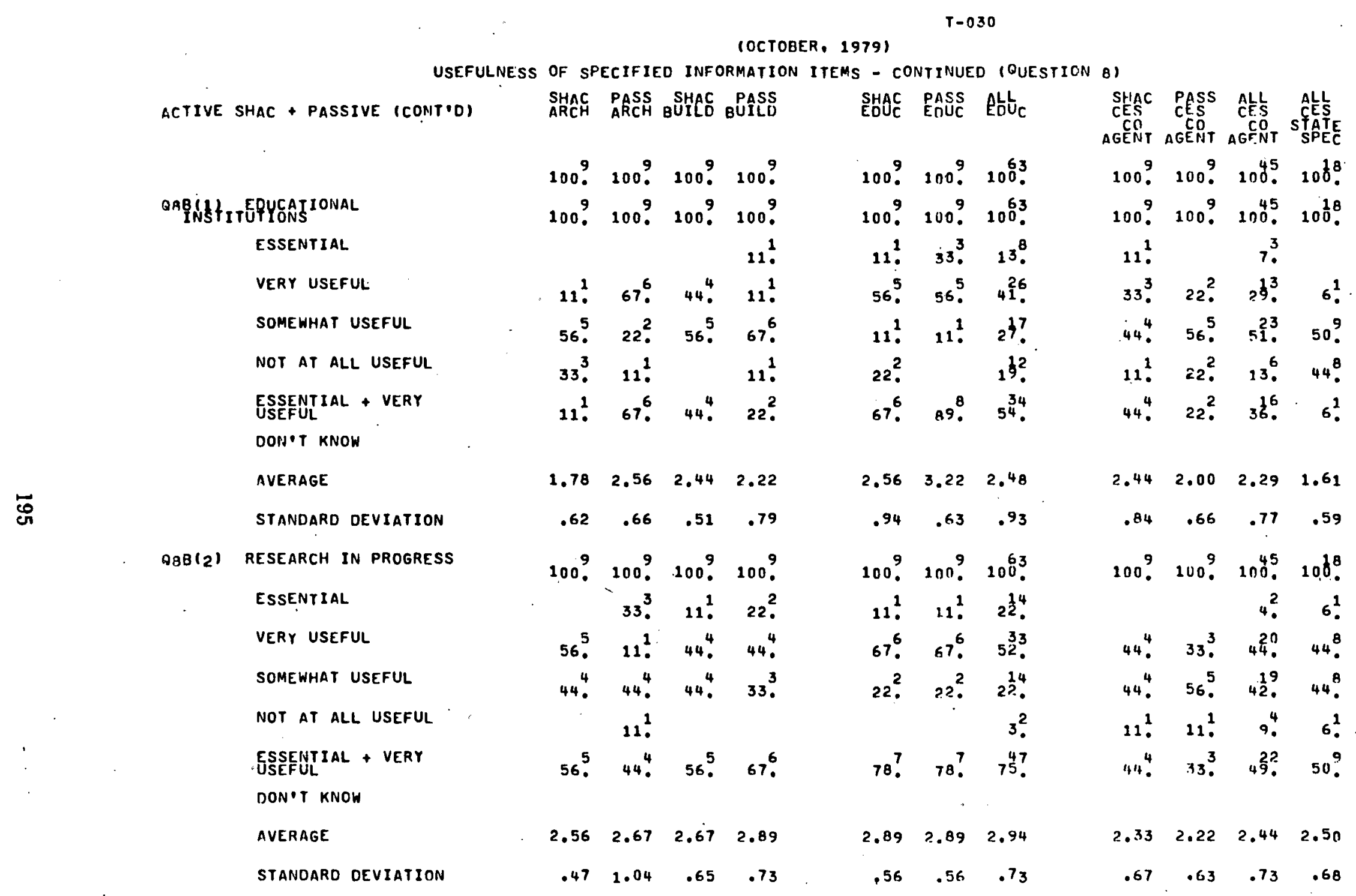

SCALE: ESSENTIAL $=4$, VERY USEFUL $=3$, SOMEWHAT USEFUL $=2$, NOT AT ALL USEFUL $=1$

Figure F-1. Passive Solar Heating and Cooling Data Tables (continued) 


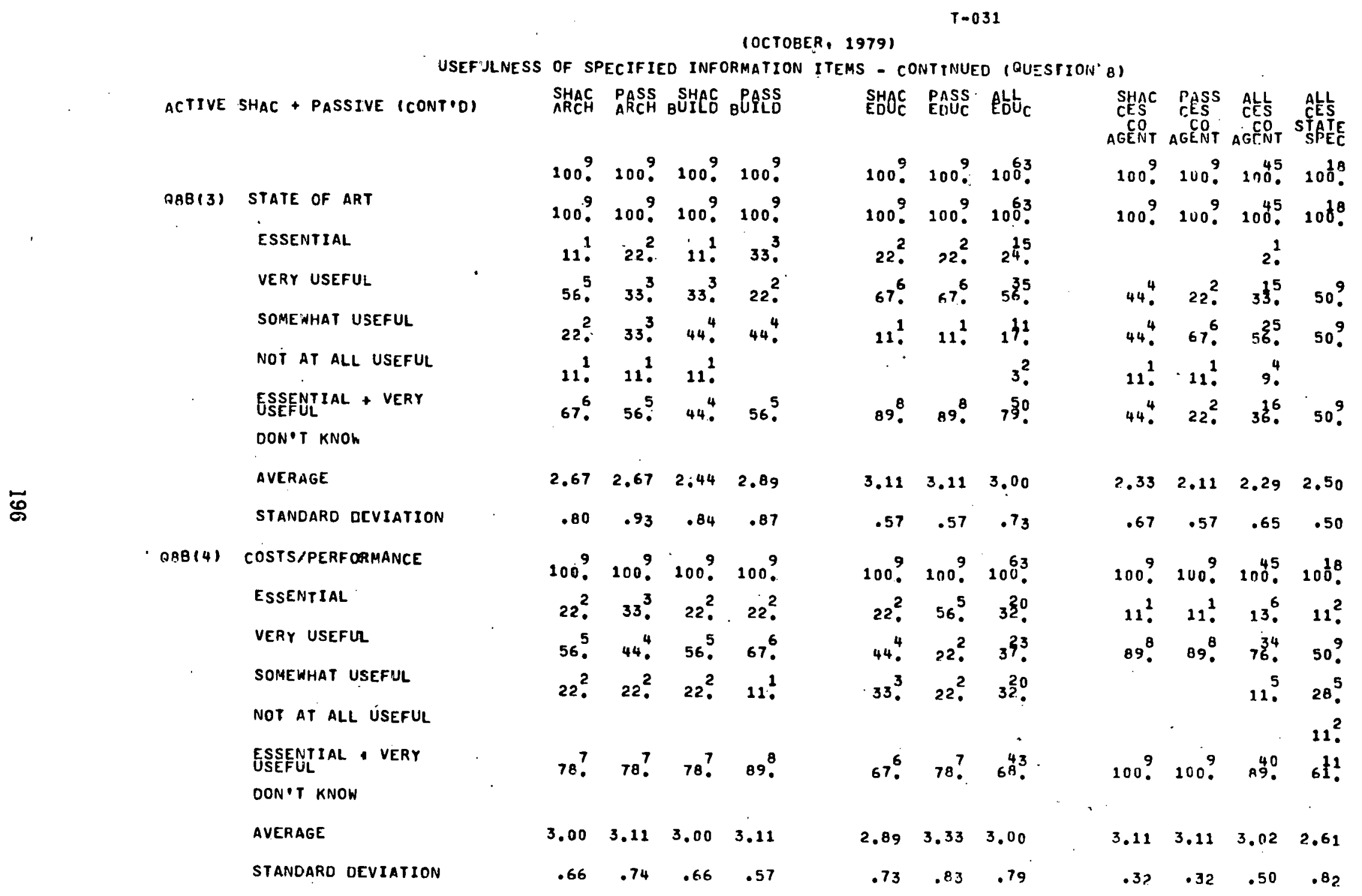

SCALE: ESSENTIAL $=4$, VERY USEFUL $=3$, SOMENHAT USEFUL $=2$, NOT AT ALL USFFUL $=1$

Figure F-1. Passive Solar Heating and Cooling Data Tables (continued) 


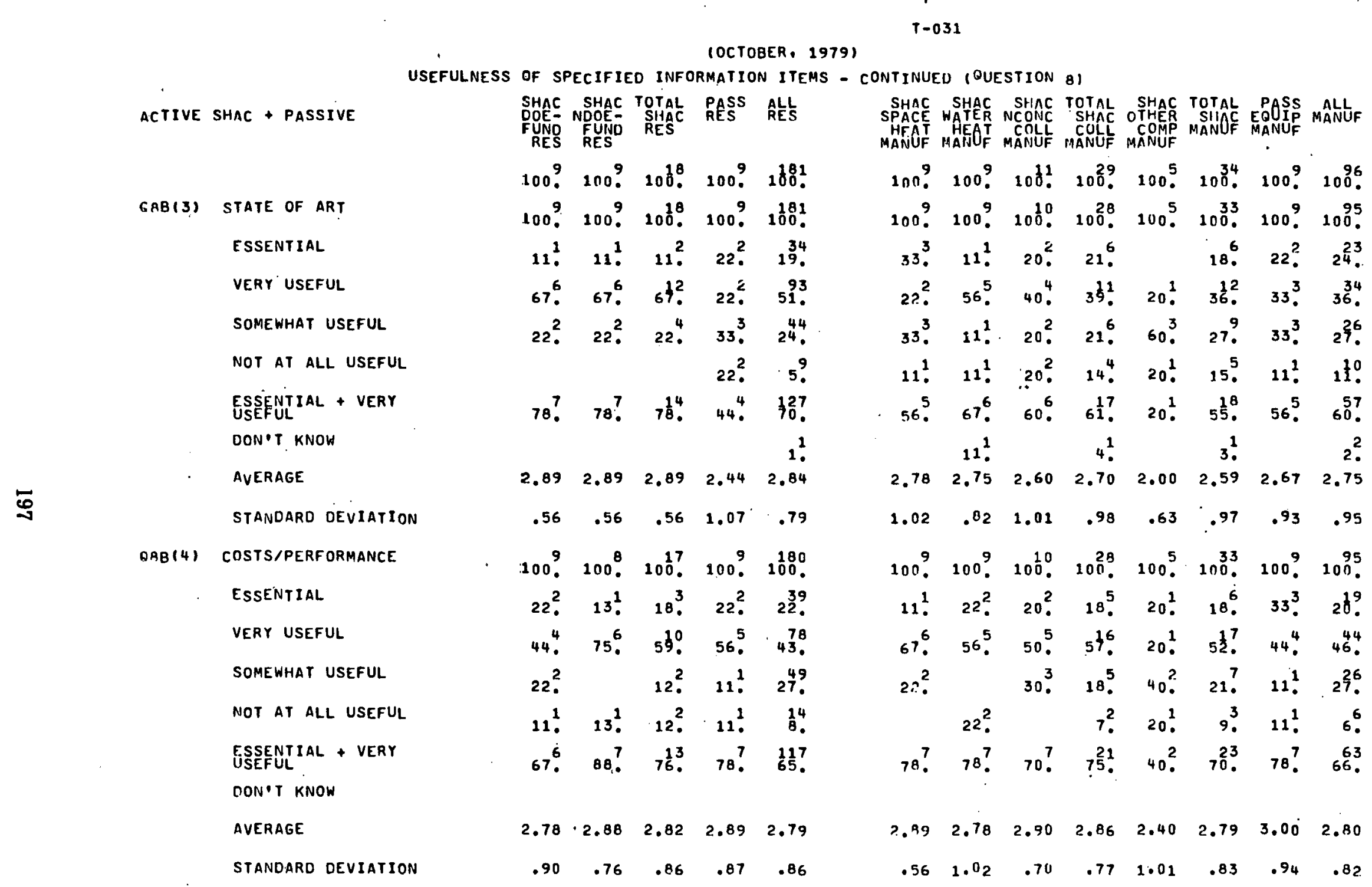

SCALE: ESSENTIAL $=4$, VERY USEFUL $=3$, SOMEWHAT USEFUL $=2$, NOT AT ALL USEFUL $=1$

Figure F-1. Passive Solar Heating and Cooling Data Tables (continued) 
(OCTOBER, 1979 )

USEFULN SSS OF SPECIFIED INFORMATION ITEMS - CONTINUED (QUESTIDN \&)

ACTIVE SHAC + PASSIVE SHAC SHAC TOTAL RASS ALL FUND FUND

$1000^{\circ} 1009$. $108^{6} \cdot 100$. $180^{8}$.

AAB (5) COSTS INSTALL,DPERATE

E.SSENTIAL

VERY USEFUL

SOMEWHAT USEFIJL

NOT AT ALL USEFUL

ESSEFUIIAL + VERY

DON'T KNOW

AVERAGE

STANDARD DEVIATION

QAB (6) BUILOING CODESIREGS

ESSENTIAL

VERY USEFUL

SOMEWHAT USEFEL

NOT AT ALL USEFUL

ESSENTIAL + VERY

DOV'T KNOW

$A V \equiv R A G E$

STINDARO OEVIATION

100 . $100,100.1009 .1003$

$11^{1} .622^{1} \quad 20^{2}$.

67. $78^{7}, \quad 72^{3} . \quad 22.2 \quad 43^{\circ}$.

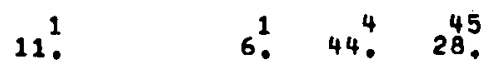

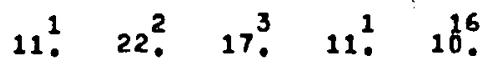

$78.78 ? .78^{4}, \quad 44^{4}, \quad 63$.

$\begin{array}{llllll}2.78 & 2.56 & 2.67 & 2.56 & 2.72\end{array}$

$\begin{array}{lllll}.77 & .81 & .80 & .94 & .90\end{array}$

100 . 100 . $108^{8}$. 100 . $160^{63}$.

$33^{3} . \quad 17^{3} .22 .01 \frac{1}{9}$.

$22^{2} . \quad 78^{7}, \quad 50^{9} . \quad 22^{2}, \quad 23$.

$33^{3} .22^{2} \cdot 28^{5}, \quad 44^{4}, \quad 36^{5}$.

11.061 .211 .298

56.58 ? $\quad 67^{2} \cdot \quad 44^{4}, \quad 357$.

$\begin{array}{lllll}2.78 & 2.78 & 2.78 & 2.56 & 2.17\end{array}$

$\begin{array}{lllll}1.02 \quad .40 \quad .77 \quad .94 & .98\end{array}$
SPHAC WHAE SHAC TOTAL SHAC TOTAL EPASS MALL HEAT HEAT COLL COLL COMP MANOF MANUTF

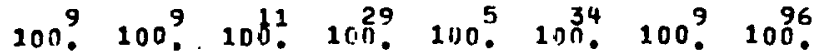

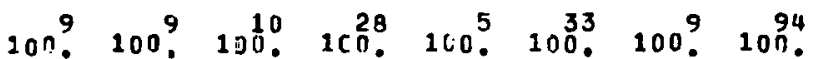

$11^{1} \quad 33^{3} \cdot 10^{1} \quad 18^{5} \quad 20^{1}, 18^{6}, 44^{4}, 20^{19}$

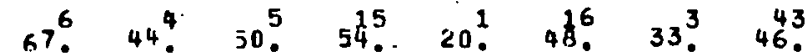

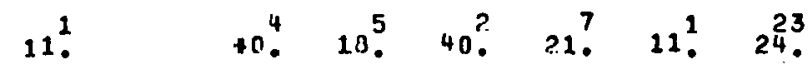

$11^{1} .22^{2} . \quad 11^{3} \cdot 200^{1} \quad 12^{4} .11^{1} .9^{8}$.

$78^{7} . \quad 78^{7}, \quad 60^{6} . \quad 71^{20} . \quad 40^{2} . \quad 67^{22} . \quad 78^{7} . \quad 66^{62}$.

$\begin{array}{llllllll}2.78 & 2.80 & 2.70 & 2.79 & 2.40 & 2.73 & 3.11 & 2.78\end{array}$

$\begin{array}{llllllll}.77 & 1.09 & .64 & .84 & 1.01 & .88 & .99 & .88\end{array}$

$100^{9}$. $100^{9}$. $100^{11}$. $100^{29}$. 100 . $100^{34}$. 100 . $100^{95}$.

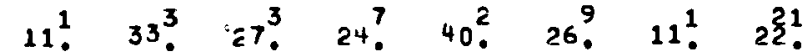

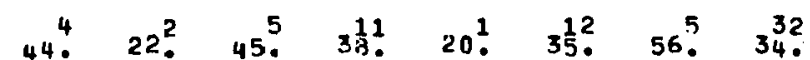

$44^{4} \cdot \quad 11^{1} \quad 9^{2} \cdot 211^{6} \quad, 18^{6} \cdot 33^{3} \cdot 2^{24} \cdot$

$33^{3} \quad 18^{2} \quad 17^{5} \quad 40^{2} \cdot 21^{7} \cdot 20^{19}$

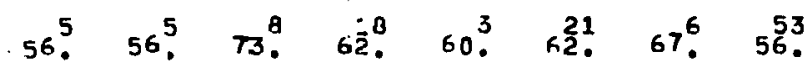

$\begin{array}{llllllll}2.67 & 2.56 & 2.82 & 2.69 & 2.60 & 2.68 & 2.78 & 2.58\end{array}$

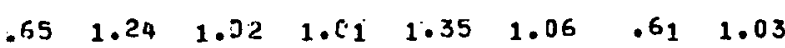

SCALE: ESSENTIAL $=4$, VERY USEF $J L=3$, SOMEWHAT USEFUL $=2$, NOT AT ALL USEFUL $=1$

Figure F-1. Passive Solar Heating and Cooling Data Tables (continued) 
(OCTOBER, 1979)

USEFULNESS OF SFECIFIED INFORMATION ITEMS - CONTINUED (QUESTION B)

\begin{tabular}{|c|c|c|c|c|c|c|c|c|c|c|c|c|c|}
\hline & & & & & & & & -0 & & & & & \\
\hline & & & & & & $100 \mathrm{CTO}$ & ER, 1979) & & & & & & \\
\hline & USEFL & NESS & OF St & ECIFIEL & $=0$ INF & ORMATION & ITEMS - $C$ & ONTINUE & D IQUESTION & (8) & & & \\
\hline A.CTIVE & SHAC + PASSIVE ICONT'DI & & $\begin{array}{l}\text { SHAC } \\
A R C H\end{array}$ & $\begin{array}{l}\text { PASS } \\
\text { ARCH }\end{array}$ & $\begin{array}{l}\text { SHAC } \\
\text { BUICD }\end{array}$ & $\begin{array}{l}\text { PASS } \\
\text { BUILD }\end{array}$ & SHAC $_{\text {EOUC }}$ & $\begin{array}{l}\text { PASS } \\
\text { EDUC }\end{array}$ & AĹ $_{C}$ & $\begin{array}{l}\text { SHAC } \\
\text { CES } \\
\text { CO } \\
\text { AGENT }\end{array}$ & $\begin{array}{l}\text { PASS } \\
\text { CES } \\
\text { CO } \\
\text { AGENT }\end{array}$ & $\begin{array}{l}\text { ALL } \\
C E S \\
C D N T \\
\text { AGENT }\end{array}$ & $\begin{array}{l}\text { ALL } \\
\text { CCES } \\
\text { SIATE } \\
\text { SPEC }\end{array}$ \\
\hline & & & $100^{9}$ & $100 \%$ & $100^{\circ}$ & 100 ? & 1009 & $100 ?$ & $100^{63}$ & 100 . & 100 ? & 100. & 108. \\
\hline$A B(5)$ & COSTS INSTALL/OPERATE & & 100 . & $100 ?$ & 100 ? & 100 . & 100 ? & $100 ?$ & $100^{63}$ & 100 ? & 100 . & $100^{45}$ & $100 \%$ \\
\hline & ESSENTIAL & & $33^{3}$ & 56 & & $33^{3}$. & $22^{2}$ & 56. & 30. & $33^{3}$ & 111 & $18^{8}$. & $11^{2}$ \\
\hline & VERY USEFUL & . & 56. & $22^{2}$ & $67^{6}$. & $22^{2}$ & $67^{6}$ & $22^{2}$ & 469 & $67^{6}$ & 89. & 733 & $33^{6}$ \\
\hline & SOMEWHAT USEFUL & & $11^{1}$ & $22^{2}$ & $22^{2}$. & $44^{4}$. & $11^{1}$ & 11. & $15^{10}$ & & & 9. & \\
\hline & NOT AT ALL USEFUL & & & & 11 & & & $11^{1}$ & $8^{5}$. & & & & $17 ?^{3}$ \\
\hline & $\begin{array}{l}\text { ESSENTIAL + VERY } \\
\text { USEFUL } \\
\text { DONPT KNOW }\end{array}$ & & $69^{8}$ & $78 ?$ & $67^{6}$ & $56^{5}$ & $899^{8}$ & 78 ? & $\begin{array}{l}48 \\
76 .\end{array}$ & $100 ?$ & 1009 & $91^{41}$ & $4.4^{8}$ \\
\hline & AVERAGE & $::$ & 3.22 & 3.33 & 2.56 & $2.89^{\circ}$ & 3.11 & 3.22 & $2.9 B$ & 3.33 & 3.11 & 3.09 & 39 \\
\hline & STANDARD OEVIATION & & .63 & .83 & .66 & .87 & .57 & 1.03 & .89 & .49 & .32 & .50 & 88 \\
\hline $8 B(6)$ & BUILDING CODES/REGS & & 100 ? & 1009 & $100 ?$ & 100 . & 100 ? & $100 \%$ & $100^{63}$ & 100 . & 100. & 1045 & $108^{A}$ \\
\hline & ESSENTI I AL & & $44^{4}$. & $44^{4}$ & $22^{2}$ & $33^{3}$ & 11 . & $22^{2}$ & ${ }_{1}^{1} b^{n}$ & $11 !$ & & 9. & $11^{2}$ \\
\hline & VERY USEFUL & & $33^{3}$. & $22^{2}$ & $44^{4}$. & 56. & $44^{4}$. & $44^{4}$. & $35^{2}$ & $22^{2}$. & $33^{3}$. & $24^{2}$. & 224 \\
\hline & SOMEWHAT USEFUL & & $22^{2}$. & $11^{2}$ & $33^{3}$. & $11 !$ & $33^{3}$ & $22^{2}$ & 320 & $44^{4}$. & $56^{5}$ & 471 & $6 \frac{11}{1}$. \\
\hline & NOT AT ALL USEFUL & & & $22^{2}$ & & & 11 ? & 11 . & $17 !$ & $22^{2}$ & 111 & $20{ }^{\circ}$ & \\
\hline & $\begin{array}{l}\text { ESSEENTIAL + VERY } \\
\text { USEFUL } \\
\text { DON'T KNOW }\end{array}$ & & $78 ?^{7}$ & $67^{6}$ & $67^{6}$. & 89. & 56 ? & $67^{6}$. & $51^{32}$ & $33^{3}$. & $33^{3}$ & $2 \frac{15}{3}$ & 33 . \\
\hline & AVERAGE & & 3.22 & 2.89 & 2.89 & 3.22 & 2.56 & 2.78 & 2.49 & 2.2 .2 & 2.22 & $2.2 ?$ & 2.39 \\
\hline & STANDARD DEVIATION & & .79 & 1.19 & .73 & .63 & .81 & .90 & .96 & .92 & .63 & .87 & \\
\hline
\end{tabular}

SCALE: ESSENTIAL $=4$, VERY USEFUL $=3$, SOMEWHAT USEFUL $=2$, NOT AT ALL USEFUL $=1$

Figure F-1. Passive Solar Heating and Cooling Data Tables (continued) 
(OCTOBER, 1979 )

USEFULNESS OF SPECIFIED INFORMATION ITEMS - CONTIPJUEO (OUESTION \&)

ACTIVE SHAC + PASSIVE ESSENT I AL

VERY USEFUL

SOMEWHAT USEFUL NOT AT ALL USEFUL

ESSENTIAL + VEAY DON T KHOH

AVERAGE

STANDARD DEVIATION SHAC SHAC TQTAL RASS ALL RES RES

100 ? 100 ? $100^{8}$. 100 ? 1001 $100^{9}$. $100^{9} .100^{18}, 1009$. 100. $111^{1} 11^{1}$ 11. 22 . 17? $56.57^{6}, \quad 61^{11}, \quad 56.527^{44}$. $22^{2} .11^{1} \cdot 17^{3}, \quad 22^{2} \cdot \quad 32^{52}$ $11^{1} 111^{1} 11^{2} . \quad 250$. $67^{6} \quad 78^{7} \cdot \quad 72^{3} \cdot \quad 78^{7} \cdot \quad 44^{71}$.

$\begin{array}{lllll}2.67 & 2.78 & 2.72 & 3.00 & 2.36\end{array}$ QQB (B) STANDARDS/SPECS

FSSENTIAL

VERY USEFUL

SOMEWHAT USEFUL

NOT AT ALL USEFLL

ESSEEUTIAL + VERT

DON'T KNOW

AVERAGE

STANDARD DEVIATION

$\begin{array}{lllll}3.00 & 2.78 & 2.89 & 2.33 & 2.33\end{array}$

$\begin{array}{lllll}.94 & .40 & .73 & 1.25 & .95\end{array}$
SPACE WATER NCONC 'SHAL OPHAC TOTAL PASS ALL HEAT HENT COLL COLL COMP MANOF MANUF

1009 , 1009 . $100^{11}, 100^{25}, 100$ ? $100^{34}, 100$ ? $100^{96}$. 100 . 100 . $100^{10}$. $100^{28}$. 100 . 100 . 100 . 1005 . $22^{2} .33^{3} .50 .536 .0 \quad 30.044^{4} .330$.

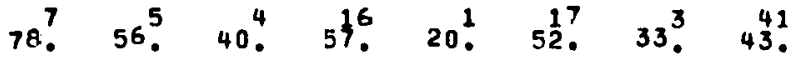
$10^{1}$ 4! $40^{2}$. 9. 11 ! $16^{5}$. 11. $\quad 4^{1} \quad 40_{0}^{2} \quad 93011^{1} \quad 9$.

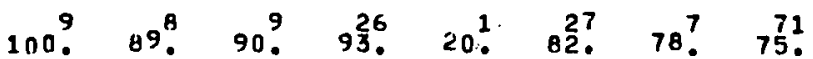
$\begin{array}{llllllll}3.22 & 3.11 & 3.40 & 3.25 & 1.80 & 3.03 & 3.11 & 2.97\end{array}$ $\begin{array}{llllllll}.43 & .87 & .66 & .68 & .74 & .87 & .99 & .91\end{array}$

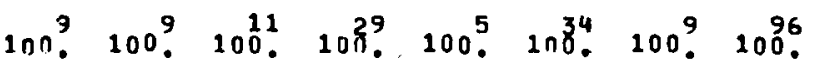

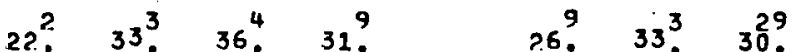
$44^{4}$. $\quad 36^{4}, \quad 28^{\circ}, \quad 20^{1}, 26^{9}, \quad 22^{2}, 29^{8}$. $33^{3}, \quad 44^{4} \cdot \quad 27^{3} \cdot \quad 34^{30} \cdot \quad 60^{3} \cdot \quad 38^{13} \cdot 33^{3} \cdot 32^{31}$. $22^{2} \quad 7^{2} \quad 200^{1} \quad 9.011^{1} \quad 8$.

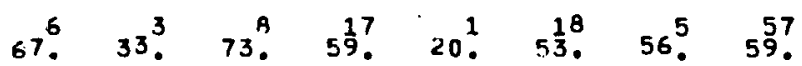

$\begin{array}{llllllll}.73 & 1.17 & .79 & .94 & .63 & .94 & 1.02 & .96\end{array}$

SCALE: ESSENTIAL $=4$, VERY USEFUL $=3$, SOMEWHAT USEFUL $=2$, NOT AT ALL USEFUL $=1$

Figure F-1. Passive Solar Heating and Cooling Data Tables (continued) 


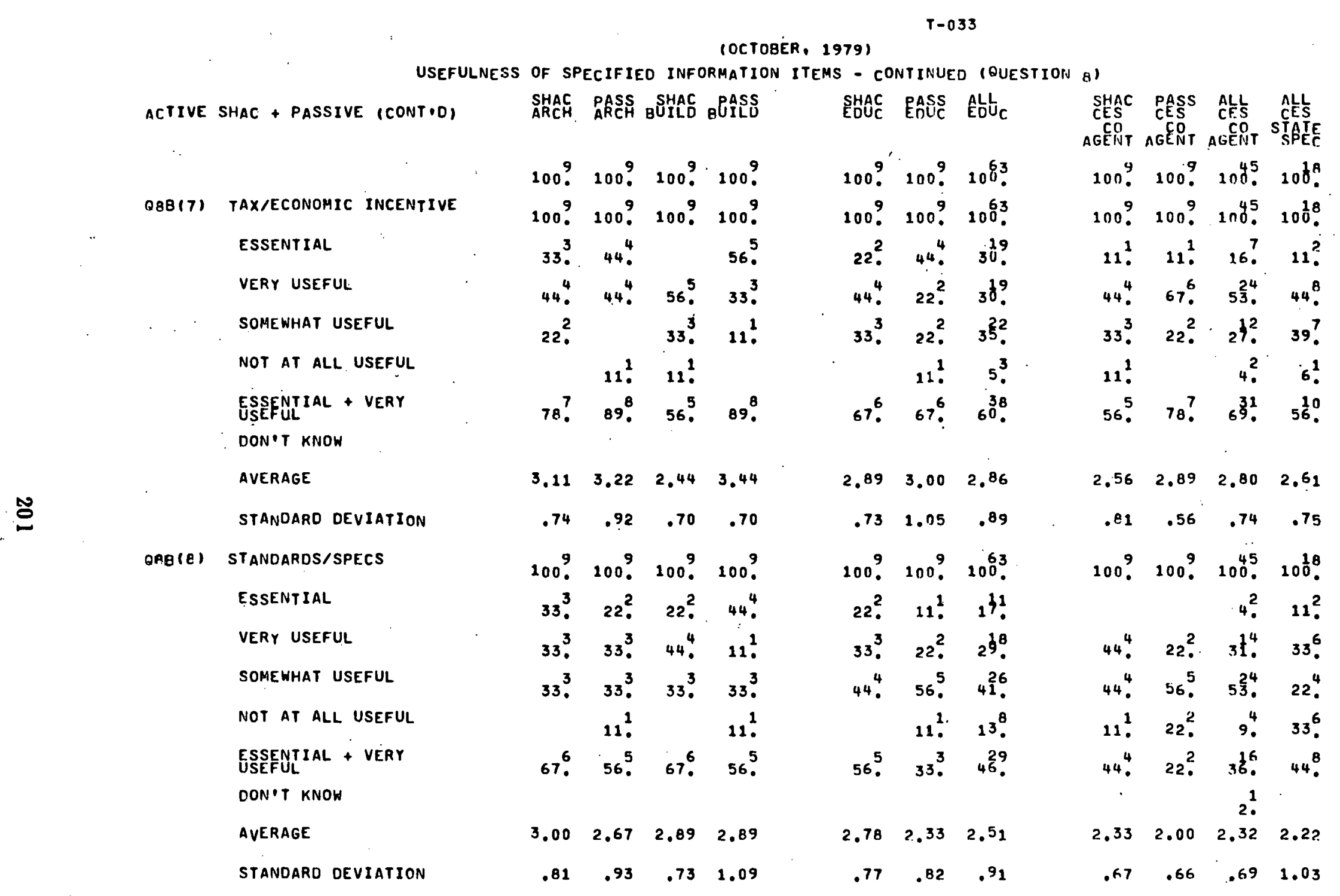

SCALE: ESSENTIAL $=4$, VERY USEFUL $=3$, SOMEWHAT USEFUL $=2$, NOT AT ALL USEFUL $=1$

Figure F-1. Passive Solar Heating and Cooling Data Tables (continued) 
IOCTOBER, 19791

USEFULNESS OF SPE:IFIED INFORMATION ITEMS - CONTINUEO (OUESTION O)

ACTIVE SHAC + PASSIJE ICONTODI SHAC PASS SHAC PASS

QBB(9) MARKETING/SALES DATA

ESSENTIAL

'VERY USEFUL

SOMEWHAT USEFJL

NOT AT ALL USEFUL

ESSENTIAL + VERY

DON'T KNOW

AVERAGE

STANOARD DEVIMTION

ARBI1O INOUSTRPUTSIDE US RESEARCF/

ESSENTIAL

VERY USEFUL

SOMEWHAT USEFLL

NOT AT ALL USEFUL

ESSENTITAL + VERY

DON'T KNOW

AVERAGE

STANDARU DEVIATION

$$
\begin{aligned}
& \text { 100. } 100^{9} .100 .900^{9} \\
& \text { 100. } 100 \text {. }
\end{aligned}
$$$$
100^{9} .1009 .100^{63} .
$$$$
100.2100^{9} .100^{63} \text {. }
$$$$
11.28 \text {. }
$$

44. $44^{4}$.

$22.244^{2}$.

33. 21 ?

44. $44^{4}$.

2.112 .33

$.87 \quad .67$

100. 100.9100 .100 .

11.

$11^{1}$. $11^{1} \cdot 22^{2} .222^{2}$

$22.42^{2} . \quad 33^{3} .560^{5}$

$560^{5} 44^{4} .44^{4} \quad 11$ ?

$22^{2} .11^{1} \cdot 22^{2} .33^{3}$.

$\begin{array}{llll}1.78 & 1.67 & 1.78 & 2.33\end{array}$

$1.02 \quad .65 \quad .78 \quad .82$

22. $11^{2} \cdot 2^{\frac{1}{4}}$.

44. $78^{7} .426$

22 . 11 . $2^{17}$ ?

$33^{3} .111^{1} \quad 320$

$.92 \quad .47 \quad .89$

$100^{9} .100^{9} .100^{63}$

11 . $8^{5}$.

33. $22^{2} .22^{\frac{1}{2}}$.

56. $44^{4}: \quad 37$.

11. $22^{2} . \quad 3^{\frac{2}{3}}$.

$33^{3} .33^{3}$. 30 .

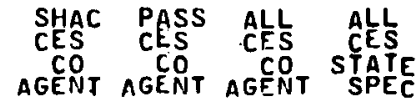

100. 100 . $100^{45} \quad 100^{8}$.

100 ?

11 ?

56.

$33^{3}$.

11 .

1.78

.62

$100^{17}$

Figure F-1. Passive Solar Heating and Cooling Data Tables (continued) 
(OCTOBER, 1979)

USEFULNESS OF SPECIFIED INFORMATION ITEMS - CONTINUED ,QUESTION B)

ACTIVE SHAC + PASSIVE

QAB(9) MARKETING/SALES DATA

\section{ESSENTIAL}

VERY USEFUL

SOMEWHAT USEFUL

NOT AT ALL USEFUL

ESSEENTILLL + VERY

DON'T KNOW SHAC SHAC TOTAL PASS ALL
DJE- NDOE SHAC RES RES
F JNO FUNO RES

100 ? 100 ? $100^{8} \cdot 100 \% 180^{\circ}$ ? $100^{9}, 100$. $100^{8}, 100$. $10^{146}$. $22^{2}$ 11. $22^{2} \cdot 1 \hbar^{4}$. 11. $44^{4}$. $28^{5}, 11^{1}$. $26^{38}$. 44. $33^{3} . \quad 39^{7} .33^{3} \quad 38^{56}$. $22^{2} \quad 22^{2} \cdot 22^{4} \cdot 33^{3} \cdot 26^{38}$. 33. $44^{4} . \quad 39^{7} . \quad 33^{3} . \quad 36^{2}$.

$\begin{array}{lllll}2.33 & 2.22 & 2.28 & 2.22 & 2.19\end{array}$

$\begin{array}{lllll}1.06 \quad .79 & .92 & 1.13 & .93\end{array}$

$1009.1009 .100^{18} \cdot 100$ ? $10^{\frac{1}{8} 0^{\circ}}$ 11. $6^{1} \quad 22^{2} \quad 7^{3}$ $33^{3} \quad 33^{3} \cdot 33^{6} \quad 11^{2} \quad 2^{5 !}$. $44^{4} .22^{2} \cdot 33^{6}, \quad 33^{3}, \quad 38^{68}$. 11. $44^{4} \cdot 28^{5}$. $33^{3} \cdot 27^{8}$. $44^{4} . \quad 33^{3} \cdot 39^{7} \cdot 33^{3} . \quad 36^{64}$.

$\begin{array}{lllll}2.44 & 1.89 & 2.17 & 2.22 & 2.16\end{array}$

$.84 \quad .87 \quad .89 \quad 1.13 \quad .90$
SPACE WAYEC NCOAE TOTAL SHANC OTHE TOTAL PASS MAL EOUIP MANUF MEAT HEAT COLL COLL CUPA MANUF MANUF

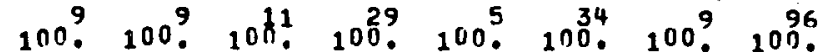
$100^{9} \cdot 100^{9}$. $10 n^{10} \cdot 100^{28} 100^{5} \cdot 1033.1009 .100^{35}$ $44^{4} \quad 22^{2} \cdot 10^{1} \cdot 25^{7} \cdot 40^{2} \cdot 27^{9} \quad 33^{3} \cdot 23^{2} \cdot$ 33. $44^{4} .210^{1} .29^{8} .20^{1}$. $27^{9} .11^{1} \quad 32^{30}$ $22^{2} \quad 33^{3} \cdot 70^{7} \cdot 43^{12}, 20^{1} \cdot 39^{13} \cdot 44^{4} \cdot 36^{34}$. 10! 4 ! 20 ! $6.211^{1}$ ? 9 $70^{7} \quad 67^{6} \cdot 20^{2} \cdot 54^{15^{\circ}} 60^{3} .55^{8} .44^{4} .55^{2}$

$\begin{array}{llllllll}3.22 & 2.89 & 2.20 & 2.75 & 2.80 & 2.76 & 2.67 & 2.68\end{array}$ $\begin{array}{llllllll}.79 & .73 & .74 & .87 & 1.16 & .91 & 1.04 & .94\end{array}$

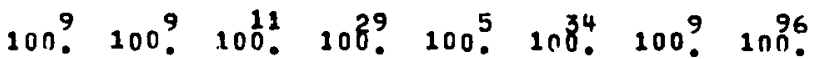
$600^{3} \quad 9^{3} \quad 22^{2} \cdot 15^{4}$. 22. $12^{2} \cdot 36^{4} \cdot 24^{7} \cdot \quad 21^{7^{1}} 22^{2} \cdot 26^{5}$ $56^{5}, 11^{1}, 55^{6}, 41^{12}, \quad 35^{2} \quad 44^{4}, 35^{4}$. $22^{2} \quad 78^{7} \quad 9^{1} \quad 34^{10} \quad 40^{2}$ 35! $11^{1} \cdot 24^{23}$ $22^{2}$. $11^{1} \cdot 36^{4} \cdot 24^{7} \cdot 60^{3} \cdot 29^{10} \cdot 44^{4} \cdot 41^{39}$

$\begin{array}{llllllll}2.00 & 1.33 & 2.27 & 1.90 & 2.80 & 2.03 & 2.56 & 2.31\end{array}$ $\begin{array}{llllllll}.66 & .67 & .62 & .74 & 1.46 & .95 & .94 & .99\end{array}$

S.CALE: ESSENTIAL $=4$, VERY USEFUL $=3$, SOMEWHAT USEFUL $=2$, NOT AT ALL USEFUL $=2$

Figure F-1. Passiye Solar Heating and Cooling Data Tables (continued) 
(OCTOBER, 1979$)$

USEFULNESS OF SPECIFIED INFORMATION ITEMS - CONTINUED (OUESTION 8 )

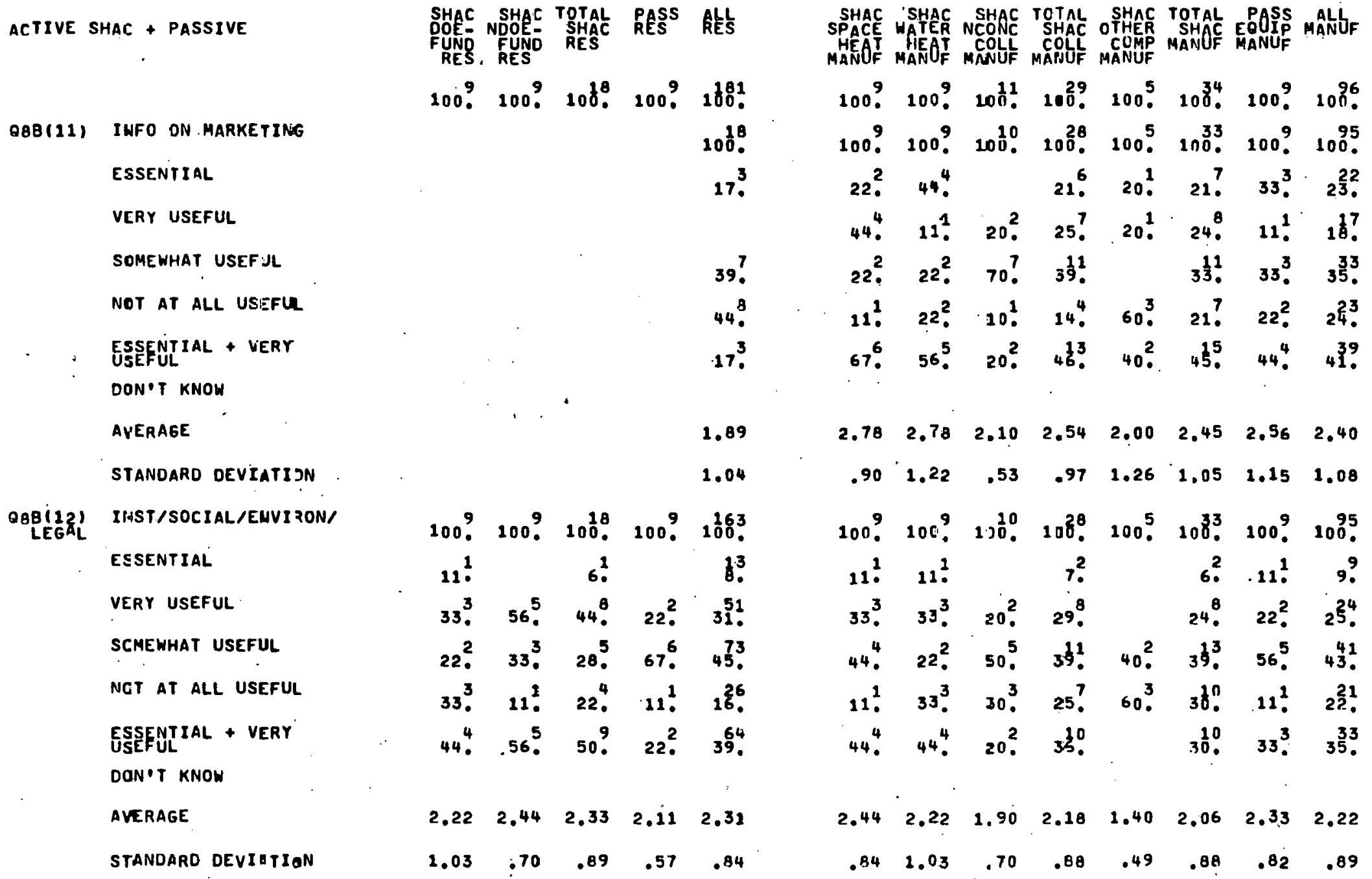

SCALE: ESSENTIAL $=40^{\circ}$ 'VERT, USEFUL $=3$, SOMEWHAT USEFUL $=2$, NOT AT ALL USEFUL $=1$

Figure F-1. Passive Solar Heating and Cooling Data Tables (continued) 
(OCTOBER, 1979$)$

USEFULNESS OF SPECIFIED INFORMATION ITEMS - CONTINUEO (OUESTION B)

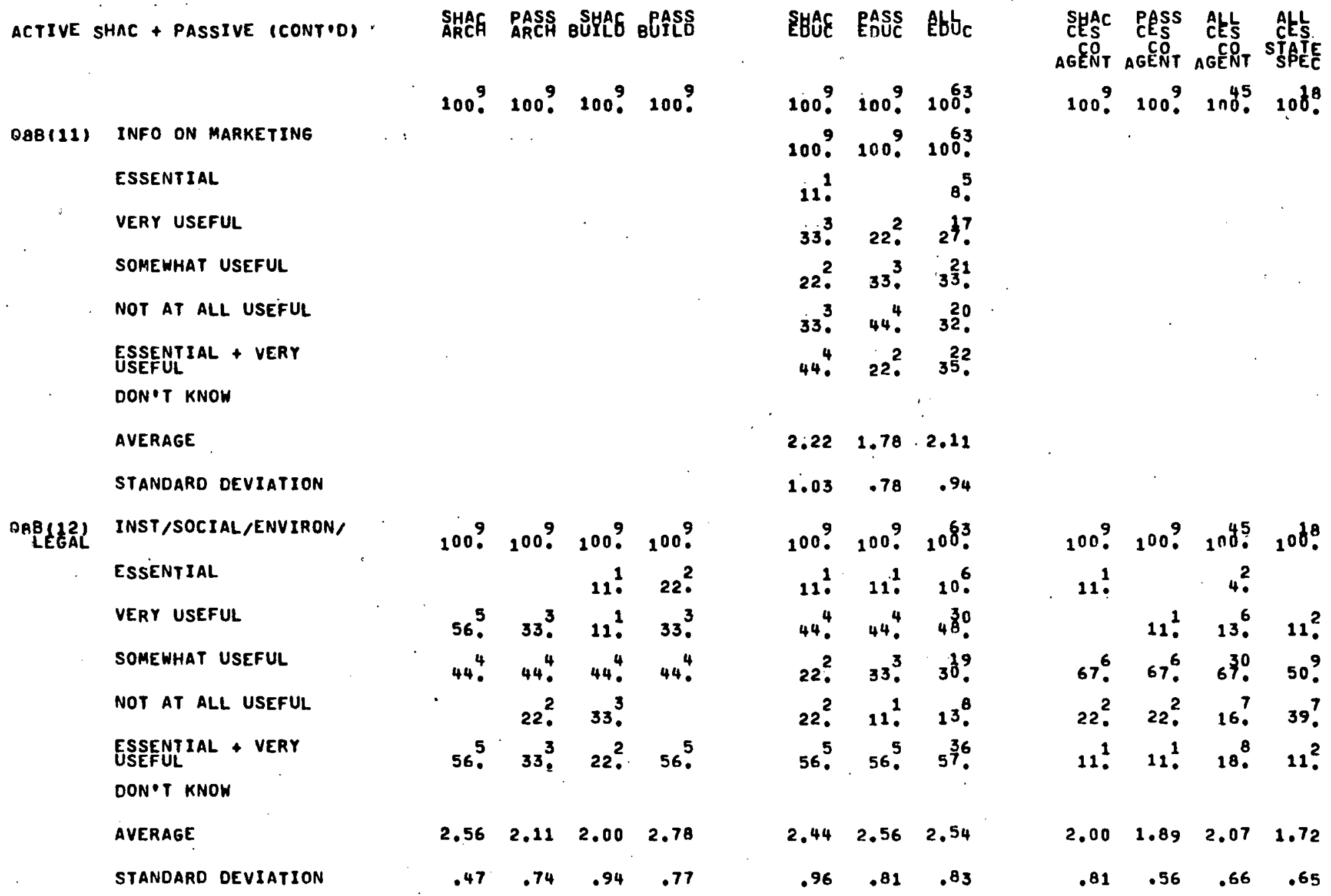

SCALE: ESSENTIAL $=4$, VERY USEFUL $=3$, SOMEHHAT USEFUL $=2$, NOT AT ALL USEFUL $=1$

Figure F-1. Passive Solar Heating and Cooling Data Tables (continued) 


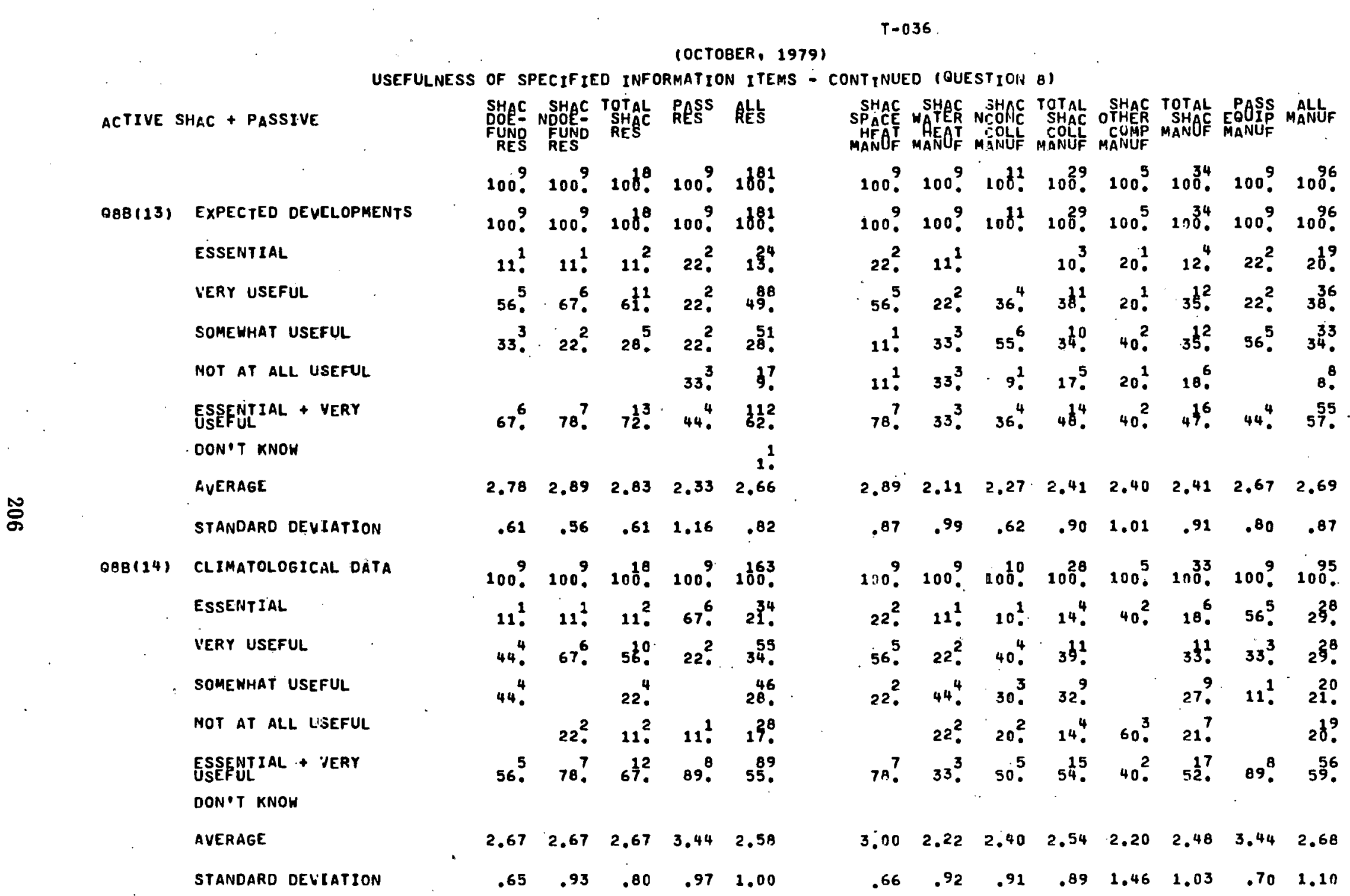

SCALE: ESSENTIAL $=4$, VERY USEFUL $=3$, SOMEWHAT USEFUL $=2$, NOT AT ALL USEFIL $=1$

Figure F-1. Passive Solar Heating and Cooling Data Tables (continued) 


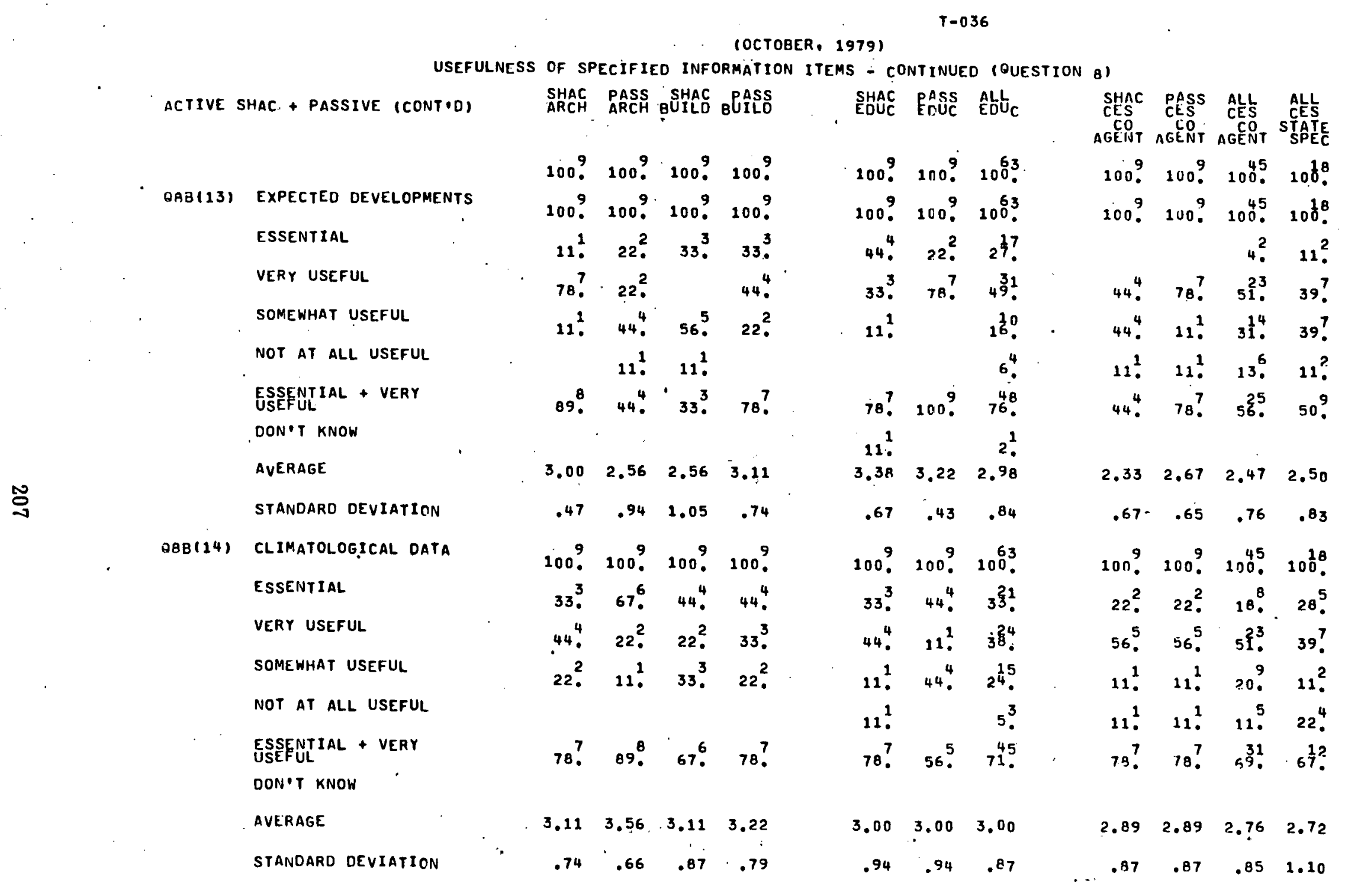

SCALE: ESSENTIAL $=4$, VERY USEFUL $=3$, SOMEWHAT USEFUL $=2$, NOT AT ALL USEFUL $=1$

Figure F-1. Passive Solar Heating and Cooling Data Tables (continued) 
(OCTOBER, 1979)

USE OF SPECIAL ACQUISITION METHOOS (OUESTION 10)

ACTIVE SHAC + PASSIVE

Q1OA COMPUTER TERMINAL
1. YES
2. NO
B. DON?T KNOW/NA

Q10B MICROFORM - COMPUTER
SHAC SHAC TOTAL PASS ALL RES QES RES

$100^{9} \cdot 100$. $100^{8} \cdot 100^{9} \cdot 1801$
SHAC SHAC SHAC TOTAL SHAC TOTAL PASS ALL SPACE WATER NCCNC SHCC OTHER SHAC EQUIP MANUT MANOF MaNNG NâUT MaNÚF MANUT $100^{9}, 100^{9}$. $100^{11}, 100^{29}, 100^{5}, 100^{3}, 1009.100^{6}$.

$44^{4}, \quad 67^{6} . \quad 56^{10}, \quad 44^{4} . \quad 34$.

$56^{5} .33^{3}, \quad 44^{8} .256^{5} .646$.

2. $78^{7} \quad 67^{6} \quad 82.076^{22} \quad 80_{0}^{4} \quad 76_{0}^{26} \quad 67^{6} . \quad 77^{4}$.

$\begin{array}{llllll}\text { 1. YES } & & 22^{2} & 11^{2} & 111^{1} & 16 \\ \text { 2. NO } \\ \text { B. DON.1 KNOW/NA }\end{array}$

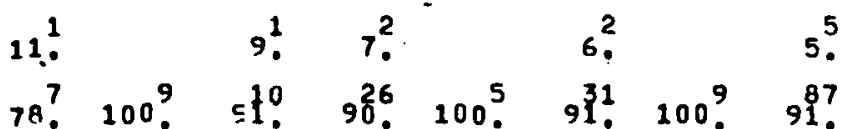

$$
\begin{aligned}
& \text { i1. } \quad 3 \text {. } 3 \text { ? }
\end{aligned}
$$

Q1OC OTHEA MICROFORM
1. YES
2. NO
8. DON!T KNOW/NA

$$
\begin{array}{rrrrr}
22^{2} & 44^{4} \cdot & 33^{6} & 11^{1} & 40^{2} \\
78^{7} & 56^{5} & 67^{2} & 89^{8} & 68^{8} \\
& & & & 1
\end{array}
$$

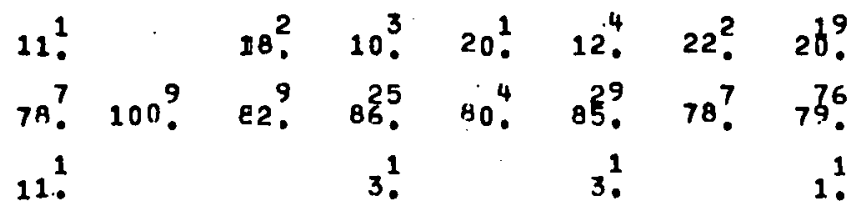

Figure F-1. Passive Solar Heating and Cooling Data Tables (continued) 
(OCTOBER, 1979 )

$T-038$

USE OF SPECIAL ACQUISITION METHODS (QUESTION 10 )

ACTIVE SHAC + FASSIVE (CONTIO)

SHAC PASS SHAC BPASS SHAC EASS ALL
ARCH ARCH BUILD BULD

$100^{9} 100^{9} 100^{9} 100^{9} \quad 1009.1009100^{63}$

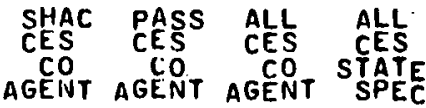

100 . 100 . $100^{45} .100^{8}$.

Q1OA COMPUTER TERHINAL
1. YES
2. NO
8. DON?T KNOW/NA

$\begin{array}{llllll}56^{5} & 44^{4} & 33^{3} & 33^{3} \\ 44^{4} & 56^{5} & 67^{6} & 56^{5} \\ & & 11^{1}\end{array} \quad 100^{9} \quad 89^{8} \quad 78^{49}$

33. $11^{1} \quad 16^{7} 44^{8}$.

$67^{6} 89^{8} .84^{38} .55^{\frac{1}{n}}$

O10B MICROFORM - COMPUTER
1. YES
2. No
8. DON.T KNOW/NA

$22^{2}$

78. 100 . 89.8100 .

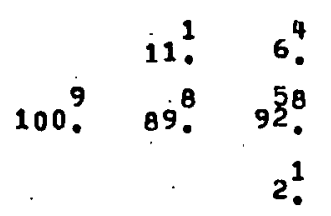
11. $11^{1}$. $7^{3} \quad 28$.
$89^{8} \quad 89^{8} . \quad 91^{41} \quad 61^{1}$.
2. $11^{2}$.

11 .

QIOC OTHER. MILROFORM
1. YES
2. NO
B. DON'T KNOW/NA

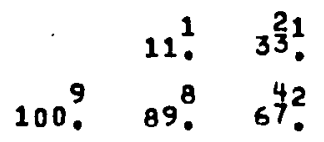

11. $11^{1}$ 9. $\quad 33^{6}$.

78 ? $1009.67^{6} .100$ ?

Figure F-1. Passive Solar Heating and Cooling Data Tables (continued) 
(OCTOBER, 19791

USE OF SELECTED SOLAR INFORMATION SOURCES IOUESTION" 111

ACTIVE SHAC + PASSIVE

DI1(1) LIBAARY (ORG/LOCAL)

1. YES

2. No

8. DON'T KNOW

Q11(2) PUBLIC UTILITY

1. YES

它

2. NO

B. DON"T KNOW

DIISTGNER INSTALLER/BUILOER/
1. YES
2. No
8. DON!T KNOW

O11(4) WORKSHOPSICONFE.ENEES

1. YES

2. NO

8. DON'T KNOW
SHAC SHAC TOTAL PASS ALL
DOE NDOE- SHAC RES RES
FUND FUND RES FUND FES

100 ? 100 ? $100^{8} \cdot 100$ ? 188 ! 100 . 100 . $100^{28}, 100 \%$. 100 . 67. $78^{7}, 72^{13}, \quad 78$. 640 33. $22^{2} \cdot 28^{5} \cdot 22^{2} \cdot 26^{28}$ 1.

$1000^{9} 100$ ? $100^{8}, 1009.160^{80}$. 44. $78^{7}, \quad 61 . \quad 44^{4} .51^{91}$. 56. $22^{2} \cdot 39^{?} \quad 560^{5} \quad 498$. 1.

$100.100^{9}, 100^{18}, 1009$. 10180 . 78. $1009.89^{6} .89 .815$. $22^{2} \quad 11^{2} \quad 11^{1} \quad 35^{63}$.

$1009.1009 .100^{8}, 100,100$. 78 . $100^{9} .89 .289^{8}$. 88 . $22^{2} .11^{2} \quad 11^{1} 1^{21}$
SHAC SHAC SHAC TOTAL SHAC TOTAL PASS ALL MABAT MEAT COLL COLL COMP MANOF MANUF

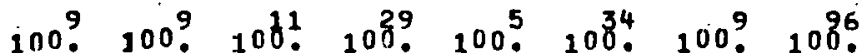

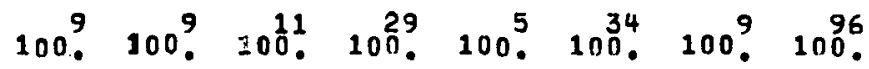
89. $56^{5} \quad 73^{8} .722^{21} \quad 60^{3} \quad 71^{24} \quad 56^{5} \quad 66^{63}$.

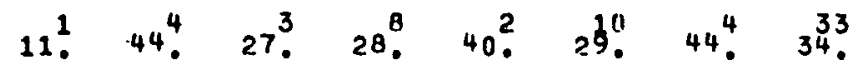

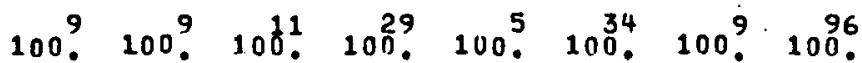
$56.533^{3} \cdot 64^{7} .52 \frac{15}{4} \quad 44^{15} .11^{1} \cdot 43^{41}$. 44. $\quad 67^{6} . \quad 36^{4} \cdot \quad 48^{14} \cdot 100^{5} \quad 56^{\frac{19}{9}} \quad 89^{8} . \quad 57^{\circ}$

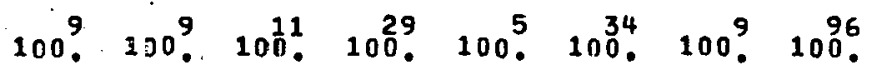

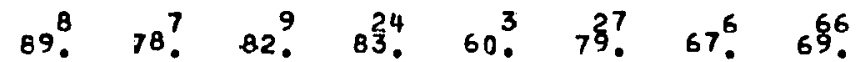
$11^{1} \quad 22^{2} \cdot 18^{2} \cdot 17^{5} \quad 40^{2} \quad 21^{7} \quad 33^{3} \quad 31^{30}$. $100^{9}, 1100^{9} .10 \hbar^{1}, 100^{29}, 1000^{5} 100^{34}, 1009.100^{96}$

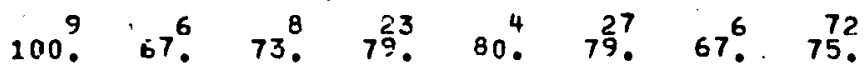
$33^{3}-27^{3} \quad 21.620^{1} \quad 21^{?} \quad 33^{3} \cdot 25^{24}$

Figure F-1. Passive Solar Heating and Cooling Data Tables (continued) 
(OCTOBER, 1979)

USE OF SELECTED SOLAR INFORMATION SOURCES (QUESTION 11)

ACTIVE SHAC + PASSIVE (CONTDD) SHAC PASS SHAC PASS ARCH ARCH BUILD BUILO SHAC PASS ALL

QI1(1) LIBRARY (ORG/LOCAL)

1. YES

2. NO

B. DON'T KNOW

Q11(2) PUBLIC UTILITY

1. YES

$\stackrel{\Xi}{\Xi}$

B. DON'T KNOW

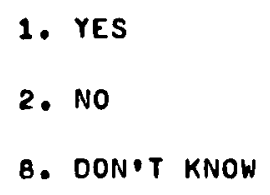

B. DON'T KNOW

211(4) WORKSHOPS/CONFERENCES
1. YES
2. NO
B. DON!T KNOW

\begin{tabular}{|c|c|c|c|c|c|c|}
\hline $100^{9}$ & $100^{9}$ & $100{ }^{9}$ & $100^{9}$ & $100^{9}$. & $100{ }^{9}$ & $100^{63}$ \\
\hline 1009 & 1009 & $100{ }^{9}$ & $100 ?$ & 1009 & $1000^{\circ}$ & $100^{63}$ \\
\hline $67^{6}$. & $33^{3}$. & 56. & $56^{5}$ & $67^{6}$. & $89^{8}$. & $86^{54}$ \\
\hline $33^{3}$ & $67^{6}$. & $44^{4}$. & $44^{4}$. & $33^{3}$ & 11 . & 14 ? \\
\hline
\end{tabular}

2009.1009 . 1009.100 ?

78?. $44^{4} \cdot 33^{3} \cdot 56^{5}$.

$22^{2} .56^{5} \quad 67^{6} \cdot 44^{4}$.

100 . 100? 100 \% 100 ?

$89.899^{8} .89 \%$

11. 11. 11! 11.

100 . 1009 . 100 ? 100 .

89. 1009 . 100 . 100 ?

11 .
$1009.1009 .100^{63}$

78. $100^{9} .896$.

$22^{2}$.

11 ?

1009.1009 .1003

22. $78^{7} \cdot 55^{36}$.

$78^{7} \cdot 22^{2} \cdot 43^{2}$.

100. $100^{9} .100^{63}$

100 . $78^{7} .90$.

$22^{2} .10^{6}$.
SHAC PASS ALL ALL
CES CES CES CEES
CO CO CO STATE
AGENT AGENT AGENT SPEEC 100 ? 100 . $100^{45} 100^{18}$. $100^{9} 1009.100^{45} 100^{18}$ $67^{6} \cdot 44^{4} \cdot 44^{20} \cdot 8^{\frac{1}{3}}$. 33. $56^{5} .56^{2} . \quad 17^{3}$.

$100^{9} 100^{9} .100^{45} 100^{18}$. $44^{4} .33^{3} .44^{20} .61^{\frac{1}{1}}$ 56. $56.56^{5}$. 39 ? $11^{1}$. ${ }^{2}$

$100^{9} \cdot 100^{9} \cdot 100^{45} \cdot 10^{18}$. 78 ? $44^{4} .533^{24} \quad 61^{11}$ $22^{2}$. $56^{5} .47^{21} \quad 39$ ?

$100^{9} 100^{9}, 100^{45} 100^{18}$ $56.544^{4} .56 .258^{\frac{15}{3}}$. $44^{4} .56^{5} . \quad 44^{20} . \quad 17^{3}$.

Figure F-1. Passive Solar Heating and Cooling Data Tables (continued) 
(OCTOBER, 1979)

USE OF SELECTED SOLAR INFORMATION SOURCES - CONTINUED (UUESTIDN 11 )

ACTIVE SHAC + PASSIVE

D11(5) COMMERCIAL DATA BASE

1. YES

2. NO

8. DON'T KNOW

Q11 16 CENTER FEOERAL LIBRARYIINI=0

$\stackrel{N}{N}$
SHAC SHAC TOTAL PASS ALL

FUNO FUND - RES

$100^{9} 100^{\circ}$ i $100^{18} 100^{9} 10^{81}$

$100^{9} .100^{9}, 100^{8}, 100 \% 10^{181}$

67. $67^{6} \cdot 67^{2} \cdot \quad 78^{7} \cdot 38^{6}$.

$33^{3}$. $33^{3}, \quad 33^{6}, 22^{2}$ है।.

$2^{3}$

$$
\begin{aligned}
& 100^{9} \cdot 100^{8} .100^{17}, 100^{9} .1180
\end{aligned}
$$

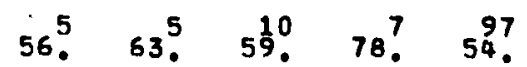

$$
\begin{aligned}
& 22^{2} \quad 38^{3} \quad 29^{5} \quad 22^{2} \quad 43^{78} . \\
& 22^{2} \\
& 12^{2} \\
& 3 .
\end{aligned}
$$

100. 100. $100^{8} .100$. 1001

$22.233^{3} .28 .511 .230$.

78. $\quad 67 . \quad 7 \frac{13}{3} . \quad 78$ ? $81^{46}$.

\begin{tabular}{|c|c|c|c|c|c|c|c|}
\hline $100^{9}$ & $100^{9}$ & yoti & $100^{29}$ & $100^{5}$ & $\operatorname{lno} 34$ & $100^{9}$ & $100^{96}$ \\
\hline $00^{9}$ & $100^{9}$ & $100^{11}$ & $100 ?$ & $100^{5}$ & 100 & $100^{9}$ & $100^{96}$ \\
\hline $33^{3}$. & $22^{2}$ & 9 & $21^{6}$ & & $18^{6}$ & $11^{1}$ & • \\
\hline & $78^{7}$ & $91^{0}$ & $79^{23}$ & vo & $B 2^{28}$. & $89^{\circ}$ & $78^{5}$ \\
\hline
\end{tabular}

11.
SPHAC WSHAC SHAC TOTAL SHAC TOTAL PASS ALLL MASOT MENOT MENUF MANUF YANUTF MANIUF. MANUF

$100^{9} 100^{9} \cdot 100^{11} 100^{29} 100^{4}, 100.1009 .1005$

\begin{tabular}{|c|c|c|c|c|c|}
\hline $100^{1}$ & $100^{1}$ & $100^{5}$ & $10 f^{6}$ & $100 ?$ & $\begin{array}{r}42 \\
100 .\end{array}$ \\
\hline 9 & 9 & & $6^{1}$ & $11^{1}$ & 7. \\
\hline 10 & 910 & $100^{5}$ & $9 \frac{15}{4}$. & $89^{8}$ & 939 \\
\hline
\end{tabular}

44. $56^{4} \cdot 36^{4} \cdot 45^{3} . \quad 33^{3} .33^{3} \cdot 46^{4}$.

$56^{5} \quad 44^{4} \cdot 54^{7} \cdot 55^{16} \quad 75^{3}, \quad 58^{9} .67^{6} .53^{\circ}$.

25. $5^{1}$. 1 .
Q11(7) SSIE - SHITHSONIAN

1. YES

B. DON'T KNOW 
IOCTOBER, 1979)

USE OF SELECTEO SOLAR INFORMATION SOURCES - CONTINUED (QUESTION 11 )

ACTIVE SHAC + PASSIVE ICONTPD

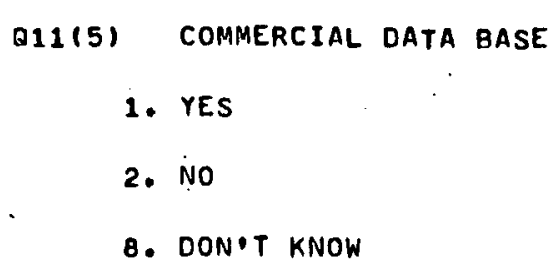

2. No

8. DON?T KNOW

011 (6) CERTER FEERAL LIBRARY/INFO

1. YES

$\stackrel{N}{\omega}$

2. NO

8. DON-T KNOW

ว11(7) SSIE - SMITHSONIAN
1. YES
2. NO
e. DON.T KNOW SHAC PASS SHAC PASS
ARCH AHCH BUYLD BUYLD

$11^{1} \quad 22^{2} \cdot 22^{2}$

$67^{6} \cdot 100^{9} \cdot 78^{7} \cdot 67^{6}$. $22^{2} .11$.$$
100 \% \text {. } 100^{9} .100^{63}
$$$$
\text { 11. } 11^{1} \cdot 2 \frac{17}{7} \text {. }
$$$$
\text { 89. } 69^{8} \text {. } 7 \frac{46}{3} \text {. }
$$

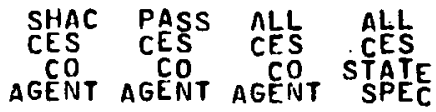

100 ? 100 ? $100^{45} 100^{8}$. $10091009100 \% 100^{18}$ $22^{2} .13^{6} \cdot 17^{3}$. 78. $100^{9}$. $87^{39} \cdot 83^{15}$.

$100^{\circ}, 100 \% 100 \% 100$ ?

44. $56^{5} .44^{4} .44^{4}$.

$56^{5} \cdot 44^{4} \cdot 44^{4} \cdot 56^{5}$

$1000^{9} 100^{9} \cdot 1003$

$44^{4} 444^{4} 52^{33}$

$56.56^{5} 48^{3}$.

$1009.1009 .100^{45}, 100^{18}$

22. $44^{4} \cdot 3^{\frac{15}{3}} \cdot 67^{2}$

$78^{7} .56 .567^{3} \cdot 33^{6}$.

11.

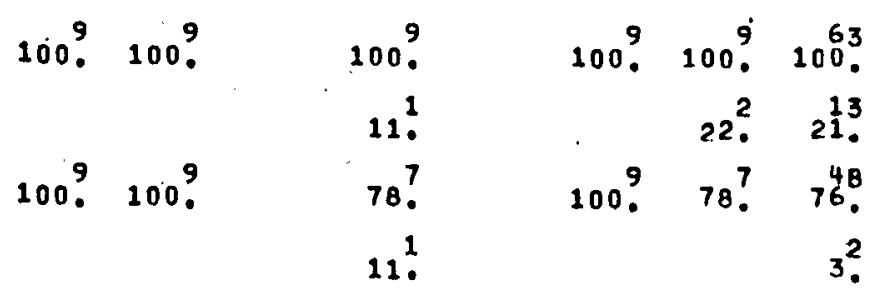

Figure F-1. Passive Solar Heating and Cooling Data Tables (continued) 
COCTOBER: 19791

USE OF SELECTEO SOLAR INFORMATION SOURCES - CONTINUEO (OUESTION 11)

ACTIVE SHAC + PASSIVE

SHAC SHAC TOTAL PASS ALL
DOE NOOE SHAC RES RES
FUND FUND RES

$1009.100 \% 100^{8} \cdot 100$ ? $10^{801}$

Q1 $\frac{1}{G P}(8)$ GOV'T PRINTING CFFICE-

1. YES

2. NO

8. DON'T KNOW

$\stackrel{N}{N}$

Q1 IN9GRMATIIONAL TECHNICAL

$$
\text { 1. YES }
$$

2. NO

8. DONTT KNOW

Q11 CENTER TECHNICAL INFORMATION

1. YES

2. NO

8. DON T KNOW
100 . 100, 100.100 . 1001 . 89.89 . 89.678 ? $44^{34}$. 11. $11^{2} .11^{2} \cdot 22^{2} .24$.

$$
2 .
$$

$1009.1009 .200^{8} .100$ ? $1800^{8}$ ?

100, 100 . 1078 . 100 ? $1800^{\circ}$.

67. 78 . $7 \frac{13}{2} .89 .84^{8}$.

33. $22^{2}$. $28.511^{1} .33^{59}$.

4?

100. 100 . $100^{2}, 100$. 1801.

100 . 100 . $100^{17}, 100$. 1000

$50.4 \quad 44^{4}, \quad 47^{8}, \quad 67^{6} . \quad 90^{72}$

50. $56^{5}, \quad 533^{9}, \quad 33^{3} . \quad 56$.

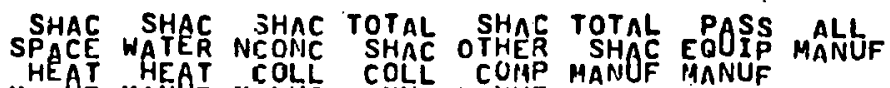
MANOF MANOF MANUF MANUF MANUF

$100^{9} .100$. $500^{11} .100^{29} .100^{5}, 100^{34}, 100^{9} .100^{96}$

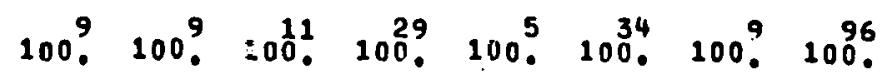

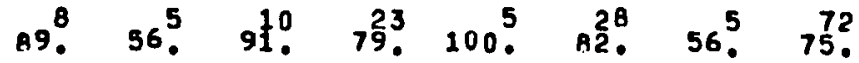
11 . $44^{4}$. $\quad 9^{1} 2^{6}$. $\quad 18^{6} \quad 44^{4}$. $25^{4}$.

100? 100 . $100^{1}$. $100^{29} \cdot 100^{5} \cdot 100^{34} \cdot 100^{9}$. $100^{96}$ 100 . 100. 105. $100^{29}$. $100^{5}$. $100^{34}$. 100 . $100^{96}$.

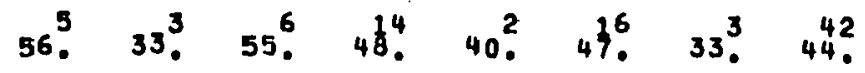

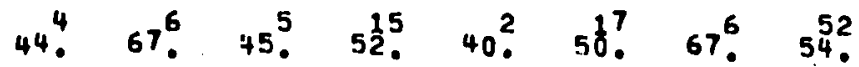
20 . 3.2 2.

100. $100^{9}$. $100^{11}, 100^{29}, 100^{5}, 100^{34}, 100$ ? $100^{96}$ 100.' 100 . $100^{11} \cdot 100^{29}, 100^{5} \quad 100^{34} \quad 100$. $100^{96}$

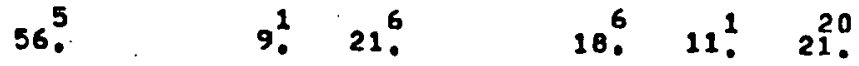

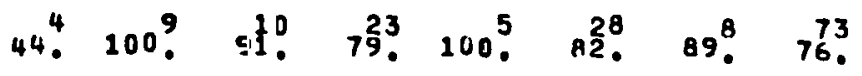

Figure F-1. Passive Solar Heating and Cooling Data.Tables (continued) 
(OCTOBEA, 1979)

USE OF SELECTED SOLAR INFORMATION SOURCES - CONTINUED (OUESTION 11)

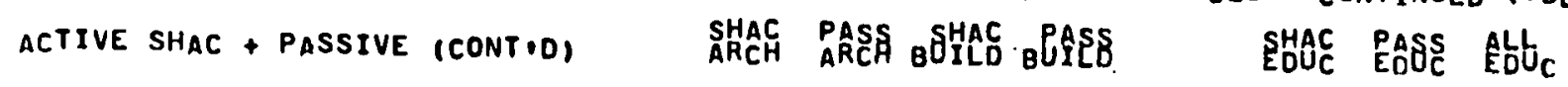

BILGPI GOV'T PFINTING OFFICE-

1. YES

2. NO

8. DON'T KNOW

Q1 INFGRMATIONONOERTECHNICAL

1. YES

2. No

8. DONIT KNOW.

O11 CEAPER IECHNICAL INFORMATION
1. YES
2. NO
8. DON T KNOW

$$
\begin{aligned}
& \text { 1009. 1009. 100? } 100 \text { ? } \\
& 100 \text { ? } 100 \text { ? 100? } 100 \text { ? } \\
& \text { 89. } 44^{4} \text {. } 89^{8} \text {. } 78^{7} \text {. } \\
& \text { 11. } 56^{5} \text {. } 11^{1} \text {. } 22^{2} \\
& \text { 100? } 200 \text { ? 100? } 100 \text { ? } \\
& 100 \text { ? } 100 \text {. 100\% } 1000^{\circ} \\
& \text { 44. } 33^{3} .44^{4} .44^{4} \\
& \text { 56. } 67^{6} \cdot 56^{5} \cdot 56^{3}
\end{aligned}
$$

$1009.1009 .100^{63}$

100 ? 100 ? 1003 .

78 . 78 . 79.

$22^{2} .22^{2} \cdot 19$.

2 .

100 ? 100 ? $100^{63}$

$1009^{\circ} 1009$ ? $100^{63}$.

33. $44^{4} .63^{4}$.

67. $44^{4} \cdot 35^{2}$.

i1! 2 ?

$\begin{array}{rrrr}1009 & 1009 & 1009 & 1009 \\ 1009 & 1009 & 1009 & 1009 \\ 22^{2} & 33^{3} & 44^{4} & 11 ! \\ 78 ? & 67^{6} & 36 ! & 78 ? \\ & & & 11 !\end{array}$

100 ? 100 ? $100^{63}$. 100 . 100 ? $100^{63}$ 44. $44^{4} \cdot 44^{28}$. 44. 44 ? 431 11. $11^{1}$. $6^{4}$
SHAC PASSS ALL CES CLLS AGENT AFEENT AGENT SISPEC 1009. 100? 1045. $100^{8}$. 100 . 100 ? $108^{45} 208^{8}$. $78^{7} \quad 67^{6} \cdot 64^{29} \cdot 63^{\frac{115}{}}$ $22^{2} \quad 33^{3} \quad 33^{5} \quad 17^{3}$. 2 .

$1009.1009 .1045 .106^{8}$. 100 . 100 ? $100^{45} 100^{2}$. 11 . 7 . 50 ? 78. 100 \% $83^{39}$. 50 ? 11 . 7 .
$1000^{9} 1009.1000^{45} 100 \%$ $1009.1009100^{45} 108^{8}$. 11 . 11 . 11 . 50 ? 89. $89^{8} .289^{39} 50^{9}$. $2^{1}$

Figure F-1. Passive Solar Heating and Cooling Data Tables (continued) 


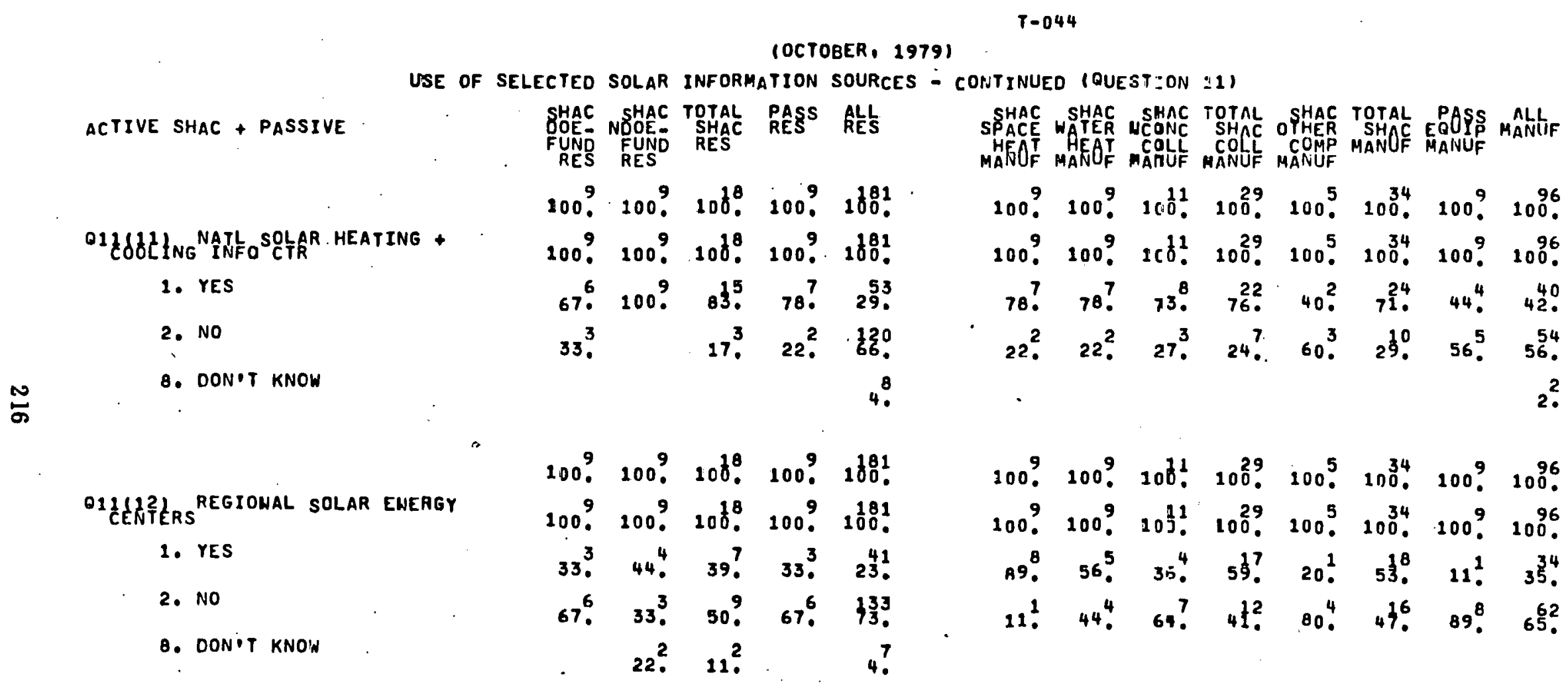

Figure F-1. Passive Solar Heating and Cooling Data Tables (continued) 


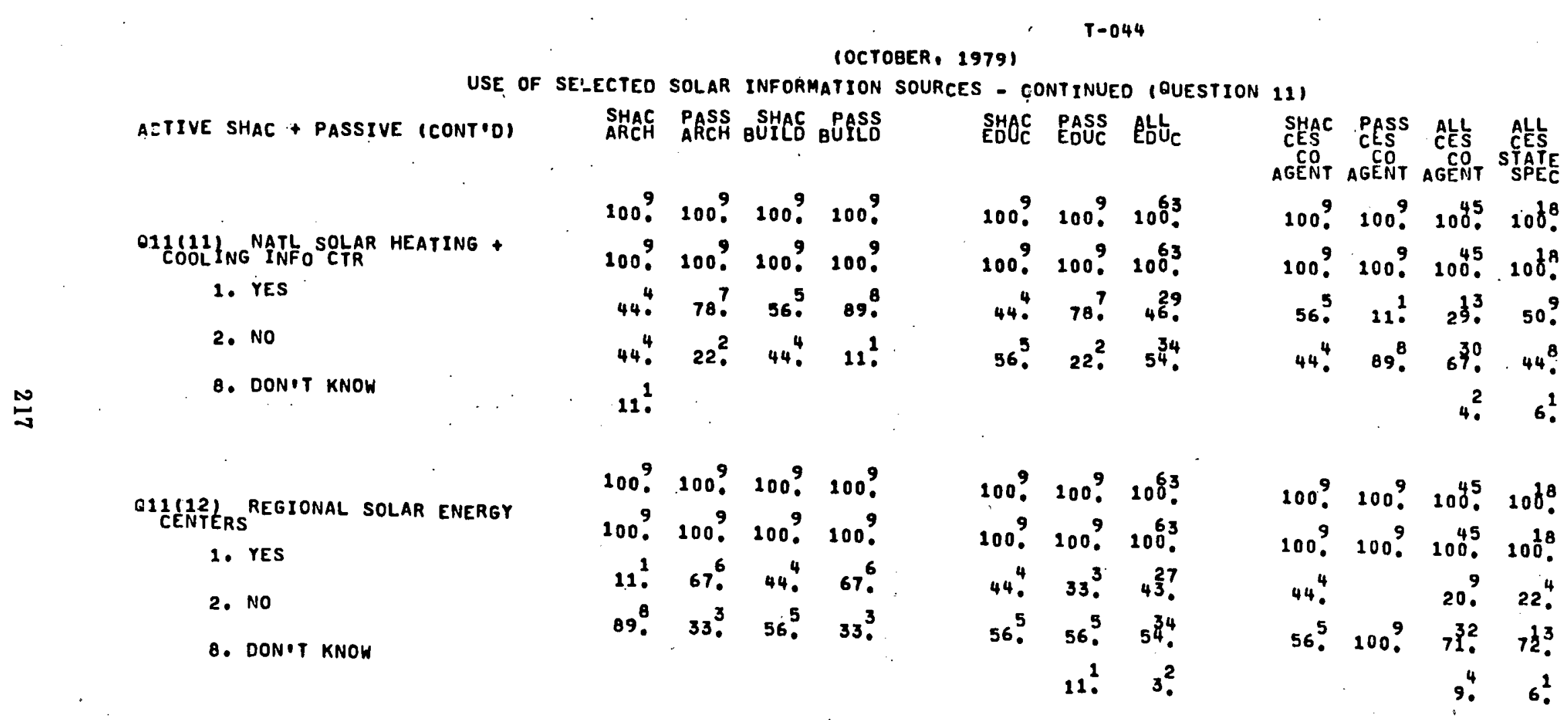

Figure F-1. Passive Solar Heating and Cooling Data Tables (continued) 
(OCTOBER, 1979 )

USE OF SELECTED SCLAR INFORMATION SOURCES - CONTINUED (QUESTION 11 ).

ACTIVE SHAC + PASSIVE

D11(13) US DEPT, OF ENERGY

1. YES

2. NO

8. DON?T KNOW

O11114) RADIOITV

1. YES

$\stackrel{\infty}{\infty}$

2. NO

8. DaN'T KNOW

D1 REDS 5 PAPERS IODICALS /

i. YES

2. NO

B. OON?T KNOW

Q1ENOEKONARIYATE SOLAR:

2. YES

2. NO

B. DOH'T KNOW
SHAC SHAC TOTAL PASS RLL
DOOE- NOOE-
FUNAC RES RUNO RES

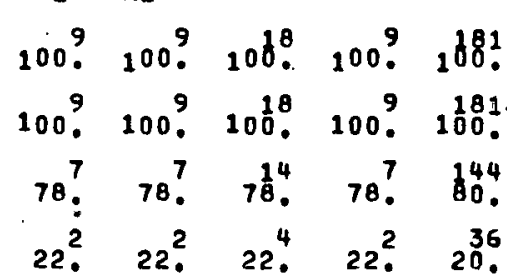

1 .

SPAAC SHAC SHAC TOTAL SHAC TOTAL PASS MALL MANOF MANOF MAGLITF MANIJF MANUF MANOF MANUF

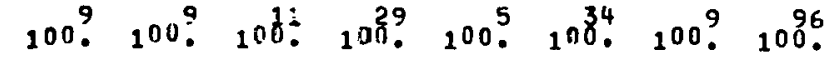
$100^{9}$. 100 . $100^{13}, 100^{29}, 100^{5}, 100^{34}, 100^{9}, 100$.

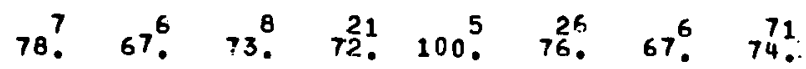

$22^{2} \quad 33^{3} \quad 27^{3} \quad 28^{8} \cdot \quad 24^{8} \quad 33^{3} \quad 25^{4}$.

1 .

100.1000.

$22^{2} 22^{22}$.

$78^{7}, 71$.

1.

$100 .{ }^{1}{ }^{1} 0^{9}$.

$1009.1009 .1001 .1029,1005,1034, \cdots 100$.

$1009.98^{3}$.

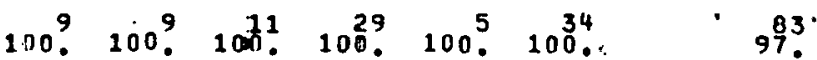

6

3.

$1009.1009 .100^{8}, 1009.180^{81}$

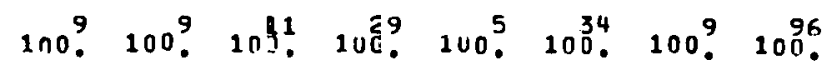

$78^{7} \cdot 78^{7}, 78^{4}, 78^{7} \quad 53^{96}$.

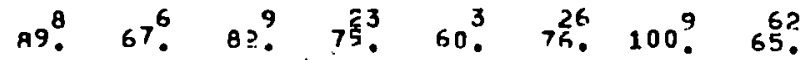

$22^{2} \cdot 22^{2} \cdot 22^{4}$. 2.? $45^{2}$.

$11^{1} \quad 33^{3} \quad 1.3^{2} \quad 21^{6} \quad 40^{?} \quad 24^{n}$. $32^{31}$

Figure F-1. Passive Solar Heating and Cooling Data Tables (continued) 
IOCTOBER, 19791

USE OF SELECTED SOLAR INFORMATION SOURCES - CONTINUED (QUESTION 11)

\begin{abstract}
aCTIVE SHAC + PASSIVE (CONTIDI SHAC PASS SHAC PASS
ARCH ARCH BUILD. BUILO SHOC PASS RLL
\end{abstract}

Q11(13) US DEPT. OF ENERGY
1. YES
2. NO
B. DON'T KNOH

Q11(14) RAOIO/TV

1. YES

$\stackrel{10}{10}$

8. DONיT KNOW

D1ALAFSAPERS TODICALS,

1. YES

2. No

B. DON'T KNOW

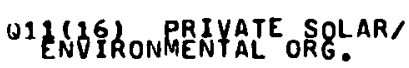

1. YES

2. NO

8. DONPT KNOW

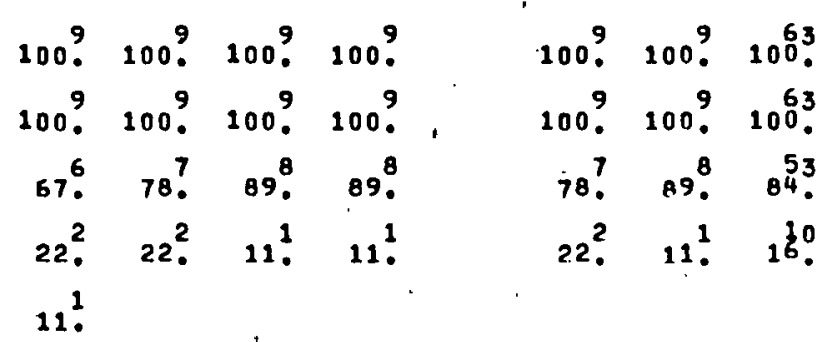

$$
\begin{array}{rrr}
1009 & 1009 & 1000^{9} \\
22^{2} \cdot & 22^{2} \cdot & 56^{\circ} \\
78^{7} & 78 ? & 44^{4}
\end{array}
$$

$1009.1009 .100^{2}$.

$56.57^{6} . \quad 53^{3}$.

$44^{4} .33^{3} .45^{3}$.

$2^{1}$

1009. 100 ?. 100 . 100?

89. $89^{8} .100^{\circ} .100$ ?

11. 11 ?
$1009.1009 .100^{63}$
89. $100^{9}$. 971
11 . 3 .

100? 100? 100? 100 ?

1009 ? 1009 . $100^{63}$

$56^{5} .09 .856^{5} .78^{7}$.

44. 11. $44^{4}$. 11.

44. $56.56^{42}$.

56. $44^{4} .33^{2}$.

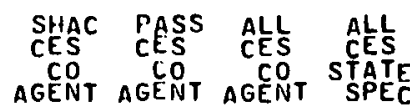
$1000^{9} 1000^{9} 100^{45} 100^{18}$. $1009.1009 .100^{45} 100$. 56. $22^{2} \cdot 5^{23} \cdot 8^{16}$. 44. 78. $44^{20}$. 11 ? 4.

100. 1009 . 1 กnก $^{45} 100^{8}$. 56. $22^{2} \cdot \quad 4 \frac{19}{2}$. $6 \frac{11}{1}$ $44^{4} \quad 78^{7} .565 .239$. 2 .

$1009.1009 .100^{45} .100^{\frac{18}{6}}$. $100^{9} .67^{6} .8^{39} .106^{8}$. $33^{3} .13^{6}$.

\begin{abstract}
1009. $1009.100^{45}, 1078$ 67. $22^{2} . \quad 36 . \quad 39 ?$ 3.3 .78 . 60.61 .
\end{abstract} 11 .

Figure F-1. Pàssive Solar Heating and Cooling Data Tables (continued) 
IOCTOBER, 1979)

USE OF SELECTED SOLAR INFORMATION SOURCES - CONTINUEO (QUESTIDN 111

ACTIVE SHAC + PASSIVE

Q11117fES STATE ENERGY OR SOLAR

1. IES

2. No

8. DONIT KNOW

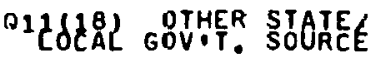

1. YES

స్ำ

2. NO

B. DON?T KNOW

OISOCIETYINIESSOLAR ENERGY

1. YES

2. No

8. LON?T KNOW

O1H(2D) INDSTRLAR ENEREY

1. TES

2. $\mathrm{NO}^{\circ}$

B. RON?T KNOW
SHAC SHAC TOTAL PASS RLL
DOE- NOOE- SHAC RES RES
FUND FUND RES

$1000^{\circ} 1000^{9} 108^{8} .100^{9} .1801$

100 \% 100 , $100^{18}, 100 \% 100^{\circ}$

33. $67^{3} \cdot 50^{9} \cdot 78^{7} \cdot 48^{86}$.

$67^{6} .33^{3} \quad 50^{9} \quad 22^{2} .52^{94}$.

1.

100 ? 100 ? $106^{8}, 100 \% 10^{\circ}$.

33. $56^{5}, 44^{8} \cdot 22^{2} \cdot 28^{49}$.

67. $44^{4} .56^{10} \quad 78^{7} \cdot 128$

1

$1009.1009 .100^{8}, 1009.1001$

$67^{6} \quad 78^{7} \cdot 72^{\frac{1}{2}} \cdot 89^{8} \cdot 48^{87}$.

33. $22^{2} \cdot 28^{5} \cdot 11^{1} \cdot 51^{92}$

1.

$1009 \cdot 1009100^{8} \cdot 1009 \cdot 10^{81}$

$78^{7} \quad 78^{7} \cdot 78^{24} \cdot 56.533^{5}$.

$22^{2} \quad 22^{2} \cdot 22^{4} .44^{4} .65^{8}$.

SHAC SHAC SHAC TOTAL SHAC TOTAL POASS MLESF HFAT AEAT CO-L COLL CUMP MANUF MANUF

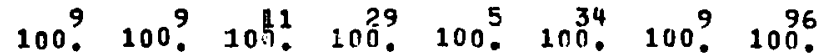

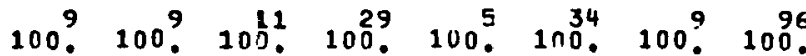
89. $89^{\circ} .79^{\circ} \quad 83^{24} \quad 80^{4} .82^{28} \cdot 44^{4} \cdot 58$.

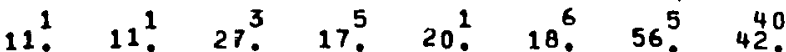

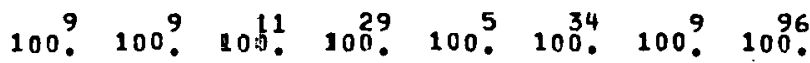
$67^{6} .44^{4} \cdot 55^{6}, \quad 55^{6} . \quad 20^{1} \cdot 50^{17} \cdot 33^{3} .42^{40}$. $22^{2} \cdot 56^{5} \cdot 45^{5} \cdot 41^{12} \quad 80^{4} \cdot 47^{6} \cdot 67^{6} \cdot 56^{4}$. $11^{1}$. $\quad 3^{1}$ 3.

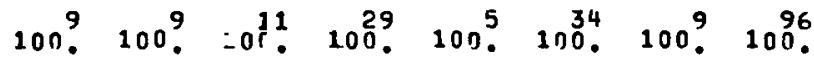
33. $67^{3} \cdot \quad 73^{8} \cdot 59^{7} \cdot 60^{3} \cdot 59.678^{7} \cdot 50^{46}$. $67^{6} \cdot 33^{3} \cdot 2 i^{3} \cdot 4 t^{2} \cdot 20^{1} \cdot 38^{3} \cdot 22^{2} \cdot 49^{4} \cdot$ $20^{1} \cdot 3^{1} \quad 1^{1}$

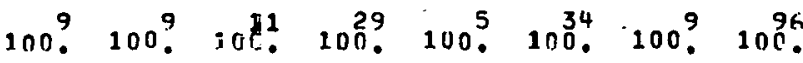
$67^{6} \quad 67^{6} \quad 8 \varepsilon^{9} \quad 72^{21} \quad 20^{1} \quad 65^{22} \quad 44^{4} \cdot 47^{45}$. $33^{3} \cdot 33^{3} \cdot 19^{2} \cdot 28^{8} \cdot 60^{3} \cdot 32^{\frac{1}{2}} \quad 56^{5} \cdot 51^{49}$.

Figure F-1. Passive Solar Heating and Cooling Data Tables (continued) 
(OCTOBER, 1979)

USE OF SELECTED SOLAR INFORMATION SOURCES - CONTINUEO (QUESTION 11)

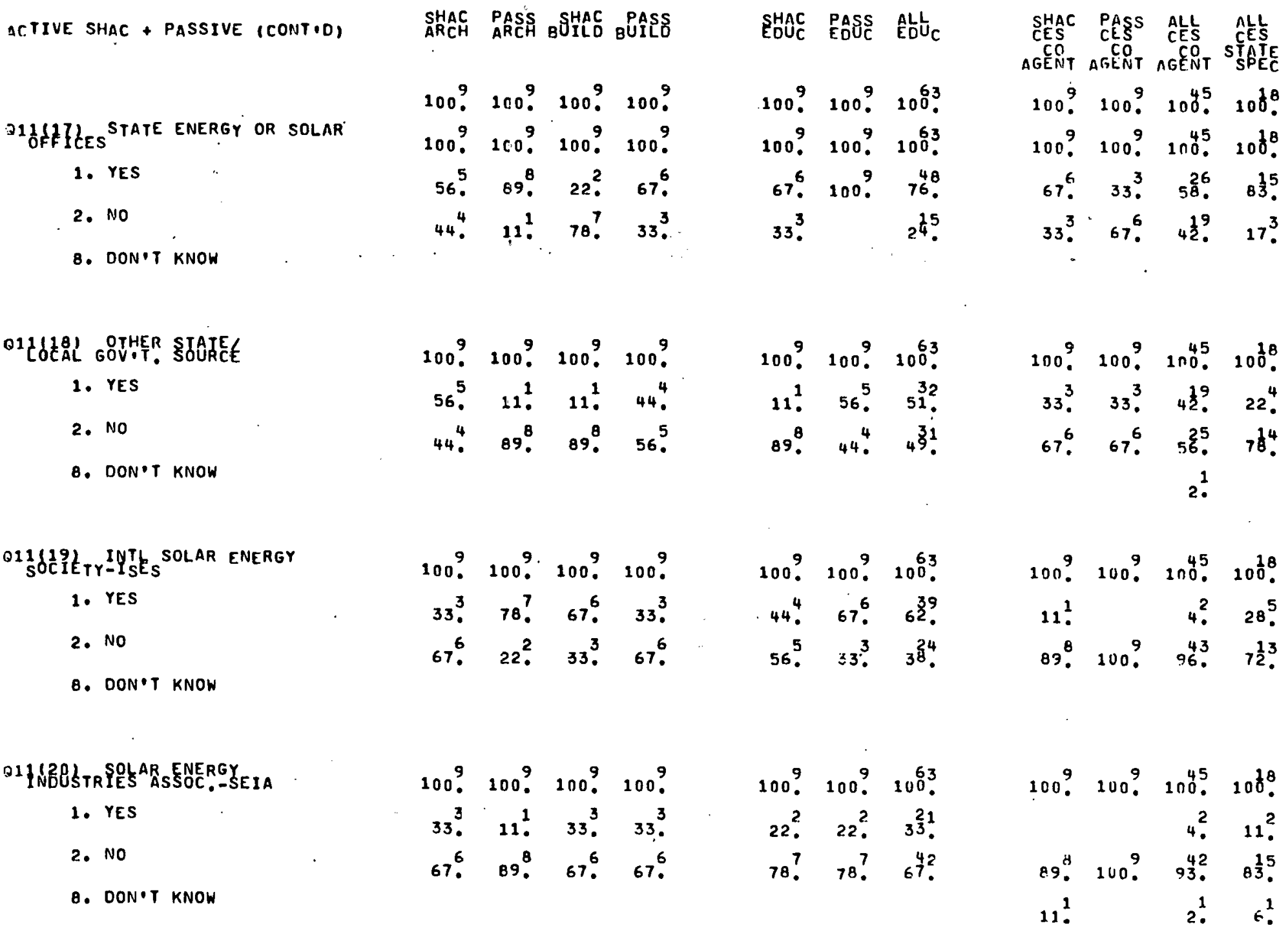

Figure F-1. Passive Solar Heating and Cooling Data Tables (continued) 
Figure F-1. Passive Solar Heating and Cooling Data Tables (continued)

USE OF SELECTED. SOLAR INFORMATION SOURCES - CONTINUED (QUESTION 11)

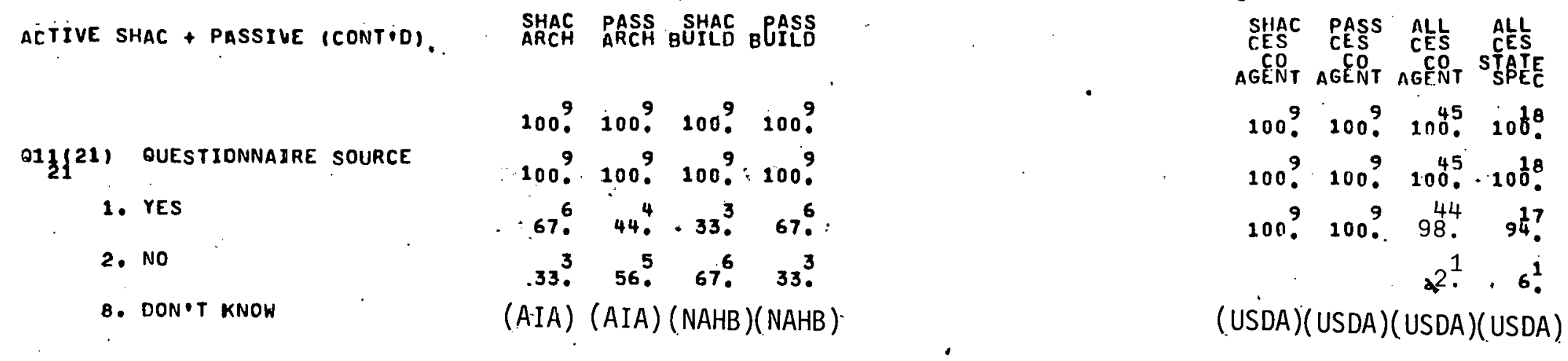




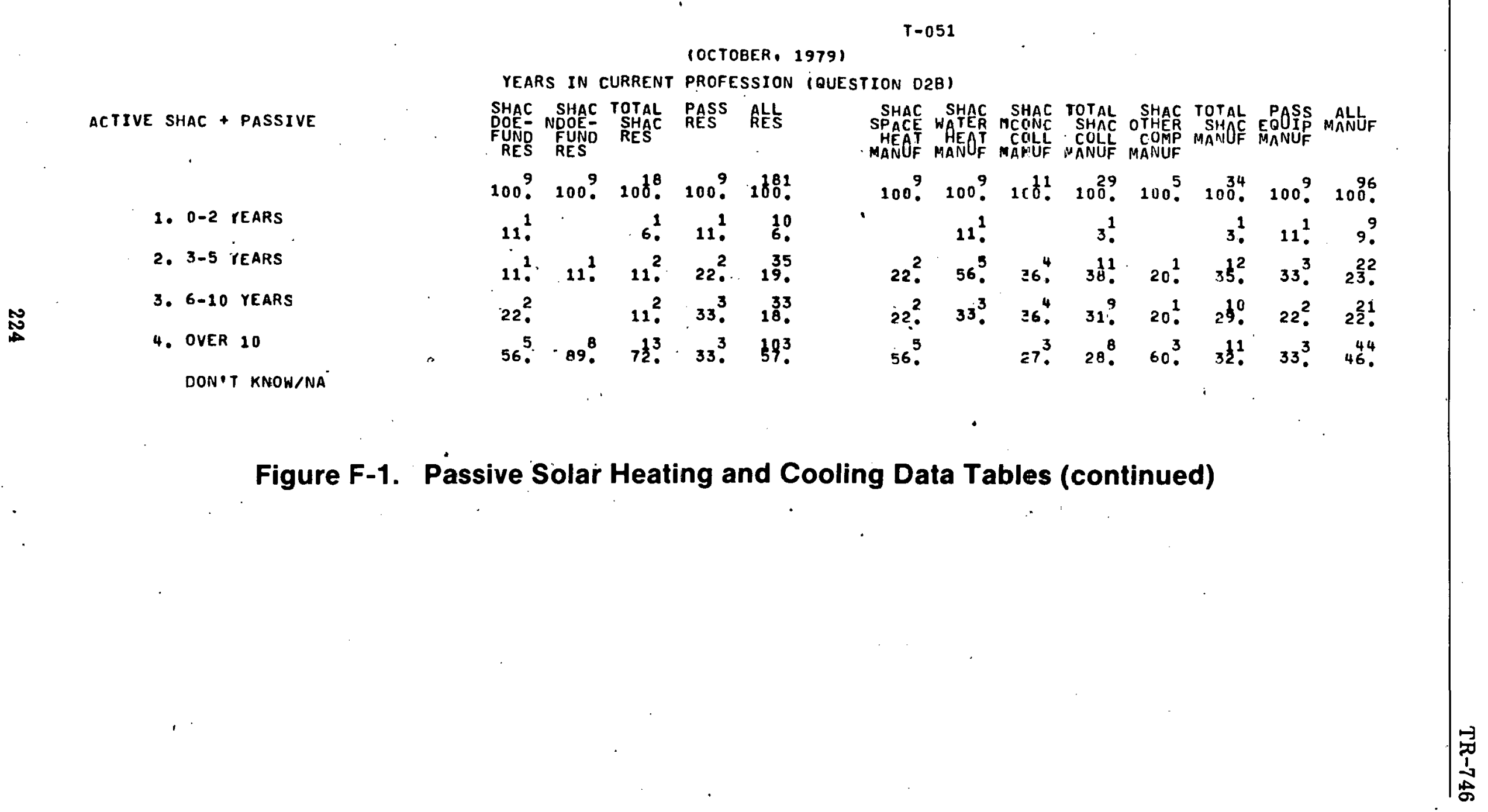




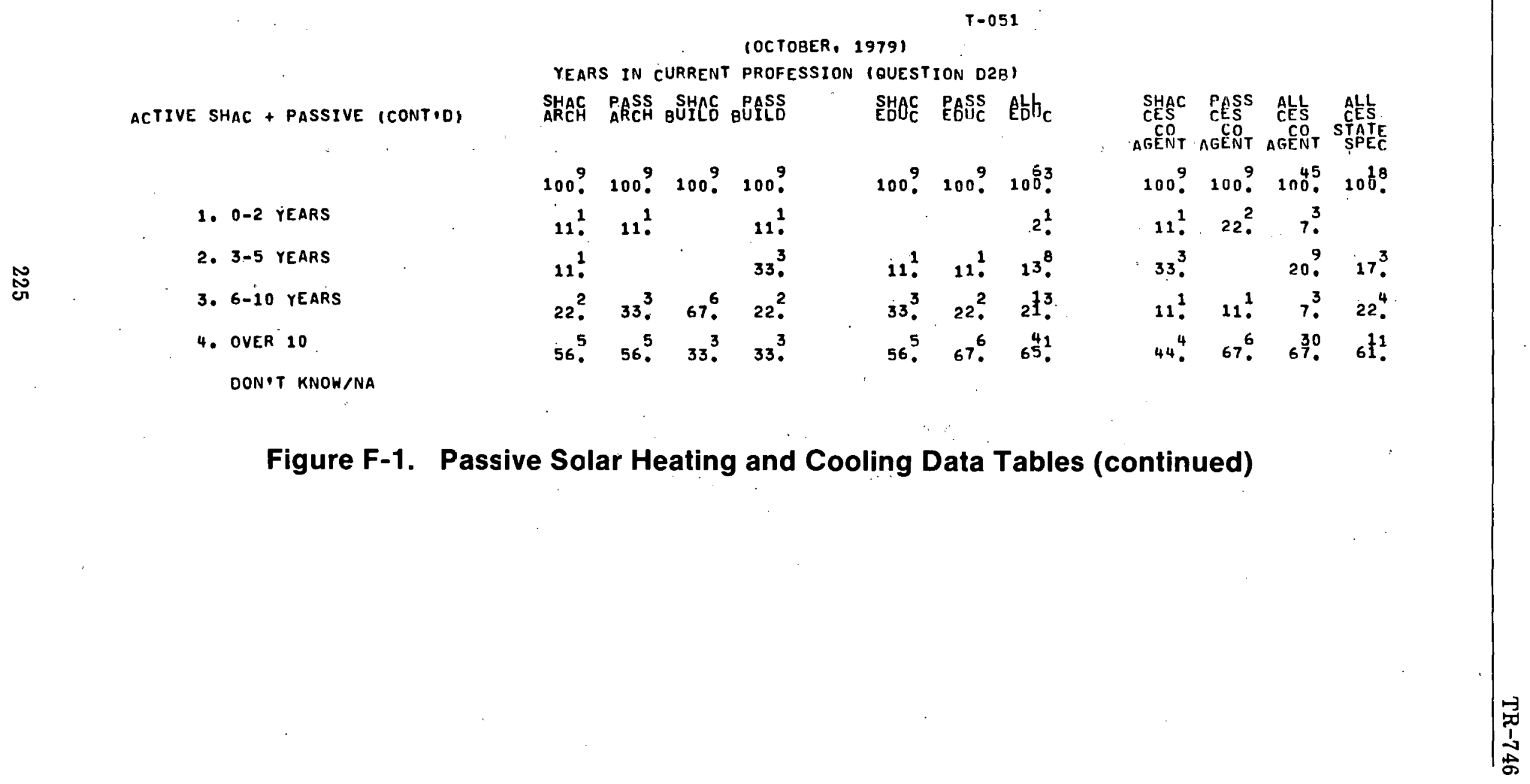




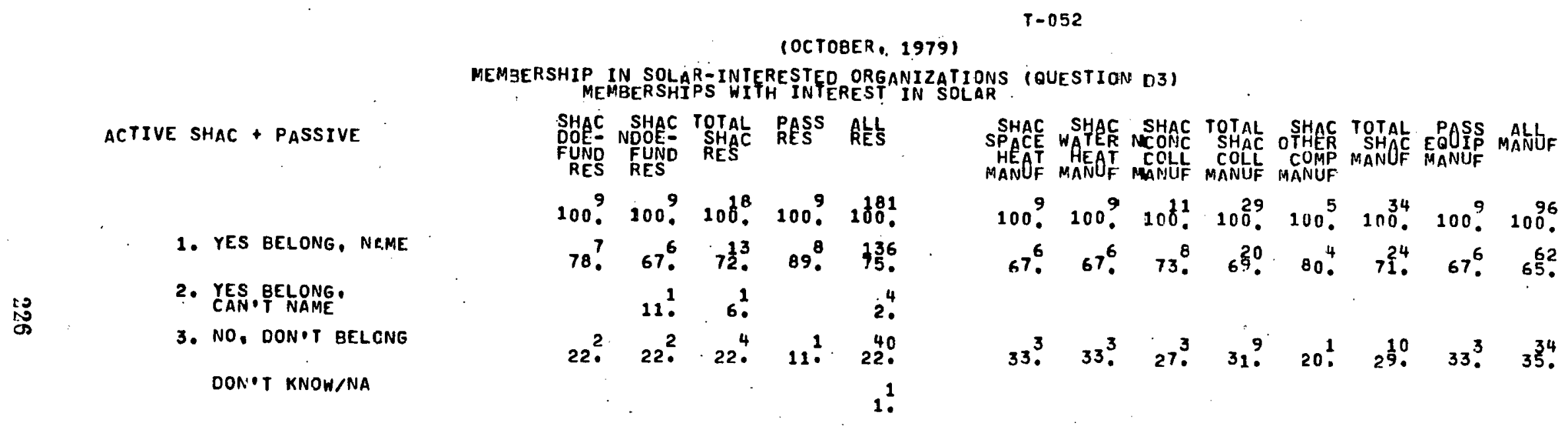

Figure F-1. Passive Solar Heating and Cooling Data Tables (continued) 


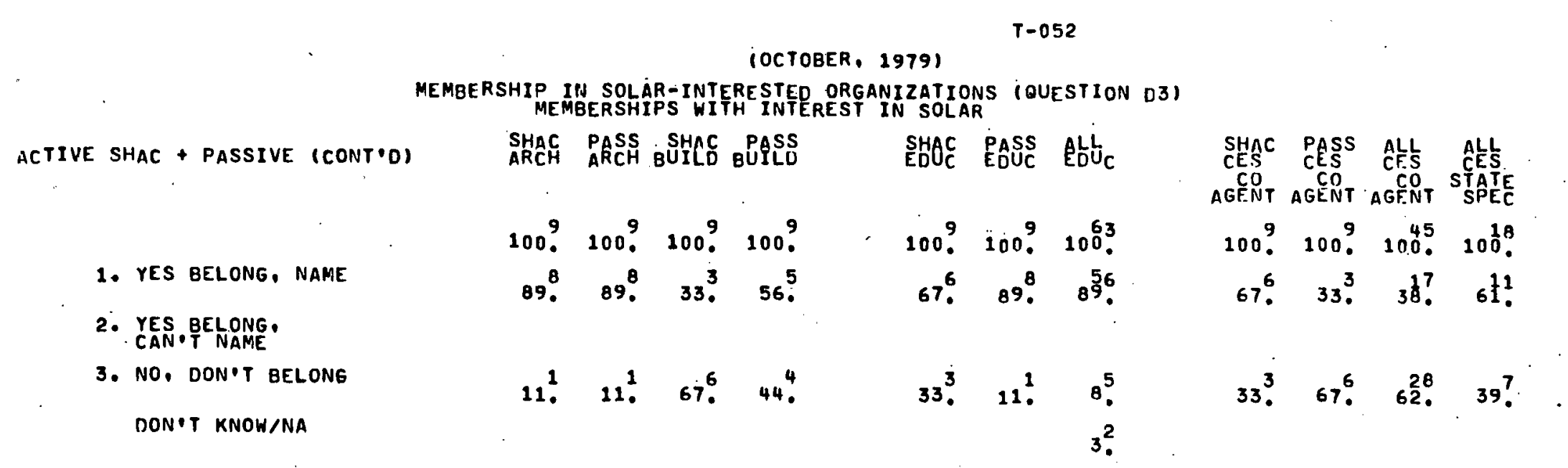

Figure F-1. Passive Solar Heating and Cooling Data Tables (continued) 
(OCTOBER, 1979)

NEED FOR JNFORMATION ON THE JOB AND OUTSILE TAE JOB (OUESTION 1)

USERS

YES FCR JOE

NO $=O A$ JOB

DONIT KNOW/NA

Q1B TOTAL
PASS

MOMEE

100 ?

56.

$33^{3}$.

11.

100 ?

44.

$44^{4}$

11 .

44.
SHAC SHAC TOTAL SHAC TOTAL

SPACE HAYER SHAC OLDG SHAC

OWNER OWNER OWNER MNGR MNGR

100 . 100 ? $100^{28}$. 100 ? 100 ?

$78^{7} \quad 67^{6} \cdot \quad 72^{13} \cdot 67^{6} \quad 7^{19}$.

$22^{2} .233^{3} \quad 28^{5}$. $22^{2} .26$ ?

11. 4 .

100 ? $1000^{9} .100^{8}$. 100 ? 10 ?

$78^{7} \quad 11^{1} .44^{8} .22^{2} . \quad 370$

$22^{2} \quad 78^{7} \cdot 50^{9} .67^{6} \quad 56$.

$11^{1} \quad 6.11^{1} \quad 7^{2}$.

$56.211^{1} \quad 33.611^{1}$. 26 .

Figure F-1. Passive Solar Heating and Cooling Data Tables (continued) 
(OCTOBER, 1979) SPECIFIEO TYPES OF. PASSIVE SYSTEM USED (DUESTION 6) PASS - SHAC SHAC TOTAL SHAC TOTAL
HOME
OWNER SPAC WATER SHAC BKLG SHAC OWNER HOME HOME HOME OWNER OWNER

LANDSCAPING OR ORIEMTATION
OF BUILING
YES
NO

DON T KNOW, NO ANSWER

GREENHOUSE

YES

$100^{9}$

56.

NO

$44^{4}$

DONET KNOW.NO ANSWER

ATRIUM/SOLARIUM

YES

$100 \%$

NO

$22^{2}$

$78^{7}$

DON'T KNOW:NO ANSWER

SOLAR POND

YES

.1009

NO

$100^{9}$

DON T KNOW/NO ANSWER

Figure F-1. Passive Solar Heating and Cooling Data Tables (continued) 
(OCTOBER; 1979)

SPECIFIED TYPES OF PASSIVE SYSTEM USEO : COP.TINUEO (QUESTIION 6)

USËFS

PASS SHAC SHAC TOTAL SHAC TOTAL

OWNER HOHE HOME HOME OWAEA OWAER

100 ?

WATER STORAGE OF HEAT

$$
\begin{aligned}
& 100.9 \\
& 33^{3} \\
& 67^{6}
\end{aligned}
$$

DON•T KNDW/NO ANSEER

ROCK STORDGE OF HEAT

$$
\begin{aligned}
& 100^{9} \\
& 44^{4} \\
& 56 .
\end{aligned}
$$

DON'T KNOW/NO ANSWER

HEAT STORAGE IN WALL

YES
MO
DON'T KNCWINO ANSWER

$$
\begin{aligned}
& 1009 \\
& 67 . \\
& 220^{2} \\
& 11^{1}
\end{aligned}
$$

Figure F-1. Passive Solar Heating and Cooling Data Tables (continued) 


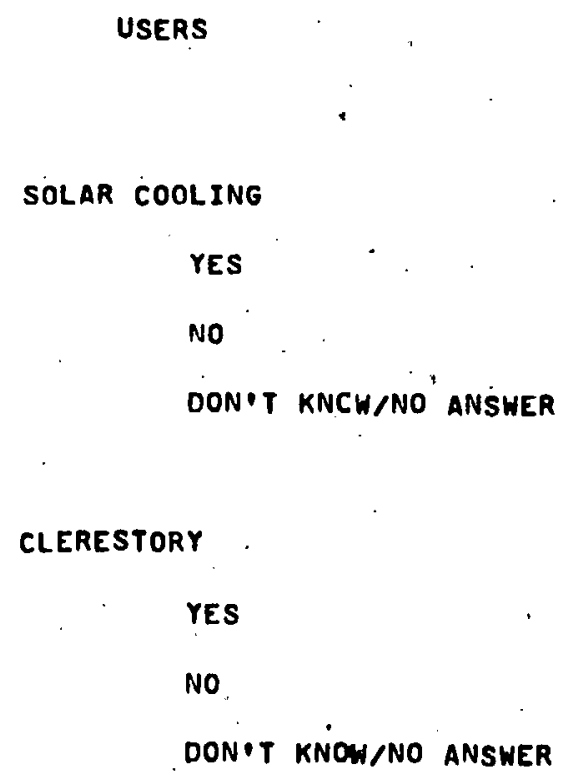
QUESTION B1-6A TYPE OF SYSTEM/USE (VERSION 12 ) PASS. SHAC SHAC TOTAL SHAC TOTAL HOME
OWNER HPACE HATER SHAC BLDG SHAC.
OWNER OWMER OWNER MNGR OWNER $100 ?$

100 ?

$22^{2}$

78 ? 1009
$33^{3}$
56.
$110^{1}$ Figure F-1. Passive Solar Heating and Cooling Data Tables (continued) 


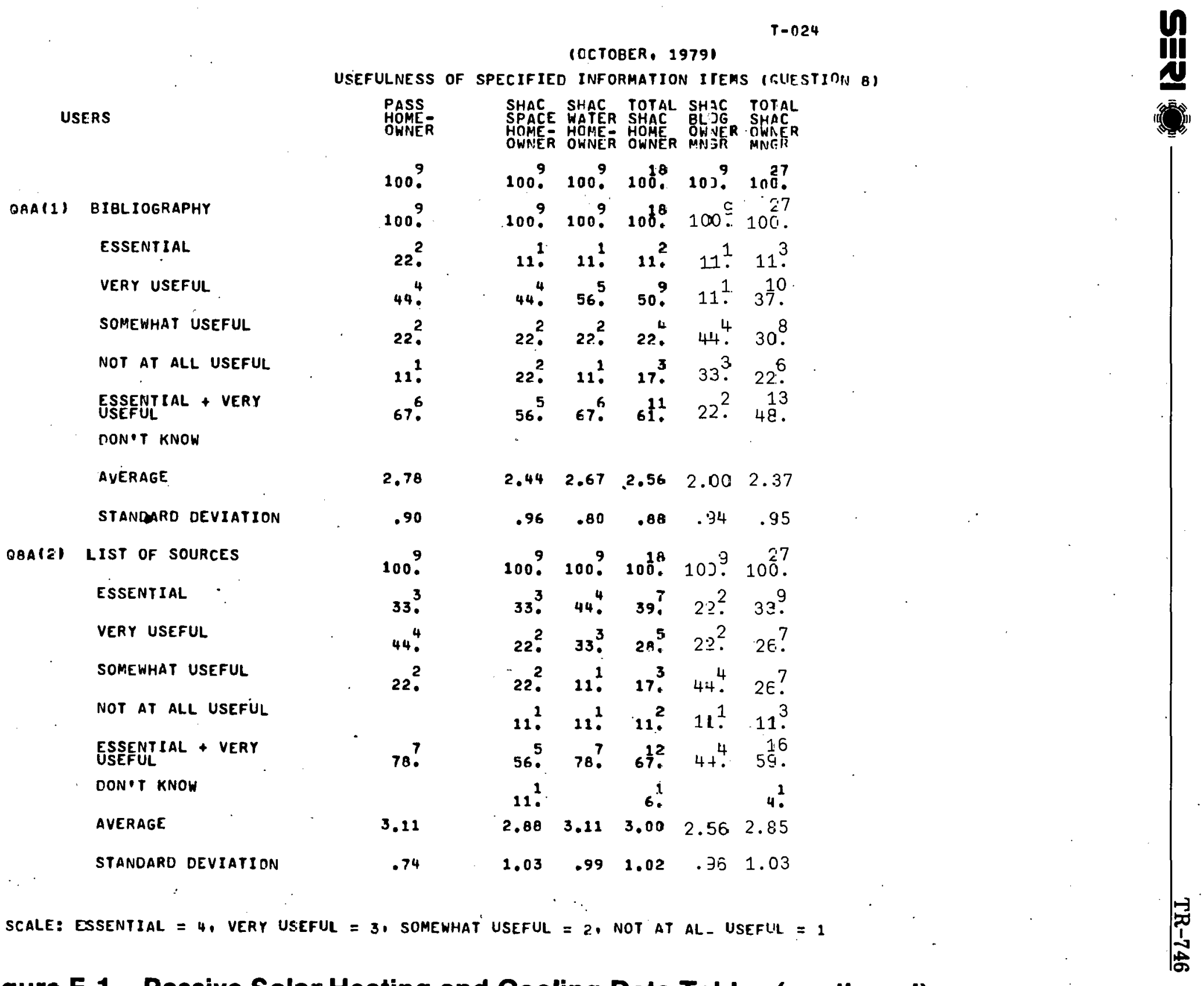

Figure F-1. Passive Solar Heating and Cooling Data Tables (continued) 


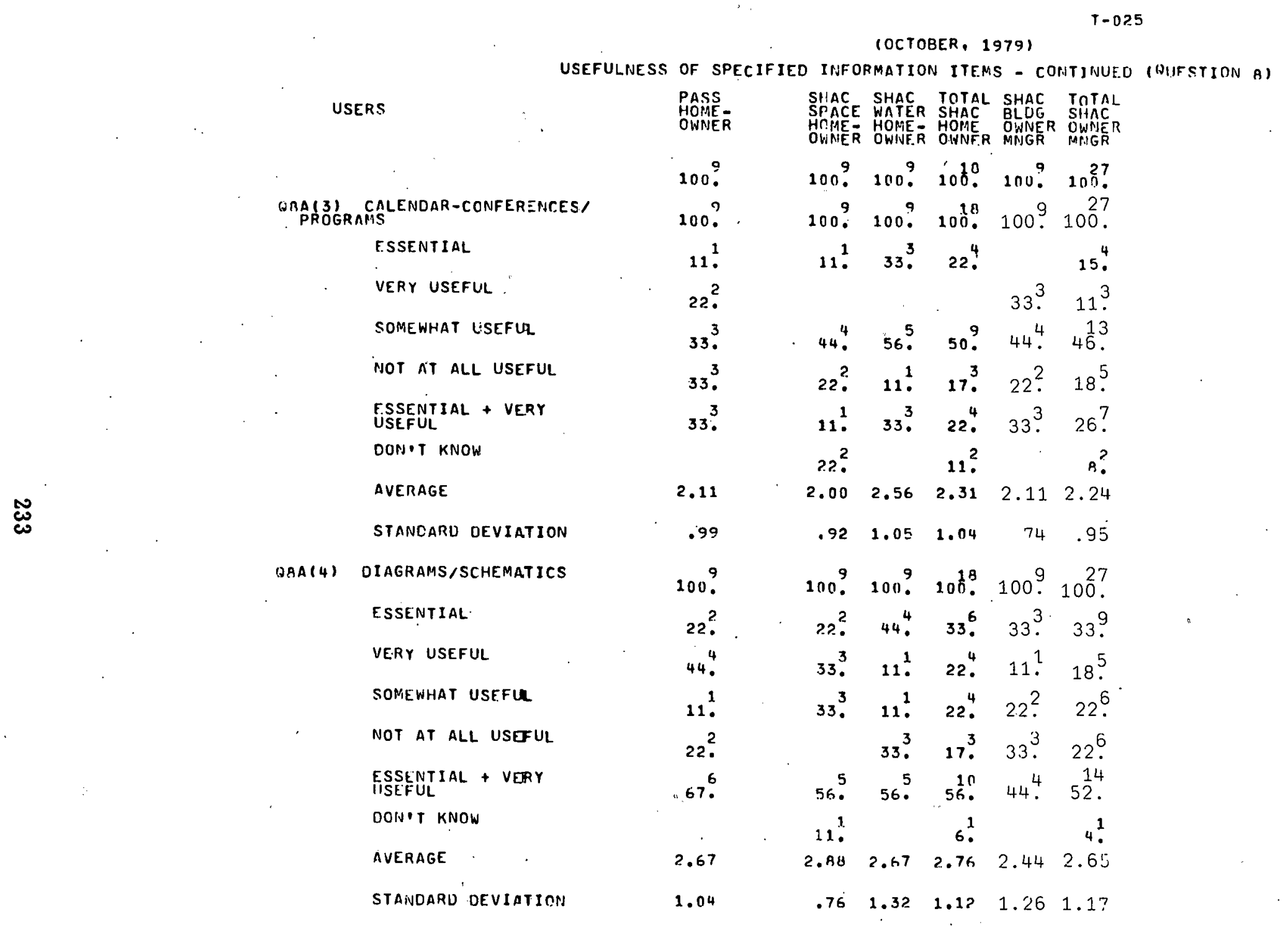

SCALE: ESSENTIAL $=4$; WERY USEFUL $=3$, SOMEWHAT USEFIJL $=2$, NOT NT ALL USEFIIL $=2$.

Figure F-1. Passive Solar Heating and Cooling Data Tables (continued) 


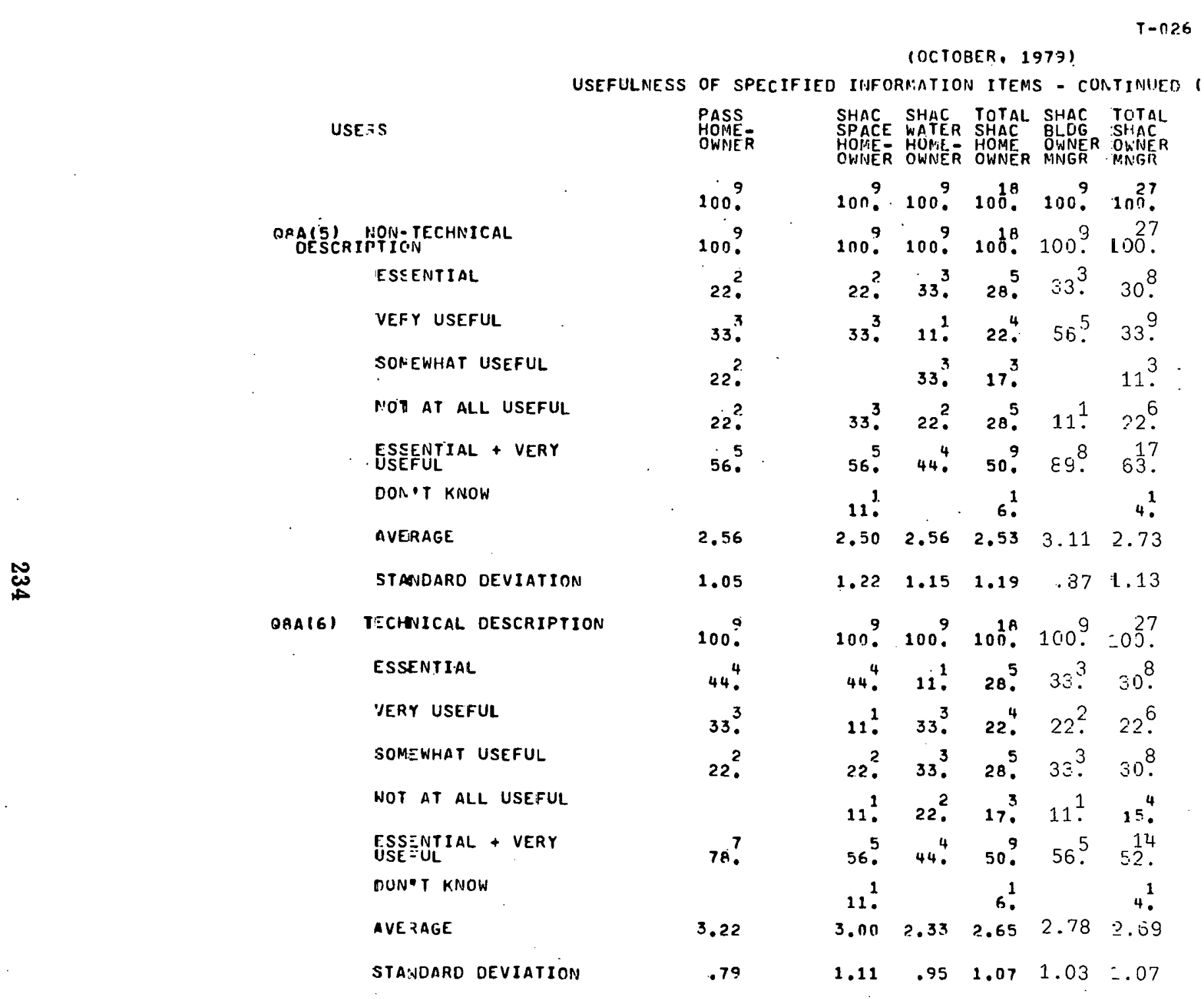

SCALE: ESSENTIAL $=4$, VERY USEFUL $=3$, SOMFWHAT USEFUL $=2$, NOT AT $A L L$ USFFUL $=1$

Figure F-1. Passive Solar Heating and Cooling Data Tables (continued) 


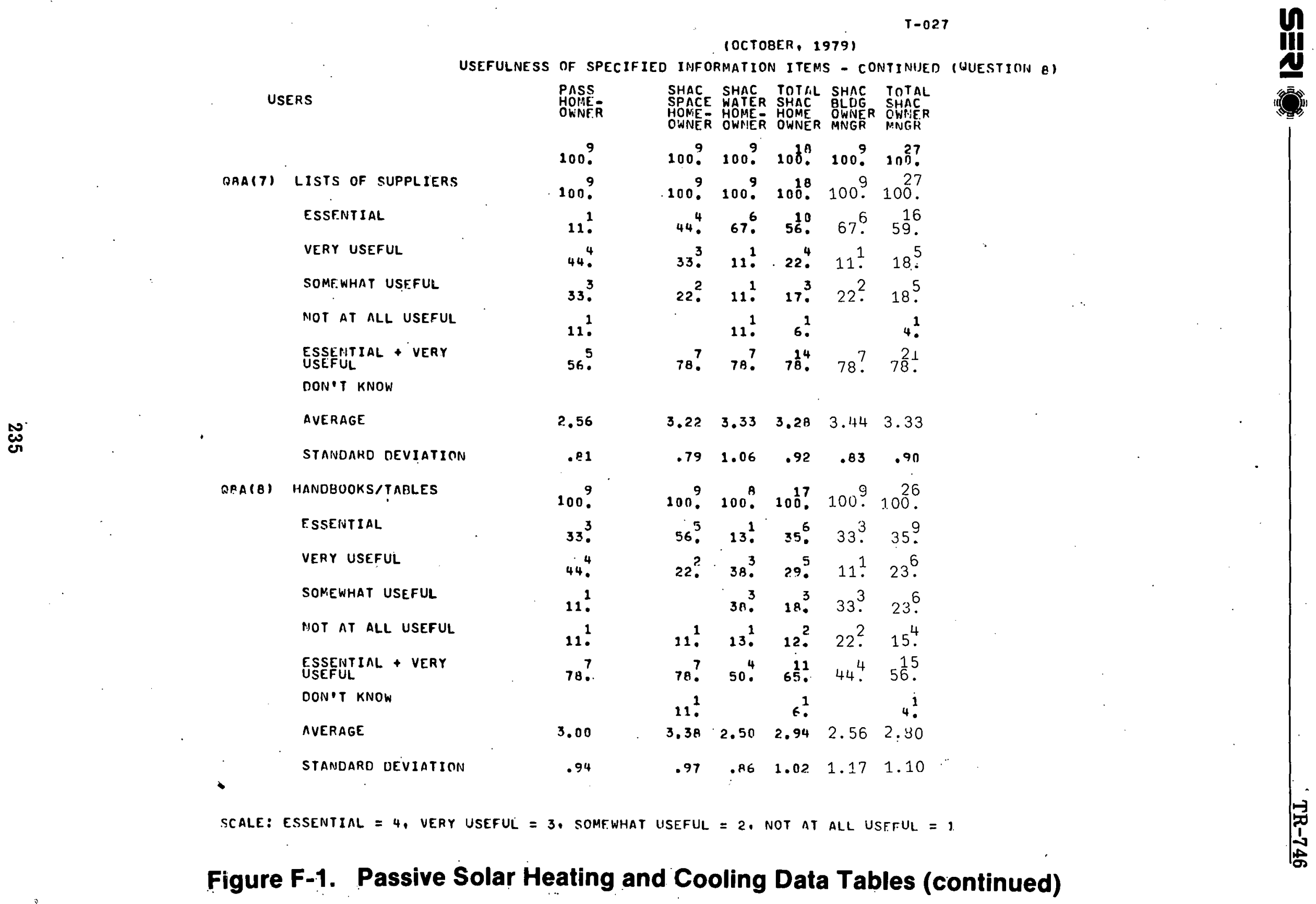




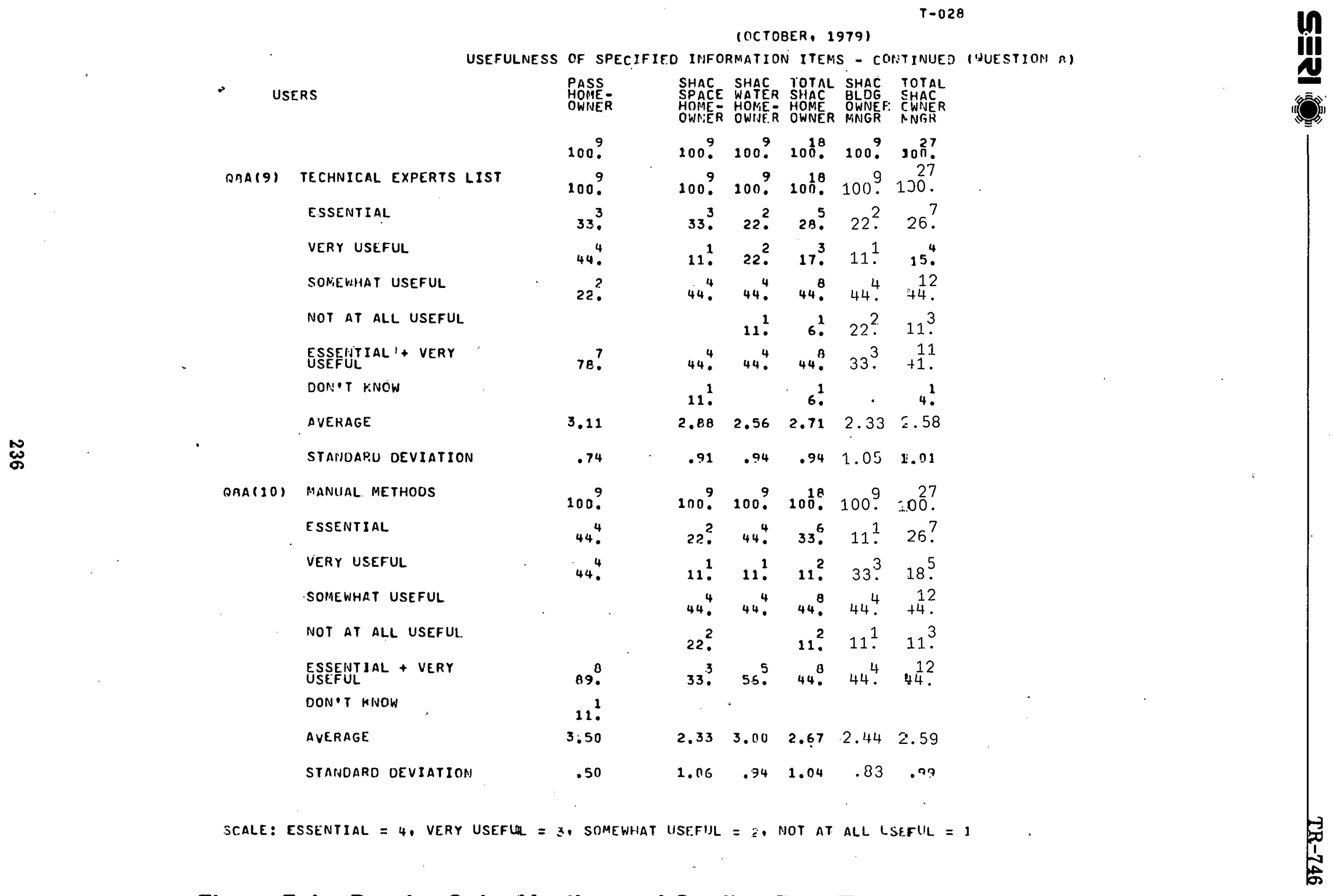

Figure F-1. Passive Solar Heating and Cooling Data Tables (continued) 
Figure F-1. Passive Solar Heating and Cooling Data Tables (continued) 


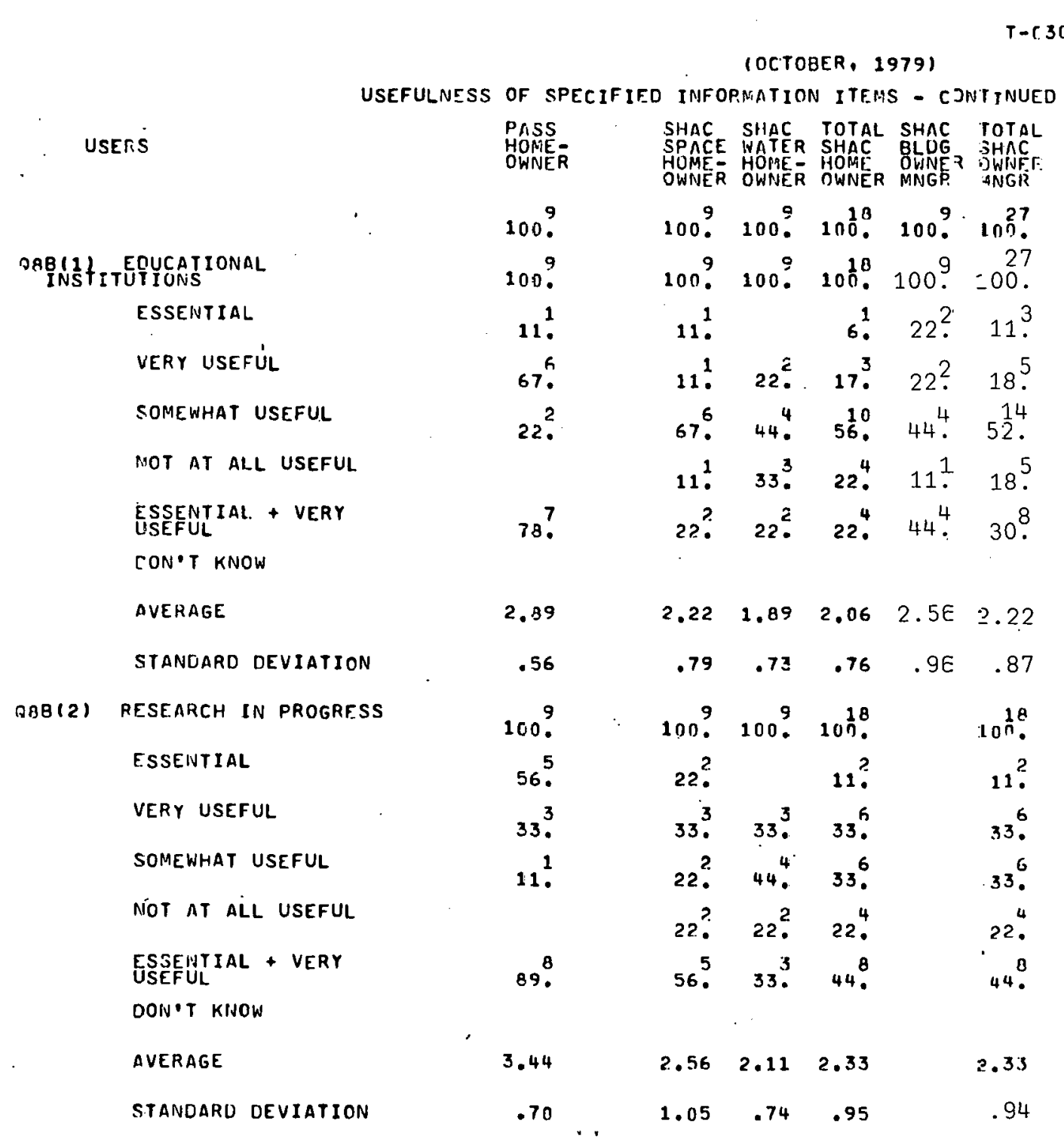

SCALE: ESSENTIAL $=4$, VERY USEFUL $=3$, SOMEWHAT USEFUL $=2$, NOT AT ALL USTFUL $=1$

Figure F-1. Passive Solar Heating and Cooling Data Tables (continued) 
(OCTOBER, 1979$)$

USEFULNFSS OF SPECIFIED INFORMATION ITEMS - CONTINUED (QUESTIOIS E)

\begin{tabular}{|c|c|c|c|c|c|c|c|c|}
\hline \multicolumn{2}{|c|}{ USERS } & \multicolumn{2}{|l|}{$\begin{array}{l}\text { PASS } \\
\text { HOME- } \\
\text { OWNER }\end{array}$} & \multirow{2}{*}{$\begin{array}{c}\text { SHAC } \\
\text { SPARE } \\
\text { HOME } \\
\text { OWNER } \\
10{ }^{2} \\
10\end{array}$} & \multirow{2}{*}{$\begin{array}{c}\text { SHAC } \\
\text { WATER } \\
\text { HOME } \\
\text { OWNER } \\
100^{9} \\
10 .\end{array}$} & \multirow{2}{*}{$\begin{array}{c}\text { TOTAL } \\
\text { SHAC } \\
\text { HOME } \\
\text { OWNER } \\
1018 \\
100 .\end{array}$} & \multirow{2}{*}{$\begin{array}{c}\text { SHAC } \\
\text { BLLG } \\
\text { OWNER } \\
\text { MNGR } \\
100^{9}\end{array}$} & \multirow{2}{*}{$\begin{array}{c}\text { TOTAL } \\
\text { SHAC } \\
\text { OWNER } \\
\text { MNGR } \\
\text { InO? } \\
\text { InO? }\end{array}$} \\
\hline & & 100 ? & & & & & & \\
\hline$A B B(3)$ & STATE OF ART & $100^{9}$ & . & 1009 & $100 \%$ & $100^{18}$ & $100^{9}$ & $100 ?$ \\
\hline & F.SSENT I AL & $33^{3}$ & & $22^{2}$ & $11^{1}$ & $17^{3}$ & $11^{1}$ & $15^{4}$ \\
\hline & VERY USEFUL & $33^{3}$ & & 67. & $33^{3}$ & $50 ?$ & $11^{1}$ & 37. \\
\hline & SOMEWHAT USEFUL & $22^{2}$ & & & $22^{2}$ & $11^{2}$ & $44^{4}$. & $22^{6}$ \\
\hline & NOT AT ALL USEFUL & & & & $33^{3}$ & $17^{3}$ & $33^{3}$ & $22^{6}$ \\
\hline & $\begin{array}{l}\text { ESSENTIAL + VERY } \\
\text { USEFUL }\end{array}$ & $67^{6}$ & & 89. & $44^{4}$ & $67 ?$ & $22^{2}$ & $52^{14}$ \\
\hline & DON'T KNOW & $11^{1}$ & & 11 & & $6 !$ & & 4. \\
\hline & AVERAGE & 3.13 & & 3.25 & 2.22 & 2.71 & 2.00 & 2.46 \\
\hline & STANUARO OEVIATION & .76 & - & .43 & 1.03 & .94 & .94 & 1.01 \\
\hline OAB $(4)$ & COSTS/PERFORMANCE & $100^{9}$ & & $100^{9}$ & $100^{9}$ & $100^{18}$ & $100^{9}$ & $\begin{array}{r}27 \\
100\end{array}$ \\
\hline & ESSENTIAL & $56^{5}$ & & 56. & $33^{3}$ & $44^{8}$. & $67^{E}$ & $52^{14}$ \\
\hline & VERY USEFUL & $33^{3}$ & & $33^{3}$ & $22^{2}$ & $28^{5}$ & $22^{2}$ & $26^{7}$ \\
\hline & SOMEWHAT USCFUL & 11 & & 11 & $33^{3}$ & $22^{4}$. & & $1.5^{4}$ \\
\hline & NOT AT ALL USEFUL & & & & $11^{1}$ & 6 & $11^{1}$ & $7^{2}$ \\
\hline & $\begin{array}{l}\text { ESSENTIAL + VERY } \\
\text { USEFUL }\end{array}$ & $89^{\circ}$ & & 89. & $5 f^{5}$ & $72^{13}$ & $89^{8}$ & $\begin{array}{r}21 \\
78\end{array}$ \\
\hline & DUN ${ }^{\circ}$ KNOW & & & & & & & \\
\hline & AVERAGE & 3.44 & & 3.44 & 2.78 & 3.11 & 3.44 & 3.22 \\
\hline & STANUARO DEVIATION & .70 & & .70 & 1.02 & .94 & .96 & .96 \\
\hline
\end{tabular}

SCALE: FSSENTIAL $=4$, VERY USEFUL $=3$, SOMEWHAT USEFUL $=2$, NOT AT ALL USEFUL $=1$

Figure F-1. Passive Solar Heating and Cooling Data Tables (continued) 


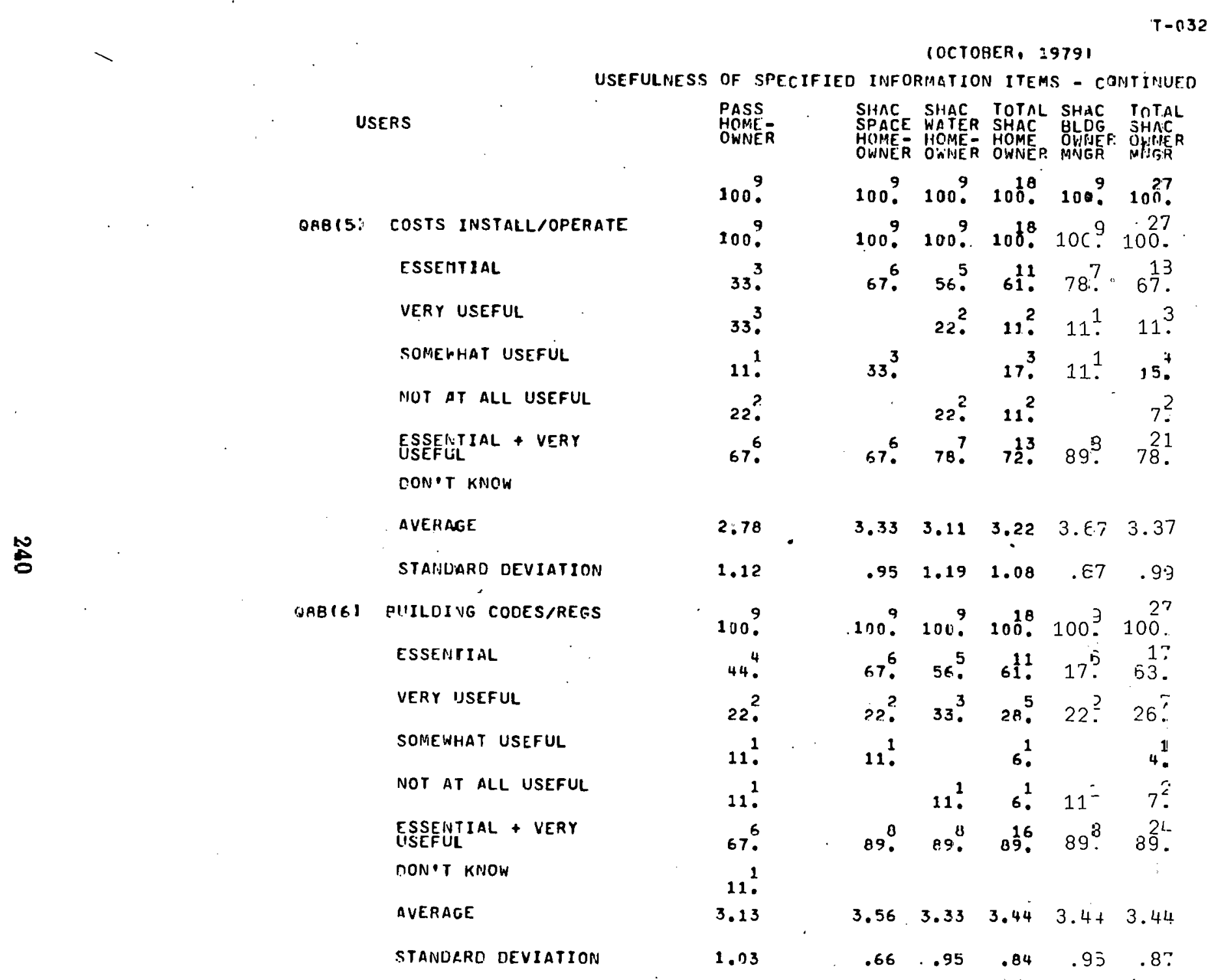

SCALE: ESSENTIAL $=4$, VERY USEFUL $=3$, SOMFWHAT USFFUL $=\because$, NOT AT ALL USEFUL $=1$

Figure F-1. Passive Solar Heating and Cooling Data Tables (continued) 
IOCTOBER, 19791

Figure F-1. Passive Solar Heating and Cooling Data Tables (continued) 


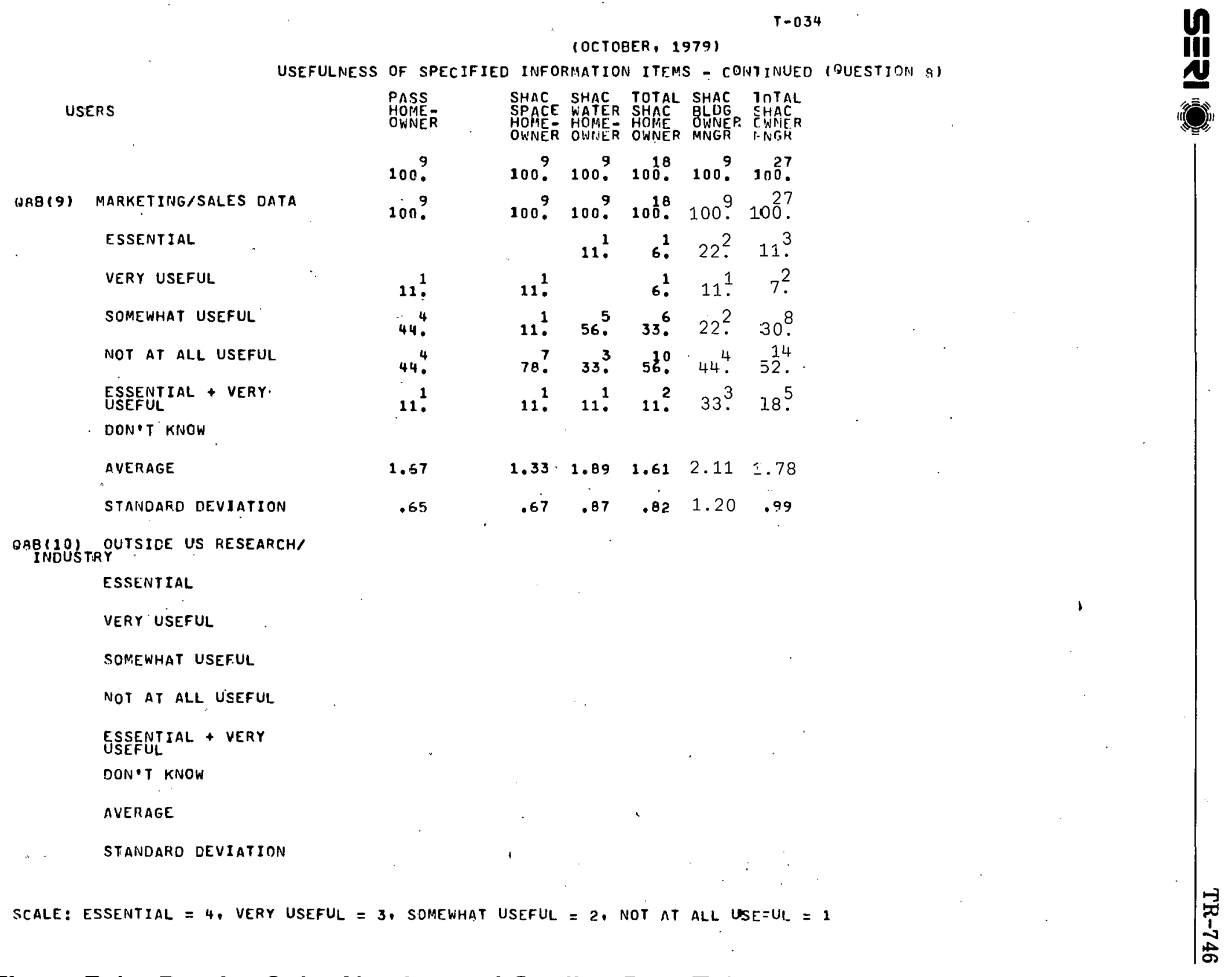

Figure F-1. Passive Solar Heating and Cooling Data Tables (continued) 
(OCTOBER, 1979 )

USEFULNESS OF SPECIFIED INFORMATION ITEMS - CONTINUED (QUESTION 8 )

USERS

PASS SHAC SHAC TOTAL SHAC TUTAL

OWNER HOME HOME HOME OWNER OWNER

100 . 100 ? 100 ? $100^{8}$. 100 ? $100^{2}$ ?

QBB(11) INFO ON MARKETING

ESSENTIAL

VERY USEFUL

SOMEWHAT USEFUL

NOT AT ALL USEFUL

ESSENTIAL + VERY

DON'T KINOW

AVERAGE

STANDARD DEVIATION

QABE12I INST/SOCIAL/ENVIRON/

ESSENTIAL

VERY USEFUL

SOMEWHAT USEFUL

NOT AT ALL USEFUL

ESSENTIAL + VERY
USEFUL.

DON'T KNOW

AVERAGE

100. $100^{9} \cdot 100^{9} \cdot 100^{18} \cdot 100^{9} \cdot 10^{27}$.

22. $11^{1}$ ? $^{1} 22^{2} \cdot 11^{3}$.

$33^{3} .22^{2} \cdot 22^{2} \cdot 22^{4} \cdot 11^{1} \cdot 18^{5}$.

44. $\quad 44^{4} . \quad 33^{3} \cdot 39^{7}$. $33^{3} \cdot 37^{10}$.

33. $33^{3} \cdot 33^{6} \cdot 33^{3} \cdot 33^{9}$

56. $22^{2} \cdot 33^{3} \cdot 28^{5} \cdot 33^{3} \cdot 30^{8}$.

STANDARD DEVIATION

$\begin{array}{rrrrrr}2.78 & 1.89 & 2.11 & 2.00 & 2.22 & 2.07 \\ .77 & .73 & 99 & .88 & 1.13 & .98\end{array}$

SCALE: ESSENTIAL $=4$, VERY USEFUL $=3$, SOMFWIAT USEFIL $=2$, NOT AT ALL USFFLL $=1$

Figure F-1. Passive Solar Heating and Cooling Data Tables (continued) 


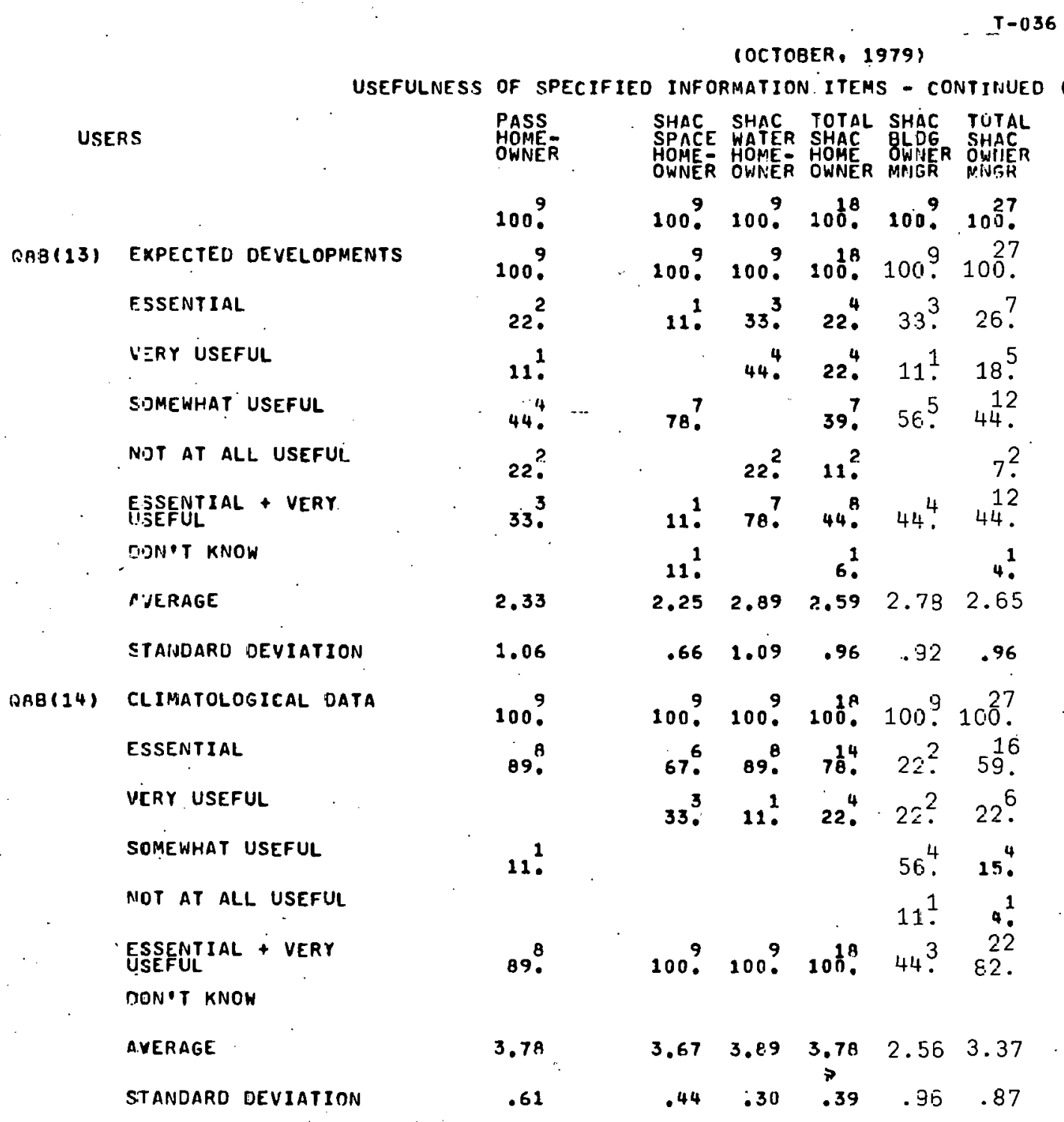

SCALE: ESSENTIAL $=4$, VERY USEFUL $=3$, SOMEWHAT USEFUL $=2$, NOT AT ALL USE.FUL $=1$

Figure F-1. Passive Solar Heating and Cooling Data Tables (continued) 


$$
\text { (OCTOBER, 1979) }
$$

USE OF SELECTED SOLAR INFORMATION SOURCES IOUESTION 19.1

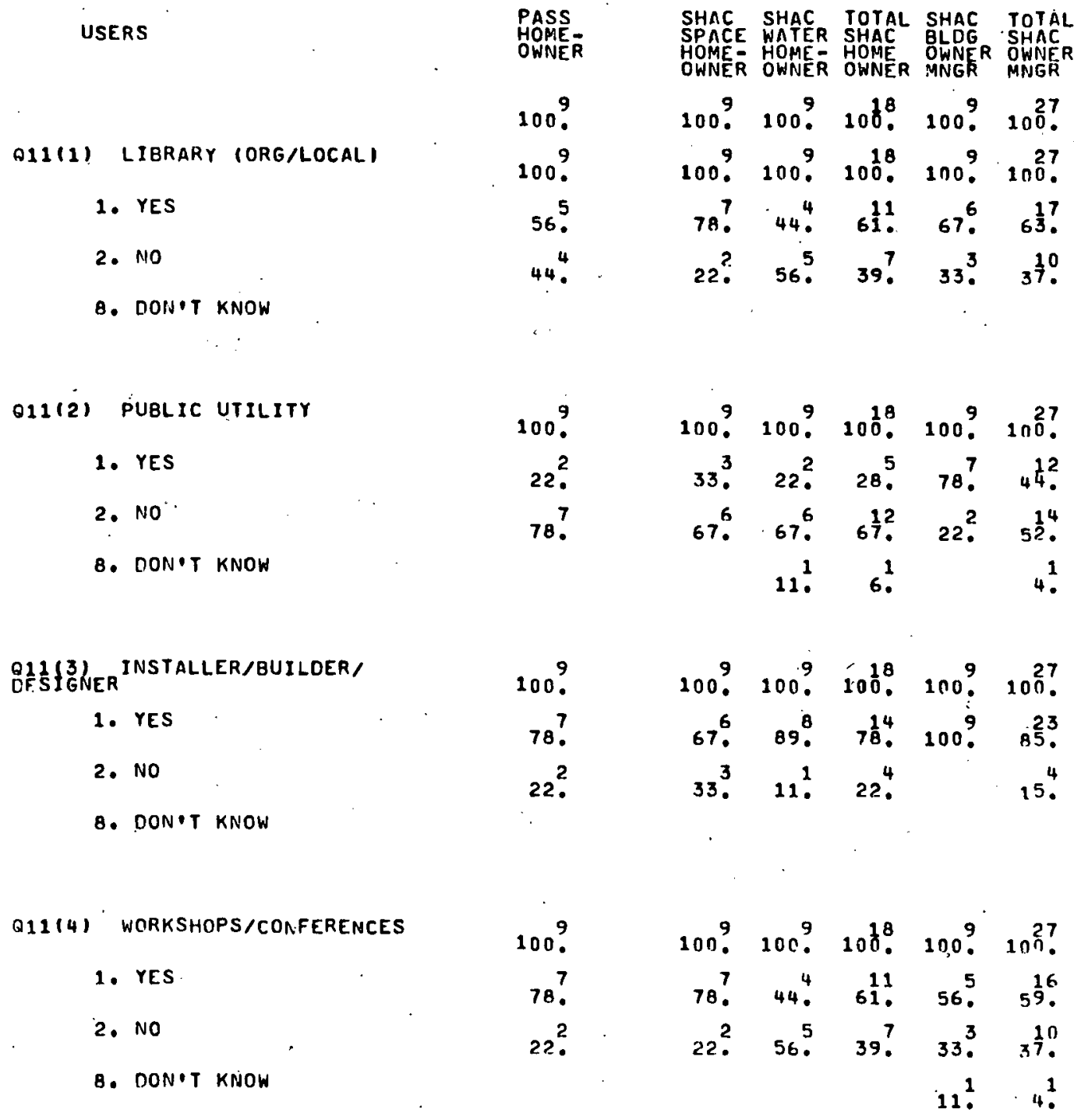

Figure F-1. Passive Solar Heating and Cooling Data Tables (continued) 
(OCTOBER, 1979)

USE OF SELECTEO SOLAR INFORMATION SOURCES - CONTTNUED (QUESTION 11)

USERS

$\begin{array}{ll}\text { PASS } & \text { SHAC SHAC TOTAL SHAC TOTAL } \\ \text { HOME } & \text { SPACE HATER SHAC OHDG SHAC }\end{array}$

HOME - HOME HOME OWWNER OWNER

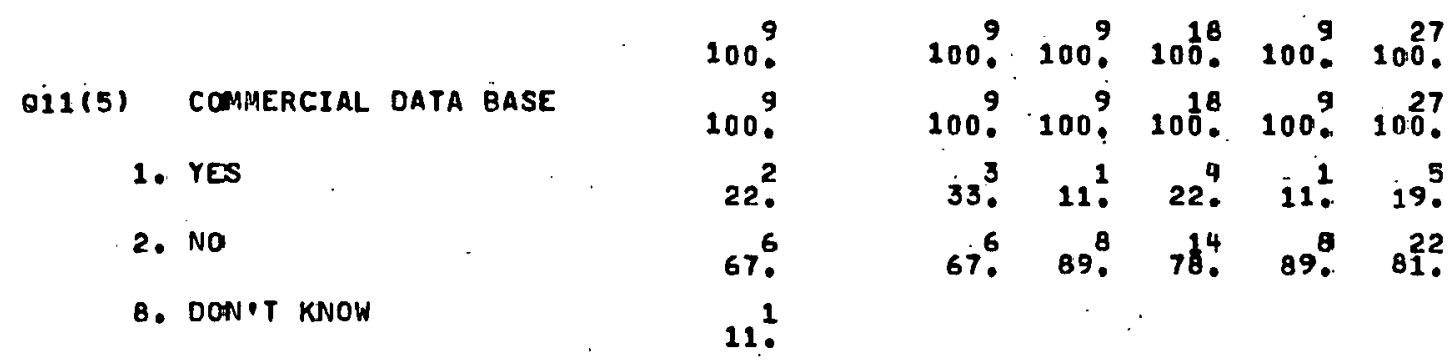

草

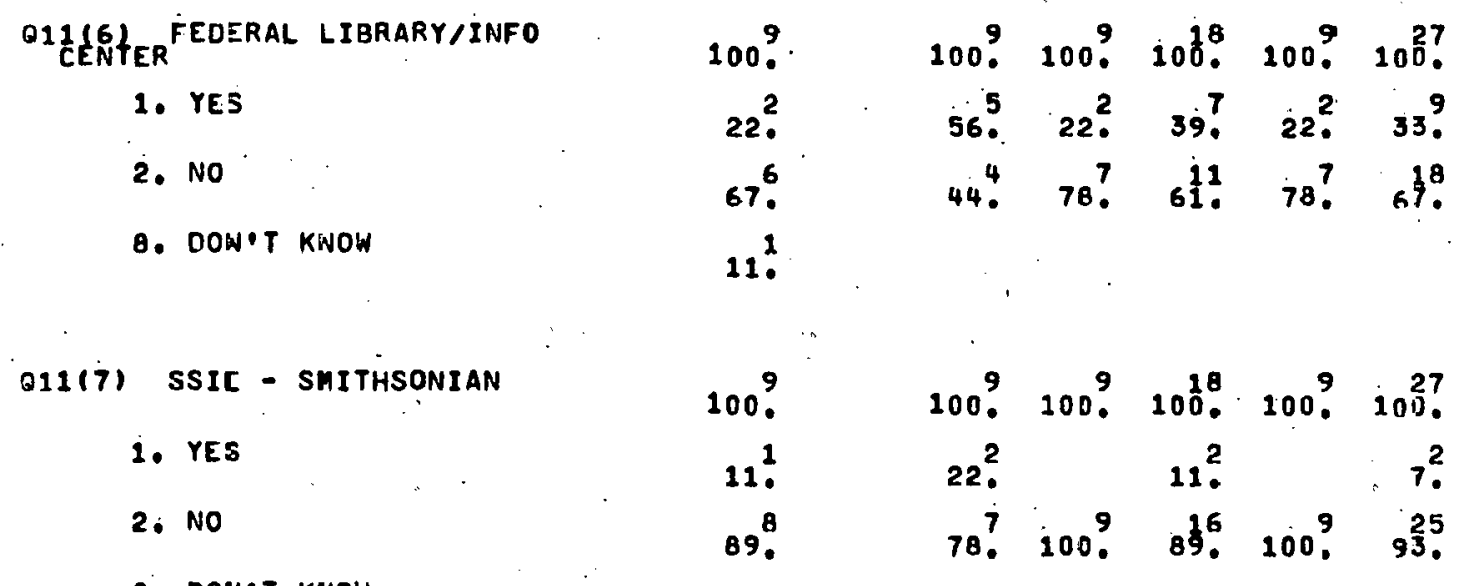

Figure F-1. Passive Solar Heating and Cooling Data Tables (continued) 
(OCTOBER, 2979)

USE OF SELECTED SOLAR INFORMATION SOURCES - CONTINUED (OUESTION 11)

USERS

PASS. SHAC SHAC TOTAL SHAC INTAL

OWNEA HOME HOMME HOME OWNER OWAER

A1 $1(8)$ GOVPT PRINTING OFFICE-

100? 100 ? 100 ? $100^{10}$. 100? $100^{27}$ ?

1. YES

100 ? $\quad 100$ ? 100 ? $100^{18}, 100$ ? $100^{27}$.

2. NO

8. DONTT KNOH

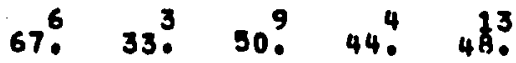

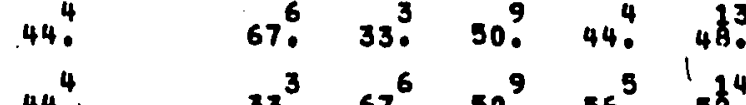

O1119\% NATIONAL TECHNYCAL

1. YES

2. NO

8. DON'T KNOW

44.

$11^{1}$

100? $100^{9} .100^{9}, 100^{18} .100$ ? $100^{27}$.

100 ? 100 ? 100 ? $100^{\circ}$. 100 ? 100 ?

33. $\quad 44^{4}, \quad 11^{2} \quad 28,533^{3}, 30^{8}$.

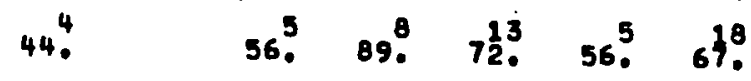

$22.211 \%$

$1009.100 \% 100$ ? $100^{8}, 1009.108$ ?

Q11 CENTER TECHNICAL INFORMATION

1. YES

2. NO

8. DON?T KNOW

$100 ? \cdot 100 ?$

$100 ? 100$ ?

Figure F-1. Passive Solar Heating and Cooling Data Tables (continued) 


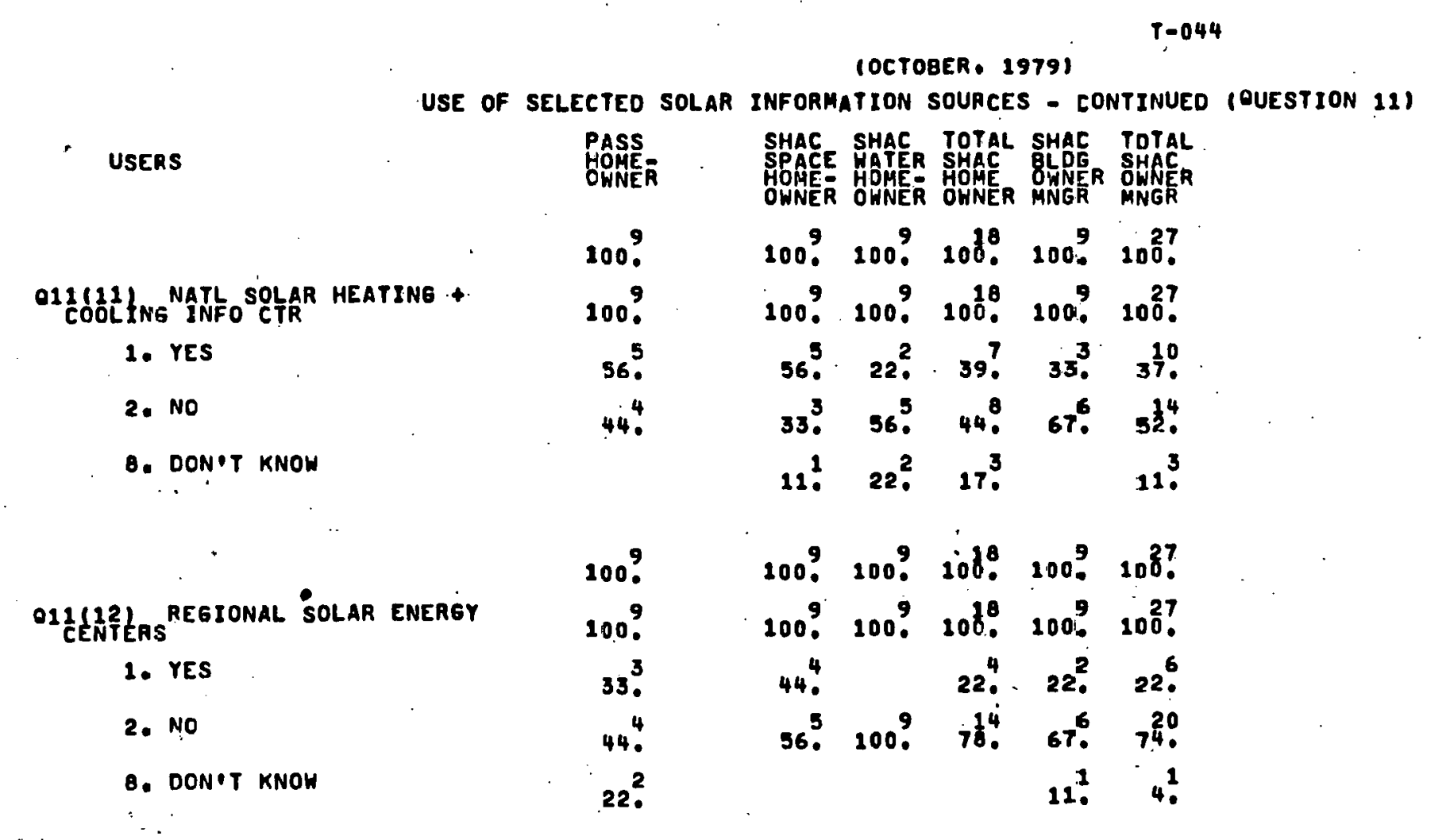

Figure F-1: Passive Solar Heating and Copoling Data Tables (continued) 
(OCTOBER, 19791

USE OF SELECTED SOLAR INFORMATION SOURCES - - CONTINUEO (QUEESTION 11)

USERS

Q1ii13, US DEPT. OF ENERGY

1. YES

2. NO

8. DON'T KNOW

Q111141 RADIO/TV

1. YES

2. No

8. DON'T KNOW

Q1 WIISS APEERIODICALS/

1. YES

2. No

8. DON.T KNOW

Q11LIG TROPRIVATE SOLAR!

1. YES

2. NO

8. DON'T KNOW
PASS SHAC SHAC TOTAL SHAC TOTAL

HOME- SHACE WATER SHAC BLDG SHAC

100 ? $\quad 100$ ? $1000^{9} 100^{18}: 100$ ? 100 ?

100? 100 ? 100 ? $100^{18}$. 100 \% 1000 .

$56^{5}$. $\quad 33^{3} .33^{3} .33^{6} .33^{3} .33^{9}$.

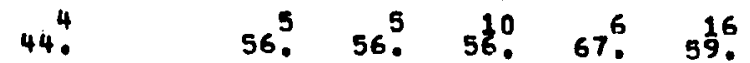

$11^{1} 11^{1} .11^{2}$ ?

\begin{tabular}{|c|c|c|c|c|c|}
\hline $100 \%$ & 100 ? & 100 ? & $108^{8}$ & $100^{9}$ & $1000^{27}$ \\
\hline $566^{5}$ & 56. & $11 \frac{1}{0}$ & $33^{6}$. & $22^{2}$ & $30^{\circ}$. \\
\hline & $44^{4}$. & 89. & $67^{2}$ & $78^{7}$ & 70 . \\
\hline
\end{tabular}

$1009.1009 .1009,100^{18}, 1009.100^{27}$

89. $\quad 89^{8} .69^{8} .99^{26} .100^{\circ} .925$.

11. $\quad 11^{1} .11^{1}, 11^{2}, \quad 7^{2}$

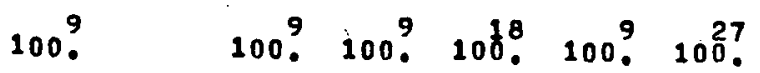

$89^{8} \quad 44^{4} \cdot 67^{6}, \quad 56 . \quad 33^{3} .44^{13}$.

$11^{1} \quad 56^{5} \quad 33^{3} .44^{8} .67^{6} .52^{14}$.

Figure F-1. Passive Solar Heating and Cooling Data Tables (continued) 


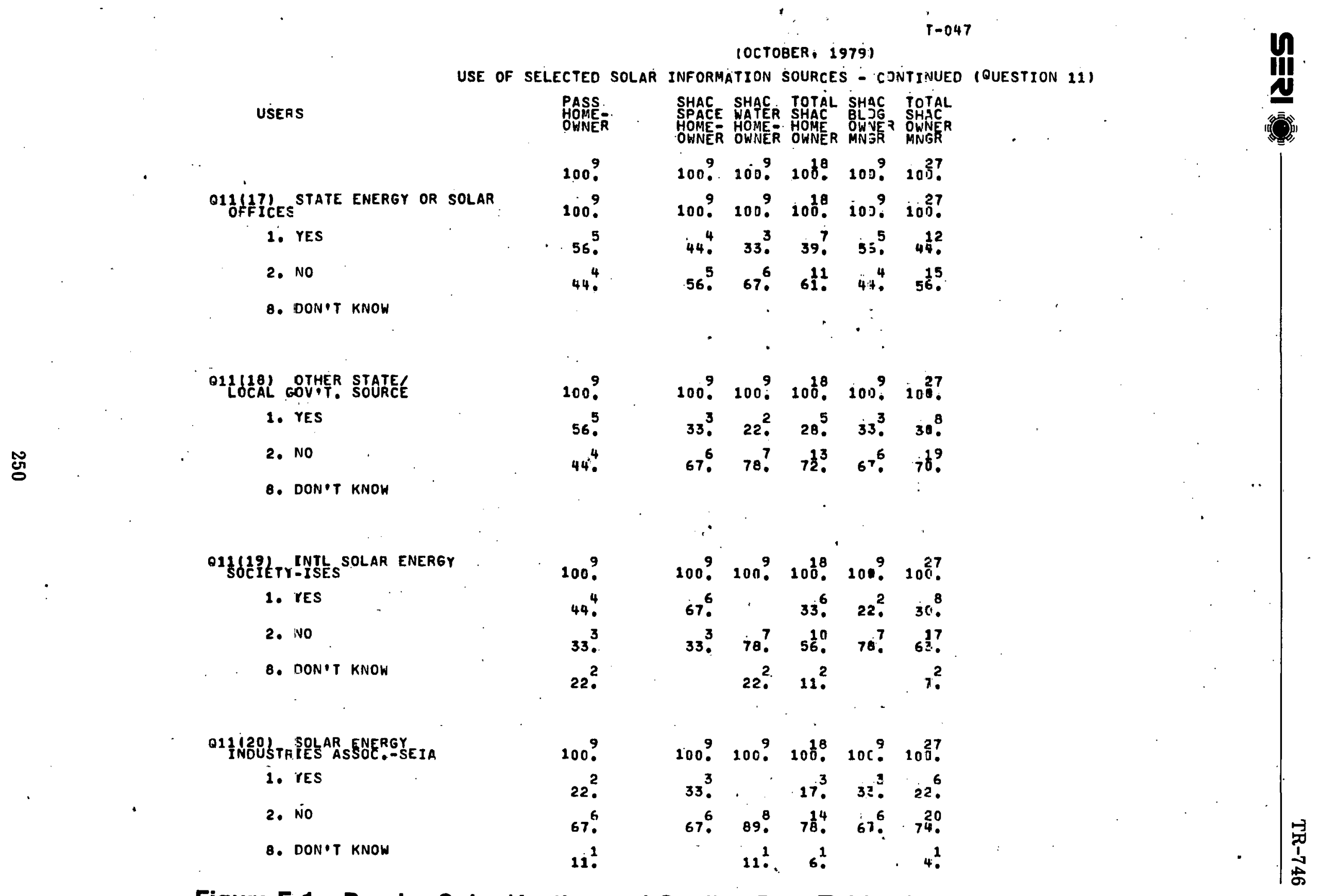

Figure F-1. Passive Solar Heating and Cooling Data Tables (continued) 
Figure F-1. Passive Solar Heating and Cooling Data Tables (continued) 


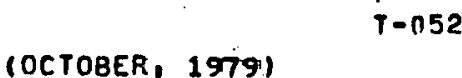

Figure F-1. Passive Solar Heating and Cooling Data Tables (continued) 
Figure F-1. Passive Solar Heating and Cooling Data Tables (continued) 


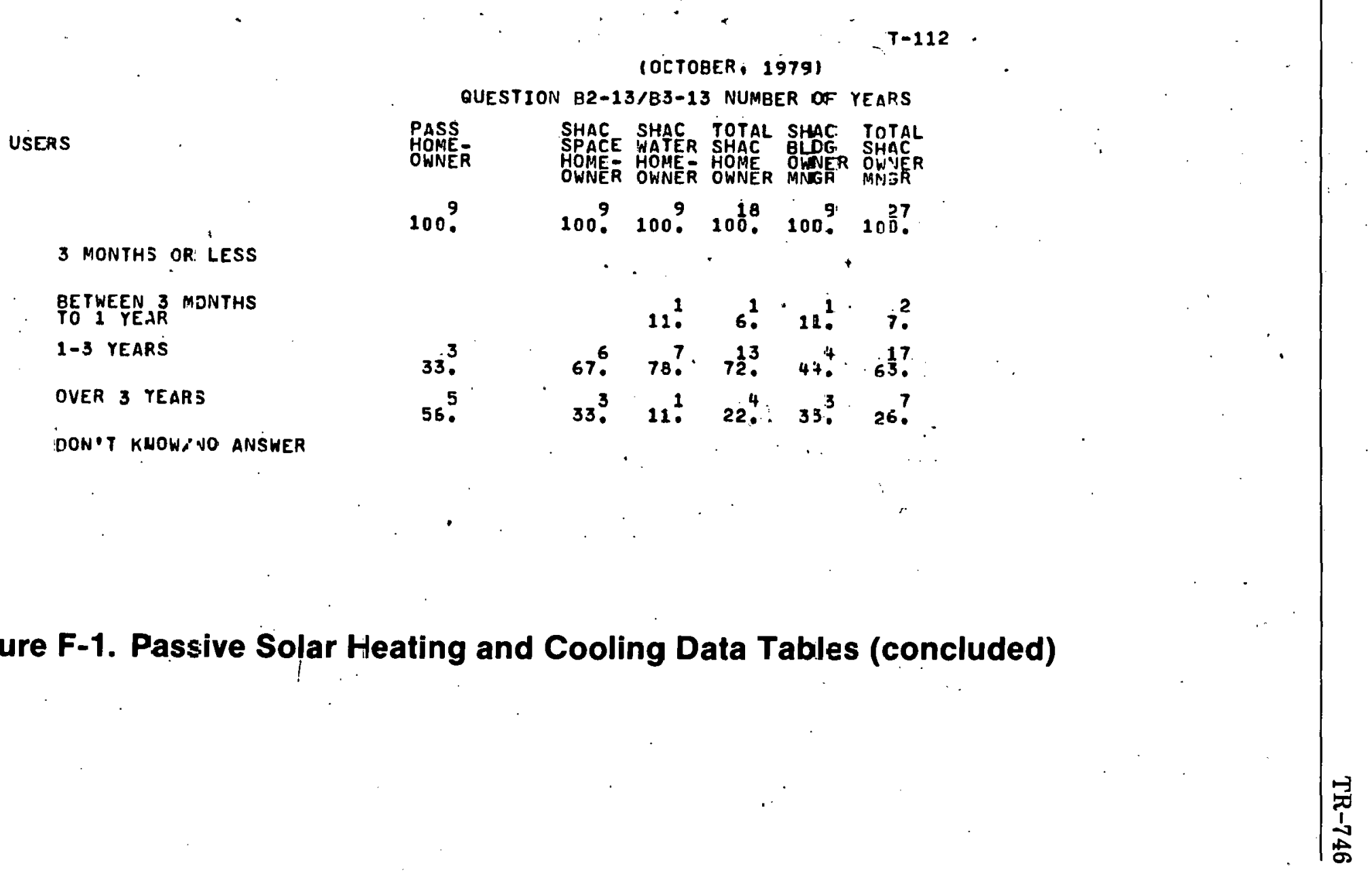




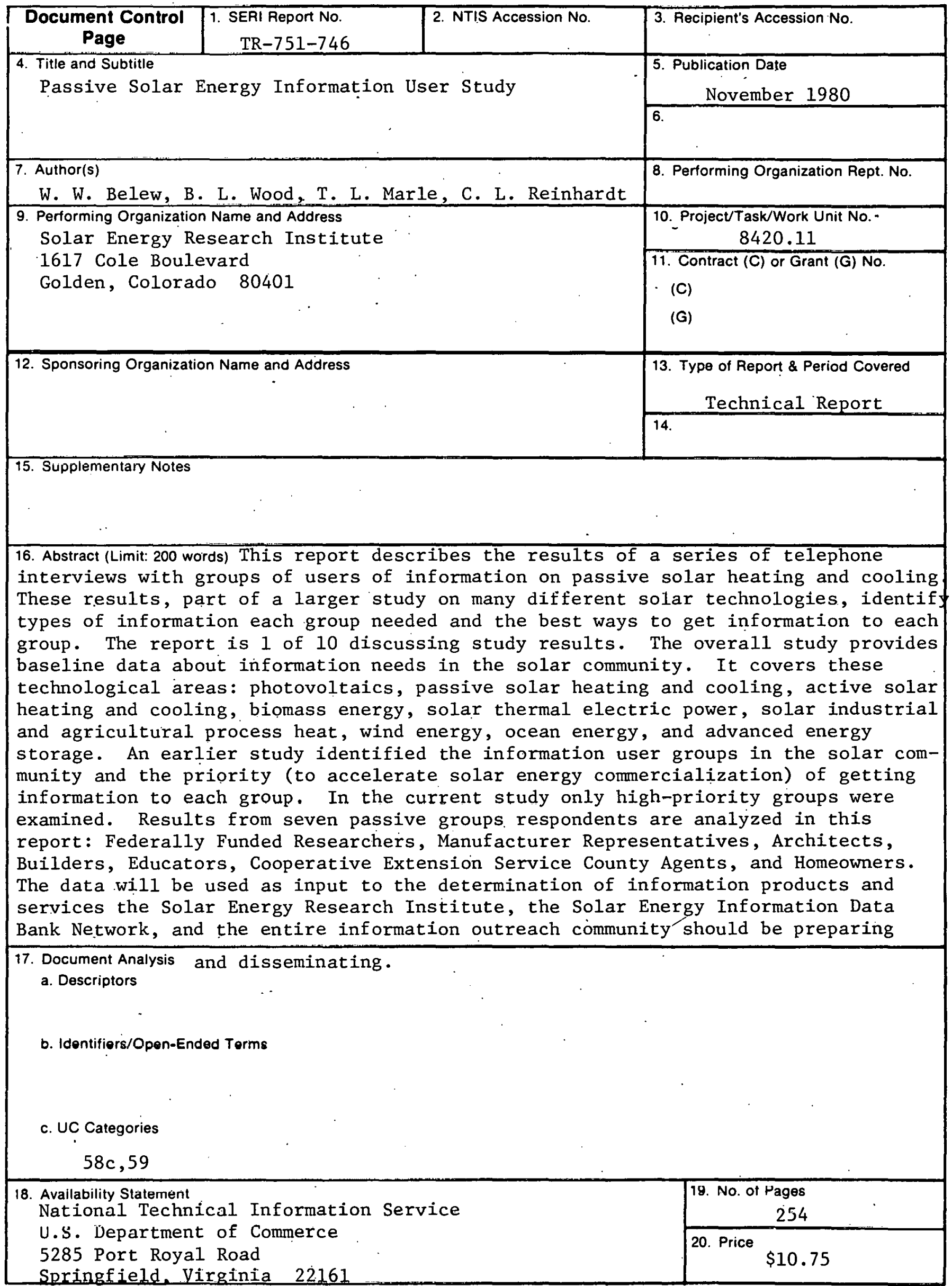

